NBER WORKING PAPER SERIES

\title{
RIGHT-TO-CARRY LAWS AND VIOLENT CRIME: A COMPREHENSIVE ASSESSMENT USING PANEL DATA AND A STATE-LEVEL SYNTHETIC CONTROL ANALYSIS
}

\author{
John J. Donohue \\ Abhay Aneja \\ Kyle D. Weber \\ Working Paper 23510 \\ http://www.nber.org/papers/w23510
NATIONAL BUREAU OF ECONOMIC RESEARCH
1050 Massachusetts Avenue
Cambridge, MA 02138 \\ June 2017, Revised November 2018
}

\begin{abstract}
Previously circulated as "Right-to-Carry Laws and Violent Crime: A Comprehensive Assessment Using Panel Data and a State-Level Synthetic Controls Analysis." We thank Dan Ho, Stefano DellaVigna, Rob Tibshirani, Trevor Hastie, StefanWager, Jeff Strnad, and participants at the 2011 Conference of Empirical Legal Studies (CELS), 2012 American Law and Economics Association (ALEA) Annual Meeting, 2013 Canadian Law and Economics Association (CLEA) Annual Meeting, 2015 NBER Summer Institute (Crime), and the Stanford Law School faculty workshop for their comments and helpful suggestions. Financial support was provided by Stanford Law School. We are indebted to Alberto Abadie, Alexis Diamond, and Jens Hainmueller for their work developing the synthetic control algorithm and programming the Stata module used in this paper and for their helpful comments. The authors would also like to thank Alex Albright, Andrew Baker, Jacob Dorn, Bhargav Gopal, Crystal Huang, Mira Korb, Haksoo Lee, Isaac Rabbani, Akshay Rao, Vikram Rao, Henrik Sachs and Sidharth Sah who provided excellent research assistance, as well as Addis O'Connor and Alex Chekholko at the Research Computing division of Stanford's Information Technology Services for their technical support. The views expressed herein are those of the author and do not necessarily reflect the views of the National Bureau of Economic Research.
\end{abstract}

NBER working papers are circulated for discussion and comment purposes. They have not been peer-reviewed or been subject to the review by the NBER Board of Directors that accompanies official NBER publications.

(C) 2017 by John J. Donohue, Abhay Aneja, and Kyle D. Weber. All rights reserved. Short sections of text, not to exceed two paragraphs, may be quoted without explicit permission provided that full credit, including $(\odot$ notice, is given to the source. 
Right-to-Carry Laws and Violent Crime: A Comprehensive Assessment Using Panel Data and a State-Level Synthetic Control Analysis

John J. Donohue, Abhay Aneja, and Kyle D. Weber

NBER Working Paper No. 23510

June 2017, Revised November 2018

JEL No. K0,K14,K4,K40,K42

\section{ABSTRACT}

This paper uses more complete state panel data (through 2014) and new statistical techniques to estimate the impact on violent crime when states adopt right-to-carry (RTC) concealed handgun laws. Our preferred panel data regression specification, unlike the statistical model of Lott and Mustard that had previously been offered as evidence of crime-reducing RTC laws, both satisfies the parallel trends assumption and generates statistically significant estimates showing RTC laws increase overall violent crime. Our synthetic control approach also strongly confirms that RTC laws are associated with 13-15 percent higher aggregate violent crime rates ten years after adoption. Using a consensus estimate of the elasticity of crime with respect to incarceration of 0.15 , the average RTC state would need to roughly double its prison population to offset the increase in violent crime caused by RTC adoption.

John J. Donohue

Stanford Law School

Crown Quadrangle

559 Nathan Abbott Way

Stanford, CA 94305

and NBER

donohue@law.stanford.edu

Abhay Aneja

Stanford Law School

559 Nathan Abbott Way

Stanford, CA 94305

abhay_aneja@haas.berkeley.edu
Kyle D. Weber

Department of Economics

Columbia University

kdw2126@columbia.edu 


\title{
Right-to-Carry Laws and Violent Crime: A Comprehensive
}

\section{Assessment Using Panel Data and a State-Level Synthetic Control}

\author{
Analysis \\ By John J. Donohue, Abhay Aneja, and Kyle D. Weber*
}

October 9, 2018

\begin{abstract}
This paper uses more complete state panel data (through 2014) and new statistical techniques to estimate the impact on violent crime when states adopt right-to-carry (RTC) concealed handgun laws. Our preferred panel data regression specification, unlike the statistical model of Lott and Mustard that had previously been offered as evidence of crime-reducing RTC laws, both satisfies the parallel trends assumption and generates statistically significant estimates showing RTC laws increase overall violent crime. Our synthetic control approach also strongly confirms that RTC laws are associated with 13-15 percent higher aggregate violent crime rates ten years after adoption. Using a consensus estimate of the elasticity of crime with respect to incarceration of 0.15 , the average RTC state would need to roughly double its prison population to offset the increase in violent crime caused by RTC adoption.
\end{abstract}

\section{Introduction}

For two decades, there has been a spirited academic debate over whether "shall issue" concealed carry laws (also known as right-to-carry or RTC laws) have an important impact on crime. The "More Guns, Less Crime" hypothesis originally articulated by John Lott and David Mustard (1997) claimed that RTC laws decreased violent crime (possibly shifting criminals in the direction of

*John J. Donohue (corresponding author): Stanford Law School, 559 Nathan Abbott Way, Stanford, CA 94305. Email: donohue@law.stanford.edu. Abhay Aneja: Haas School of Business, 2220 Piedmont Avenue, Berkeley, CA 94720. Email: aaneja@law.stanford.edu. Kyle D. Weber: Columbia University, 420 W. 118th Street, New York, NY 10027. Email: kdw2126@columbia.edu. We thank Dan Ho, Stefano DellaVigna, Rob Tibshirani, Trevor Hastie, Stefan Wager, Jeff Strnad, and participants at the 2011 Conference of Empirical Legal Studies (CELS), 2012 American Law and Economics Association (ALEA) Annual Meeting, 2013 Canadian Law and Economics Association (CLEA) Annual Meeting, 2015 NBER Summer Institute (Crime), and the Stanford Law School faculty workshop for their comments and helpful suggestions. Financial support was provided by Stanford Law School. We are indebted to Alberto Abadie, Alexis Diamond, and Jens Hainmueller for their work developing the synthetic control algorithm and programming the Stata module used in this paper and for their helpful comments. The authors would also like to thank Alex Albright, Andrew Baker, Jacob Dorn, Bhargav Gopal, Crystal Huang, Mira Korb, Haksoo Lee, Isaac Rabbani, Akshay Rao, Vikram Rao, Henrik Sachs and Sidharth Sah who provided excellent research assistance, as well as Addis O'Connor and Alex Chekholko at the Research Computing division of Stanford's Information Technology Services for their technical support. 
committing more property crime to avoid armed citizens). This research may well have encouraged state legislatures to adopt RTC laws, arguably making the pair's 1997 paper in the Journal of Legal Studies one of the most consequential criminological articles published in the last twentyfive years.

The original Lott and Mustard paper as well as subsequent work by John Lott in his 1998 book More Guns, Less Crime used a panel data analysis to support their theory that RTC laws reduce violent crime. A large number of papers examined the Lott thesis, with decidedly mixed results. An array of studies, primarily those using the limited data initially employed by Lott and Mustard for the period 1977-1992, supported the Lott and Mustard thesis, while a host of other papers were skeptical of the Lott findings. ${ }^{1}$

It was hoped that the 2005 National Research Council report Firearms and Violence: A Critical Review (hereafter the NRC Report) would resolve the controversy over the impact of RTC laws, but this was not to be. While one member of the committee-James Q. Wilson-did partially endorse the Lott thesis by saying there was evidence that murders fell when RTC laws were adopted, the other 15 members of the panel pointedly criticized Wilson's claim, saying that "the scientific evidence does not support his position." The majority emphasized that the estimated effects of RTC laws were highly sensitive to the particular choice of explanatory variables and thus concluded that the panel data evidence through 2000 was too fragile to support any conclusion about the true effects of these laws.

This paper answers the call of the NRC report for more and better data and new statistical techniques to be brought to bear on the issue of the impact of RTC laws on crime. First, we revisit the panel data evidence to see if extending the data for an additional 14 years, thereby providing additional crime data for prior RTC states as well as on eleven newly adopting RTC states, offers any clearer picture of the causal impact of allowing citizens to carry concealed weapons. Across an array of different permutations from two major sets of explanatory variables-including our preferred model (DAW) plus the models used by Lott and Mustard (LM) — all of the statistically significant results show RTC laws are associated with higher rates of overall violent crime and/or murder.

Second, to address some of the weaknesses of panel data models, we undertake an extensive synthetic control analysis in order to present the type of convincing and robust results that can

\footnotetext{
${ }^{1}$ In support of Lott and Mustard (1997), see Lott's 1998 book More Guns, Less Crime (and the 2000 and 2010 editions). Ayres and Donohue (2003) and the 2005 National Research Council report Firearms and Violence: A Critical Review dismissed the Lott/Mustard hypothesis as lacking credible statistical support, as did Aneja, Donohue, and Zhang (2011) (and Aneja, Donohue, and Zhang (2014) further expanding the latter). Moody and Marvell (2008) and Moody et al. (2014) continued to argue in favor of a crime-reducing effect of RTC laws, although Zimmerman (2014) and McElroy and Wang (2017) find that RTC laws increase violent crime and Siegel et al. (2017) find RTC laws increase murders, as discussed in Section III(B).
} 
reliably guide policy in this area. ${ }^{2}$ This synthetic control methodology—-first introduced in Abadie and Gardeazabal (2003) and expanded in Abadie, Diamond, and Hainmueller (2010) and Abadie, Diamond, and Hainmueller (2014) — uses a matching methodology to create a credible "synthetic control" based on a weighted average of other states that best matches the pre-passage pattern of crime for each "treated" state, which can then be used to estimate the likely path of crime if RTC-adopting states had not adopted an RTC law. By comparing the actual crime pattern for RTC-adopting states with the estimated synthetic controls in the post-passage period, we derive year-by-year estimates for the impact of RTC laws in the ten years following adoption. ${ }^{3}$

To preview our major findings, the synthetic control estimate of the average impact of RTC laws across the 33 states that adopt between 1981 and $2007^{4}$ indicates that violent crime is substantially higher after ten years than would have been the case had the RTC law not been adopted. Essentially, for violent crime, the synthetic control approach provides a similar portrayal of RTC laws as that provided by the DAW panel data model and undermines the results of the LM panel data model. According to the aggregate synthetic control models-whether one uses the DAW or LM covariates-RTC laws led to increases in violent crime of 13-15 percent after ten years, with positive but not statistically significant effects on property crime and murder. The median effect of RTC adoption after ten years is 12.3 percent if one considers all 31 states with ten years of data and 11.1 if one limits the analysis to the 26 states with the most compelling pre-passage fit between the adopting states and their synthetic controls. Comparing our DAW-specification findings with the results generated using placebo treatments, we are able to reject the null hypothesis that RTC laws have no impact on aggregate violent crime.

The structure of the paper proceeds as follows. Part II begins with a discussion of the ways in which increased carrying of guns could either dampen crime (by thwarting or deterring criminals) or increase crime by directly facilitating violence or aggression by permit holders (or others), greatly expanding the loss and theft of guns, and burdening the functioning of the police in ways that diminish their effectiveness in controlling crime. We then show that a simple comparison of the drop in violent crime from 1977-2014 in the states that have resisted the adoption of RTC laws

\footnotetext{
${ }^{2}$ Abadie, Diamond, and Hainmueller (2014) identify a number of possible problems with panel regression techniques, including the danger of extrapolation when the observable characteristics of the treated area are outside the range of the corresponding characteristics for the other observations in the sample.

${ }^{3}$ The accuracy of this matching can be qualitatively assessed by examining the root mean square prediction error (RMSPE) of the synthetic control in the pre-treatment period (or a variation on this RMSPE implemented in this paper), and the statistical significance of the estimated treatment effect can be approximated by running a series of placebo estimates and examining the size of the estimated treatment effect in comparison to the distribution of placebo treatment effects.

${ }^{4}$ Note that we do not supply a synthetic control estimate for Indiana, even though it passed its RTC law in 1980, owing to the fact that we do not have enough pre-treatment years to accurately match the state with an appropriate synthetic control. Including Indiana as a treatment state, though, would not meaningfully change our results. Similarly, we do not generate synthetic control estimates for Iowa and Wisconsin (whose RTC laws went into effect in 2011) and for Illinois (2014 RTC law), because of the limited post-passage data.
} 
is almost an order of magnitude greater than in RTC adopting states (a 42.3 percent drop versus a 4.3 percent drop), although a spartan panel data model with only state and year effects reduces the differential to 20.2 percent. Part III discusses the panel data results, showing that the DAW model indicates that RTC laws have increased violent and property crime, while the LM model provides evidence that RTC laws have increased murder. Importantly, the DAW violent crime model satisfies the critical parallel trends assumption, while the LM model does not.

The remainder of the paper shows that, using either the DAW or LM explanatory variables, the synthetic control approach uniformly supports the conclusion that RTC laws lead to substantial increases in violent crime. Part IV describes the details of our implementation of the synthetic control approach and shows that the mean and median estimates of the impact of RTC laws show greater than double digit increases by the tenth year after adoption. Part $\mathrm{V}$ provides aggregate synthetic control estimates of the impact of RTC laws, and Part VI concludes.

\section{The Impact of RTC Laws: Theoretical Considerations and Simple Comparisons}

\section{A. Gun Carrying and Crime}

\section{Mechanisms of Crime Reduction}

Allowing citizens to carry concealed handguns can influence violent crime in a number of ways, some benign and some invidious. Violent crime can fall if criminals are deterred by the prospect of meeting armed resistance, and potential victims or armed bystanders may thwart or terminate attacks by either brandishing weapons or actually firing on the potential assailants. For example, in 2012, a Pennsylvania concealed carry permit holder got angry when he was asked to leave a bar because he was carrying a weapon and in the ensuing argument, he shot two men, killing one, before another permit holder shot him (Kalinowski 2012). Two years later, a psychiatric patient in Pennsylvania killed his caseworker, and grazed his psychiatrist before the doctor shot back with his own gun, ending the assault by wounding the assailant (Associated Press 2014).

The impact of the Pennsylania RTC law is somewhat ambiguous in both these cases. In the bar shooting, it was a permit holder who started the killing and another who ended it, so the RTC law may actually have increased crime. The case of the doctor's use of force is more clearly benign, although the RTC law may have made no difference: a doctor who routinely deals with violent and deranged patients would typically be able to secure a permit to carry a gun even under a may-issue 
regime. Only an overall statistical analysis can reveal whether extending gun carrying beyond those with a demonstrated need and good character, as shall-issue laws do, imposes or reduces overall costs.

Some defensive gun uses can be socially costly and contentious even if they do avoid a robbery or an assault. For example, in 1984, when four teens accosted Bernie Goetz on a New York City subway, he prevented an anticipated robbery by shooting all four, permanently paralyzing one. ${ }^{5}$ In 2010, a Pennsylvania concealed carry holder argued that he used a gun to thwart a beating. After a night out drinking, Gerald Ung, a 28 year old Temple University law student, shot a 23 year old former star lacrosse player from Villanova, Eddie DiDonato, when DiDonato rushed Ung angrily and aggressively after an altercation that began when DiDonato was bumped while doing chin ups on scaffolding on the street in Philadelphia. When prosecuted, Ung testified that he always carried his loaded gun when he went out drinking. A video of the incident shows that Ung was belligerent and had to be restrained by his friends before the dispute became more physical, which raises the question of whether his gun-carrying contributed to his belligerence, and hence was a factor that precipitated the confrontation. Ung, who shot DiDonato six times, leaving DiDonato partially paralyzed with a bullet lodged in his spine, was acquitted of attempted murder, aggravated assault, and possessing an instrument of crime (Slobodzian 2011). While Ung avoided criminal liability and a possible beating, he was still prosecuted and then hit with a major civil action, and did impose significant social costs, as shootings frequently do. ${ }^{6}$

In any event, the use of a gun by a concealed carry permit holder to thwart a crime is a statistically rare phenomenon. Even with the enormous stock of guns in the U.S., the vast majority of the time that someone is threatened with violent crime no gun will be wielded defensively. A five-year study of such violent victimizations in the United States found that victims failed to defend or to threaten the criminal with a gun 99.2 percent of the time - this in a country with 300 million guns in civilian hands (Planty and Truman 2013). Adding 16 million permit holders who often dwell in low-crime areas may not yield many opportunities for effective defensive use for the roughly 1 percent of Americans who experience a violent crime in a given year, especially since criminals tend to attack in ways that preempt defensive measures.

\section{Mechanisms of Increasing Crime}

Since the statistical evidence presented in this paper suggests that the benign effects of RTC laws are outweighted by the harmful effects, we consider five ways in which RTC laws could increase

\footnotetext{
${ }^{5}$ The injury to Darrell Cabey was so damaging that he remains confined to a wheelchair and functions with the intellect of an 8-year-old, for which he received a judgment of $\$ 43$ million against Goetz, albeit without satisfaction (Biography.com 2016).

${ }^{\circ}$ According to the civil lawsuit brought by DiDonato, his injuries included "severe neurological impairment, inability to control his bowels, depression and severe neurologic injuries" (Lat 2012).
} 
crime: a) elevated crime by RTC permit holders or by others, which can be induced by the greater belligerence of permit holders that can attend gun carrying or even through counterproductive attempts by permit holders to intervene protectively; b) increased crime by those who acquire the guns of permit holders via loss or theft; c) a change in culture induced by the hyper-vigilance about one's rights and the need to avenge wrongs that the gun culture can nurture; d) elevated harm as criminals respond to the possibility of armed resistance by increasing their gun carrying and escalating their level of violence; and e) all of the above factors will either take up police time or increase the risks the police face, thereby impairing the crime-fighting ability of police in ways that can increase crime.

\section{a. Crime Committed or Induced by Permit Holders}

RTC laws can lead to an increase in violent crime by increasing the likelihood a generally lawabiding citizen will commit a crime or increasing the criminal behavior of others. Moreover, RTC laws may facilitate the criminal conduct of those who generally have a criminal intent. We consider these two avenues below.

\section{1) The Pathway from the Law-abiding Citizen}

Evidence from a nationally representative sample of 4947 individuals indicates that Americans tend to overestimate their gun-related abilities. For example, 82.6 percent believed they were less likely than the average person to use a gun in anger. When asked about their "ability to responsibly own a handgun," 50 percent of the respondents deemed themselves to be in the top 10 percent and 23 percent placed their ability within the top 1 percent of the U.S. population. Such overconfidence has been found to increase risk-taking and could well lead to an array of socially harmful consequences ranging from criminal misconduct and gun accidents to lost or stolen guns (Stark and Sachau 2016).

There are clearly cases in which concealed carry permit holders have increased the homicide toll by killing someone with whom they became angry over an insignificant issue, ranging from merging on a highway and talking on a phone in a theater to playing loud music at a gas station (Lozano 2017; Levenson 2017; Scherer 2016). For example, on July 19, 2018, Michael Drejka started to hassle a woman sitting in a car in a disabled parking spot while her husband and 5 year old son ran into a store. When the husband emerged, he pushed Drejka to the ground, who then killed him with a shot to the chest. The killing is caught on video and Drejka is being prosecuted for manslaughter in Clearwater, Florida (Simon 2018).

When Philadelphia permit holder Louis Mockewich shot and killed a popular youth football coach (another permit holder carrying his gun) over a dispute concerning snow shoveling in Jan- 
uary 2000, Mockewich's car had an NRA bumper sticker reading "Armed with Pride" (Gibbons and Moran 2000). An angry young man, with somewhat of a paranoid streak, who hasn't yet been convicted of a crime or adjudicated as a "mental defective," may be encouraged to carry a gun if he resides in an RTC state. ${ }^{7}$ That such individuals will be more likely to be aggressive once armed and hence more likely to stimulate violence by others should not be surprising.

Recent evidence suggests that as gun carrying is increasing with the proliferation of RTC laws, road rage incidents involving guns are rising (Biette-Timmons 2017; Plumlee 2012). In the nightmare case for RTC, two Michigan permit-holding drivers pulled over to battle over a tailgating dispute in September of 2013 and each shot and killed the other (Stuart|2013). Without Michigan's RTC law, this would likely have not been a double homicide. Indeed, two studies - one for Arizona and one for the nation as a whole - found that "the evidence indicates that those with guns in the vehicle are more likely to engage in "road rage"" (Hemenway, Vriniotis and Miller 2006, Miller et al. 2002). ${ }^{8}$ These studies may suggest either that gun carrying emboldens more aggressive behavior or reflects a selection effect for more aggressive individuals. ${ }^{9}$ If this is correct, then it may not be a coincidence that there are so many cases in which a concealed carry holder acts belligerently and is shot by another permit holder. ${ }^{10}$

In general, the critique that the relatively low number of permit revocations proves that permit holders don't commit enough crime to substantially elevate violent criminality is misguided for a variety of reasons. First, only a small fraction of one percent of Americans commits a gun crime each year, so we do not expect even a random group of Americans to commit much crime, let alone a group purged of convicted felons. Nonetheless, permit revocations clearly understate the criminal misconduct of permit holders, since not all violent criminals are caught and we have

\footnotetext{
${ }^{7}$ The Gun Control Act of 1968 prohibits gun possession by felons and adjudicated "mental defectives" (18 U.S.C. 922 (d) (4) 2016).

${ }^{8} \mathrm{~A}$ perfect illustration was provided by 25 -year-old Minnesota concealed carry permit holder Alexander Weiss, who got into an argument after a fender bender caused by a 17 year old driver. Since the police had been called, it is hard to imagine that this event could end tragically - unless someone had a gun. Unfortunately, Weiss, who had a bumper sticker on his car saying "Gun Control Means Hitting Your Target," killed the 17-year-old with one shot to the chest and has been charged with second-degree murder (KIMT 2018).

${ }^{9}$ While concealed carry permit holders should be free of any felony conviction, and thus show a lower overall rate of violence than a group that contains felons, a study in Texas found that when permit holders do commit a crime, it tends to be a severe one: "the concentration of convictions for weapons offenses, threatening someone with a firearm, and intentionally killing a person stem from the ready availability of a handgun for CHL holders" (Phillips et al.2013).

${ }^{10}$ We have just cited three of them: the 2012 Pennsylvania bar shooting, the 2000 Philadelphia snow shoveling dispute, and the 2013 Michigan road-rage incident. In yet another recent case, two permit holders glowered at each other in a Chicago gas station, and when one drew his weapon, the second man pulled out his own gun and killed the 43-year old instigator, who died in front of his son, daughter, and pregnant daughter-in-law (Hernandez 2017). A video of the encounter can be found at https://www.youtube.com/watch?v=I2j9vvDHIBU. According to the police report obtained by the Chicago Tribune, a bullet from the gun exchange broke the picture window of a nearby garden apartment and another shattered the window of a car with four occupants that was driving past the gas station. No charges were brought against the surviving permit holder, who shot first but in response to the threat initiated by the other permit holder.
} 
just seen four cases where five permit holders were killed, so no permit revocation or criminal prosecution would have occurred regardless of any criminality by the deceased. ${ }^{11}$ Second, and perhaps more importantly, RTC laws increase crime by individuals other than permit holders in a variety of ways. The messages of the gun culture, perhaps reinforced by the adoption of RTC laws, can promote fear and anger, which are emotions that can invite more hostile confrontations leading to violence. For example, if permit holder George Zimmerman hassled Trayvon Martin only because he was carrying his weapon, the presence of Zimmerman's gun could be deemed to have encouraged a hostile confrontation, regardless of who ultimately becomes violent.

Even well-intentioned interventions by permit holders intending to stop a crime have elevated the crime count when they ended with the permit holder either being killed by the criminal $^{12}$ or shooting an innocent party by mistake. ${ }^{13}$ Indeed, an FBI study of 160 active shooter incidents found that in almost half ( 21 of 45 ) of the situations in which police engaged the shooter to end the threat, law enforcement suffered casualties, totaling nine killed and 28 wounded (Blair and Schweit 2014). One would assume the danger to an untrained permit holder trying to confront an active shooter would be greater than that of a trained professional, which may in part explain why effective intervention in such cases by permit holders to thwart crime is so rare. While the same FBI report found that in 21 of a total of 160 active shooter incidents between 2000 and 2013, "the situation ended after unarmed citizens safely and successfully restrained the shooter," there was only one case - in a bar in Winnemucca, Nevada in 2008 - in which a private citizen other than an armed security guard stopped a shooter, and that individual was an active-duty Marine (Holzel 2008).

\footnotetext{
${ }^{11}$ In addition, NRA efforts to pass state laws that ban the release of information about whether those arrested for even the most atrocious crimes are RTC permit holders make it extremely difficult to monitor their criminal conduct.

${ }^{12}$ In 2016 in Arlington, Texas, a man in a domestic dispute shot at a woman and then tried to drive off (under Texas law it was lawful for him to be carrying his gun in his car, even though he did not have a concealed carry permit.) When he was confronted by a permit holder, the shooter slapped the permit holder's gun out of his hand and then killed him with a shot to the head. Shortly thereafter, the shooter turned himself into the police (Mettler 2016).

In 2014, when armed criminals entered a Las Vegas Walmart and told everyone to get out because "This is a revolution," one permit holder told his friend he would stay to confront the threat. He was gunned down shortly before the police arrived, adding to the death toll rather than reducing it (NBC News 2014).

${ }^{13}$ In 2012, "a customer with a concealed handgun license ... accidentally shot and killed a store clerk" during an attempted robbery in Houston (MacDonald 2012). Similarly, in 2015, also in Houston, a bystander who drew his weapon upon seeing a carjacking incident ended up shooting the victim in the head by accident (KHOU 2015).

An episode in June 2017 underscored that interventions even by well-trained individuals can complicate and exacerbate unfolding crime situations. An off-duty Saint Louis police officer with eleven years of service was inside his home when he heard the police exchanging gunfire with some car thieves. Taking his police-issued weapon, he went outside to help, but as he approached he was told by two officers to get on the ground and then shot in the arm by a third officer who "feared for his safety" (Hauser 2017).
} 


\section{2) The Pathway from those Harboring Criminal Intent}

Over the ten-year period from May 2007 through January 2017, the Violence Policy Center (2017) lists 31 instances in which concealed carry permit holders killed three or more individuals in a single incident. Many of these episodes are disturbingly similar in that there was substantial evidence of violent tendencies and/or serious mental illness, but no effort was made to even revoke the carry permit, let alone take effective action to prevent access to guns. For example, on January 6, 2017, concealed handgun permit holder Esteban Santiago, 26, killed five and wounded six others at the Fort Lauderdale-Hollywood Airport, before sitting on the floor and waiting to be arrested as soon as he ran out of ammunition. In the year prior to the shooting, police in Anchorage, Alaska, charged Santiago with domestic violence in January 2016, and visited the home five times during the year for various other complaints (KTUU 2017). In November 2016, Santiago entered the Anchorage FBI office and spoke of "mind control" by the CIA and having "terroristic thoughts," (Hopkins 2017). Although the police took his handgun at the time, it was returned to him on December 7, 2016 after Santiago spent four days in a mental health facility because, according to federal officials, "there was no mechanism in federal law for officers to permanently seize the weapon"14 (Boots 2017). Less than a month later, Santiago flew with his gun to Florida and opened fire in the baggage claim area. ${ }^{15}$

In January 2018, the FBI charged Taylor Wilson, a 26-year-old Missouri concealed carry permit holder, with terrorism on an Amtrak train when, while carrying a loaded weapon, he tried to interfere with the brakes and controls of the moving train. According to the FBI, Wilson had 1) previously joined an "alt-right" neo-Nazi group and travelled to the Unite the Right rally in Charlottesville, Virginia in August 2017; 2) indicated his interest in "killing black people" and was the perpetrator of a road-rage incident in which he pointed a gun at a black woman for no apparent reason while driving on an interstate highway in April 2016; and 3) possessed devices and weapons "to engage in criminal offenses against the United States." It sounds as though Wilson was a person with various criminal designs, and, conceivably, having the permit to legally carry weapons facilitated those designs (Pilger 2018).

In June 2017, Milwaukee Police Chief Ed Flynn pointed out that criminal gangs have taken advantage of RTC laws by having gang members with clean criminal records obtain concealed carry permits and then hold the guns after they are used by the active criminals (Officer.com2017). Flynn was referring to so-called "human holsters" who have RTC permits and hold guns for those barred from possession. For example, Wisconsin permit holder Darrail Smith was stopped three

\footnotetext{
${ }^{14}$ Moreover, in 2012, Puerto Rican police confiscated Santiago's handguns and held them for two years before returning them to him in May 2014, after which he moved to Alaska (Clary, O'Matz and Arthur 2017).

${ }^{15}$ For a similar story of repeated gun violence and signs of mental illness by a concealed carry permit holder, see the case of Aaron Alexis, who murdered 12 at the Washington Navy Yard in September 2013 (Carter, Lavandera and Perez 2013).
} 
times while carrying guns away from crime scenes before police finally charged him with criminal conspiracy. In the second of these, Smith was "carrying three loaded guns, including one that had been reported stolen," but that was an insufficient basis to charge him with a crime or revoke his RTC permit (DePrang 2015). Having a "designated permit holder" along to take possession of the guns when confronted by police may be an attractive benefit for criminal elements acting in concert (Fernandez, Stack, and Blinder 2015; Luthern 2015).

\section{b. Increased Gun Thefts}

The most frequent occurrence each year involving crime and a good guy with a gun is not selfdefense but rather the theft of the good guy's gun, which occurs hundreds of thousands of times each year. ${ }^{16}$ Data from a nationally representative web-based survey conducted in April 2015 of 3949 subjects revealed that those who carried guns outside the home had their guns stolen at a rate over one percent per year (Hemenway, Azrael and Miller 2017). Given the current level of roughly 16 million permit holders, a plausible estimate is that RTC laws result in permit holders furnishing more than 100,000 guns per year to criminals. ${ }^{17}$ As Phil Cook has noted, the relationship between gun theft and crime is a complicated one for which little definitive data is currently available (Cook 2018). But if there was any merit to the outrage over the loss of about 1400 guns during the Fast and Furious program that began in 2009 and the contribution that these guns made to crime (primarily in Mexico), it highlights the severity of the vastly greater burdens of guns lost by and stolen from U.S. gun carriers. ${ }^{18}$ A 2013 report from the Bureau of Alcohol, Tobacco, Firearms and Explosives concluded that "lost and stolen guns pose a substantial threat to public safety and to law enforcement. Those that steal firearms commit violent crimes with stolen guns, transfer stolen

\footnotetext{
${ }^{16}$ According to Larry Keane, senior vice president of the National Shooting Sports Foundation (a trade group that represents firearms manufacturers), "There are more guns stolen every year than there are violent crimes committed with firearms." More than 237,000 guns were reported stolen in the United States in 2016, according to the FBI's National Crime Information Center. The actual number of thefts is obviously much higher since many gun thefts are never reported to police, and "many gun owners who report thefts do not know the serial numbers on their firearms, data required to input weapons into the NCIC." The best survey estimated 380,000 guns were stolen annually in recent years, but given the upward trend in reports to police, that figure likely understates the current level of gun thefts (Freskos 2017b).

${ }^{17}$ While the Hemenway, Azrael and Miller study is not large enough and detailed enough to provide precise estimates, it establishes that those who have carried guns in the last month are more likely to have them stolen. A recent Pew Research Survey found that 26 percent of American gunowners say they carry a gun outside of their home "all of most of the time" (Igielnik and Brown 2017, surveying 3930 U.S. adults, including 1269 gunowners). If one percent of 16 million permit holders have guns stolen each year, that would suggest 160,000 guns were stolen. Only guns stolen outside the home would be attributable to RTC laws, so a plausible estimate of guns stolen per year owing to gun carrying outside the home might be 100,000.

18 "Of the 2,020 guns involved in the Bureau of Alcohol, Tobacco, Firearms, and Explosives probe dubbed 'Operation Fast and Furious,' 363 have been recovered in the United States and 227 have been recovered in Mexico. That leaves 1,430 guns unaccounted for" (Schwarzschild and Griffin 2011). Wayne LaPierre of the NRA was quoted as saying, "These guns are now, as a result of what [ATF] did, in the hands of evil people, and evil people are committing murders and crimes with these guns against innocent citizens" (Horwitz 2011).
} 
firearms to others who commit crimes, and create an unregulated secondary market for firearms, including a market for those who are prohibited by law from possessing a gun" (Office of the Director - Strategic Management 2013; Parsons and Vargas 2017).

For example, after Sean Penn obtained a permit to carry a gun, his car was stolen with two guns in the trunk. The car was soon recovered, but the guns were gone (Donohue 2003). In July 2015 in San Francisco, the theft of a gun from a car in San Francisco led to a killing of a tourist on a city pier that almost certainly would not have occurred if the lawful gun owner had not left it in the car (Ho 2015). Just a few months later, a gun stolen from an unlocked car was used in two separate killings in San Francisco and Marin in October 2015 (Ho and Williams 2015). According to the National Crime Victimization Survey, in 2013 there were over 660,000 auto thefts from households. More guns being carried in vehicles by permit holders means more criminals will be walking around with the guns stolen from permit holders. ${ }^{19}$

As Michael Rallings, the top law enforcement official in Memphis, Tennessee, noted in commenting on the problem of guns being stolen from cars: "Laws have unintended consequences. We cannot ignore that as a legislature passes laws that make guns more accessible to criminals, that has a direct effect on our violent crime rate" (Freskos 2017a). An Atlanta police sergeant elaborated on this phenomenon: "Most of our criminals, they go out each and every night hunting for guns, and the easiest way to get them is out of people's cars. We're finding that a majority of stolen guns that are getting in the hands of criminals and being used to commit crimes were stolen out of vehicles" (Freskos 2017c $)$. Another Atlanta police officer stated that weapons stolen from cars "are used in crimes to shoot people, to rob people," because criminals find these guns to be easy to steal and hard to trace. "For them, it doesn't cost them anything to break into a car and steal a gun“ (Freskos 2016). ${ }^{20}$

Of course, the permit holders whose guns are stolen are not the killers, but they can be the butfor cause of the killings. Lost, forgotten, and misplaced guns are another dangerous by-product of RTC laws. ${ }^{21}$

\footnotetext{
${ }^{19}$ In early December 2017, the Sheriff in Jacksonville, Florida announced that his office knew of 521 guns that had been stolen so far in 2017 - from unlocked cars alone! (Campbell 2017).

${ }^{20}$ Examples abound: Tario Graham was shot and killed during a domestic dispute in February 2012 with a revolver stolen weeks earlier out of pickup truck six miles away in East Memphis (Perrusquia 2017). In Florida, a handgun stolen from an unlocked Honda Accord in mid-2014 helped kill a police officer a few days before Christmas that year (Sampson 2014). A gun stolen from a parked car during a Mardi Gras parade in 2017 was used a few days later to kill 15-year-old Nia Savage in Mobile, Alabama, on Valentine's Day (Freskos 2017a).

${ }^{21}$ The growing TSA seizures in carry-on luggage are explained by the increase in the number of gun carriers who simply forget they have a gun in their luggage or briefcase (Williams and Waltrip 2004). A chemistry teacher at Marjory Stoneman Douglas High School in Parkland, Fla., who had said he would be willing to carry a weapon to protect students at the school, was criminally charged for leaving a loaded pistol in a public restroom. The teacher's $9 \mathrm{~mm}$ Glock was discharged by an intoxicated homeless man who found it in the restroom (Stanglin 2018).
} 


\section{c. Enhancing a Culture of Violence}

The South has long had a higher rate of violent crime than the rest of the country. For example, in 2012, while the South had about one-quarter of the U.S. population, it had almost 41 percent of the violent crime reported to police (Fuchs 2013). Social psychologists have argued that part of the reason the South has a higher violent crime rate is that it has perpetuated a "subculture of violence" predicated on an aggrandized sense of one's rights and honor that responds negatively to perceived insults. A famous experiment published in the Journal of Personality and Social Psychology found that Southern males were more likely than Northern males to respond aggressively to being bumped and insulted. This was confirmed by measurement of their stress hormones and their frequency of engaging in aggressive or dominant behavior after being insulted (Cohen et al.|1996). To the extent that RTC laws reflect and encourage this cultural response, they can promote violent crime not only by permit holders, but by all those with or without guns who are influenced by this crime-inducing worldview.

Even upstanding citizens, such as Donald Brown, a 56-year-old retired Hartford firefighter with a distinguished record of service, can fall prey to the notion that resort to a lawful concealed weapon is a good response to a heated argument. Brown was sentenced to seven years in prison in January 2018 by a Connecticut judge who cited his "poor judgment on April 24, 2015, when he drew his licensed 9mm handgun and fired a round into the abdomen of Lascelles Reid, 33." The shooting was prompted by a dispute "over renovations Reid was performing at a house Brown owns" (Owens 2018). Once again, we see that the RTC permit was the pathway to serious violent crime by a previously law abiding citizen.

\section{d. Increasing Violence by Criminals}

The argument for RTC laws is often predicated on the supposition that they will encourage good guys to have guns, leading only to benign effects on the behavior of bad guys. This is highly unlikely to be true. ${ }^{22}$ Indeed, the evidence that gun prevalence in a state is associated with higher

\footnotetext{
${ }^{22}$ Consider in this regard, David Friedman's theoretical analysis of how right to carry laws will reduce violent crime: "Suppose one little old lady in ten carries a gun. Suppose that one in ten of those, if attacked by a mugger, will succeed in killing the mugger instead of being killed by him-or shooting herself in the foot. On average, the mugger is much more likely to win the encounter than the little old lady. But-also on average-every hundred muggings produce one dead mugger. At those odds, mugging is a very unattractive profession-not many little old ladies carry enough money in their purses to justify one chance in a hundred of being killed getting it. The number of muggers-and muggings-declines drastically, not because all of the muggers have been killed but because they have, rationally, sought safer professions" (Friedman|1990).

There is certainly no empirical support for the conjecture that muggings will "decline drastically" in the wake of RTC adoption. What Friedman's analysis overlooks is that muggers can decide not to mug (which is what Friedman posits) or they can decide to initiate their muggings by cracking the old ladies over the head or by getting prepared to shoot them if they start reaching for a gun (or even wear body armor). Depending on the response of the criminals to increased gun carrying by potential victims, the increased risk to the criminals may be small compared to the increased
} 
rates of lethal force by police (even controlling for homicide rates) suggests that police may be more fearful and shoot quicker when they are more likely to interact with an armed individual (Nagin 2018). ${ }^{23}$ Presumably, criminals would respond in a similar fashion, leading them to arm themselves more frequently, attack more harshly, and shoot more quickly when citizens are more likely to be armed. In one study, two-thirds of prisoners incarcerated for gun offenses "reported that the chance of running into an armed victim was very or somewhat important in their own choice to use a gun" (Cook, Ludwig and Samaha 2009). Such responses by criminals will elevate the toll of the crimes that do occur.

Indeed, a panel data estimate over the years 1980 to 2016 reveals that the percentage of robberies committed with a firearm rises by 18 percent in the wake of RTC adoption $(t=2.60) .{ }^{24}$ Our synthetic controls assessment similarly shows that the percentage of robberies committed with a firearm increases by 35 percent over 10 years $(t=4.48) .{ }^{25}$ Moreover, there is no evidence that RTC laws are reducing the overall level of robberies: the panel data analysis associates RTC laws with a 9 percent higher level of overall robberies $(\mathrm{t}=1.85)$ and the synthetic controls analysis suggests a 7 percent growth over 10 years $(\mathrm{t}=1.19)$.

\section{e. Impairing Police Effectiveness}

According to an April 2016 report of the Council of Economic Advisers, "Expanding resources for police has consistently been shown to reduce crime; estimates from economic research suggests that a $10 \%$ increase in police size decreases crime by 3 to 10\%" (CEA|2016, p. 4). In summarizing the evidence on fighting crime in the Journal of Economic Literature, Aaron Chalfin and Justin McCrary note that adding police manpower is almost twice as effective in reducing violent crime as it is in reducing property crime (Chalfin and McCrary 2017). Therefore, anything that RTC laws do to occupy police time, from processing permit applications to checking for permit validity to dealing with gunshot victims, inadvertent gun discharges, and the staggering number of stolen guns is likely to have an opportunity cost expressed in higher violent crime.

The presence of more guns on the street can complicate the job of police as they confront (or shy away from) armed citizens. A Minnesota police officer who stopped Philando Castile for a broken tail light shot him seven times only seconds after Castile indicated he had a permit to carry a weapon because the officer feared the permit holder might be reaching for the gun. After a similar experience between an officer and a permit holder, the officer told the gun owner, "Do you realize

risk to the victims. Only an empirical evaluation can answer this question.

${ }^{23}$ See footnote 28 and accompanying text for examples of this pattern of police use of lethal force.

${ }^{24}$ The panel data model uses the DAW explanatory variables set forth in Table 2

${ }^{25}$ The weighted average proportion of robberies committed by firearm in the year prior to RTC adoption (for states that adopted RTC between 1981 and 2014) is 36 percent while the similar proportion in 2014 for the same RTC states is 43 percent (and for non-RTC states is 29 percent). 
you almost died tonight?" (Kaste 2016). ${ }^{26}$

A policemen trying to give a traffic ticket has more to fear if the driver is armed. When a gun is found in a car in such a situation, a greater amount of time is needed to ascertain the driver's status as a permit holder. A lawful permit holder who happens to have forgotten his permit may end up taking up more police time through arrest and/or other processing.

Moreover, police may be less enthusiastic about investigating certain suspicious activities or engaging in effective crime-fighting actions given the greater risks that widespread gun carrying poses to them, whether from permit holders or the criminals who steal their guns. ${ }^{27}$ In a speech at the University of Chicago Law School in October of 2015, then-FBI Director James Comey argued that criticism of overly aggressive policing led officers to back away from more involved policing, causing violent crime to rise (Donohue 2017a). If the more serious concern of being shot by an angry gun toter impairs effective policing, the prospect of increased crime following RTC adoption could be far more substantial than the issue that Comey highlighted. ${ }^{28}$

The presence of multiple gun carriers can also complicate police responses to mass shootings and other crimes. For example, according to the police, when a number of Walmart customers (fecklessly) pulled out their weapons during a shooting on November 1, 2017, their "presence 'absolutely' slowed the process of determining who, and how many, suspects were involved in the shootings, said Thornton [Colorado] police spokesman Victor Avila" (Simpson 2017).

Similarly, in 2014, a concealed carry permit holder in Illinois fired two shots at a fleeing armed

\footnotetext{
${ }^{26}$ A permit to carry instructor has posted a YouTube video about "How to inform an officer you are carrying a handgun and live" that is designed to "keep yourself from getting shot unintentionally" by the police. The video, which has over 4.2 million views, has generated comments from non-Americans that it "makes the US look like a war zone" and leads to such unnatural and time-consuming behavior that "an English officer ... would look at you like a complete freak" (Soderling 2016).

27،"Every law enforcement officer working today knows that any routine traffic stop, delivery of a warrant or court order, or response to a domestic disturbance anywhere in the country involving people of any race or age can put them face to face with a weapon. Guns are everywhere, not just in the inner city" (Wilson|2016).

In offering an explanation for why the US massively leads the developed world in police shootings, criminologist David Kennedy stated that "Police officers in the United States in reality need to be conscious of and are trained to be conscious of the fact that literally every single person they come in contact with may be carrying a concealed firearm." For example, police in England and Wales shot and killed 55 people over the 15 year period from 1990-2014, while in just the first 24 days of 2015, the US (with six times the population) had a higher number of fatal shootings by police (Lopez 2018).

${ }^{28} \mathrm{~A}$ vivid illustration of how even the erroneous perception that someone accosted by the police is armed can lead to deadly consequences is revealed in the chilling video of five Arizona police officers confronting an unarmed man they incorrectly believed had a gun. During the prolonged encounter, the officers shouted commands at an intoxicated 26 year-old father of two, who begged with his hands in the air not to be shot. The man was killed by five bullets when, following orders to crawl on the floor towards police, he paused to pull up his slipping pants.

A warning against the open carry of guns issued by the San Mateo County, California, Sheriff's Office makes the general point that law enforcement officers become hypervigilant when encountering an armed individual: "Should the gun carrying person fail to comply with a law enforcement instruction or move in a way that could be construed as threatening, the police are forced to respond in kind for their own protection. It's well and good in hindsight to say the gun carrier was simply 'exercising their rights' but the result could be deadly" (Lunny 2010).
} 
robber at a phone store, thereby interfering with a pursuing police officer. According the the police, "Since the officer did not know where the shots were fired from, he was forced to terminate his foot pursuit and take cover for his own safety" (Glanton and Sadovi 2014).

Even benign interventions can end in tragedy for the good guy with a gun. On July 27, 2018, police officers arrived as a "good Samaritan" with a concealed carry permit was trying to break up a fight in Portland, Oregon. The police saw the gun held by the permit holder - a Navy veteran, postal worker, and father of three - and in the confusion shot and killed him (Gueverra 2018).

Indeed, preventive efforts to get guns off the street in high-crime neighborhoods are less feasible when carrying guns is presumptively legal. The passage of RTC laws normalizes the practice of carrying guns in a way that may enable criminals to carry guns more readily without prompting a challenge, while making it harder for the police to know who is and who is not allowed to possess guns in public.

Furthermore, negligent discharges of guns, although common, rarely lead to charges of violent crime but they can take up valuable police time for investigation and in determining whether criminal prosecution or permit withdrawal is warranted. For example, on November 16, 2017, Tennessee churchgoers were reflecting on the recent Texas church massacre in Sutherland Springs when a permit holder mentioned he always carries his gun, bragging that he would be ready to stop any mass shooter. While proudly showing his Ruger handgun, the permit holder inadvertently shot himself in the palm, causing panic in the church as the bullet "ripped through [his wife's] lower left abdomen, out the right side of her abdomen, into her right forearm and out the backside of her forearm. The bullet then struck the wall and ricocheted, landing under the wife's wheelchair." The gun discharge prompted a 911 call, which in the confusion made the police think an active shooting incident was underway. The result was that the local hospital and a number of schools were placed on lockdown for 45 minutes until the police finally ascertained that the shooting was accidental (Eltagouri 2017). ${ }^{29}$

Everything that takes up added police time or complicates the job of law enforcement will serve as a tax on police, rendering them less effective on the margin, and thereby contributing to

\footnotetext{
${ }^{29}$ Negligent discharges by permit holders have occurred in public and private settings from parks, stadiums, movie theaters, restaurants, and government buildings to private households (WFTV 2015, Heath 2015). 39-year-old Mike Lee Dickey, who was babysitting an eight year old boy, was in the bathroom removing his handgun from his waistband when it discharged. The bullet passed through two doors, before striking the child in his arm while he slept in a nearby bedroom (Associated Press 2015).

In April 2018, a 21-year-old pregnant mother of two in Indiana was shot by her 3-year-old daughter, when the toddler's father left the legal but loaded $9 \mathrm{~mm}$ handgun between the console and the front passenger seat after he exited the vehicle to go inside a store. The child climbed over from the backseat and accidentally fired the gun, hitting her mother though the upper right part of her torso. (Palmer 2018)

See also: (Barbash 2018) (California teacher demonstrating gun safety accidentally discharges weapon in a high school classroom in March 2018, injuring one student); (Fortin 2018) (in February 2018, a Georgia teacher fired his gun while barricaded in his classroom); and (US News 2018)(in April 2018, an Ohio woman with a valid concealed carry permit accidentally killed her 2-year-old daughter at an Ohio hotel while trying to turn on the gun's safety).
} 
crime. Indeed, this may in part explain why RTC states tend to increase the size of their police forces (relative to non-adopting states) after RTC laws are passed, as shown in Table 1, below. ${ }^{30}$

\section{B. A Simple Difference-in Differences Analysis}

We begin by showing how violent crime evolved over our 1977-2014 data period for RTC and non-RTC states. ${ }^{31}$ Figure 1 depicts percentage changes in the violent crime rate over our entire data period for three groups of states: those that never adopted RTC laws, those that adopted RTC laws sometime between 1977 and before 2014, and those that adopted RTC laws prior to 1977. It is noteworthy that the 42.3 percent drop in violent crime in the nine states that never adopted RTC laws is almost an order of magnitude greater than the 4.3 percent reduction experienced by states that adopted RTC laws during our period of analysis. ${ }^{32}$

The NRC Report presented a "no-controls" estimate, which is just the coefficient estimate on the variable indicating the date of adoption of an RTC law in a crime rate panel data model with state and year fixed effects. According to the NRC Report, "Estimating the model using data to 2000 shows that states adopting right-to-carry laws saw 12.9 percent increases in violent crime-and 21.2 percent increases in property crime-relative to national crime patterns." Estimating this same model using 14 additional years of data (through 2014) and eleven additional adopting states (listed at the bottom of Appendix Table C1) reveals that the average post-passage increase in violent crime was 20.2 percent, while the comparable increase in property crime was 19.2 percent (both having p-values less than 5 percent). ${ }^{33}$

Of course, simply because RTC states experience a worse post-passage crime pattern, this does not prove that RTC laws increase crime. For example, it might be the case that some states decided to fight crime by allowing citizens to carry concealed handguns while others decided to hire more police and incarcerate a greater number of convicted criminals. If police and prisons were more effective in stopping crime, the "no controls" model might show that the crime experience in RTC states was worse than in other states even if this were not a true causal result of the adoption of

\footnotetext{
${ }^{30}$ See Adda, McConnell and Rasul (2014), describing how local depenalization of cannabis enabled the police to re-allocate resources, thereby reducing violent crime.

${ }^{31}$ The FBI violent crime category includes murder, rape, robbery, and aggravated assault.

${ }^{32}$ Over the same 1977-2014 period, the states that avoided adopting RTC laws had substantially smaller increases in their rates of incarceration and police employment. The nine never-adopting states increased their incarceration rate by 205 percent, while the incarceration rates in the adopting states rose by 262 and 259 percent, for those adopting RTC laws before and after 1977 respectively. Similarly, the rate of police employment rose by 16 percent in the never-adopting states and by 38 and 55 percent, for those adopting before and after 1977, respectively.

${ }^{33}$ The dummy variable model reports the coefficient associated with an RTC variable that is given a value of zero if an RTC law is not in effect in that year, a value of one if an RTC law is in effect that entire year, and a value equal to the portion of the year an RTC law is in effect otherwise. The date of adoption for each RTC state is shown in Appendix Table A1
} 
The decline in violent crime rates has been far greater in states with no RTC laws, 1977-2014 Data Sources: UCR for crime rates; Census for state populations.
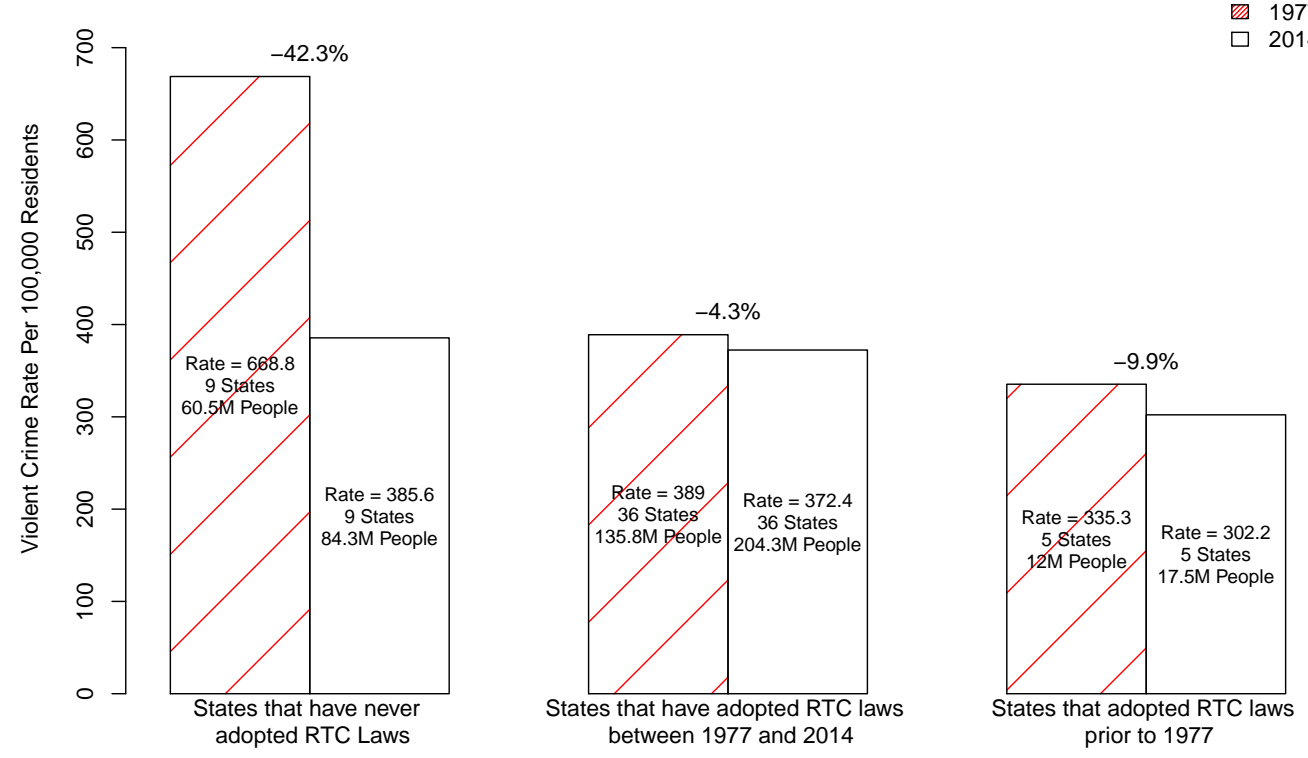

Note: Illinois excluded since its concealed carry law did not go into effect until 2014. From 1977-2013, the violent crime rate in Illinois fell by 36 percent, from 631 to 403 crimes per 100,000 people.

Figure 1

RTC laws. As it turns out, though, RTC states not only experienced higher rates of violent crime but they also had larger increases in incarceration and police than other states. Table 1 provides panel data evidence on how incarceration and two measures of police employment changed after RTC adoption (relative to non-adopting states). All three measures rose in RTC states, and the 7-8 percent greater increases in police in RTC states are statistically significant. In other words, Table 1 confirms that RTC states did not have relatively declining rates of incarceration or total police employees after adopting their RTC laws that might explain their comparatively poor post-passage crime performance.

\section{A Panel Data Analysis of RTC Laws}

\section{A. Estimating Two Models on the Full Data Period 1977-2014}

We have just seen that RTC law adoption is followed by higher rates of violent and property crime (relative to national trends) and that the poorer crime performance after RTC law adoption occurs 
Table 1: Panel Data Estimates Showing Greater Increases in Incarceration and Police Following RTC Adoption: State- and Year-Fixed Effects, and No Other Regressors, 1977-2014

\section{Incarceration Police Employment Per 100k Police Officers Per 100k}

(1)

(2)

(3)

\begin{tabular}{l} 
Dummy variable model $6.78(6.22) \quad 8.39^{* * *}(3.15)$ \\
\hline \hline OLS estimations include state- and year-fixed effects and are weighted by population. Robust standard \\
errors (clustered at the state level) are provided next to point estimates in parentheses. The police em- \\
ployment and sworn police officer data is from the Uniform Crime Reports (UCR). The source of the \\
incarceration rate is the Bureau of Justice Statistics (BJS). ${ }^{*} \mathrm{p}<.1, * * \mathrm{p}<.05, * * * \mathrm{p}<.01$. All figures \\
reported in percentage terms.
\end{tabular}

despite the fact that RTC states actually invested relatively more heavily in prisons and police than non-RTC states. While the theoretical predictions about the effect of RTC laws on crime are indeterminate, these two empirical facts based on the actual patterns of crime and crime-fighting measures in RTC and non-RTC states suggest that the most plausible working hypothesis is that RTC laws increase crime. The next step in a panel data analysis of RTC laws would be to test this hypothesis by introducing an appropriate set of explanatory variables that plausibly influence crime.

The choice of these variables is important because any variable that both influences crime and is simultaneously correlated with RTC laws must be included if we are to generate unbiased estimates of the impact of RTC laws. At the same time, including irrelevant and/or highly collinear variables can also undermine efforts at valid estimation of the impact of RTC laws. At the very least, it seems advisable to control for the levels of police and incarceration because these have been the two most important criminal justice policy instruments in the battle against crime.

\section{The DAW Panel Data Model}

In addition to the state and year fixed effects of the no-controls model and the identifier for the presence of an RTC law, our preferred "DAW model" includes an array of other factors that might be expected to influence crime, such as the levels of police and incarceration, various income, poverty and unemployment measures, and six demographic controls designed to capture the presence of males in three racial categories (Black, White, other) in two high-crime age groupings (15-19 and 20-39). Table 2 lists the full set of explanatory variables for both the DAW model and the comparable panel data model used by Lott and Mustard (LM). ${ }^{34}$

\footnotetext{
${ }^{34}$ While we attempt to include as many state-year observations in these regressions as possible, District of Columbia incarceration data is missing after the year 2001. In addition, a handful of observations are also dropped from the LM
} 


\section{Table 2: Table of Explanatory Variables For Four Panel Data Studies}

\section{Explanatory Variables}

Right to carry law

Lagged per capita incarceration rate

Lagged police staffing per 100,000 residents

Poverty rate

Unemployment rate

Per capita ethanol consumption from beer

Percentage of state population living in metropolitan statistical areas (MSA)

Real per capita personal income

Real per capita income maintenance

Real per capita retirement payments

Real per capita unemployment insurance payments

Population density

Lagged violent or property arrest rate

State population

\section{$\underline{D A W} \underline{L M}$}

$\mathrm{X} \quad \mathrm{X}$

$\mathrm{x}$

$\mathrm{X}$

$\mathrm{X}$

$\mathrm{X}$

$\mathrm{X}$

$\mathrm{X}$

$\mathrm{X} \quad \mathrm{X}$

$\mathrm{X}$

$\mathrm{X}$

$\mathrm{X}$

$\mathrm{X}$

$\mathrm{X}$

$\mathrm{X}$

$\mathrm{X}$

6 Age-sex-race demographic variables

-all 6 combinations of black, white, and other males in 2 age groups (15-19,

20-39) indicating the percentage of the population in each group

36 Age-sex-race demographic variables

$\mathrm{X}$

-all possible combinations of black and white males in 6 age groups (10-19,

20-29, 30-39, 40-49, 50-64 and over 65) and repeating this all for females,

indicating the percentage of the population in each group

Note: The DAW model is advanced in this paper and the LM model was previously published by Lott and Mustard.

Mathematically, the dummy model takes the following form:

$$
\ln \left(\text { crime rate }_{i t}\right)=\beta X_{i t}+\gamma R T C_{i t}+\alpha_{t}+\delta_{i}+\varepsilon_{i t}
$$

where $\gamma$ is the coefficient on the RTC dummy, reflecting the average estimated impact of adopting a RTC law on crime. The matrix $X_{i t}$ contains either the DAW or LM covariates and demographic controls for state $i$ in year $t$. The vectors $\alpha$ and $\delta$ are year and state fixed effects, respectively, while $\varepsilon_{i t}$ is the error term.

The spline model uses the same set of covariates and comparable state and year fixed effects

regressions owing to states that did not report any usable arrest data in various years. Our regressions are performed with robust standard errors that are clustered at the state level, and we lag the arrest rates used in the LM regression models. The rationales underlying both of these changes are described in more detail in Aneja, Donohue, and Zhang (2014). All of the regressions presented in this paper are weighted by state population. 
and error term, but drops the RTC dummy and allows RTC laws to change the trend in crime, as reflected in the following equation: ${ }^{35}$

$$
\ln \left(\text { crime rate }_{i t}\right)=\beta X_{i t}+\gamma A F T E R_{i t} * C H G_{i}+\zeta \operatorname{REND}_{t} * C H G_{i}+\alpha_{t}+\delta_{i}+\varepsilon_{i t}
$$

The coefficient of interest, $\gamma$, now measures the change in trend for each post-passage year in RTC adopting states relative to those that do not adopt RTC. AFTER measures the number of years after RTC adoption. CHG (change) is a binary variable that is equal to one if the state adopts an RTC law during our analysis period. TREND is a time trend that measures the number of years since the beginning of the analysis period (1979 for the DAW panel data model). ${ }^{36}$

The DAW panel data estimates of the impact of RTC laws on crime are shown in Table $3^{37}$ The results are consistent with, although smaller in magnitude than, those observed in the nocontrols model: RTC laws on average increased violent crime by 9.0 percent and property crime by 6.5 percent in the years following adoption according to the dummy model, but again showed no statistically significant effect in the spline model. ${ }^{38}$ As in the no-controls model, the estimated effect of RTC laws in Table 3 on the murder rate is very imprecisely estimated and not statistically significant.

We should also note one caveat to our results. Panel data analysis assumes that the treatment in any one state does not influence crime in non-treatment states. But as we noted above, ${ }^{39}$ RTC laws tend to lead to substantial increases in gun thefts and those guns tend to migrate to states with more restrictive gun laws, where they elevate violent crime. This flow of guns from RTC to nonRTC states has been documented by gun trace data $\left(\right.$ Knight 2013). ${ }^{40}$ As a result, our panel data estimates of the impact of RTC laws are downward biased by the amount that RTC laws induce

\footnotetext{
${ }^{35}$ The spline model reports results for a variable that is assigned a value of zero before the RTC law is in effect and a value equal to the portion of the year the RTC law was in effect in the year of adoption. After this year, the value of this variable is incremented by one annually for states that adopted RTC laws between 1977 and 2014 . The spline model also includes a second trend variable representing the number of years that have passed since 1977 for the states adopting RTC laws over the sample period.

${ }^{36} t$ starts with 1977 for LM. The interaction of AFTER and TREND with CHG in equation (2) ensures that pre-1977 adopters such as Vermont do not contribute to our spline effect.

${ }^{37}$ The complete set of estimates for all explanatory variables (except the demographic variables) for the DAW and LM dummy and spline models is shown in appendix Table B1.

${ }^{38}$ Defensive uses of guns are more likely for violent crimes because the victim will clearly be present. For property crimes, the victim is typically absent, thus providing less opportunity to defend with a gun. It is unclear whether the many ways in which RTC laws could lead to more crime, which we discuss in Section II(A.2), would be more likely to facilitate violent or property crime, but our intuition is that violent crime would be more strongly influenced, which is in fact what Table 3 suggests.

${ }^{39}$ See text at footnotes 17,19

40 "Seventy-five percent of traceable guns recovered by authorities in New Jersey [a non-RTC state] are purchased in states with weaker gun laws, according to ... firearms trace data ... compiled by the federal Bureau of Alcohol, Tobacco, Firearms and Explosives ... between 2012 and 2016" (Pugliese 2018). See also (Freskos 2018).
} 
crime spillovers into non-RTC states. ${ }^{41}$

Table 3: Panel Data Estimates Suggesting that RTC Laws increase Violent and Property Crime: State and Year Fixed Effects, DAW Regressors, 1979-2014

\begin{tabular}{lcccc}
\hline \hline & & & & \\
& Murder Rate & Murder Count & Violent Crime Rate & Property Crime Rate \\
& $(1)$ & $(2)$ & $(3)$ & $(4)$ \\
\hline Dummy variable model & $0.21(5.33)$ & $1.05(0.05)$ & $9.02^{* * *}(2.90)$ & $6.49^{* *}(2.74)$ \\
Spline model & $-0.33(0.53)$ & $1.00(0.00)$ & $0.01(0.64)$ & $0.11(0.39)$ \\
\hline \hline
\end{tabular}

All models include year and state fixed effects, and OLS estimates are weighted by state population. Robust standard errors (clustered at the state level) are provided next to point estimates in parentheses. In Column 2 we present Incidence Rate Ratios (IRR) estimated using negative binomial regression, where population is included as a control variable, as STATA does not have a weighting function for nbreg. The null hypothesis is that the IRR equals 1 . The crime data is from the Uniform Crime Reports (UCR). Six demographic variables (based on different age-sex-race categories) are included as controls in the regression above. Other controls include the lagged incarceration rate, the lagged police employee rate, real per capita personal income, the unemployment rate, poverty rate, beer, and percentage of the population living in MSAs. $* \mathrm{p}<.1,{ }^{*} \mathrm{p}<.05, * * * \mathrm{p}<.01$. All figures reported in percentage terms.

\section{The LM Panel Data Model}

Table 2 s recitation of the explanatory variables contained in the Lott and Mustard (LM) panel data model reveals two obvious omissions: there are no controls for the levels of police and incarceration in each state, even though a substantial literature has found that these factors have a large impact on crime. Indeed, as we saw above in Table 1, both of these factors grew substantially and statistically significantly after RTC law adoption. A Bayesian analysis of the impact of RTC laws found that "the incarceration rate is a powerful predictor of future crime rates," and specifically faulted this omission from the Lott and Mustard model (Strnad 2007: 201, fn. 8). Without more, then, we have reason to believe that the LM model is mis-specified, but in addition to the obvious omitted variable bias, we have discussed an array of other infirmities with the LM model in Aneja, Donohue, and Zhang (2014), including their reliance on flawed pseudo-arrest rates, and highly collinear demographic variables.

As noted in Aneja, Donohue, and Zhang (2014),

\footnotetext{
${ }^{41}$ Some of the guns stolen from RTC permit holders may also end up in foreign countries, which will stimulate crime there but not bias our panel data estimates. For example, a recent analysis of guns seized by Brazilian police found that 15 percent came from the United States. Since many of these were assault rifles, they were probably not guns carried by American RTC permit holders (Paraguassu and Brito 2018).
} 
"The Lott and Mustard arrest rates ... are a ratio of arrests to crimes, which means that when one person kills many, for example, the arrest rate falls, but when many people kill one person, the arrest rate rises, since only one can be arrested in the first instance and many can in the second. The bottom line is that this "arrest rate" is not a probability and is frequently greater than one because of the multiple arrests per crime. For an extended discussion on the abundant problems with this pseudo arrest rate, see Donohue and Wolfers (2009)."

The LM arrest rates are also econometrically problematic since the denominator of the arrest rate is the numerator of the dependent variable crime rate, improperly leaving the dependent variable on both sides of the regression equation. We lag the arrest rates by one year to reduce this problem of ratio bias.

Lott and Mustard's use of 36 demographic variables is also a potential concern. With so many enormously collinear variables, the high likelihood of introducing noise into the estimation process is revealed by the wild fluctuations in the coefficient estimates on these variables. For example, consider the LM explanatory variables "neither black nor white male aged 30-39" and the identical corresponding female category. The LM dummy variable model for violent crime suggests that the male group will vastly increase crime (the coefficient is 219 !), but their female counterparts have an enormously dampening effect on crime (with a coefficient of -258!). Both of those highly implausible estimates (not shown in Appendix Table B1) are statistically significant at the 0.01 level, and they are almost certainly picking up noise rather than revealing true relationships. Bizarre results are common in the LM estimates among these 36 demographic variables. ${ }^{42}$

Table 4, Panel A shows the results of the LM panel data model estimated over the period 1977-2014. As seen above, the DAW model generated estimates that RTC laws raised violent and property crime (in the dummy model of Table 3), while the estimated impact on murders was too imprecise to be informative. The LM model flips these predictions by showing strong estimates of increased murder (in the spline model) and imprecise and not statistically significant estimates for violent and property crime. We can almost perfectly restore the DAW Table 3 findings, however, by simply limiting the inclusion of 36 highly collinear demographic variables to the more typical array used in the DAW regressions, as seen in Panel B of Table 4. This modified LM dummy variable model suggests that RTC laws increase violent and property crime, mimicking the DAW

\footnotetext{
${ }^{42}$ Aneja, Donohue, and Zhang (2014) test for the severity of the multicollinearity problem using the 36 LM demographic variables, and the problem is indeed serious. The Variance Inflation Factor (VIF) is shown to be in the range of six to seven for the RTC variable in both the LM dummy and spline models when the 36 demographic controls are used. Using the six DAW variables reduces the multicollinearity for the RTC dummy to a tolerable level (with VIFs always below the desirable threshold of 5). Indeed, the degree of multicollinearity for the individual demographics of the black-male categories are astonishingly high with 36 demographic controls - with VIFs in the neighborhood of 14,000 ! This analysis makes us wary of estimates of the impact of RTC laws that employ the LM set of 36 demographic controls.
} 
dummy variable model estimates, and this same finding persists if we add in controls for police and incarceration, as seen in Panel C of Table 4

Table 4: Panel Data Estimates of the Impact of RTC Laws: State and Year Fixed Effects, Using Actual and Modified LM Regressors, 1977-2014

\begin{tabular}{lcccc}
\hline \hline \multicolumn{5}{c}{ Panel A: LM Regressors Including 36 Demographic Variables } \\
& Murder Rate & Murder Count & Violent Crime Rate & Property Crime Rate \\
& $(1)$ & $(2)$ & $(3)$ & $(4)$ \\
\hline Dummy variable model & $-4.60(3.43)$ & $1.03(0.03)$ & $-1.38(3.16)$ & $-0.34(1.71)$ \\
Spline model & $0.65^{* *}(0.33)$ & $1.01^{* *}(0.00)$ & $0.41(0.47)$ & $0.28(0.28)$ \\
\hline \hline
\end{tabular}

Panel B: LM Regressors with 6 DAW Demographic Variables

Murder Rate Murder Count Violent Crime Rate Property Crime Rate

(1)

Dummy variable model

$2.81(6.04)$

(2)

$1.07(0.05)$

$0.37(0.46)$

$1.00(0.00)$

Spline model
(3)

(4)

$7.59^{* *}(3.72)$

$0.49(0.35)$

Panel C: LM Regressors with 6 DAW Demographic Variables and Adding Controls for Incarceration and Police Murder Rate Murder Count Violent Crime Rate Property Crime Rate

(3)

(4)

Dummy variable model $\quad 3.61(5.69) \quad 1.06(0.05) \quad 10.05^{* *}(4.54) \quad 8.10^{* *}(3.63)$

$\begin{array}{lllll}\text { Spline model } & 0.30(0.43) & 1.00(0.00) & 0.50(0.57) & 0.50(0.34)\end{array}$

All models include year and state fixed effects, and OLS estimates are weighted by state population. Robust standard errors (clustered at the state level) are provided next to point estimates in parentheses. In Panel A, 36 demographic variables (based on different age-sex-race categories) are included as controls in the regressions above. In Panel B, only 6 demographic variables are included. In Panel C, only 6 demographic variables are included and controls are added for incarceration and police. For both Panels, other controls include the previous year's violent or property crime arrest rate (depending on the crime category of the dependent variable), state population, population density, real per capita income, real per capita unemployment insurance payments, real per capita income maintenance payments, and real retirement payments per person over 65 . * $\mathrm{p}<.1$, ** $\mathrm{p}<.05$, *** $\mathrm{p}<.01$. All figures reported in percentage terms.

In summary, the LM model that had originally been employed using data through 1992 to 
argue that RTC laws reduce crime, no longer shows any statistically significant evidence of crime reduction. Indeed, using more complete data, the LM spline model (Panel A of Table 4) suggests that RTC laws increase the murder rate by 6-7 percent (and the murder count by ten percent) after ten years, which are the only statistically significant results in Panel A. Those who are skeptical of these results because the LM specification includes too many highly collinear demographic variables might prefer the estimates in Panel B and C, which simply limit the LM demographic variables from 36 to 6 , thereby restoring the Table 3 DAW dummy variable model result that RTC laws increase both violent and property crime. The following section reveals the fundamental problem with the LM model, which confirms why it cannot generate reliable estimates of the impact of RTC laws.

We also conducted a panel data assessment looking at the 11 states that adopted RTC laws in the period from 2000-2014 when the confounding effect of the crack epidemic had subsided. The results provide further support that RTC laws increase crime. See discussion and relevant estimates in Appendix C.

\section{Testing the DAW and LM Models for the Parallel Trends Assumption}

We have already registered concerns about the choice of controls included in the LM model, but we have yet to evaluate whether either the DAW or LM models satisfy the critical assumption of parallel trends in the period prior to adoption of the RTC laws. As we will see, the LM model uniformly violates the assumption of parallel trends, and the DAW model - particularly for violent crime - illustrates nearly perfect parallel trends in the decade prior to RTC adoption.

To implement this test, we ran regressions showing the values on dummy variables for 10 years prior to RTC adoption to 10 years after RTC adoption. If the key parallel trends assumption of panel data analysis is valid, we should see values of the pre-adoption dummies that show no trend and are close to zero. Figure 2 shows that the DAW violent crime model performs extremely well: the pre-adoption dummies are virtually all zero (and hence totally flat) for the 8 years prior to adoption, and violent crime starts rising in the year of adoption, showing statistically significant increases after the law has been in effect for at least a full year. The upward trend in violent crime continues for the entire decade after adoption.

In contrast to the ideal performance of the DAW violent crime model, the LM violent crime model performs extremely poorly, as shown in Appendix Figure D1. The pattern of declining dummy estimates throughout the decade prior to adoption shows that the parallel trends assumption is violated in the LM model. Appendix Figure D1 also illustrates why the LM dummy model estimate on violent crime in Table 4.A was not positive and statistically significant (as it was for the DAW model in Table 3 and the modified LM models in Table 4.B and 4.C): Appendix Figure 


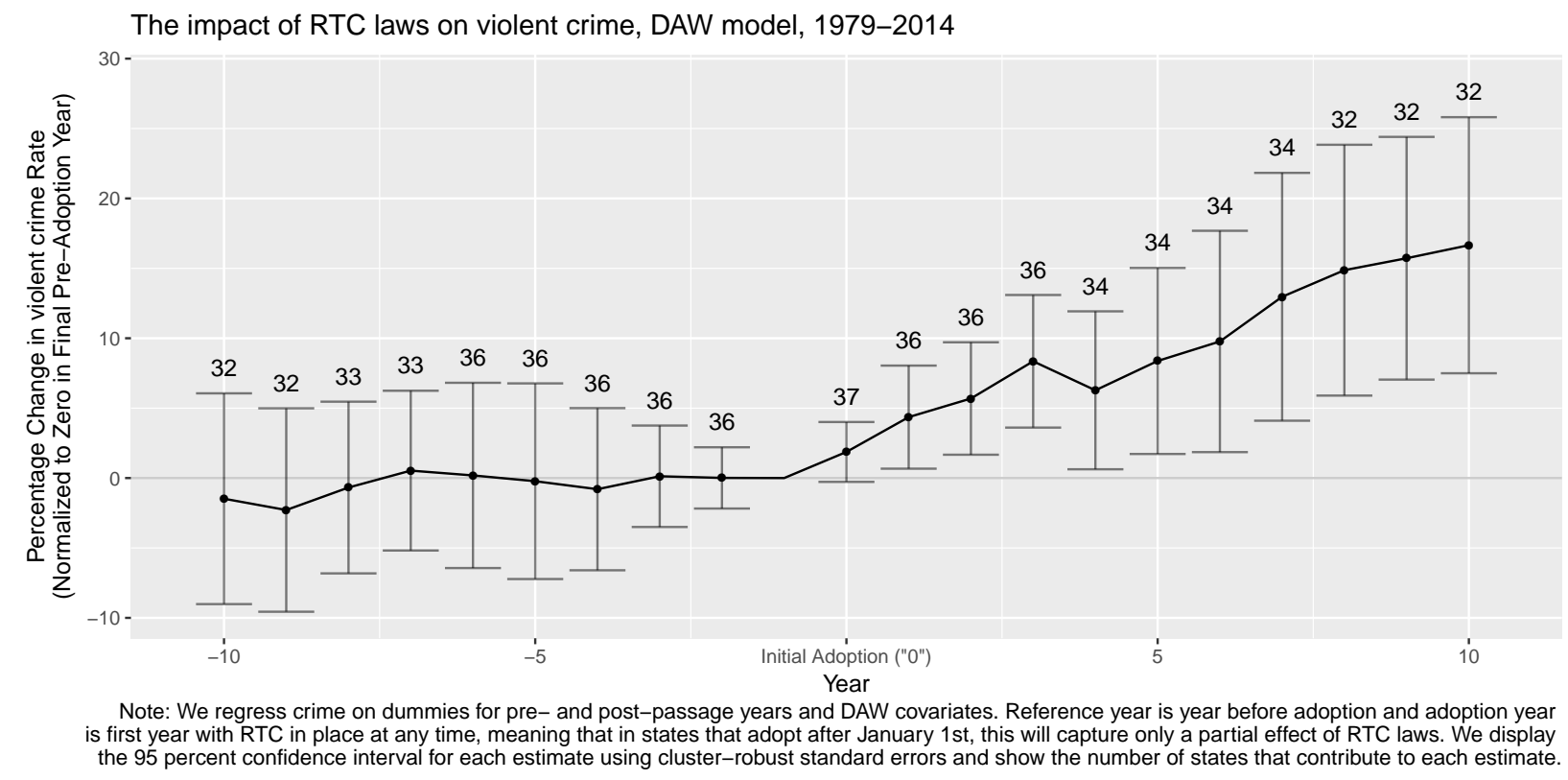

Figure 2

D1 reveals that, for the LM model, violent crime was trending down throughout the pre-adoption period dropping from 5 percentage points to zero over that decade, at which point it reverses and violent crime increases to roughly a 6 percent increase by 10 years after RTC adoption. The vshape pattern over that two-decade period leads the LM dummy model to obscure the increase in violent crime that is clearly seen in Appendix Figure D1.

For the DAW and LM property crime panel data estimates, we see almost the same pattern. While the pre-adoption performance of the DAW property crime model (see Appendix Figure D2) is not quite as perfect as it was for violent crime, it still shows a roughly flat pattern for the eight years prior to adoption, followed by a persistent pattern of increasing property crime in the ten years after RTC adoption. The increase in property crime turns statistically significant at the time of adoption. In Appendix Figure D3, however, we again see the same deficient pattern observed for the LM model in Appendix Figure D1; property crime falls in the 10 years prior to adoption, and the pattern reverses itself leading to increasing property crime in the decade following RTC adoption.

Repeating this exercise for the DAW and LM murder rate estimates in Appendix Figures D4 and D5 once again confirms that the LM model clearly violates the parallel trends assumption, now falling from 10 percent down to zero in the decade prior to RTC adoption. The downward trend levels out about two years after adoption, suggesting that adoption of a RTC law puts an end to a benign pre-passage trend in the murder rate. The DAW murder rate graph of Appendix Figure D4 is again not quite as pristine as the near-perfect fit of the violent crime graph (Figure 2), but 
it performs reasonably well, at least in the six years prior to RTC adoption. Nine of the eleven post-adoption dummies are positive, suggesting increases in murder, but the increases are rather small and the confidence intervals are so wide that we can't say much about the likely impact of RTC laws on murder from this panel data analysis. ${ }^{43}$

\section{B. Summary of Panel Data Analysis}

The uncertainty about the impact of RTC laws on crime expressed in the NRC Report was based on an analysis of data only through 2000. The preceding evaluation of an array of different specifications over the full data period from the late 1970s through 2014 has eliminated any statistically significant evidence of benign effects on crime from the adoption of RTC laws. Considerable evidence that RTC laws increase murder and/or overall violent crime has now been amassed. In addition, two of the three models estimated on post-crack-era data (Zimmerman 2014, and DAW) provide further support for this conclusion, as does the recent work by Donohue $(2017 b)$ and Siegel et al. (2017) concluding that RTC laws increase firearm and handgun homicide. Pending work by McElroy and Wang (2017) reinforces this conclusion, with results from a dynamic model that accounts for forward-looking behavior finding that violent crime would be one-third lower if RTC laws had not been passed.

Despite the substantial panel data evidence in the post-NRC literature that supports the finding of the pernicious influence of RTC laws on crime, the NRC suggestion that new techniques should be employed to estimate the impact of these laws is fitting. The important paper by Strnad (2007) used a Bayesian approach to argue that none of the published models used in the RTC evaluation literature rated highly in his model selection protocol when applied to data from 1977-1999.

Durlauf, Navarro, and Rivers (2016) attempt to sort out the different specification choices in evaluating RTC laws by using their own Bayesian model averaging approach using county data from 1979-2000. Applying this technique, the authors find that in their preferred spline (trend) model, RTC laws elevate violent crime in the three years after RTC adoption: "As a result of the law being introduced, violent crime increases in the first year and continues to increase afterwards" (50). By the third year, their preferred model suggests a 6.5 percent increase in violent crime. Since their paper only provides estimates for three post-passage years, we cannot draw conclusions beyond this but note that their finding that violent crime increases by over two percent per year owing to RTC laws is a substantial crime increase. Moreover, the authors note that "For our

\footnotetext{
${ }^{43}$ Appendix D also shows the comparable set of graphs for the negative binomial estimates of the impact of RTC laws on murders (as opposed to the murder rate) - see Appendix Figures D6 and D7 Since the dummy values in these two figures are even more volatile in the pre-adoption period and have even wider confidence intervals in the post-adoption period than the comparable murder rate dummy values of Appendix Figures D4 and D5, there is less to be learned from these negative binomial results.
} 
estimates, the effect on crime of introducing guns continues to grow over time" (50).

Owing to the substantial challenges of estimating effects from observational data, it will be useful to see if yet another statistical approach that has different attributes from the panel data methodology can enhance our understanding of the impact of RTC laws. The rest of this paper will use this synthetic control approach, which has been deemed "arguably the most important innovation in the policy evaluation literature in the last 15 years" (Athey and Imbens 2017).

\section{Estimating the Impact of RTC Laws Using Synthetic Controls}

The synthetic control methodology, which is becoming increasingly prominent in economics and other social sciences, is a promising new statistical approach for addressing the impact of RTC laws. ${ }^{44}$ While most synthetic control papers focus on a single treatment in a single geographic region, we look at 33 RTC adoptions occurring over three decades throughout the country. For each adopting ("treated") state we will find a weighted average of other states ("a synthetic control") designed to serve as a good counter-factual for the impact of RTC laws because it had a similar pattern of crime to the adopting state prior to RTC adoption. By comparing what actually happened to crime after RTC adoption to the crime performance of the synthetic control over the same period, we generate estimates of the causal impact of RTC laws on crime. ${ }^{45}$

\section{A. The Basics of the Synthetic Control Methodology}

The synthetic control method attempts to generate representative counterfactual units by comparing a treatment unit (i.e., a state adopting an RTC law) to a set of control units across a set of explanatory variables over a pre-intervention period. The algorithm searches for similarities between the treatment state of interest and the control states during this period and then generates a synthetic counterfactual unit for the treatment state that is a weighted combination of the component control states. ${ }^{46}$ Two conditions are placed on these weights: they must be non-negative

\footnotetext{
${ }^{44}$ The synthetic control methodology has been deployed in a wide variety of fields, including health economics (Engelen, Nonnemaker, and Shive 2011), immigration economics (Bohn, Lofstrom, and Raphael 2014), political economy (Keele 2009), urban economics (Ando 2015), the economics of natural resources (Mideksa 2013), and the dynamics of economic growth (Cavallo et al.2013).

${ }^{45}$ For a more detailed technical description of this method, we direct the reader to Abadie and Gardeazabal (2003), Abadie, Diamond, and Hainmueller (2010), and Abadie, Diamond, and Hainmueller (2014).

${ }^{46}$ Our analysis is done in Stata using the synth software package developed by Alberto Abadie, Alexis Diamond, and Jens Hainmueller.
} 
and they must sum to one. In general, the matching process underlying the synthetic control technique uses pre-treatment values of both the outcome variable of interest (in our case, some measure of crime) and other predictors believed to influence this outcome variable. ${ }^{47}$ For the reasons set forth in Appendix $\mathrm{J}$, we use every lag of the dependent variable as predictors in the DAW and LM specifications. Once the synthetic counterfactual is generated and the weights associated with each control unit are assigned, the synth program then calculates values for the outcome variable associated with this counterfactual and the root mean squared prediction error (RMSPE) based on differences between the treatment and synthetic control units in the pre-treatment period. The effect of the treatment can then be estimated by comparing the actual values of the dependent variable for the treatment unit to the corresponding values of the synthetic control.

\section{B. Generating Synthetic Controls for 33 States Adopting RTC Laws During our Data Period}

To illustrate the procedure outlined above, consider the case of Texas, whose RTC law went into effect on January 1, 1996. The potential control group for each treatment state consists of all nine states with no RTC legislation as of the year 2014, as well as states that pass RTC laws at least ten years after the passage of the treatment state (e.g., in this case, the five states passing RTC laws after 2006, such as Nebraska and Kansas, whose RTC laws went into effect at the beginning of 2007). Since we estimate results for up to ten years post-passage, ${ }^{48}$ this restriction helps us avoid including states with their own permissive concealed carry laws in the synthetically constructed unit (which would mar the control comparison).

After entering the necessary specification information into the synth program (e.g., treatment unit, list of control states, explanatory variables, etc.), the algorithm proceeds to construct the synthetic unit from the list of control states specific to Texas and generates values of the dependent variable for the counterfactual for both the pre-treatment and post-treatment periods. The rationale behind this methodology is that a close fit in the pre-passage time series of crime between the treatment state and the synthetic control generates greater confidence in the accuracy of the constructed counterfactual. Computing the post-treatment difference between the dependent variables

\footnotetext{
${ }^{47}$ Roughly speaking, the algorithm that we use finds $\mathbf{W}$ (the weights of the components of the synthetic control) that minimizes $\sqrt{\left(\mathbf{X}_{\mathbf{1}}-\mathbf{X}_{\mathbf{0}} \mathbf{W}\right)^{\prime} \mathbf{V}\left(\mathbf{X}_{\mathbf{1}}-\mathbf{X}_{\mathbf{0}} \mathbf{W}\right)}$, where $\mathbf{V}$ is a diagonal matrix incorporating information about the relative weights placed on different predictors, $\mathbf{W}$ is a vector of non-negative weights that sum to one, $\mathbf{X}_{\mathbf{1}}$ is a vector containing pre-treatment information about the predictors associated with the treatment unit, and $\mathbf{X}_{\mathbf{0}}$ is a matrix containing pretreatment information about the predictors for all of the control units.

${ }^{48}$ Our choice of ten years is informed by the tradeoffs associated with using a different time frame. Tables 5 and 6 indicate that the increase in violent crime due to RTC laws is statistically significant at the .01 level for all years after 7 years post-adoption.
} 
of the treatment state and the synthetic control unit provides the synthetic control estimate of the treatment effect attributable to RTC adoption in that state.

\section{Synthetic Control Estimates of Violent Crime in Two States}

Figure 3 shows the synthetic control graph for violent crime in Texas over the period from 1977 through 2006 (ten years after the adoption of Texas's RTC law). The solid black line shows the actual pattern of violent crime for Texas, and the vertical line indicates when the RTC law went into effect. Implementing the synthetic control protocol identifies three states that generate a good fit for the pattern of crime experienced by Texas in the pre-1996 period. These states are California, which gets a weight of 57.7 percent owing to its similar attributes compared to Texas, Nebraska with a weight of 9.7 percent, and Wisconsin with a weight of 32.6 percent.

One of the advantages of the synthetic control methodology is that one can assess how well the synthetic control (call it "synthetic Texas," which is identified in Figure 3 by the dashed line) matches the pre-RTC-passage pattern of violent crime to see whether the methodology is likely to generate a good fit in the ten years of post-passage data. Here the fit looks rather good in mimicking the rises and falls in Texas violent crime from 1977-1995. This pattern increases our confidence that synthetic Texas will provide a good prediction of what would have happened in Texas had it not adopted an RTC law.

Looking at Figure 3, we see that while both Texas and synthetic Texas (the weighted average violent crime performance of the three mentioned states) show declining crime rates in the postpassage decade after 1996, the crime drop is substantially greater in synthetic Texas, which had no RTC law over that period, than in actual Texas, which did. As Figure 3 notes, ten years after adopting its RTC law, violent crime in Texas was 16.9 percent higher than we would have expected had it not adopted an RTC law. 49

Figure 3 also illustrates perhaps the most important lesson of causal inference: one cannot simply look before and after an event to determine the consequence of the event. Rather, one needs to estimate the difference between what did unfold and the counterfactual of what would have unfolded without the event. The value of the synthetic control methodology is that it provides a highly transparent estimate of that counterfactual. Thus, when Lott (2010) quotes a Texas District Attorney suggesting that he had reversed his earlier opposition to the state's RTC law in light of the

\footnotetext{
${ }^{49}$ Texas' violent crime rate ten years post-adoption exceeds that of "synthetic Texas" by 20.41 percent $=$ $\frac{517.3-429.6}{429.6} \times 100 \%$. While some researchers would take that value as the estimated effect of RTC, we chose to subtract off the discrepancy in 1996 between the actual violent crime rate and the synthetic control value in that year. This discrepancy is 3.55 percent $=\frac{644.4-622.3}{622.3} \times 100 \%$ (shown in the line just below the graph of Figure 3). See footnote 55 for further discussion of this calculation. Figure 3 shows a (rounded) estimated violent crime increase in Texas of 16.9 percent. We arrive at this estimate by subtracting the 1996 discrepancy of 3.55 percent from the 20.41 percent tenth year discrepancy, which generates a TEP of 16.86 percent.
} 
perceived favorable experience with the law, we see why it can be quite easy to draw the inaccurate causal inference that Texas' crime decline was facilitated by its RTC law. The public may perceive the falling crime rate post-1996 (the solid black line) but our analysis suggests that Texas would have experienced a more sizable violent crime decline if it had not passed an RTC law (the dotted line). More specifically, Texas experienced a 19.7 percent decrease in its aggregate violent crime rate in the ten years following its RTC law (between 1996 and 2006), while the state's synthetic control experienced a larger 31.0 percent decline. This counterfactual would not be apparent to residents of the state or to law enforcement officials, but our results suggest that Texas's RTC law imposed a large social cost on the state.

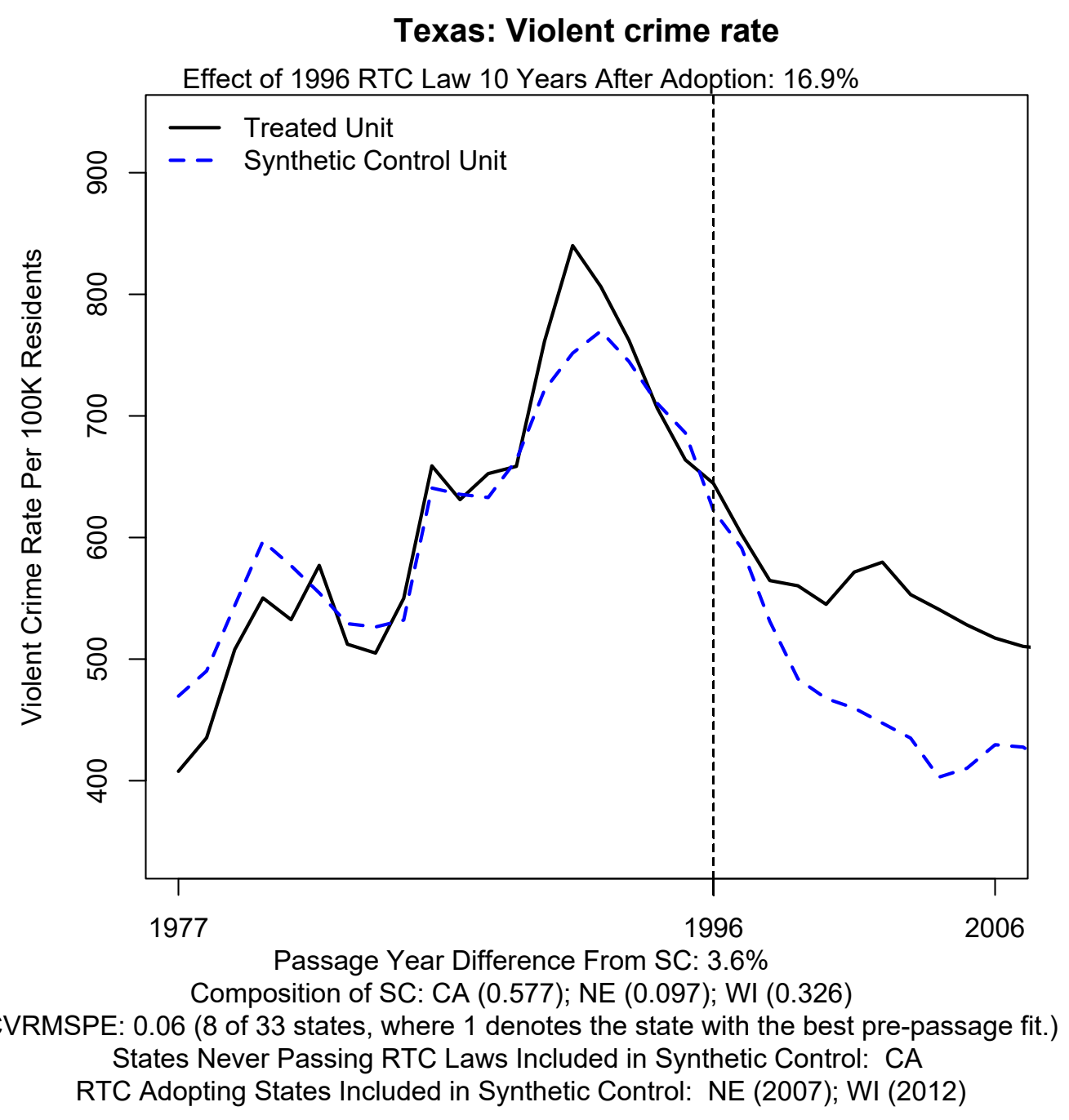

Figure 3

The greater transparency of the synthetic control approach is one advantage of this methodology over the panel data models that we considered above. Figure 3 makes clear what Texas is being 
compared to, and we can reflect on whether this match is plausible and whether anything other than RTC laws changed in these three states during the post-passage decade that might compromise the validity of the synthetic control estimate of the impact of RTC laws.

Figure 4 shows our synthetic control estimate for Pennsylvania, which adopted an RTC law in 1989 that did not extend to Philadelphia until a subsequent law went into effect on October 11, 1995. In this case, synthetic Pennsylvania is comprised of eight states and the pre-passage fit is nearly perfect. Following adoption of the RTC laws, synthetic Pennsylvania shows substantially better crime performance than actual Pennsylvania after the RTC law is extended to Philadelphia in late 1995, as illustrated by the second vertical line at 1996. The synthetic control method estimates that RTC laws in Pennsylvania increased its violent crime rate by 24.4 percent after ten years. ${ }^{50}$

\footnotetext{
${ }^{50}$ In Appendix I, we include all 33 graphs showing the path of violent crime for the treatment states and the synthetic controls, along with information about the composition of these synthetic controls, the dates of RTC adoption (if any) for states included in these synthetic controls, and the estimated treatment effect (expressed in terms of the percent change in a particular crime rate) ten years after adoption (or seven years after adoption for two states that adopted RTC laws in 2007, since our data ends in 2014). The figures also document the discrepancy in violent crime in the year of adoption between the actual and synthetic control values.
} 


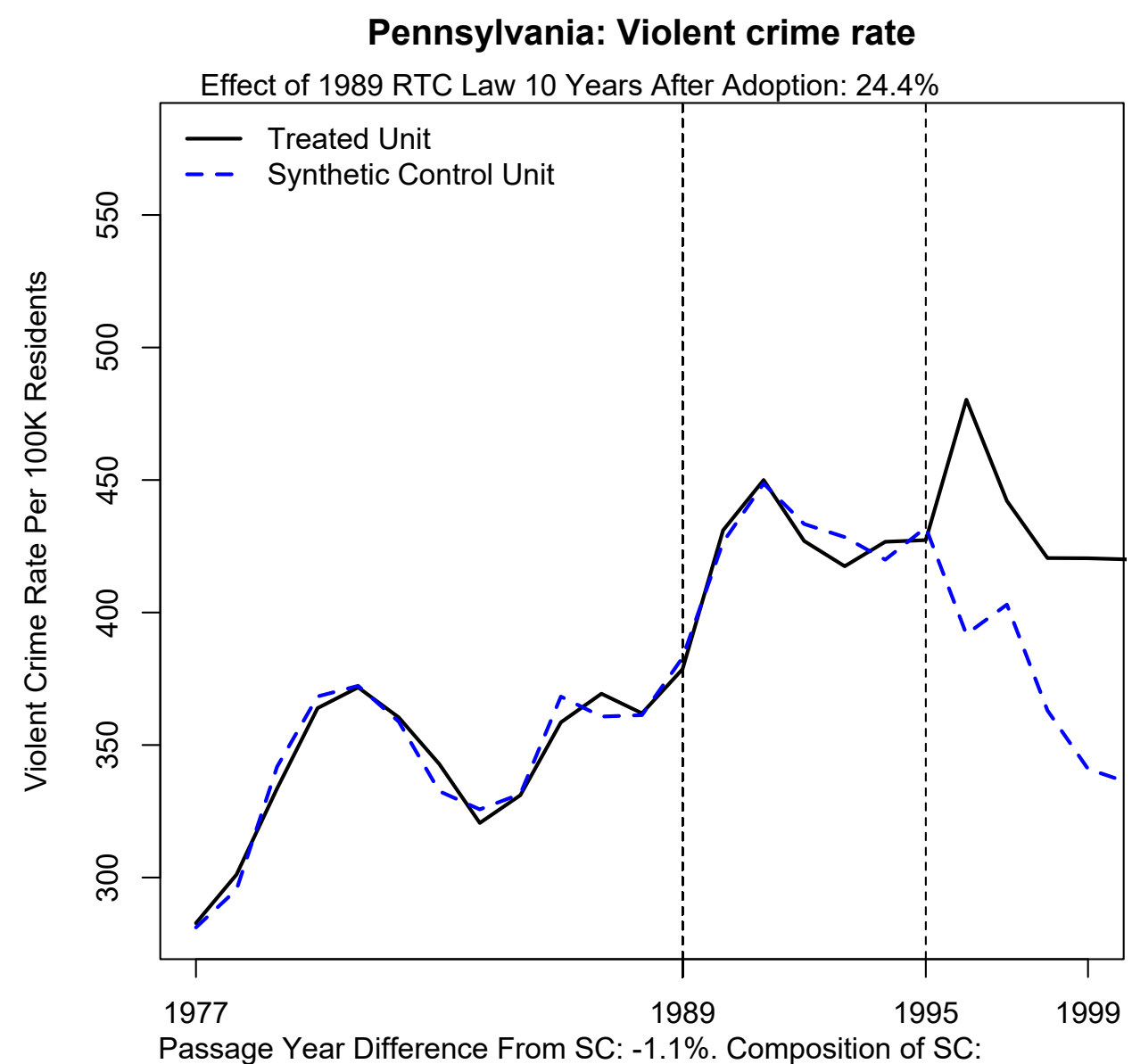

DE (0.078); HI (0.073); MD (0.038); NE (0.016); NJ (0.103); OH (0.27); WI (0.424)

CVRMSPE: 0.017 ( 1 of 33 states, where 1 denotes the state with the best pre-passage fit.)

States Never Passing RTC Laws Included in Synthetic Control: DE ; HI ; MD ; NJ

RTC Adopting States Included in Synthetic Control: NE (2007); OH (2004); WI (2012)

Figure 4

\section{State-Specific Estimates Across all RTC States}

Because we are projecting the violent crime experience of the synthetic control over a ten-year period, there will undoubtedly be a deviation from the "true" counterfactual and our estimated counterfactual. If we were only estimating the impact of a legal change for a single state, we would have an estimate marred by this purely stochastic aspect of changing crime. Since we are estimating an average effect across a large number of states, the stochastic variation will be diminished as the over-estimates and under-estimates will tend to wash out in our mean treatment estimates. Figure 5 shows the synthetic control estimates on violent crime for all 31 states for which we have ten years of post-passage data. For 23 of the 31 states adopting RTC laws, the increase in 
violent crime is noteworthy. ${ }^{51}$ While three states were estimated to have crime reductions greater than the -1.6 percent estimate of South Dakota, if one averages across all 31 states, the (populationweighted) mean treatment effect after ten years is a 14.3 percent increase in violent crime. If one instead uses an (unweighted) median measure of central tendency, RTC laws are seen to increase crime by 12.3 percent.

\section{Less Effective Pre-Passage Matches}

Section 1 above provided two examples of synthetic controls that matched the crime of the treatment states well in the pre-passage period, but this does not always happen. For example, we would have considerably less confidence in the quality of the synthetic control estimates for Maine, whose poor estimate is depicted in Appendix Figure I11. Maine also happens to be the state showing the greatest reduction in violent crime following RTC adoption, as indicated in Figure 5 .

For Maine, one sees that the synthetic control and the state violent crime performance diverged long before RTC adoption in 1986, and that, by the date of adoption, Maine's violent crime rate was already 37.9 percent below the synthetic control estimate. The violent crime rate of actual Maine was trending down, while the synthetic control estimate had been much higher and trending up in the immediate pre-adoption period. The difficulty in generating good pre-passage matches for states like Maine stems from their unusually low violent crime in the pre-passage period.

Appendix Figure D9 reproduces Figure 5 while leaving out the five states for which the quality of pre-passage fit is clearly lower than in the remaining 26 states. $^{52}$ This knocks out ND, SD, ME, MT, and WV, thereby eliminating three of the five outlier estimates at both ends of the scale, and leaving the mean and median effects of RTC laws relatively unchanged from Figure 5. As Appendix Figure D9 shows, the (weighted) mean increase in crime across the listed 26 RTC-adopting states is 13.7 percent while the (unweighted) median increase is now 11.1 percent. Increases in violent crime of this magnitude are troubling. Consensus estimates of the elasticity of crime with respect to incarceration hover around .15 today, which suggests that to offset the increase in crime caused by RTC adoption, the average RTC state would need to approximately double its prison population.

\footnotetext{
${ }^{51}$ The smallest of these, Kentucky, had an increase of 4.6 percent.

${ }^{52}$ In particular, for these five states, the pre-passage CVRMSPE - that is, the RMSPE transformed into a coefficient of variation by dividing by the average pre-passage crime rate-was 19 percent or greater. See Footnote 58 for further discussion of this statistic.
} 
The effect of RTC laws on violent crime after 10 years, synthetic control estimates for 31 states $(1977-2014)$

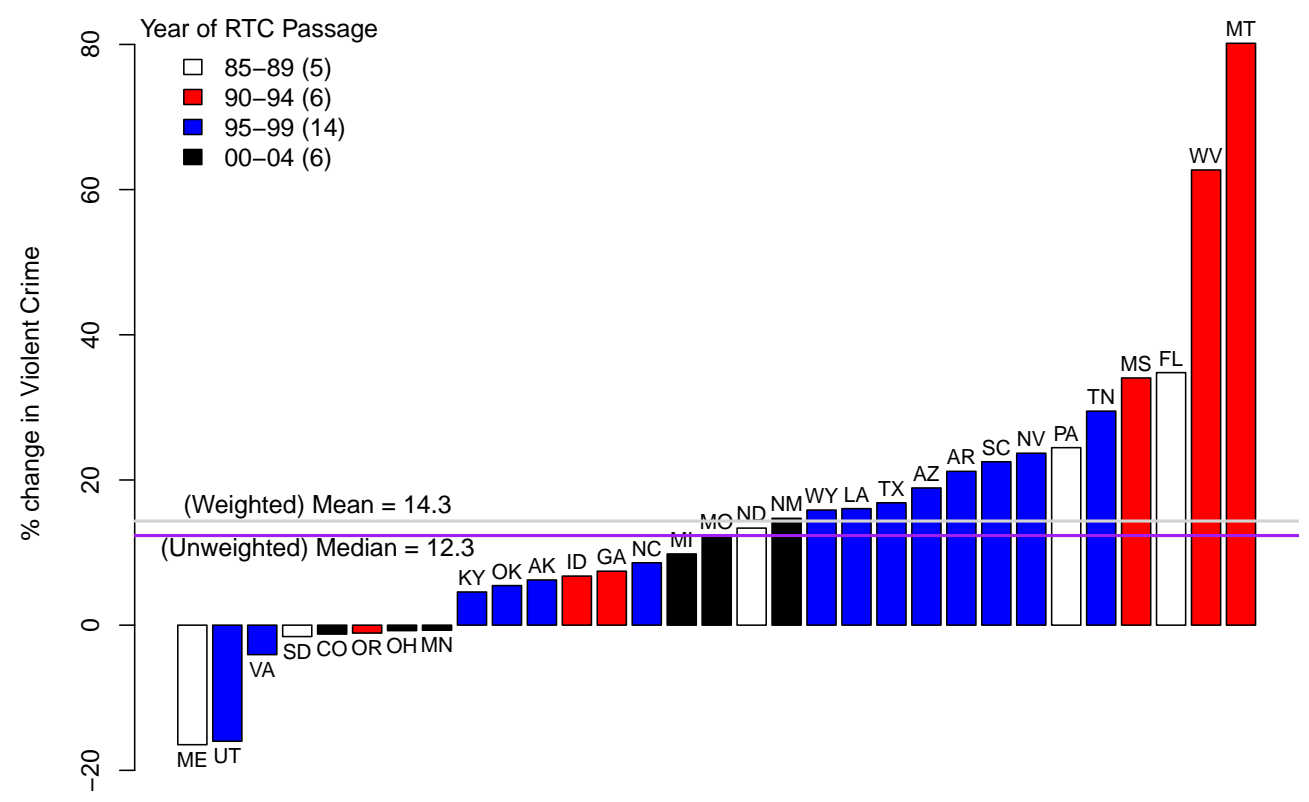

Figure 5

\section{Aggregation Analysis Using Synthetic Controls}

A small but growing literature applies synthetic control techniques to the analysis of multiple treatments. ${ }^{53}$ We estimate the percentage difference in violent crime between each treatment (RTCadopting) state and the corresponding synthetic control in both the year of the treatment and in the ten years following it. This estimate of the treatment effect percentage (TEP) obviously uses data

\footnotetext{
${ }^{53}$ The closest paper to the present study is Arindrajit Dube and Ben Zipperer (2013), who introduce their own methodology for aggregating multiple events into a single estimated treatment effect and calculating its significance. Their study centers on the effect of increases in the minimum wage on employment outcomes, and, as we do, the authors estimate the percentage difference between the treatment and the synthetic control in the post-treatment period. While some papers analyze multiple treatments by aggregating the areas affected by these treatments into a single unit, this approach is not well-equipped to deal with a case such as RTC law adoption where treatments affect the majority of panel units and more than two decades separate the dates of the first and last treatment under consideration, as highlighted in Figure 5 .
} 
from fewer post-treatment years for the two treatment states ${ }^{54}$ in which RTC laws took effect less than ten years before the end of our sample.

We could use each of these ten percentage differences as our estimated effects of RTC laws on violent crime for the ten post-passage years, but, as noted above, we make one adjustment to these figures by subtracting from each the percentage difference in violent crime in the adoption year between the treatment and synthetic control states. In other words, if ten years after adopting an RTC law, the violent crime rate for the state was 440 and the violent crime rate for the synthetic control was 400, one estimate of the effect of the RTC law could be ten percent $\left(=\frac{440-400}{400}\right)$. Rather than use this estimate, however, we have subtracted from this figure the percentage difference between the synthetic and treatment states in the year of RTC adoption. If, say, the violent crime rate in the treatment state that year was two percent higher than the synthetic control value, we would subtract two from ten to obtain an estimated tenth-year effect of RTC laws of eight percent. ${ }^{55}$ We then look across all the state-specific estimates of the impact of RTC laws on violent crime for each of the ten individual post-passage years and test whether they are significantly different from zero. ${ }^{56}$

\footnotetext{
${ }^{54}$ These two states are Kansas and Nebraska, which adopted RTC laws in 2007. See footnote 4 discussing the states for which we cannot estimate the impact of RTC laws using synthetic controls.

${ }^{55}$ It is unclear whether one should implement this subtraction. The intuitive rationale for our choice of outcome variable was that pre-treatment differences between the treatment state and its synthetic control at the time of RTC adoption likely reflected imperfections in the process of generating a synthetic control and should not contribute to our estimated treatment effect if possible. In other words, if the treatment state had a crime rate that was five percent greater than that of the synthetic control in both the pre-treatment and post-treatment period, it would arguably be misleading to ignore the pre-treatment difference and declare that the treatment increased crime rates by five percent. On the other hand, subtracting off the initial discrepancy might be adding noise to the subsequent estimates.

We resolve this issue with the following test of our synthetic control protocol: we pretend that each RTC-adopting state actually adopted its RTC law five years before it did. We then generate synthetic control estimates of this phantom law over the next five years of actual pre-treatment data. If our synthetic control approach is working perfectly, it should simply replicate the violent crime pattern for the five pre-treatment years. Consequently, the estimated "effect" of the phantom law should be close to zero. Indeed, when we follow our subtraction protocol, the synthetic controls match the pre-treatment years more closely than when we do not provide this normalization. Specifically, with subtraction the estimated "effect" in the final pre-treatment year is a wholly insignificant 3.2 percent; without subtraction, it jumps to a statistically significant 5.3 percent. Consequently, normalization is the preferred approach for violent crime. It should also be noted that our actual synthetic control estimates will be expected to perform better than this phantom RTC estimate since we will be able to derive our synthetic controls from five additional years of data, thereby improving our pre-treatment fit.

As it turns out, the choice we made to subtract off the initial-year crime discrepancy is a conservative one, in that the estimated crime increases from RTC laws would be greater without subtraction. We provide synthetic control estimates for the DAW model without subtraction of the adoption-year percentage difference for violent crime, murder and property crime in Appendix F. Comparison of these Appendix F estimates with those in the text (Table 5) reveals that our preferred method of subtracting yields more conservative results (i.e., a smaller increase in violent crime due to RTC). In Table 5, we estimate the tenth year TEP for violent crime is roughly 13.5 to 14 percent, while the comparable estimates without subtraction are roughly 17-18 percent, as seen in Appendix Tables F1, F2 and F3.

${ }^{56}$ This test is performed by regressing these differences in a model using only a constant term and examining whether that constant is statistically significant. These regressions are weighted by the population of the treatment state in the post-treatment year under consideration. Robust standard errors corrected for heteroskedasticity are used in this analysis.
} 


\section{A. RTC Laws Increase Violent Crime}

We begin our analysis of the aggregated synthetic control results using predictors derived from the DAW specification. Table 5 shows our results on the full sample examining violent crime. ${ }^{57}$ Our estimates of the normalized average treatment effect percentage (TEP) suggest that states that passed RTC laws experienced more deleterious changes in violent criminal activity than their synthetic controls in the ten years after adoption. On average, treatment states had aggregate violent crime rates that were almost seven percent higher than their synthetic controls five years after passage and around 14 percent higher ten years after passage. Table 5 suggests that the longer the RTC law is in effect (up to the tenth year that we analyze), the greater the cost in terms of increased violent crime.

Table 5: The Impact of RTC Laws on the Violent Crime Rate, DAW covariates, 1977-2014

\begin{tabular}{|c|c|c|c|c|c|c|c|c|c|c|}
\hline & (1) & (2) & (3) & (4) & (5) & (6) & (7) & (8) & (9) & (10) \\
\hline Average normalized TEP & $\begin{array}{l}-0.117 \\
(1.076)\end{array}$ & $\begin{array}{l}2.629^{*} \\
(1.310)\end{array}$ & $\begin{array}{l}3.631^{*} \\
(1.848)\end{array}$ & $\begin{array}{l}4.682^{* *} \\
(2.068)\end{array}$ & $\begin{array}{c}6.876^{* * *} \\
(2.499)\end{array}$ & $\begin{array}{l}7.358^{* *} \\
(3.135)\end{array}$ & $\begin{array}{c}10.068^{\text {*** }} \\
(2.823)\end{array}$ & $\begin{array}{c}12.474^{* * *} \\
(3.831)\end{array}$ & $\begin{array}{c}14.021^{* * *} \\
(3.605)\end{array}$ & $\begin{array}{l}14.344^{\text {**** }} \\
(2.921)\end{array}$ \\
\hline $\mathrm{N}$ & 33 & 33 & 33 & 33 & 33 & 33 & 33 & 31 & 31 & 31 \\
\hline Pseudo p-value & 0.936 & 0.274 & 0.220 & 0.192 & 0.094 & 0.106 & 0.060 & 0.038 & 0.032 & 0.032 \\
\hline
\end{tabular}

Standard errors in parentheses

Column numbers indicate post-passage year under consideration; $\mathrm{N}=$ number of states in sample

Dependent variable is the difference between the percentage difference in the violent crime rate in treatment and synthetic control states at given post-treatment interval and at time of the treatment

Results reported for the constant term resulting from this regression

States in group: AK AR AZ CO FL GA ID KS KY LA ME MI MN MO MS MT NC ND NE NM NV OH OK OR PA SC SD TN TX UT VA WV WY

States excluded for poor pre-treatment fit:

The synthetic controls used to generate the placebo estimates in the table above were generated using the optimization technique described in our main text. ${ }^{*} p<0.10,{ }^{* *} p<0.05,{ }^{* * *} p<0.01$

As we saw in Figures 4 (Pennsylvania) and I11.(Maine), the validity of using the post-treatment difference between crime rates in the treatment state (the particular state adopting an RTC law that we are analyzing) and its corresponding synthetic control as a measure of the effect of the RTC law depends on the strength of the match between these two time series in the pre-treatment period. To generate an estimate of pre-treatment fit that takes into account differences in pre-treatment crime levels, we estimate the coefficient of variation for the root mean squared prediction error (RMSPE), which is the ratio of the synthetic control's pre-treatment RMSPE to the pre-treatment average level of the outcome variable for the treatment state. ${ }^{58}$

\footnotetext{
${ }^{57}$ We discuss the synthetic control estimates for murder and property crime in section $\mathrm{V}(\mathrm{F})$ below.

${ }^{58}$ While the RMSPE is often used to assess this fit, we believe that the use of this measure is not ideal for comparing fit across states, owing to the wide variation that exists in the average pre-treatment crime rates among the 33 treatment states that we consider. For example, the pre-treatment RMPSE associated with our synthetic control analysis using the DAW predictor variables and aggregate violent crime as the outcome variable is nearly identical for Texas (37.1) and Maine (36.4), but the pre-treatment levels of Texas's aggregate violent crime rate are far greater than Maine's. To be more specific, Texas's average violent crime rate prior to the implementation of its RTC law (from 1977 through 1995) was 617 violent crimes per 100,000 residents, while the corresponding figure for Maine was 186 violent crimes per 100,000 residents, less than one-third of Texas's rate. The more discerning CV of the RMSPE is .06 for Texas
} 
To evaluate the sensitivity of the aggregate synthetic control estimate of the crime impact of RTC laws in Table 5, we consider two subsamples of treatment states: states whose coefficients of variation are less than two times the average coefficient of variation for all thirty-three treatments and states whose coefficients of variation are less than this average. We then re-run our synthetic control protocol using each of these two subsamples to examine whether restricting our estimation of the average treatment effect to states for which a relatively "better" synthetic control could be identified would meaningfully change our findings.

It is striking how all three samples yield roughly identical conclusions: RTC laws are consistently shown to increase violent crime, with the tenth-year increase ranging from a low of 13.5 to a high of 14.3 percent (Table 5).

\section{B. The Placebo Analysis}

Our ability to make valid inferences from our synthetic control estimates depends on the accuracy of our standard error estimation. To test the robustness of the standard errors that we present under the first row of Table 5, we incorporate an analysis using placebo treatment effects similar to Ando (2015). ${ }^{59}$ For this analysis, we generate 500 sets of randomly generated RTC dates that are designed to resemble the distribution of actual RTC passage dates that we use in our analysis. ${ }^{60}$ For each of the 500 sets of randomly generated RTC dates, we then use the synthetic control methodology and the DAW predictors to estimate synthetic controls for each of the 33 states whose randomly generated adoption year is between 1981 and 2010. We use this data to estimate the per-

(with a year of adoption discrepancy of only 3.6 percent), while for Maine, the CV is a dramatically higher .196 (with an initial year discrepancy of -37.9 percent). Accordingly, since the percentage imprecision in our synthetic pre-treatment match for Maine is so much greater than for Texas, we have greater confidence in our estimates that in the tenth year, Texas's RTC law had increased violent crime by 16.9 percent than we do in an estimate that Maine's law had decreased violent crime by 16.5 percent.

59 Ando (2015) examines the impact of constructing nuclear plants on local real per capita taxable income in Japan by generating a synthetic control for every coastal municipality that installed a nuclear plant. While the average treatment effect measured in our paper differs from the one used by Ando, we follow Ando in repeatedly estimating average placebo effects by randomly selecting different areas to serve as placebo treatments. (The sheer number of treatments that we are considering in this analysis prevents us from limiting our placebo treatment analysis to states that never adopt RTC laws, but this simply means that our placebo estimates will likely be biased against finding a qualitatively significant effect of RTC laws on crime, since some of our placebo treatments will be capturing the effect of the passage of RTC laws on crime rates.) Our estimated average treatment effect can then be compared to the distribution of average placebo treatment effects. Heersink and Peterson (2014) and Cavallo et al. (2013) also perform a similar randomization procedure to estimate the significance of their estimated average treatment effects, although the randomization procedure in the latter paper differs from ours by restricting the timing of placebo treatments to the exact dates when actual treatments took place.

${ }^{60}$ More specifically, we randomly choose eight states to never pass RTC laws, six states to pass RTC laws before 1981, 33 states to pass RTC laws between 1981 and 2010, and three states to pass their RTC laws between 2011 and 2014. (Washington, D.C. is not included in the placebo analysis since it is excluded from our main analysis.) These figures were chosen to mirror the number of states in each of these categories in our actual data set. 
centage difference between each placebo treatment and its corresponding synthetic control during both the year of the treatment and each of the ten post-treatment years (for which we have data) that follow it. Using the methodology described in footnotes 49 and 55, we then test whether the estimated treatment effect for each of the ten post-treatment years is statistically significant.

To further assess the statistical significance of our results, we compare each of the ten coefficient estimates in Table 5 with the distribution of the 500 average placebo treatment effects that use the same crime rate, post-treatment year, and sample as the given estimate. To assist in this comparison process, we report a pseudo p-value which is equal to the proportion of our placebo treatment effects whose absolute value is greater than the absolute value of the given estimated treatment effect. This pseudo p-value provides another intuitive measure of whether our estimated average treatment effects are qualitatively large compared to the distribution of placebo effects. Our confidence that the treatment effect that we are measuring for RTC laws is real increases if our estimated treatment effect is greater than the vast majority of our estimated average placebo treatment effects. Examining our pseudo p-values in Table 5, we see that our violent crime results are always statistically significant in comparison to the distribution of placebo coefficients at the .05 level eight years or more past RTC adoption.

\section{Synthetic Control Estimates Using LM's Explanatory Vari- ables}

In our Part III panel data analysis, we saw that RTC laws were associated with significantly higher rates of violent crime in the DAW model (Table 3), but not in the LM model (Table 4, Panel A), although the LM spline model did show RTC laws increased murder. Table 6 estimates the impact of RTC laws on violent crime using the LM specification in the synthetic control methodology. The detrimental effects of RTC laws on violent crime rates are statistically significant at the 05 level starting three years after the passage of an RTC law, and appear to increase over time. The treatment effects associated with violent crime in Table 6 range from 11.7 percent in the seventh post-treatment year to 14.3 percent in the ninth post-treatment year. Remarkably, the DAW and LM synthetic control estimates of the impact of RTC laws on violent crime are nearly identical (compare Tables 5 and 6), and this is true even when we limit the sample of states in the manner described above. ${ }^{61}$

\footnotetext{
${ }^{61}$ The tenth-year effect in the synthetic control analysis using the LM variables is 13.9 percent when we eliminate the three states with more than twice the average CV of the RMSPE. Knocking out the six states with above-average values of this $\mathrm{CV}$ generates a similar 13.5 percent effect.
} 
Table 6: The Impact of RTC Laws on the Violent Crime Rate, LM covariates, Full Sample, 1977-2014

\begin{tabular}{lcccccccccc}
\hline \hline & $(1)$ & $(2)$ & $(3)$ & $(4)$ & $(5)$ & $(6)$ & $(7)$ & $(8)$ & $(9)$ & $(10)$ \\
\hline Average normalized TEP & 0.280 & $2.934^{*}$ & $4.716^{* *}$ & $5.509^{* *}$ & $7.630^{* * *}$ & $8.027^{* *}$ & $11.741^{* * *}$ & $13.292^{* * *}$ & $14.306^{* * *}$ & $14.199^{* * *}$ \\
& $(1.182)$ & $(1.503)$ & $(1.949)$ & $(2.153)$ & $(2.544)$ & $(3.121)$ & $(2.957)$ & $(3.930)$ & $(3.751)$ & $(2.888)$ \\
\hline $\mathrm{N}$ & 33 & 33 & 33 & 33 & 33 & 33 & 33 & 31 & 31 & 31 \\
Pseudo p-value & 0.852 & 0.214 & 0.088 & 0.110 & 0.064 & 0.090 & 0.034 & 0.028 & 0.036 & 0.034 \\
\hline \hline
\end{tabular}

Standard errors in parentheses

Column numbers indicate post-passage year under consideration; $\mathrm{N}=$ number of states in sample

Dependent variable is the difference between the percentage difference in the violent crime rate in treatment and synthetic control states at given post-treatment interval and at time of the treatment

Results reported for the constant term resulting from this regression

States in group: AK AR AZ CO FL GA ID KS KY LA ME MI MN MO MS MT NC ND NE NM NV OH OK OR PA SC SD TN TX UT VA WV WY

States excluded for poor pre-treatment fit:

The synthetic controls used to generate the placebo estimates in the table above were generated using the regression methodology described in the main text.

${ }^{*} p<0.10,{ }^{* *} p<0.05,{ }^{* * *} p<0.01$

\section{The Contributions of Donor States to the Synthetic Control Estimates: Evaluating Robustness}

One of the key elements of the synthetic control approach is its selection among plausible control states. For each state adopting an RTC law in year X, the approach selects among states that do not have RTC laws through at least ten years after X, including never-adopting states. Appendix Figure D8 lists all the states that are eligible under this criterion to serve as synthetic controls for one or more of the 33 adopting states, and shows how often they are selected. The horizontal length of each bar tells us how much that state contributes to our synthetic control violent crime estimates. ${ }^{62}$ As the Figure indicates, Hawaii appears most frequently-contributing to a synthetic control 18 of the 33 times it is eligible and averaging a 15.2 percent contribution-but California, a substantial contributor to multiple large states, edges it out for the largest average contribution (18.1 percent).

Hawaii's relatively large contribution as a donor state in the synthetic control estimates has some advantages but also raises concern that this small state might be unrepresentative of the states for which it is used as a control. For example, note that the largest share of Virginia's synthetic control comes from Hawaii (27.9 percent) with Rhode Island, Kansas, and Nebraska making up the lion's share of the remaining synthetic control. We had already mentioned one problem with the panel data analysis caused by the tendency of lax gun control states to serve as a source for guns that contribute to crime in the non-RTC states, and Virginia has always been a major source of that interstate flow. Since Virginia's guns are not likely to end up in Hawaii, the bias that the treatment infects the control is reduced for that particular match. Nonetheless, one may be concerned that

\footnotetext{
${ }^{62}$ In particular, it reflects the portion of each synthetic state it becomes part of, weighted by the treated state's population. For example, Texas' population is 13.6 percent of the total treated states' population. As a result, a state that makes up 50 percent of synthetic Texas (but is not a donor for any other treatment state) would have a bar of size 6.8 percent.
} 
Hawaii might be unduly skewing the estimates of the impact of RTC laws on violent crime.

To address this, as well as the analogous concern for other potentially idiosyncratic control states, we generated 18 additional TEP estimates, with each one generated by dropping a single one of the 18 states that appears as an element of our synthetic control analysis (as identified in Appendix Figure D8). The results of this exercise are presented in Appendix Figure D10, which shows that our estimated increase in violent crime resulting from the adoption of an RTC law is extremely robust: All 18 estimates remain statistically significant at the .01 percent level, and the smallest TEP, which comes from dropping Illinois as a control state, is 12.0 percent. Note

in particular that dropping Hawaii from the list of potential donor states slightly increases the estimate of the increase in violent crime caused by RTC laws. In fact, when we dropped Hawaii completely as a potential control and repeated the previous protocol of dropping one state at a time, the estimated increase in violent crime from RTC never fell below 12 percent (which was the value when New York was dropped as well as Hawaii). Indeed, the synthetic control finding that RTC laws increase violent crime is so robust that, even if we drop California, New York, and Hawaii from the pool of potential donor states, RTC laws still increase violence crime by 8.9 percent after 10 years $(\mathrm{p}=0.018)$.

\section{E. Does Gun Prevalence Influence the Impact of RTC Laws?}

The wide variation in the state-specific synthetic control estimates that was seen in Figures 5 and D9 suggests that there is considerable noise in some of the outlier estimates of a few individual states. For example, it is highly improbable that RTC laws led to a 16.5 percent decrease in violent crime in Maine and an 80.2 percent increase in violent crime in Montana, the two most extreme estimates seen in Figure 5. Since averaging across a substantial number of states will tend to eliminate the noise in the estimates, one should repose much greater confidence in the aggregated estimates than in any individual state estimate. Indeed, the fact that we can average across 33 separate RTC-adopting states is what generates such convincing and robust estimates of the impact of RTC laws on violent crime.

Another way to distill the signal from the noise in the state-specific estimates is to consider whether there is a plausible factor that could explain underlying differences in how RTC adoption influences violent crime. For example, RTC laws might influence crime differently depending on the level of gun prevalence in the state.

Figure 6 shows the scatter diagram for 33 RTC-adopting states, and relates the estimated impact on violent crime to a measure of gun prevalence in each RTC-adopting state. The last line of the note below the Figure provides the regression equation, which shows that gun prevalence is 
positively related to the estimated increase in crime $(\mathrm{t}=2.39) .{ }^{63}$

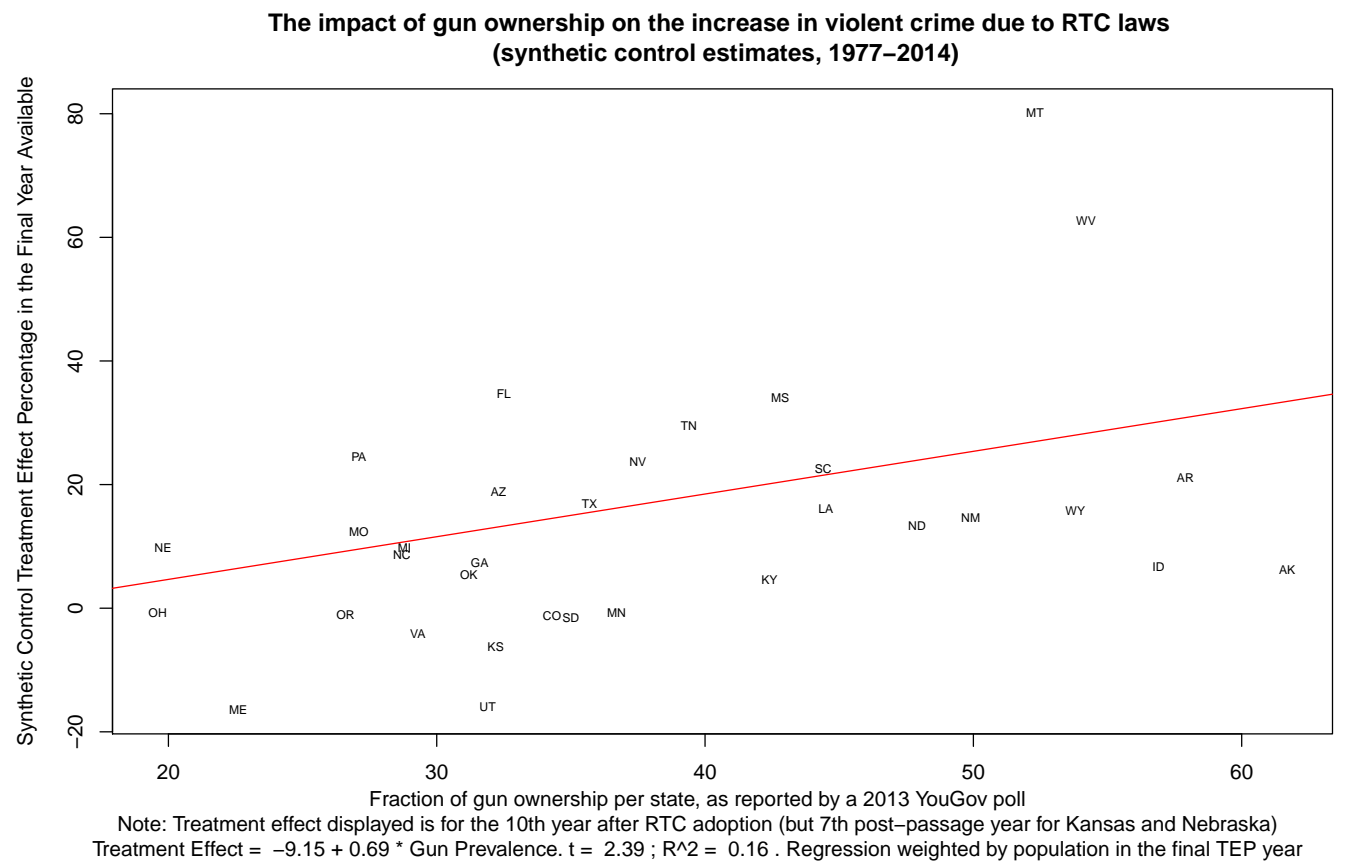

Figure 6

\section{F. The Murder and Property Crime Assessments with Synthetic Controls}

The synthetic control estimates of the impact of RTC laws on violent crime uniformly generate statistically significant estimates, and our phantom RTC law synthetic control estimates for the five pre-treatment years (described in footnote 55) give us confidence that the synthetic control approach is working well for our violent crime estimates. Using this phantom law approach for murder and property crime, however, yields less encouraging estimates. While our estimated "effect" in the year prior to adoption would ideally be close to zero in this test, for murder it is 7.8 percent and for property crime it is 6.9 percent, with the latter significant at the .01 level. Without normalization, these estimates jump to 9.9 percent (significant at the .10 level) for murder and 16.7 percent (significant at the .01 level) for property crime. (The full results of this test for all the crime categories are shown in Appendix K). In other words, our synthetic control estimates for violent

\footnotetext{
${ }^{63}$ The gun prevalence data was collected by the data analytics firm YouGov in a 2013 online survey (Kalesan et al. 2016). 4,486 people were initially surveyed, although only 4,000 people's results are used in the final dataset. YouGov used a proximity matching method to select the survey results for inclusion, matching respondents by race, age, gender, and education to the demographic breakdown of the 2010 American Community Survey.
} 
crime are far more validated by our phantom adoption test than the murder and property crime estimates. For that reason and the uniform and highly robust results whether dropping selected donor states or states with poor fit, or using either the DAW or LM models, we have greater confidence in and therefore highlight our violent crime estimates. Accordingly, we consign our discussion of the synthetic control estimates of murder and property crime to Appendix E. ${ }^{64}$

\section{Conclusion}

The extensive array of panel data and synthetic control estimates of the impact of RTC laws that we present uniformly undermine the "More Guns, Less Crime" hypothesis. There is not even the slightest hint in the data that RTC laws reduce violent crime. Indeed, the weight of the evidence from the panel data estimates as well as the synthetic control analysis best supports the view that the adoption of RTC laws substantially raises overall violent crime in the ten years after adoption.

In our initial panel data analysis, our preferred DAW specification predicted that RTC laws have led to statistically significant and substantial increases in violent crime. When the LM model was appropriately adjusted, it generated the same findings, but even without adjustment, the LM spline model that Lott and Mustard once championed showed RTC laws increased murder significantly. Moreover, to the extent the massive theft of guns from carrying guns outside the home generates crime spillovers to non-RTC states, our estimated increases in violent crime are downward-biased.

We then supplemented our panel data results using our synthetic control methodology, again using the DAW and LM specifications. Now the results were uniform: for both specifications, states that passed RTC laws experienced 13-15 percent higher aggregate violent crime rates than their synthetic controls after ten years (results that were significant at either the .05 or .01 level after five years).

The synthetic control effects that we measure represent meaningful increases in violent crime rates following the adoption of RTC laws, and this conclusion remained unchanged after restricting the set of states considered based on model fit and after considering a large number of robustness checks. The consistency across different specifications and methodologies of the finding that RTC elevates violent crime enables far stronger conclusions than were possible over a decade ago when the NRC Report was limited to analyzing data only through 2000 with the single tool of panel data

\footnotetext{
${ }^{64}$ Nevertheless, the synthetic control estimates for the impact of RTC laws on murder range from 4.3 (Appendix Table E1) to 6.4 percent (when states with poorer fit are dropped) higher after ten years (but are not statistically significant). If one adjusts the synthetic control estimates to control for the increased rates of police and incarceration that follow RTC adoption, the RTC-induced increases in murder are almost nine percent with a p-value of 0.089 . (See Appendix E.) In addition, the murder effects rise to 11-14 percent for the DAW model and become statistically significant at the .05 level if we do not subtract off the initial year differential between the actual and synthetic control murder rates (see Appendix F).
} 
evaluation.

The best available evidence using different statistical approaches-panel data regression and synthetic control-with varying strengths and shortcomings and with different model specifications all suggest that the net effect of state adoption of RTC laws is a substantial increase in violent crime. 


\section{References}

Abadie, Alberto, Alexis Diamond, and Jens Hainmueller. 2010. "Synthetic Control Methods for Comparative Case Studies: Estimating the Effect of California's Tobacco Control Program." Journal of the American Statistical Association, 105(490): 493-505.

Abadie, Alberto, Alexis Diamond, and Jens Hainmueller. 2014. "Comparative Politics and the Synthetic Control Method." American Journal of Political Science, 59(2): 495-510.

Abadie, Alberto, and Javier Gardeazabal. 2003. "The Economic Costs of Conflict: A Case Study of the Basque Country." American Economic Review, 93(1): 113-132.

Adda, Jérôme, Brendon McConnell, and Imran Rasul. 2014. "Crime and the Depenalization of Cannabis Possession: Evidence from a Policing Experiment." Journal of Political Economy, 122(5): 1130-1202.

Ando, Michihito. 2015. "Dreams of Urbanization: Quantitative Case Studies on the Local Impacts of Nuclear Power Facilities Using the Synthetic Control Method." Journal of Urban Economics, 85: 68-85.

Aneja, Abhay, John J Donohue, and Alexandria Zhang. 2011. "The Impact of Right to Carry Laws and the NRC Report: The Latest Lessons for the Empirical Evaluation of Law and Policy." American Law and Economics Review, 13(2): 565-631.

Aneja, Abhay, John J. Donohue, and Alexandria Zhang. 2014. "The Impact of Right to Carry Laws and the NRC Report: The Latest Lessons for the Empirical Evaluation of Law and Policy." National Bureau of Economic Research Working Paper 18294.

Associated Press. 2014. "Official: Suspect in deadly hospital shooting had lengthy history of gun arrests, violence." Fox News. 7/26/2014. http://www.foxnews.com/us/2014/07/ 26/official-suspect-in-deadly-hospital-shooting-had-lengthy-history-gunarrests.html.

Associated Press. 2015. "8-year-old Arizona boy accidentally shot by baby sitter." Daily Record. 9/8/2015. http://www.canoncitydailyrecord.com/ci_28778997/8-year-old-arizonaboy-accidentally-shot-by.

Athey, Susan, and Guido W. Imbens. 2017. "The State of Applied Econometrics: Causality and Policy Evaluation.” Journal of Economic Perspectives, 31(2): 3-32.

Ayres, Ian, and John J Donohue. 2003. "The Latest Misfires in Support of the "More Guns, Less Crime" Hypothesis." Stanford Law Review, 55: 1371-1398. 
Barbash, Fred. 2018. "Calif. teacher resigns after unintentionally firing weapon in gun safety class." Washington Post. 4/12/2018. https://www.washingtonpost.com/news/morning$\mathrm{mix} / \mathrm{wp} / 2018 / 04 / 12 / \mathrm{calif}$-teacher-resigns-after-unintentionally-firingweapon-in-gun-safety-class/?noredirect=on\&utm_term=.68faa7eb0133.

Biette-Timmons, Nora. 2017. "More People are Pulling Guns During Road-Rage Incidents." The Trace. 8/10/2017. https://www.thetrace.org/2017/08/guns-road-ragecleveland-2017.

Biography.com. 2016. "Bernhard Goetz." Online, 11/15/2017. https://www.biography.com/ people/bernhard-goetz-578520

Blair, J. Pete, and Katherine W. Schweit. 2014. A Study of Active Shooter Incidents in the United States Between 2000 and 2013. Washington, D.C.:Texas State University and Federal Bureau of Investigation, U.S. Department of Justice.

Bohn, Sarah, Magnus Lofstrom, and Steven Raphael. 2014. "Did the 2007 Legal Arizona Workers Act Reduce the State's Unauthorized Immigrant Population?" The Review of Economics and Statistics, 96(2): 258-269.

Boots, Michelle Theriault. 2017. "In Alaska, a high bar for taking guns from the mentally ill." Anchorage Daily News. 1/9/2017 (updated 12/2/2017). https://www.adn.com/alaska-news/ 2017/01/09/in-alaska-a-high-bar-for-the-mentally-ill-to-part-with-theirguns/.

Bureau of Alcohol, Tobacoo, Firearms, and Explosives. 2016. "Identify Prohibited Persons." Bureau of Alcohol, Tobacco, Firearms, and Explosives. 9/22/2016. https://www.atf.gov/ firearms/identify-prohibited-persons

Campbell, Elizabeth. 2017. "521 guns stolen in 2017 from unlocked cars, Jacksonville police say." News 4 Jax. 12/11/2017. https://www.news4jax.com/news/local/jacksonville/ 521-guns-stolen-in-2017-from-unlocked-cars-jacksonville-police-say.

Carter, Chelsea J, Ed Lavandera, and Evan Perez. 2013. "Who is Navy Yard gunman Aaron Alexis?" CNN. Updated 9/17/2013. http://www.cnn.com/2013/09/16/us/navyyard-suspects/index.html.

Cavallo, Eduardo, Sebastian Galiani, Ilan Noy, and Juan Pantano. 2013. "Catastrophic natural disasters and economic growth." Review of Economics and Statistics, 95(5): 1549-1561. 
CEA. 2016. "Economic Perspectives on Incarceration and the Criminal Justice System." Council of Economic Advisors, Executive Office of the President of the United States.

Chalfin, Aaron, and Justin McCrary. 2013. "The Effect of Police on Crime: New Evidence From U.S. Cities, 1960-2010.” National Bureau of Economic Research Working Paper 18815.

Chalfin, Aaron, and Justin McCrary. 2017. "Criminal Deterrence: A Review of the Literature." Journal of Economic Literature, 55(1): 5-48.

Clary, Mike, Megan O’Matz, and Lisa Arthur. 2017. "Puerto Rico police seized guns from airport shooter Esteban Santiago." Sun Sentinel. 1/13/2017. http://www.sun-sentinel.com/ news/fort-lauderdale-hollywood-airport-shooting/fl-santiago-guns-puertorico-20170113-story.html.

Cohen, Dov, Richard E. Nisbett, Brian F. Bowdle, and Norbert Schwarz. 1996. "Insult, Aggression, and the Southern Culture of Honor: An "Experimental Ethnography"." Journal of Personality and Social Psychology, 70(5): 945-960.

Cook, Philip J. 2018. “Gun theft and crime.” Journal of Urban Health, 95(1): 305-312.

Cook, Philip J., Jens Ludwig, and Adam M. Samaha. 2009. "Gun Control after Heller: Threats and Sideshows from a Social Welfare Perspective." UCLA Law Review, 56(5): 1041-1093.

DePrang, Emily. 2015. “The Mystery of Milwaukee's 'Human Holster'”, The Trace. 7/16/2015. https://www.thetrace.org/2015/07/concealed-carry-wisconsin-human-holster/.

Donohue, John J. 2003. "The Final Bullet in the Body of the More Guns, Less Crime Hypothesis.” Criminology and Public Policy, 2(3): 397-410.

Donohue, John J. 2017a. "Comey, Trump, and the Puzzling Pattern of Crime in 2015 and Beyond." Columbia Law Review, 117(5): 1297-1354.

Donohue, John J. 2017b. “Laws Facilitating Gun Carrying and Homicide.” American Journal of Public Health, 107(12): 1864-1865.

Donohue, John J., and Justin Wolfers. 2009. "Estimating the Impact of the Death Penalty on Murder." American Law and Economics Review, 11(2): 249-309.

Dube, Arindrajit, and Ben Zipperer. 2013. "Pooled Synthetic Control Estimates for Recurring Treatments: An Application to Minimum Wage Case Studies."

Durlauf, Steven N., Salvado Navarro, and David A. Rivers. 2016. "Model uncertainty and the effect of shall-issue right-to-carry laws on crime." European Economic Review, 81: 32-67. 
Eltagouri, Marwa. 2017. "Man accidentally shoots himself and his wife at a church, shortly after a discussion on shootings." Washington Post. 11/17/2017. https://www.washingtonpost.com/ news/acts-of-faith/wp/2017/11/17/a-man-accidentally-shot-himself.

Fernandez, Manny, Liam Stack, and Alan Blinder. 2015. "9 Are Killed in Biker Gang Shootout in Waco." New York Times. 5/17/2015. http: //www.nytimes.com/2015/05/18/us/ motorcycle-gang-shootout-in-waco-texas.html.

Fortin, Jacey. 2018. "Georgia Teacher Fired Gun While Barricaded in Classroom, Police Say." New York Times. 2/28/2018. https://www.nytimes.com/2018/02/28/us/georgiateacher-gun-shooting.html.

Freskos, Brian. 2016. "Guns Are Stolen in America Up to Once Every Minute. Owners Who Leave Their Weapons in Cars Make It Easy for Thieves." The Trace. 9/21/2016. https:// www.thetrace.org/2016/09/stolen-guns-cars-trucks-us-atlanta/.

Freskos, Brian. 2017a. "As Thefts of Guns from Cars Surge, Police Urge Residents to Leave Their Weapons at Home." The Trace. 3/6/2017. https://www.thetrace.org/2017/03/ as-thefts-of-guns-from-cars-surge-police-urge-residents-to-leave-theirweapons-at-home/,

Freskos, Brian. 2017b. "Missing Pieces." The Trace. 11/20/2017. https://www.thetrace.org/ features/stolen-guns-violent-crime-america/.

Freskos, Brian. 2017c. "These Gun Owners Are at the Highest Risk of Having Their Firearms Stolen." The Trace. 4/11/2017. https://www.thetrace.org/2017/04/gun-owners-highrisk-firearm-theft/.

Freskos, Brian. 2018. "Maryland Will Invest in Gun Trafficking Crackdown." The Trace. 4/30/2018. https://www.thetrace.org/2018/04/maryland-gun-trafficking-taskforce-wiretapping-baltimore/

Friedman, David D. 1990. Price Theory: An Intermediate Text. South-Western Publishing Co. http://www.daviddfriedman.com/Academic/Price_Theory/PThy_Chapter_20/ PThy_Chapter_20.html.

Fuchs, Erin. 2013. "Why The South Is More Violent Than The Rest Of America." Business Insider. 9/18/2013. http://www.businessinsider.com/south-has-more-violentcrime-fbi-statistics-show-2013-9. 
Gibbons, Thomas, and Robert Moran. 2000. "Man Shot, Killed in Snow Dispute." Philadelphia Inquirer. 1/27/2000. http://articles.philly.com/2000-01-27/news/25598207_1_snowdispute-man-shot-christian-values

Glanton, Dahleen, and Carlos Sadovi. 2014. "Concealed carry shooting reignites debate." The Chicago Tribune. 7/31/2014. http://www.chicagotribune.com/news/ct-crestwoodconcealed-carry-0730-20140730-story.html.

Gueverra, Ericka Cruz. 2018. "Man killed by armed PSU officers had valid concealed carry permit." OPB. 6/30/2018. https://www.opb.org/news/article/portland-state-shootingvictim-jason-erik-washington/.

Hauser, Christine. 2017. "White Police Officer in St. Louis Shoots Off-Duty Black Colleague." The New York Times. 6/26/2017. https://www.nytimes.com/2017/06/26/us/saint-louisblack-officer.html?_r=0.

Heath, Michelle. 2015. "Gun goes off inside Christus facility, injures woman." Beaumont Enterprise. 10/19/2015. http://www.beaumontenterprise.com/news/article/Gun-goes-offinside-Christus-facility-injures-6578001.php.

Heersink, Boris, and Brenton Peterson. 2014. "Strategic Choices in Election Campaigns: Measuring the Vice-Presidential Home State Advantage with Synthetic Controls." Available at SSRN 2464979.

Hemenway, David, Deborah Azrael, and Matthew Miller. 2017. "Whose guns are stolen? The epidemiology of Gun theft victims." Injury Epidemiology, 4(1): 11.

Hemenway, David, Mary Vriniotis, and Matthew Miller. 2006. "Is an armed society a polite society? Guns and road rage." Accident Analysis and Prevention, 38(4): 687-695.

Hernandez, Alex V. 2017. "Police: No charges in fatal shootout at Elmwood Park gas station." Chicago Tribune. 4/10/2017. http://www.chicagotribune.com/suburbs/elmwood-park/ news/ct-elm-elmwood-park-shooting-tl-0413-20170409-story.html.

Holzel, Dee. 2008. "Shootout in Winnemucca: Three dead, two injured in early-morning gunfight." Elko Daily Free Press. 5/24/2008. https://elkodaily.com/news/local/shootoutin-winnemucca-three-dead-two-injured-in-early-morning/article_83fe3832cc3b-528b-88bd-a85ce65f5967.html.

Hopkins, Kyle. 2017. "Accused Florida airport shooter to appear in Alaska case by phone." 2 KTUU Anchorage. 3/28/2017. http://www.ktuu.com/content/news/Diagnosed-with- 
serious-mental-illness-accused-airport-shooter-to-appear-in-Alaska-caseby-phone-417394013.html.

Horwitz, Josh. 2011. "Speaking of "Fast and Furious": NRA Leaders Well-Versed in Fomenting Foreign Conflicts." Huffington Post. 9/13/2011 (updated 11/13/2011). https:// WwW.huffingtonpost.com/josh-horwitz/speaking-of-fast-and-furi_b_959633.html.

Ho, Vivian. 2015. "Gun linked to pier killing stolen from federal ranger." San Francisco Chronicle. 7/8/2015. http://www.sfchronicle.com/crime/article/Gun-linked-to-S-F-pierkilling-was-BLM-6373265.php.

Ho, Vivian, and Kale Williams. 2015. "Gun in 2 killings stolen from unlocked car in Fisherman's Wharf, cops say." San Francisco Chronicle. 10/9/2015. http://www.sfgate.com/ crime/article/Gun-in-2-killings-stolen-from-unlocked-car-in-6562039.php.

Igielnik, Ruth, and Anna Brown. 2017. "Key takeaways on Americans' views of guns and gun ownership." Pew Research Center, http: //www.pewresearch.org/fact-tank/2017/06/22/ key-takeaways-on-americans-views-of-guns-and-gun-ownership.

Kalesan, Bindu, Marcos D Villarreal, Katherine M Keyes, and Sandro Galea. 2016. "Gun ownership and social gun culture.” Injury Prevention, 22(3): 216-220.

Kalinowski, Bob. 2012. "Police: Plymouth homicide suspect shot by patron." The Citizens' Voice. 9/10/2012. http://citizensvoice.com/news/police-plymouth-homicidesuspect-shot-by-patron-1.1370815.

Kaste, Martin. 2016. “Gun Carry Laws Can Complicate Police Interactions.” NPR. 7/19/2016. https://www.npr.org/2016/07/19/486453816/open-carry-concealed-carry-gunpermits-add-to-police-nervousness.

Kaul, Ashok, Stefan Klobner, Gregor Pfeifer, and Manuel Schieler. 2016. "Synthetic Control Methods: Never Use All Pre-Intervention Outcomes as Economic Predictors."

Keele, Luke. 2009. "An observational study of ballot initiatives and state outcomes." Working paper.

KHOU. 2015. "One man injured after carjacking, shooting at gas station." KHOU 11. 9/27/2015. http://www.khou.com/news/one-man-injured-after-carjacking-shooting-at-gasstation/142447940. 
KIMT. 2018. "Update: Court Documents Chronicle Tense Moments Prior to Rochester Shooting." KIMT 3 News. 1/17/2018 (updated 1/18/2018). http://www.kimt.com/content/news/ Rochester-shooting-Weiss-charged-with-2nd-degree-murder-469747873.html.

Knight, Brian. 2013. "State Gun Policy and Cross-State Externalities: Evidence from Crime Gun Tracing." American Economic Journal: Economic Policy, 5(4): 200-229.

KTUU. 2017. "Esteban Santiago, accused Fort Lauderdale shooter, agreed to anger management courses in Alaska." 2 KTUU Anchorage. 1/9/2017. http://www.ktuu.com/content/ news/Esteban-Santiago-accused-Fort-Lauderdale-shooter-had-agreed-to-underanger-management-in-Alaska-410177225.html.

Kulp, James. 1993. In re Application of Douglas G. Mack. Circuit Court of Virginia, Henrico County. WL 13030879.

Lat, David. 2012. "DiDonato v. Ung: The Temple Law Shooter Gets Hit - With a Civil Suit." Above the Law. 1/12/2012. https://abovethelaw.com/2012/01/didonato-v-ungthe-sequelor-the-temple-law-shooter-gets-hit-with-a-lawsuit.

Levenson, Eric. 2017. "Judge denies 'stand your ground' defense in movie theater shooting." CNN. 3/11/2017. http://www.cnn.com/2017/03/10/us/stand-your-ground-movietrial/index.html.

Lopez, German. 2018. "Police shootings are also part of America, s gun problem." Vox. 4/09/2018. https://www.vox.com/2018/4/9/17205256/gun-violence-us-police-shootings.

Lott, John R. 2010. More Guns, Less Crime: Understanding Crime and Gun Control Laws. University of Chicago Press.

Lott, John R, and David B Mustard. 1997. "Crime, deterrence, and right-to-carry concealed handguns." The Journal of Legal Studies, 26(1): 1-68.

Lozano, Alicia Victoria. 2017. "28-Year-Old David Desper Charged in Road Rage Killing of 18-Year-Old Bianca Roberson." NBC Philadelphia. 7/2/2017 (updated 7/3/2017). https://www.nbcphiladelphia.com/news/local/Police-Update-on-Road-RageKilling-of-18-Yr-0ld-432100983.html.

Lunny, SanRay. 2010. "Unloaded Open Carry." San Mateo County Sheriff's Office. http://www.calgunlaws.com/wp-content/uploads/2012/09/San-Mateo-CountySheriffs-Office_Unloaded-Open-Carry.pdf. 
Luthern, Ashley. 2015. "Concealed carry draws opposite views - and a murky middle." Milwaukee Wisconsin Journal Sentinel. 6/11/2015. http://www.jsonline.com/news/crime/ concealed-carry-draws-opposite-views--and-a-murky-middle-b99510854z1307079321.html.

MacDonald, Sally. 2012. "CHL holder fired shot that killed store clerk." Free Republic. 5/31/2012. http://www.freerepublic.com/focus/f-news/2889792/posts

McElroy, Majorie B., and Will Peichun Wang. 2017. "Seemingly Inextricable Dynamic Differences: The Case of Concealed Gun Permit, Violent Crime and State Panel Data."

Mettler, Katie. 2016. "'He thought he could help": Concealed carry gun-wielder intervenes in domestic dispute and is shot dead." Washington Post. 5/3/2016. https: //www.washingtonpost.com/news/morning-mix/wp/2016/05/03/he-thought-hecould-help.

Mideksa, Torben K. 2013. "The economic impact of natural resources." Journal of Environmental Economics and Management, 65(2): 277-289.

Miller, Matthew, Deborah Azrael, David Hemenway, and Frederic I. Solop. 2002. "'Road rage' in Arizona: armed and dangerous." Accident Analysis and Prevention, 34(6): 807-814.

Moody, Carlisle E, and Thomas B Marvell. 2008. "The debate on shall-issue laws." Econ Journal Watch, 5(3): 269-293.

Moody, Carlisle E, Thomas B Marvell, Paul R Zimmerman, and Fasil Alemante. 2014. "The Impact of Right-to-Carry Laws on Crime: An Exercise in Replication." Review of Economics \& Finance, 4: 33-43.

Nagin, Daniel S. 2018. "Firearm Availability and Police Use of Lethal Force.” Working Paper.

National Research Council. 2005. Firearms and Violence: A Critical Review. National Academies Press.

NBC News. 2014. "Cost of Bravery: Vegas Bystander Died Trying to Stop Rampage." NBC News. 6/10/2014. https://www.nbcnews.com/storyline/vegas-cop-killers/costbravery-vegas-bystander-died-trying-stop-rampage-n127361.

Nonnemaker, James, Mark Engelen, and Daniel Shive. 2011. "Are methamphetamine precursor control laws effective tools to fight the methamphetamine epidemic?" Health economics, 20(5): 519-531. 
Office of the Director - Strategic Management. 2013. "2012 Summary: Firearms Reported Lost and Stolen." U.S. Department of Justice, Bureau of Alcohol, Tobacco, Firearms and Explosives. https://www.atf.gov/resource-center/docs/2012-firearmsreported-lost-and-stolenpdf-1/download

Officer.com. 2017. "Chief: Concealed-Carry Law is 'Irresponsible'." Officer.com. 6/29/2017. https://www.officer.com/command-hq/news/12348064/milwaukee-police-chiefcalls-concealedcarry-law-irresponsible

Owens, David. 2018. "Retired Hartford Firefighter Donald Brown Sentenced To 7 Years In Shooting." Hartford Courant. 1/9/2018. http://www.courant.com/news/connecticut/hchartford-donald-brown-sentenced-0110-story.html.

Palmer, Ewan. 2018. "Pregnant Woman shot by Daughter, 3, after finding Gun in Car." Newsweek. 4/18/2018. http: //www.newsweek.com/pregnant-woman-shot-daughter3-after-finding-gun-car-outisde-platos-closet-891073.

Paraguassu, Lisandra, and Ricardo Brito. 2018. "U.S. biggest source of illegal foreign guns in Brazil: report." Reuters. 1/10/2018. https://www.reuters.com/article/us-usabrazil-arms/u-s-biggest-source-of-illegal-foreign-guns-in-brazil-reportidUSKBN1EZ2M5,

Parsons, Chelsea, and Eugenio Weigend Vargas. 2017. "Stolen Guns in America: A Stateby-State Analysis." Center for American Progress. https://cdn.americanprogress.org/ content/uploads/2017/07/25052308/StolenGuns-report.pdf.

Perrusquia, Marc. 2017. "Stolen Guns: "Getting Them is the Easy Part"." The Commercial Appeal. http://projects.commercialappeal.com/woundedcity/stolen-gunsthis-fence-makes-a-bad-neighbor.php.

\section{Phillips, Charles D., Obioma Nwaiwu, Darcy K. McMaughan Moudouni, Rachel Edwards,} and Szu hsuan Lin. 2013. "When Concealed Handgun Licensees Break Bad: Criminal Convictions of Concealed Handgun Licensees in Texas, 2001-2009.” American Journal of Public Health, 103(1): 86-91.

Pilger, Lori. 2018. "FBI accuses white supremacist of terror attack on Amtrak train in rural Nebraska." Lincoln Journal Star. 1/4/2018 (updated 1/5/2018). http://journalstar.com/ news/state-and-regional/nebraska/fbi-accuses-white-supremacist-of-terrorattack-on-amtrak-train/article_82f0860e-3c75-5a66-ab0c-a2e3a3c16aab.html. 
Planty, Michael, and Jennifer Truman. 2013. "Firearm Violence, 1993-2011.” U.S. Department of Justice Bureau of Justice Statistics BJS Special Report 241730.

Plumlee, Rick. 2012. "Eight with concealed-carry permits charged with felonies in Sedgwick County." The Wichita Eagle. 11/17/2012 (updated 8/5/2014). http://www.kansas.com/ latest-news/article1103131.html.

Pugliese, Nicholas. 2018. "It's tough to buy a gun in New Jersey. So where do all the guns used in crimes come from?" NorthJersey.com. 4/16/2018. https: //www.northjersey.com/story/news/new-jersey/2018/04/16/nj-new-jersey-wheredo-guns-used-crimes-come/503115002/.

RAND. 2018. "The Science of Gun Policy: A Critical Synthesis of Research Evidence on the Effects of Gun Policies in the United States.” RAND Corporation.

Sampson, Zachary T. 2014. "Stolen guns, like one used to kill Tarpon Springs officer, routine at crime scenes." Tampa Bay Times. 12/24/2014 (updated 12/25/2014). http://www.tampabay.com/news/publicsafety/crime/gun-police-say-was-usedto-kill-tarpon-springs-officer-stolen-from/2211436.

Scherer, Jasper. 2016. "Fla. 'loud music' murder: Firing into car full of teens playing rap music not 'self-defense,' court rules." Washington Post. 11/18/2016. https://www.washingtonpost.com/news/morning-mix/wp/2016/11/18/fla-loudmusic-murder-firing.

Schwarzschild, Todd, and Drew Griffin. 2011. "ATF loses track of 1,400 guns in criticized probe." CNN. 7/12/2011. http://www.cnn.com/2011/POLITICS/07/12/atf.guns/ index.html

\section{Siegel, Michael, Molly Pahn, Ziming Xuan, Craig S. Ross, Sandro Galea, Bindu Kalesan, Eric} Fleegler, and Kristin A. Goss. 2017. "Easiness of Legal Access to Concealed Firearm Permits and Homicide Rates in the United States." American Journal of Public Health, 107(12): 19231929.

Simon, Darran. 2018. "Manslaughter defendant in 'stand your ground' case said he felt scared in altercation." CNN. 9/03/2018. https://www.cnn.com/2018/09/03/us/michael-drejkastand-your-ground-jailhouse-interview/index.html.

Simpson, Kevin. 2017. "Shoppers pulled guns in response to Thornton Walmart shooting, but police say that slowed investigation." Denver Post. 11/2/2017. http://www.denverpost.com/ 2017/11/02/shoppers-pulled-weapons-walmart-shooting/. 
Slobodzian, Joseph A. 2011. "Ung acquitted in wounding of DiDonato in Old City." The Inquirer. 2/16/2011. http://www.philly.com/philly/news/local/ 20110216_Ung_acquitted_in_wounding_of_DiDonato_in_0ld_City.html.

Soderling, Luke. 2016. "How to inform an officer you are carrying a handgun and live [Video File]." 7/09/2018. https://www.youtube.com/watch?v=f0099qcASEM.

Stanglin, Doug. 2018. "Parkland teacher charged with leaving loaded gun in public restroom." USA Today. 4/13/2018. https://www.usatoday.com/story/news/2018/04/13/parklandteacher-charged-leaving-loaded-gun-public-restroom/514855002/.

Stark, Emily, and Daniel Sachau. 2016. "Lake Wobegon's Guns: Overestimating our gun-related competences." Journal of Social and Political Psychology, 4(1): 8-23.

Strnad, Jeff. 2007. "Should Legal Empiricists Go Bayesian?" American Law and Economics Review, 9(1): 195-303.

Stuart, Hunter. 2013. "2 Concealed Carry Holders Kill Each Other In Road Rage Incident." Huffington Post. 9/19/2013. http://www.huffingtonpost.com/2013/09/19/michiganconcealed-carry-road-rage-two-dead_n_3956491.html.

US News. 2018. "Cops: Mom Was Turning on Safety When Gun Fired, Killing Girl." US News. 4/23/2018. https://www.usnews.com/news/best-states/ohio/articles/201804-23/cops-mom-was-turning-on-safety-when-gun-fired-killing-girl.

Violence Policy Center. 2017. "Mass Shootings Committed by Concealed Carry Killers: May 2007 to the Present." http://concealedcarrykillers.org/wp-content/uploads/2017/ 06/ccwmassshootings.pdf.

Virginia, Supreme Court. 1999. "The Virginia 1999 State of the Judiciary Report.” A-70. http: //worldcat.org/arcviewer/1/LEGAL/2007/05/15/0000064816/viewer/file18.pdf.

WFTV. 2015. "3 injured when man's gun goes off in Sanford Cracker Barrel." WFTV 9. 11/2/2015. http://www.wftv.com/news/local/man-not-charged-after-gun-goessanford-cracker-bar/26880670

Williams, Clois., and Steven Waltrip. 2004. Aircrew Security: A Practical Guide. New York, NY: Ashgate Publishing.

Wilson, Robert. 2016. “Common Sense." The American Scholar. 2/29/2016. https:// theamericanscholar.org/common-sense/\#. 
Zimmerman, Paul R. 2014. "The deterrence of crime through private security efforts: Theory and evidence." International Review of Law and Economics, 37: 66-75. 
"FOR ONLINE PUBLICATION" 


\section{Online Appendix}

\section{Appendix A: RTC Adoption Dates}

Table A1 of Appendix A lists each state's original RTC effective date and adjusted effective date (for our synthetic control analysis). For our panel data analyses, we use the same effective RTC dates used in Aneja, Donohue, and Zhang (2014), while specifying in column 2 the precise date on which an RTC law takes effect. Owing to the fact that the mechanics of the synthetic control methodology require us to specify a specific year for each state's RTC date, we alter the year used in the synthetic control analysis if the RTC law is in effect for less than half the year. Specifically, each state's effective year of passage in the synthetic control analysis is defined as the first year in which an RTC law was in effect for the majority of that year. This causes some of the values of our RTC variable to shift by one year (for instance, Wisconsin's RTC date shifts from 2011 to 2012 for our synthetic control analysis, since the state's RTC law took effect on November 1, 2011). The states in column 4 that show an RTC date of 0 are states that did not adopt an RTC law between 1977 and 2014.

While there have been numerous disagreements about the exact laws that should be used to determine when states made the transition to a "shall issue" state, we believe that the dates used in this paper accurately reflect relevant RTC effective dates. ${ }^{65}$ We supplemented our analysis of the statutory history of RTC laws in different states with an extensive search of newspaper archives to ensure that our chosen dates represented concrete changes in concealed carry policy. We document the changes that were made to earlier selection of RTC dates and the rationales underlying these changes in Appendix G of Aneja, Donohue, and Zhang (2014). The coding of these dates may not reflect administrative or logistical delays that may have limited the full implementation of an RTC law after authorities were legally denied any discretion in rejecting the issuing of RTC permits. Ideally, we would be able to control for the actual level of RTC permits in existence each year for each state, instead of simply relying on a mere indicator variable for the presence of an RTC law, but unfortunately such comprehensive information is not available. ${ }^{66}$

We also note that there has been confusion over the proper date of Virginia's RTC law, which we place in 1995, while Lott and Mustard (1997) had used 1988. Although many studies that have

\footnotetext{
${ }^{65}$ For instance, the Illinois shall issue law (430 ILCS 66/1) took effect on 7/9/13. It included the following provision: "The Department [of State Police] shall make applications for a license available no later than 180 days after the effective date of this Act." It did take the department the full 180 days until it opened the application process to citizens on 1/5/2014. Hence, January 5th 2014 is our effective RTC date for Illinois.

${ }^{66}$ RTC dates before the year 1977 may not be exact, since differences between these dates would neither affect our regression results nor our synthetic control tables. We follow earlier convention in the academic literature on the RTC issue in assigning pre-1977 RTC adoption dates for Alabama and Connecticut.
} 
relied on the Lott and Mustard data have used the earlier adoption date for Virginia, the recent Rand report on gun science concluded that 1995 was the appropriate date that RTC (shall-issue) was established in Virginia (RAND 2018, p.173).

Appendix Figure A1 presents data on concealed carry permit applications from 1984-2008 from the relevant Virginia State of the Judiciary Reports. ${ }^{67}$ The fact that permit applications were small in number and flat until 1995 when they jumped sharply confirms that Virginia's shift from a may-issue to a shall-issue (RTC) regime occurred in 1995.

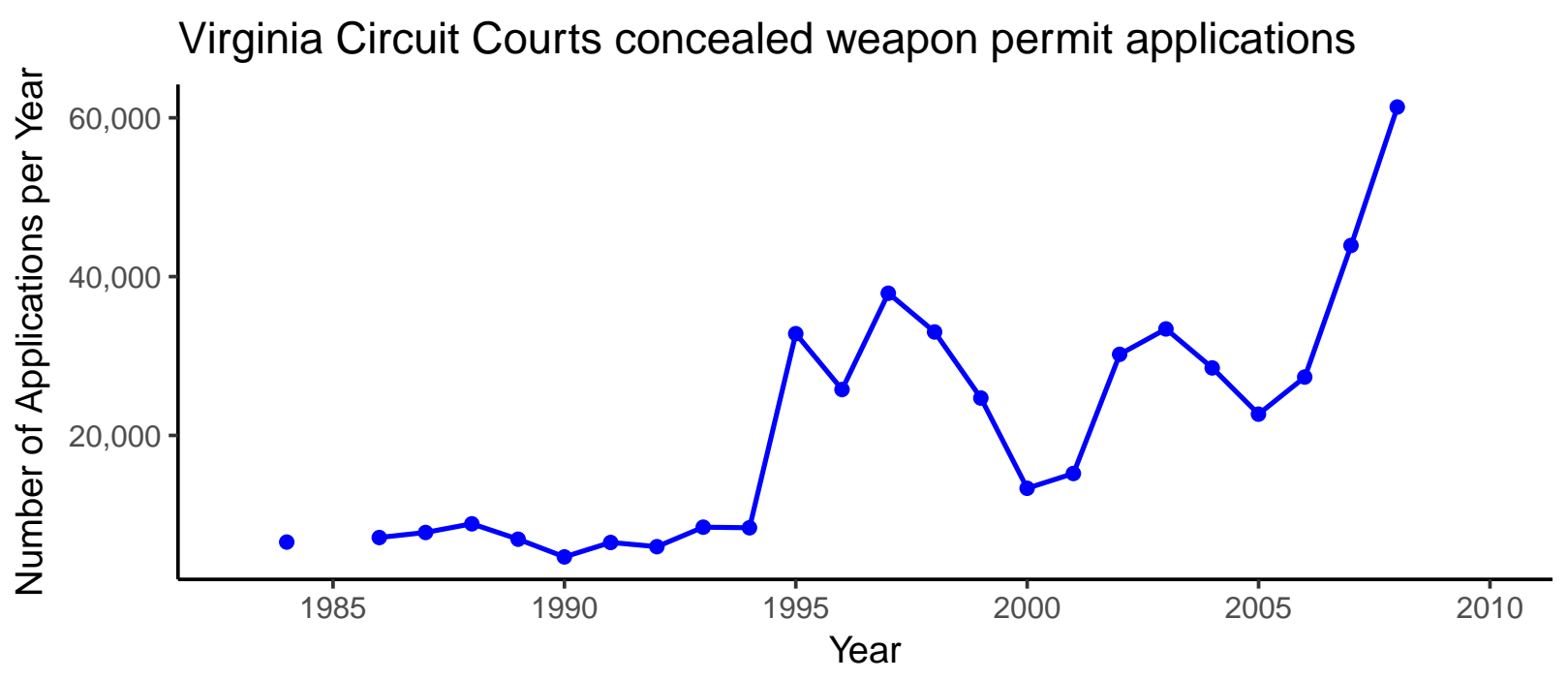

Figure A1

Prior to 1995, the number of concealed carry permits remained low because of the requirement to establish "a need to carry" such weapons. So, for example, in February 1993, the Circuit Court of Virginia (Kulp 1993) stated:

"The Court found Mr. Mack to be of good character but found that he had failed to demonstrate a need for a concealed weapon. An order was entered denying the application on January 8, 1993. [...]

"The Court further finds that the other reasons outlined by Mr. Mack do not in themselves warrant the issuance of a concealed weapon permit. From time to time, most citizens carry valuables, including cash, in their vehicles. If this were sufficient criteria for the issuance of a concealed weapon permit, then all citizens are entitled to a concealed weapon permit. If the legislature had intended such a result, it surely would have said so."

\footnotetext{
${ }^{67}$ See for example, “The Virginia 1999 State of the Judiciary Report" (1999). The 1985 and 2008-2015 reports do not contain permit application data.
} 
In 1995, Virginia Code Section 18.2-308 was modified to eliminate the requirement to demonstrate a need to carry. Thus, legally and practically, May 5, 1995 is the correct shall-issue law adoption date for Virginia. 


\section{Table A1: RTC Adoption Dates}

\begin{tabular}{|c|c|c|c|}
\hline State & Effective Date of RTC Law & Fraction of Year In Effect Year of Passage & RTC Date (Synthetic Controls Analysis) \\
\hline Alabama & 1975 & & 1975 \\
\hline Alaska & $10 / 1 / 1994$ & 0.252 & 1995 \\
\hline Arizona & $7 / 17 / 1994$ & 0.460 & 1995 \\
\hline Arkansas & $7 / 27 / 1995$ & 0.433 & 1996 \\
\hline California & N/A & & 0 \\
\hline Colorado & $5 / 17 / 2003$ & 0.627 & 2003 \\
\hline Connecticut & 1970 & & 1970 \\
\hline Delaware & N/A & & 0 \\
\hline District of Columbia & N/A & & 0 \\
\hline Florida & $10 / 1 / 1987$ & 0.252 & 1988 \\
\hline Georgia & $8 / 25 / 1989$ & 0.353 & 1990 \\
\hline Hawaii & N/A & & 0 \\
\hline Idaho & $7 / 1 / 1990$ & 0.504 & 1990 \\
\hline Illinois & $1 / 5 / 2014$ & & 2014 \\
\hline Indiana & $1 / 15 / 1980$ & 0.962 & 1980 \\
\hline Iowa & $1 / 1 / 2011$ & 1.000 & 2011 \\
\hline Kansas & $1 / 1 / 2007$ & 1.000 & 2007 \\
\hline Kentucky & $10 / 1 / 1996$ & 0.251 & 1997 \\
\hline Louisiana & 4/19/1996 & 0.702 & 1996 \\
\hline Maine & 9/19/1985 & 0.285 & 1986 \\
\hline Maryland & N/A & & 0 \\
\hline Massachusetts & N/A & & 0 \\
\hline Michigan & $7 / 1 / 2001$ & 0.504 & 2001 \\
\hline Minnesota & $5 / 28 / 2003$ & 0.597 & 2003 \\
\hline Mississippi & $7 / 1 / 1990$ & 0.504 & 1990 \\
\hline Missouri & $2 / 26 / 2004$ & 0.847 & 2004 \\
\hline Montana & 10/1/1991 & 0.252 & 1992 \\
\hline Nebraska & $1 / 1 / 2007$ & 1.000 & 2007 \\
\hline Nevada & $10 / 1 / 1995$ & 0.252 & 1996 \\
\hline New Hampshire & 1959 & & 1959 \\
\hline New Jersey & N/A & & 0 \\
\hline New Mexico & $1 / 1 / 2004$ & 1.000 & 2004 \\
\hline New York & N/A & & 0 \\
\hline North Carolina & $12 / 1 / 1995$ & 0.085 & 1996 \\
\hline North Dakota & $8 / 1 / 1985$ & 0.419 & 1986 \\
\hline Ohio & $4 / 8 / 2004$ & 0.732 & 2004 \\
\hline Oklahoma & $1 / 1 / 1996$ & 1.000 & 1996 \\
\hline Oregon & 1/1/1990 & 1.000 & 1990 \\
\hline Pennsylvania & 6/17/1989 & 0.542 & 1989 \\
\hline Philadelphia & $10 / 11 / 1995$ & 0.225 & 1996 \\
\hline Rhode Island & N/A & & 0 \\
\hline South Carolina & $8 / 23 / 1996$ & 0.358 & 1997 \\
\hline South Dakota & $7 / 1 / 1985$ & 0.504 & 1985 \\
\hline Tennessee & $10 / 1 / 1996$ & 0.251 & 1997 \\
\hline Texas & 1/1/1996 & 1.000 & 1996 \\
\hline Utah & $5 / 1 / 1995$ & 0.671 & 1995 \\
\hline Vermont & 1970 & & 1970 \\
\hline Virginia & $5 / 5 / 1995$ & 0.660 & 1995 \\
\hline Washington & 1961 & & 1961 \\
\hline West Virginia & 7/7/1989 & 0.488 & 1990 \\
\hline Wisconsin & $11 / 1 / 2011$ & 0.167 & 2012 \\
\hline Wyoming & $10 / 1 / 1994$ & 0.252 & 1995 \\
\hline
\end{tabular}


Appendix B: Complete Regression Output 


\section{Table B1: Panel Data Violent Crime Coefficients using DAW and LM models, State}

and Year Fixed Effects

Panel A: Dummy Variable Model Results

\begin{tabular}{lcc} 
& (Table 3) & (Table 4.A) \\
& DAW Model & LM Model \\
& $(1)$ & $(2)$ \\
\hline Right-to-carry law & $9.02^{* * *}(2.90)$ & $-1.38(3.16)$ \\
Lagged incarceration rate & $0.04^{*}(0.02)$ & \\
Lagged police employee rate & $-0.05(0.04)$ & \\
Lagged arrest rate for violent crimes & & $-0.16^{* *}(0.08)$ \\
Real per capita personal income $(\times 100)$ & $0.00(0.00)$ & $0.00^{*}(0.00)$ \\
Real per capita unemployment insurance $(\times 100)$ & & $0.00(0.01)$ \\
Real per capita income maintenance & & $0.04(0.03)$ \\
Real per capita retirement payments and other (Lott version) $(\times 100)$ & & $0.00(0.01)$ \\
Unemployment rate & $-0.02(0.78)$ & \\
Poverty rate & $-0.32(0.49)$ & \\
Beer & $60.82^{* * *}(17.55)$ & $0.00(0.00)$ \\
Population & & \\
Percent of the population living in MSAs & $1.10^{* * *}(0.32)$ & $-0.01(0.02)$ \\
Population density & & 1823 \\
Observations & & 1896 \\
\hline \hline
\end{tabular}

Panel B: Spline Model Results

$\begin{array}{cc}\text { (Table 3) } & \text { (Table 4.A } \\ \text { DAW Model } & \text { LM Model }\end{array}$

(1)

(2)

Right-to-carry law (change in trend)

$0.01(0.64)$

$0.41(0.47)$

Pre-passage trend for changer states

$0.92^{*}(0.49)$

$0.12(0.39)$

Lagged incarceration rate

$0.03^{*}(0.02)$

Lagged police employee rate

$-0.05(0.04)$

Lagged arrest rate for violent crimes

Real per capita personal income $(\times 100)$

$0.00(0.00)$

$-0.17^{* *}(0.08)$

Real per capita unemployment insurance $(\times 100)$

$0.00^{* *}(0.00)$

Real per capita income maintenance

$-0.00(0.02)$

$0.03(0.03)$

$0.00(0.01)$

Unemployment rate

$0.52(0.87)$

Poverty rate

$-0.42(0.50)$

Beer $62.09^{* * *}(16.18)$

Population

Percent of the population living in MSAs

$0.92^{* * *}(0.29)$

$0.00(0.00)$

Population density

Observations

1823

$0.00(0.02)$

1896

Estimations include year and state fixed effects and are weighted by state population. Coefficients on demographic variables and the constant omitted Robust standard errors (clustered at the state level) are provided next to point estimates in parentheses. The crime data is from the Uniform Crime Reports (UCR). $* \mathrm{p}<.1, * * \mathrm{p}<.05, * * * \mathrm{p}<.01$. All figures reported in percentage terms. The DAW model is run on data from 1979-2014, the BC model from 1978-2014, the LM model from 1977-2014, and the MM model (without the crack cocaine index) from 1979-2014. 


\section{Appendix C: Panel Data Models Estimated for the Post-Crack Period}

Our previous discussion has focused on panel data estimates of the impact of RTC laws on crime over the full period from the late 1970s through 2014. Zimmerman (2014) examines the impact of various crime prevention measures on crime using a state panel data set from 1999-2010. He finds that RTC laws increased murder by 15.5 percent for the eight states that adopted RTC laws over the period he analyzed. The advantage of using this data period to explore the impact of RTC laws is that it largely avoids the problem of omitted variable bias owing to the crack phenomenon, since the crack effect had largely subsided by 1999 . The disadvantage is that one can only gain estimates based on the eight states that adopted RTC laws over that twelve-year spell. ${ }^{68}$ Zim- $^{-}$ merman describes his finding as follows: "The shall-issue coefficient takes a positive sign in all regressions save for the rape model and is statistically significant in the murder, robbery, assault, burglary, and larceny models. These latter findings may imply that the passage of shall-issue laws increases the propensity for crime, as some recent research (e.g., Aneja, Donohue, \& Zhang, 2012) has suggested" (71). ${ }^{69}$

In Appendix Table C1, we show the results of running the DAW model for four crime measures over the period 2000-2014 for eleven RTC-adopting states. ${ }^{70}$ The DAW model mimics the Zimmerman finding of a large jump in murder, rising at a rate of over one percent each year the RTC law is in effect. But if one compares Appendix Figures $\mathrm{C} 1$ and $\mathrm{C} 2$, one sees that only the violent crime set of year-by-year estimates confirms the parallel trends assumption by displaying a generally flat series of pre-treatment dummies followed by a change in crime right at the time of the adoption of the RTC law. ${ }^{71}$ Indeed, even though the Appendix Table C1 DAW violent crime RTC dummy is not statistically significant ( $\mathrm{p}$-value $=0.165$ ), Appendix Figure C1 further buttresses our earlier conclusion that RTC laws are associated with increases in violent crime. Again, as we saw in Figure 2, this increase becomes statistically significant after the RTC law has been in effect for at least a full year and does so for the next four years, after which the diminishing number of

\footnotetext{
${ }^{68}$ The relatively short time span of the Zimmerman analysis makes the assumption of state fixed effects more plausible but it also limits the amount of pre-adoption data for an early adopter such as Michigan (2001) and the amount of post-adoption data for the late adopters Nebraska and Kansas (both in 2007).

69 Aneja, Donohue and Zhang (2014) also ran the ADZ model over the same 1999-2010 period that Zimmerman employs, which generated an estimate that murder rates rose about 1.5 percentage points each year that an RTC law was in effect.

${ }^{70} \mathrm{We}$ started this time period in 2000 because the sharp crime decreases of the 1990 s ended by then, and starting in 2000, crime was more stable for the remainder of our data period than it had previously been.

${ }^{71}$ Appenidx Figure C2 shows a strong upward trend in murder prior to RTC adoption. In passing, we note that the serious violation of the parallel trends assumption that marred the LM model panel data regressions of Table 4 is equally profound for LM regressions run on the post-crack period, so we do not present any additional LM estimates for this time frame (although we note none are statistically significant).
} 
RTC-adopting states with more than 4 years of data and the widening confidence intervals render the unvaryingly positive subsequent year estimates statistically insignificant.

Table C1: Panel Data Estimates of the Impact of RTC Laws, DAW specification, 2000 - 2014.

Panel A: Panel Data Estimates, State and Year Fixed Effects, DAW Regressors, 2000-2014

Murder Rate Murder Count Violent Crime Rate Property Crime Rate

(1)

(3)

(4)

\begin{tabular}{lcccc}
\hline Dummy variable model & $5.58(3.58)$ & $1.02(0.04)$ & $5.00(3.55)$ & $-1.50(2.29)$ \\
Spline model & $1.08^{*}(0.58)$ & $1.01^{* *}(0.01)$ & $0.54(1.12)$ & $0.41(0.43)$ \\
\hline \hline
\end{tabular}

All models include year and state fixed effects, and the OLS estimates are weighted by state population.

Robust standard errors (clustered at the state level) are provided next to point estimates in parentheses. In

Column 2 we present IRRs estimated using negative binomial regression, where population is included as a control variable. The following 11 states adopted RTC Laws during the period of consideration: CO (2003), IA (2011), IL (2014), KS (2007), MI (2001), MN (2003), MO (2004), NE (2007), NM (2004), OH (2004), and WI (2011).

$* \mathrm{p}<.1, * * \mathrm{p}<.05, * * * \mathrm{p}<.01$. All figures reported in percentage terms.

The impact of RTC laws on violent crime, DAW model, 2000-2014

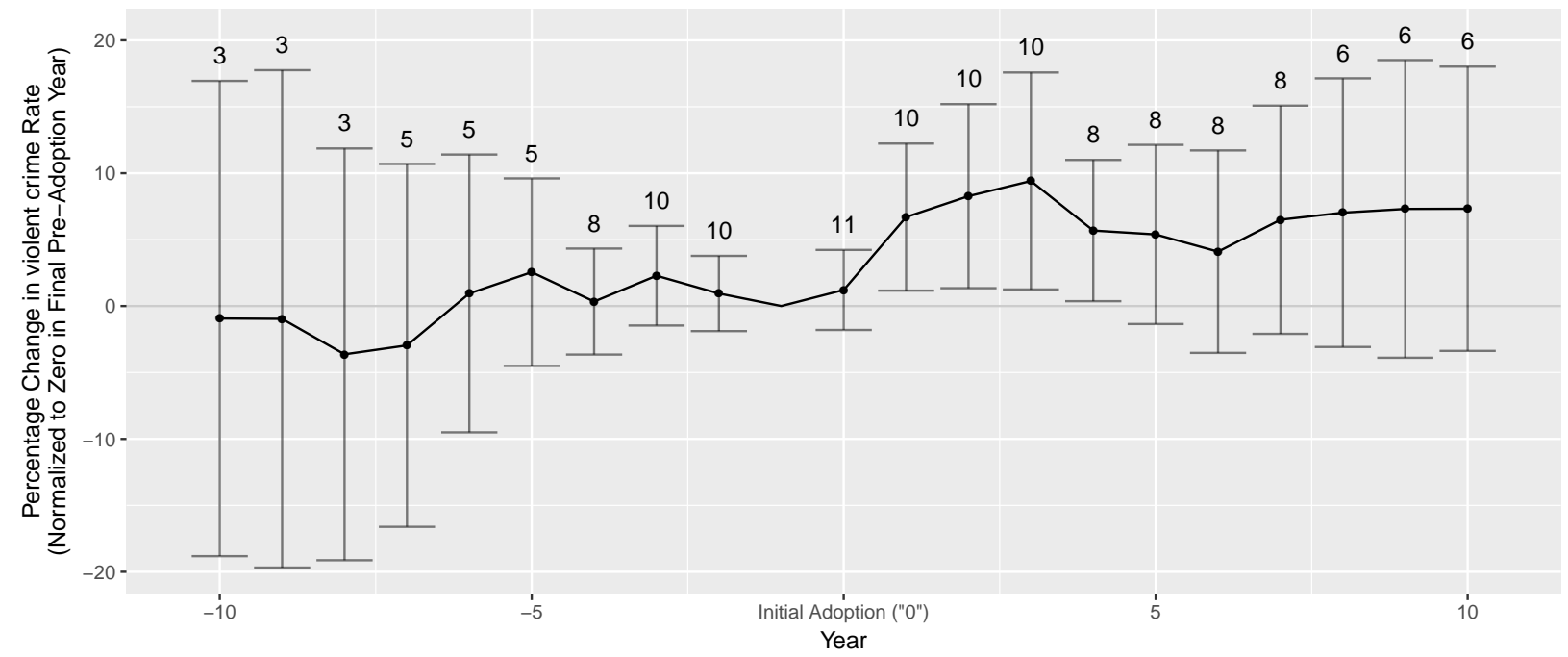

Note: We regress crime on dummies for pre- and post-passage years and DAW covariates. Reference year is year before adoption and adoption year is first year with RTC in place at any time, meaning that in states that adopt after January 1st, this will capture only a partial effect of RTC laws. We display the 95 percent confidence interval for each estimate using cluster-robust standard errors and show the number of states that contribute to each estimate.

Figure C1

A recent paper by Siegel et al. (2017) uses a negative binomial model for data from 1991 to 2015 to estimate the impact of RTC laws on five homicide measures based on Centers for Disease Control and Supplemental Homicide Report data, rather than the UCR crime data used throughout this paper. Controlling for year and state fixed effects and an array of time-varying, 
The impact of RTC laws on murder, DAW model, 2000-2014

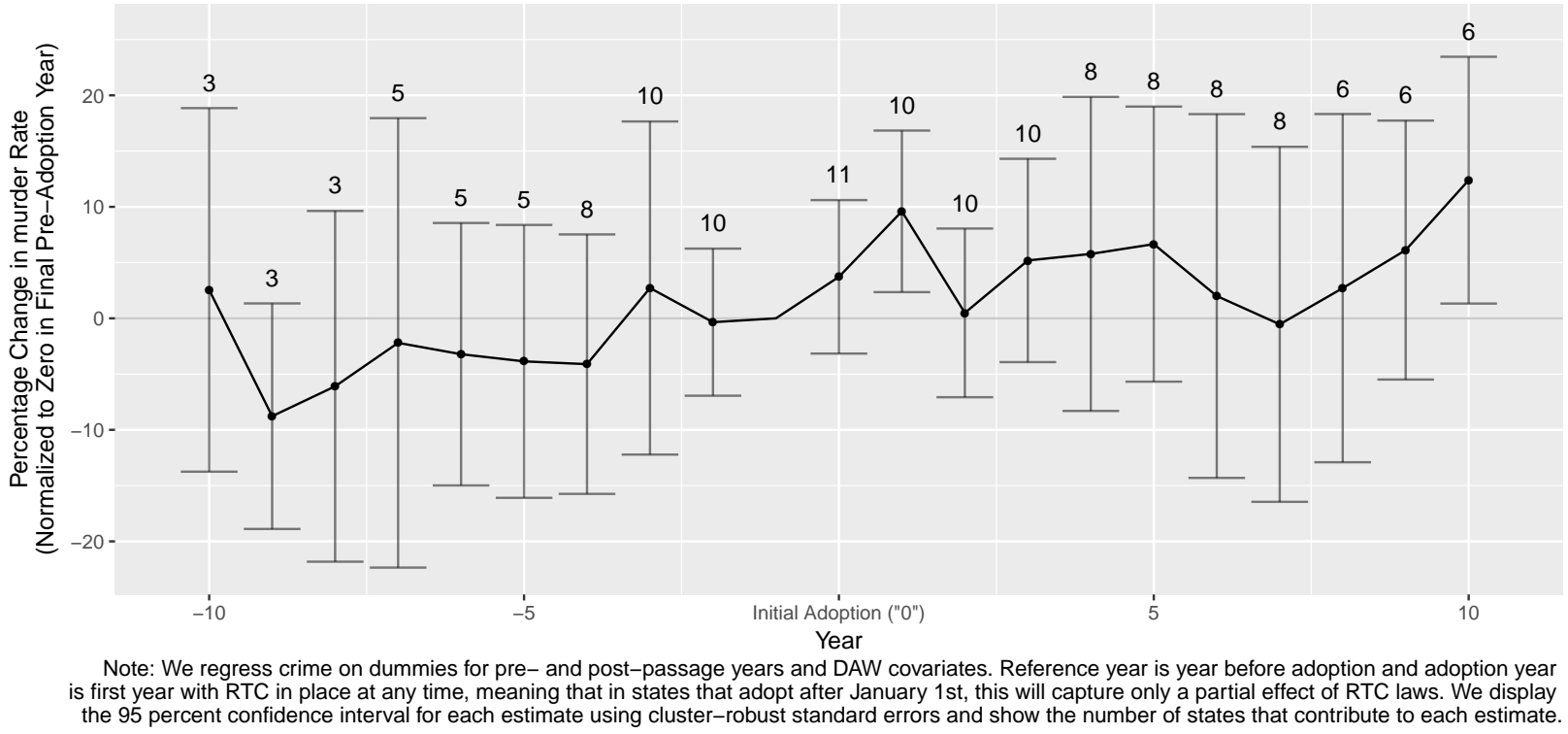

Figure C2

state-level factors, Siegel et al. conclude that RTC laws increase murders, particularly firearm and handgun murders, but seem to have virtually no effect on non-gun murders or long gun murders. Donohue (2017b) uses the same data used by Siegel et al., but limits the analysis to the 2000-2014 post-crack period. While Siegel et al. using their own model on the 1991-2015 CDC data found that overall homicides rose by 6.5 percent, firearm homicides rose by 8.6 percent, and handgun homicides rose by 10.6 percent, Donohue (2017b) running the DAW model on the 2000-2014 period generated comparable estimates of 6.0 percent, 9.5 percent, and 15.8 percent for overall, firearm, and handgun homicides, respectively (although the 6.0 estimate for overall homicides lost statistical significance at the .05 level). 


\section{Appendix D: Figures}

\section{A. Year-by-year Panel Data Estimates}

The impact of RTC laws on violent crime, LM model, 1977-2014

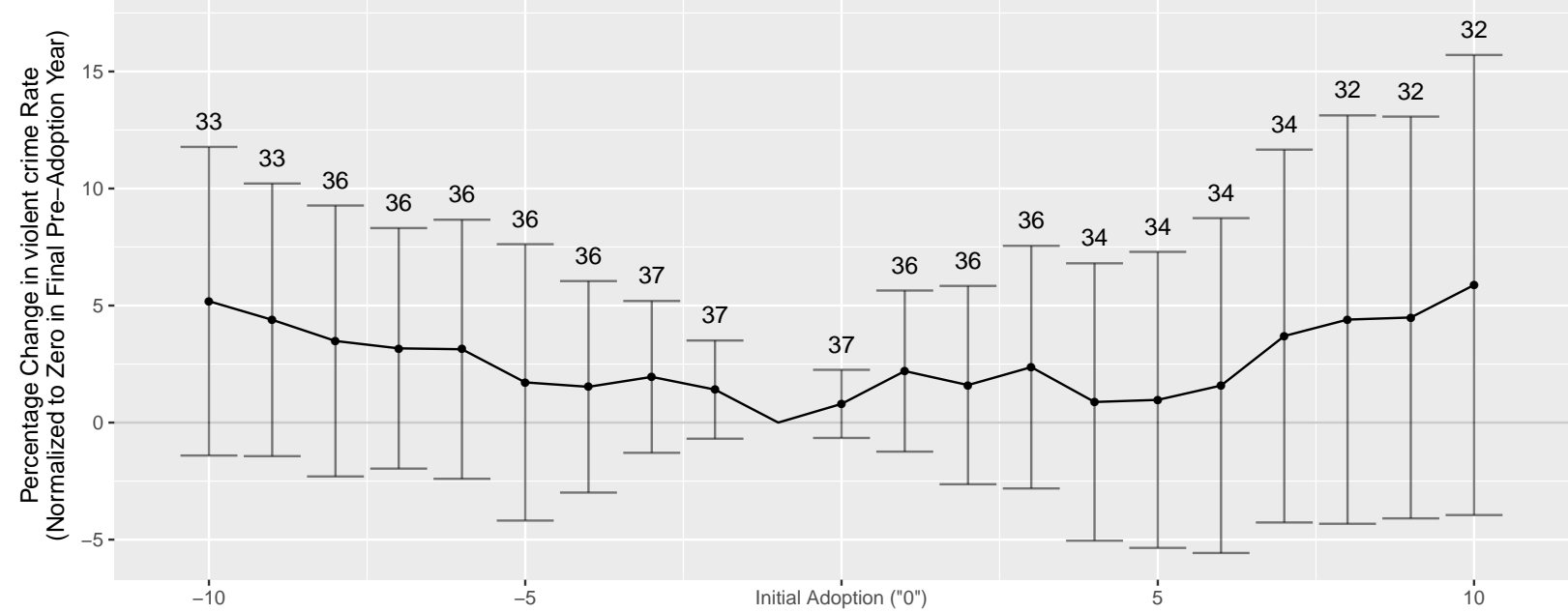

Year

Note: We regress crime on dummies for pre- and post-passage years and LM covariates. Reference year is year before adoption and adoption year is first year with RTC in place at any time, meaning that in states that adopt after January 1st, this will capture only a partial effect of RTC laws. We display the 95 percent confidence interval for each estimate using cluster-robust standard errors and show the number of states that contribute to each estimate.

\section{Figure D1}

The impact of RTC laws on property crime, DAW model, 1979-2014

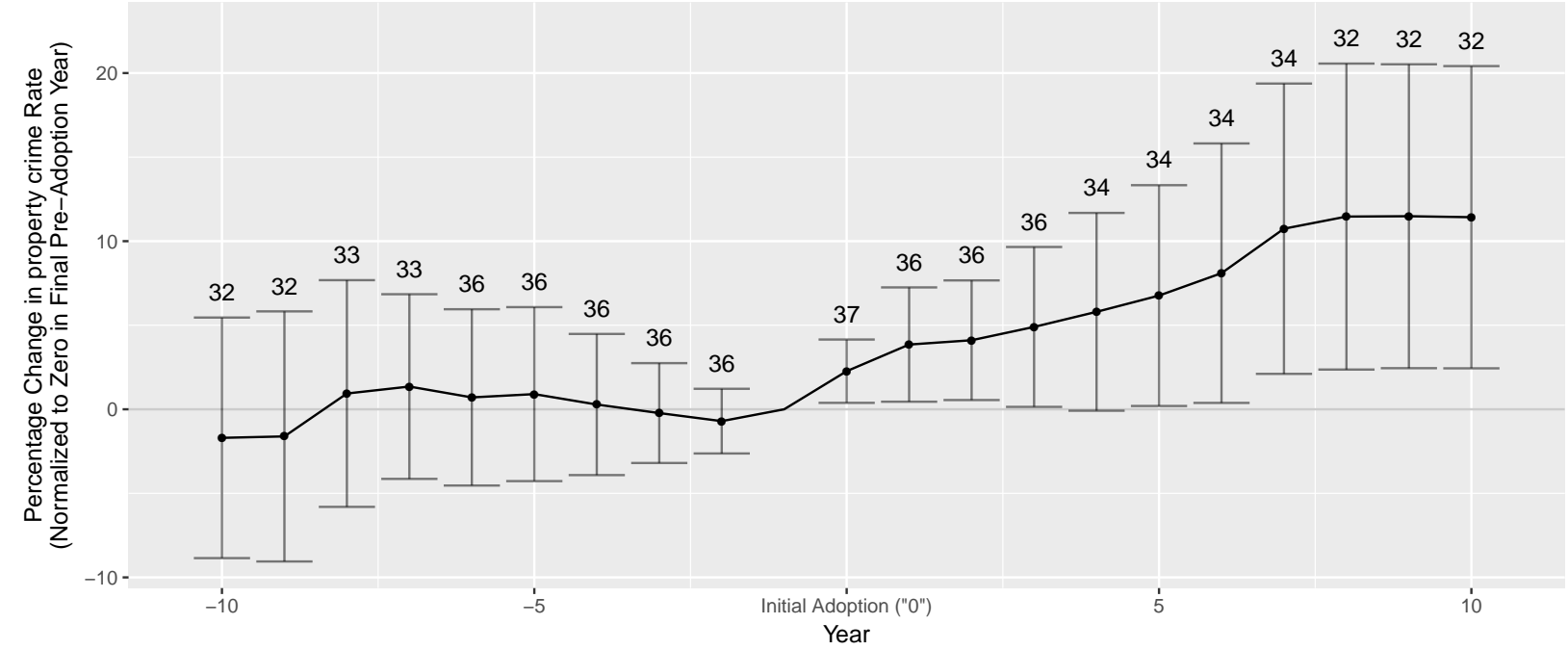

Note: We regress crime on dummies for pre- and post-passage years and DAW covariates. Reference year is year before adoption and adoption year is first year with RTC in place at any time, meaning that in states that adopt after January 1st, this will capture only a partial effect of RTC laws. We display the 95 percent confidence interval for each estimate using cluster-robust standard errors and show the number of states that contribute to each estimate.

Figure D2 
The impact of RTC laws on property crime, LM model, 1977-2014

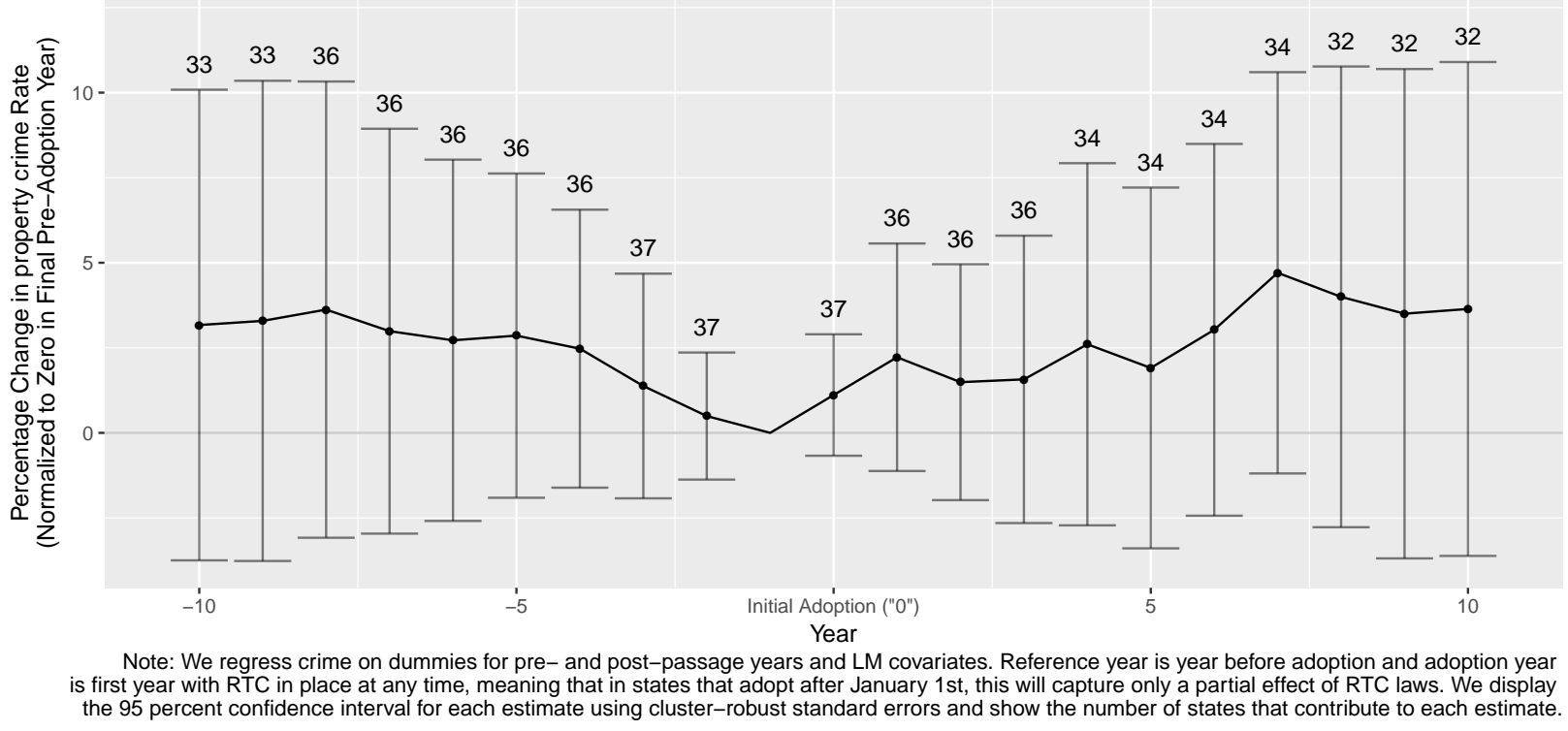

Figure D3

The impact of RTC laws on murder, DAW model, 1979-2014

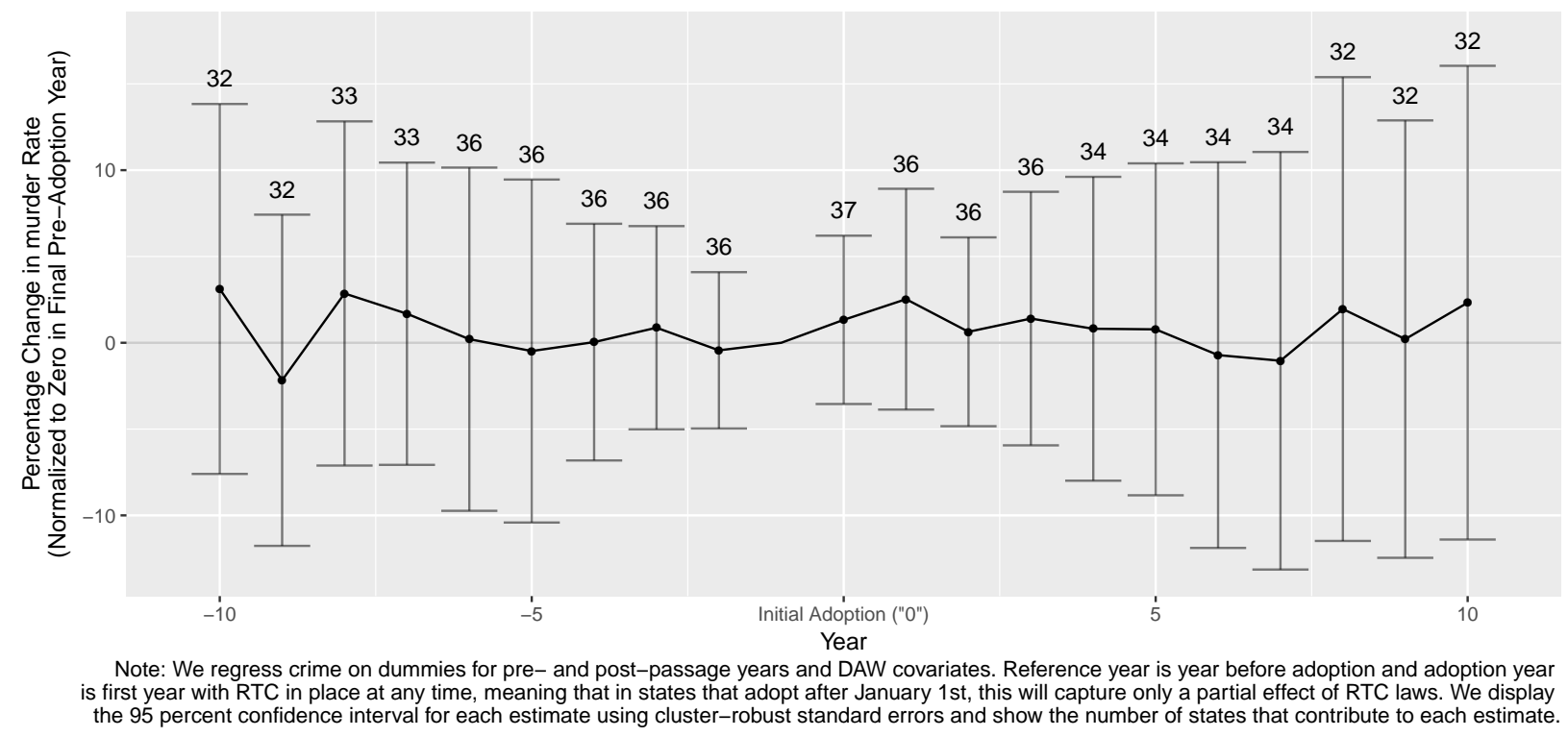

Figure D4 
The impact of RTC laws on murder, LM model, 1977-2014

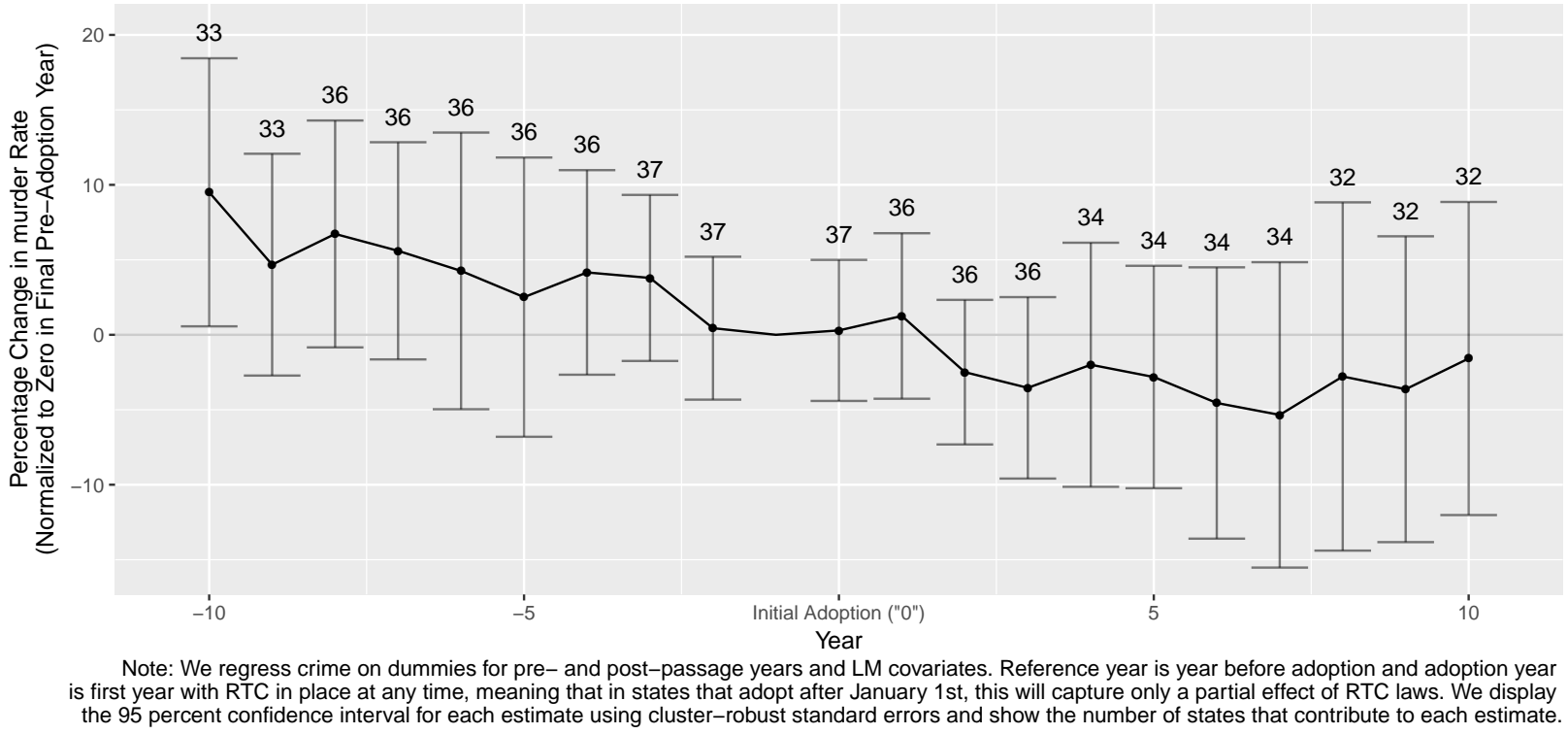

\section{Figure D5}

The impact of RTC laws on murder, DAW model, negative binomial model,1979-2014

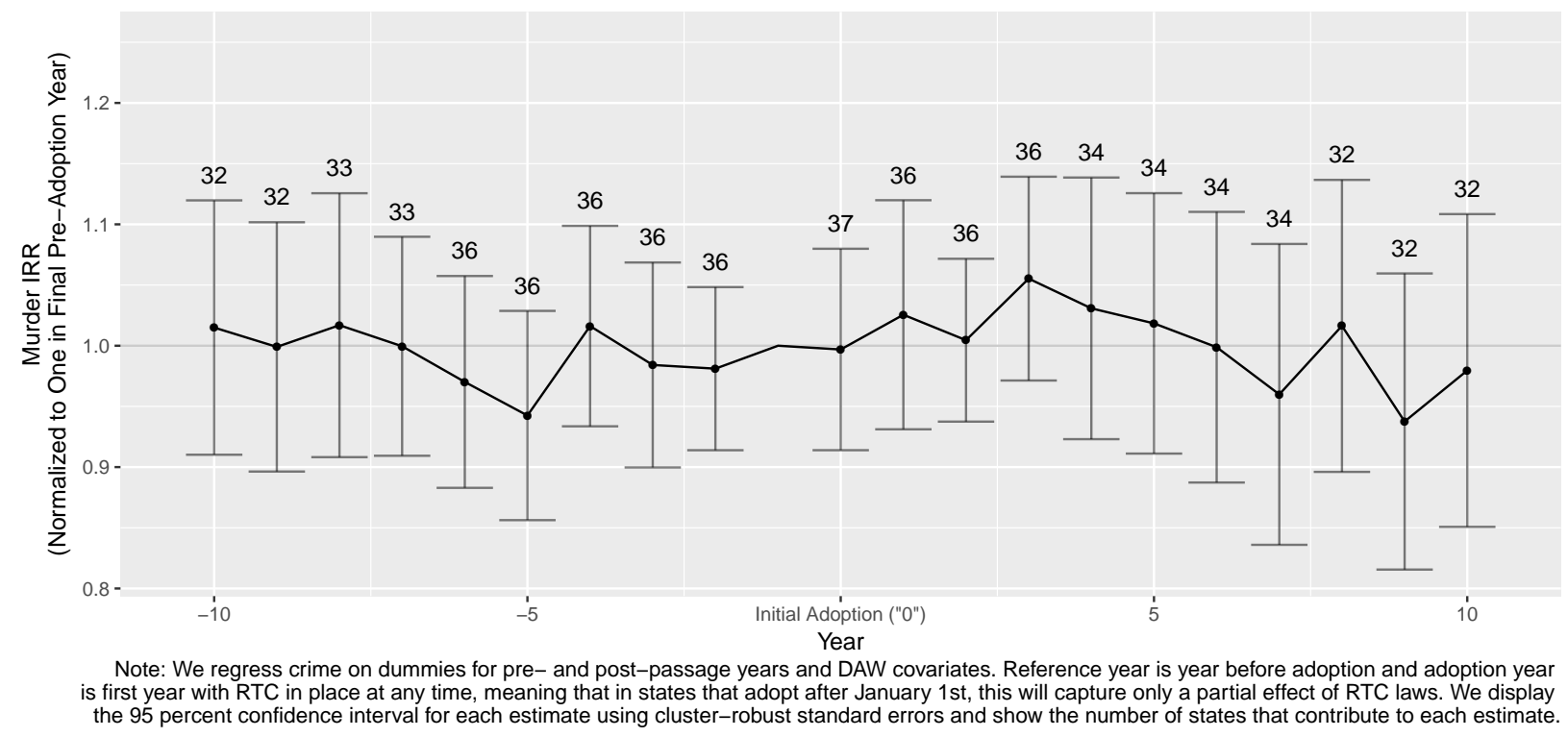

Figure D6 
The impact of RTC laws on murder, LM model, negative binomial model,1977-2014

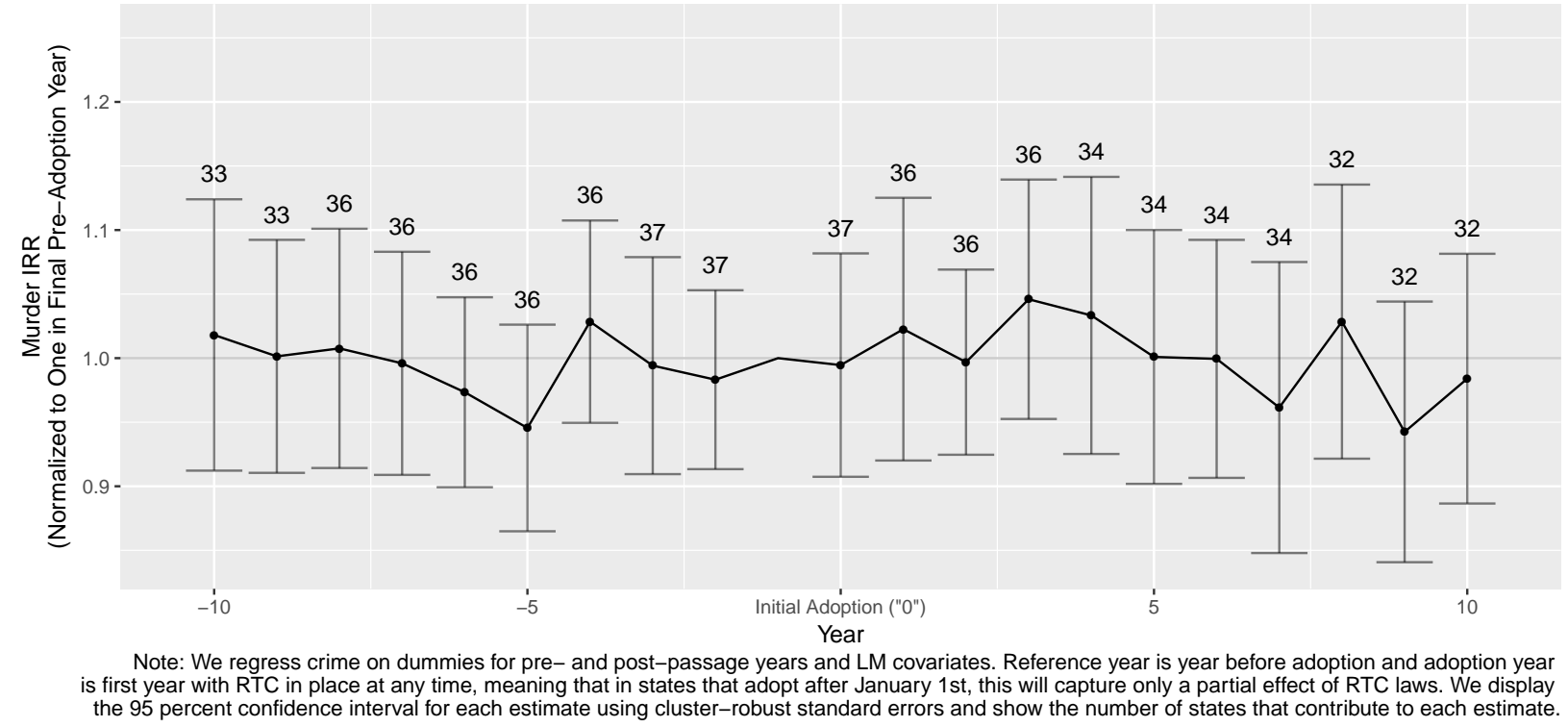

Figure D7

\section{B. State Contributions to Synthetic Control Estimates}

Frequency of potential donor states to appear as synthetic controls in violent crime estimates

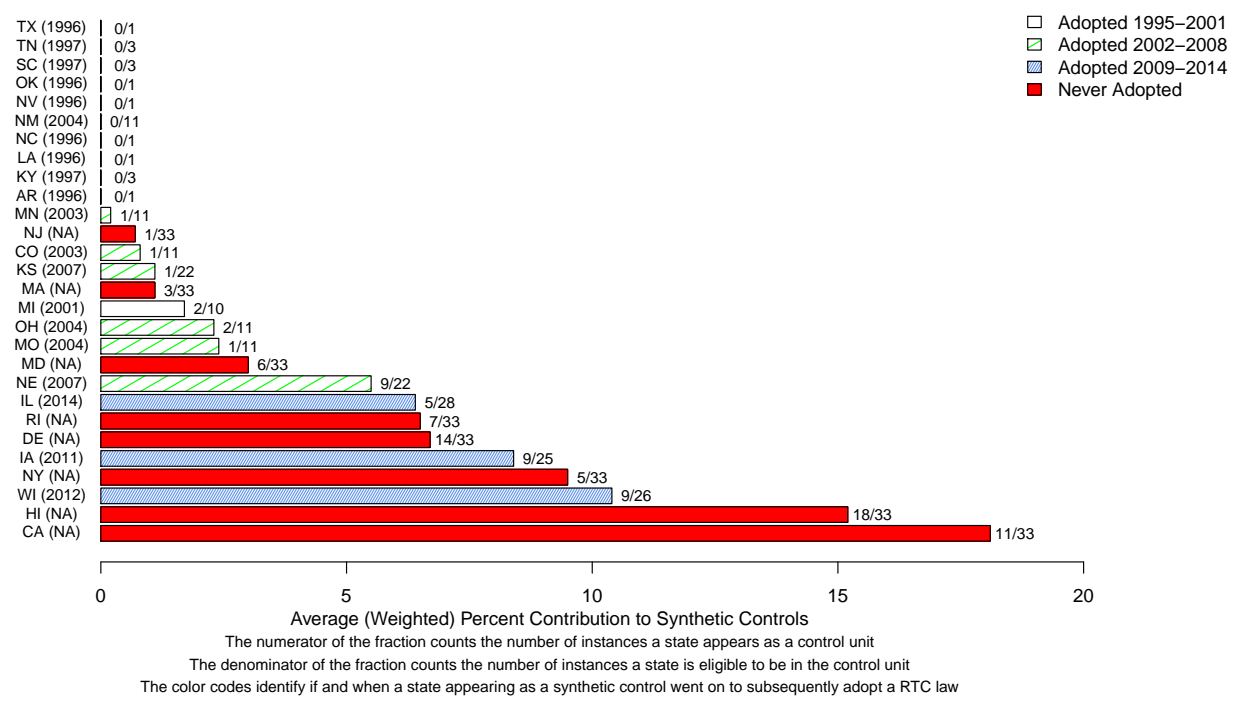

Figure D8 


\section{Synthetic Control Estimates for Impact on Violent Crime}

The effect of RTC laws on violent crime after 10 years, synthetic control estimates for 26 states (1977 - 2014)

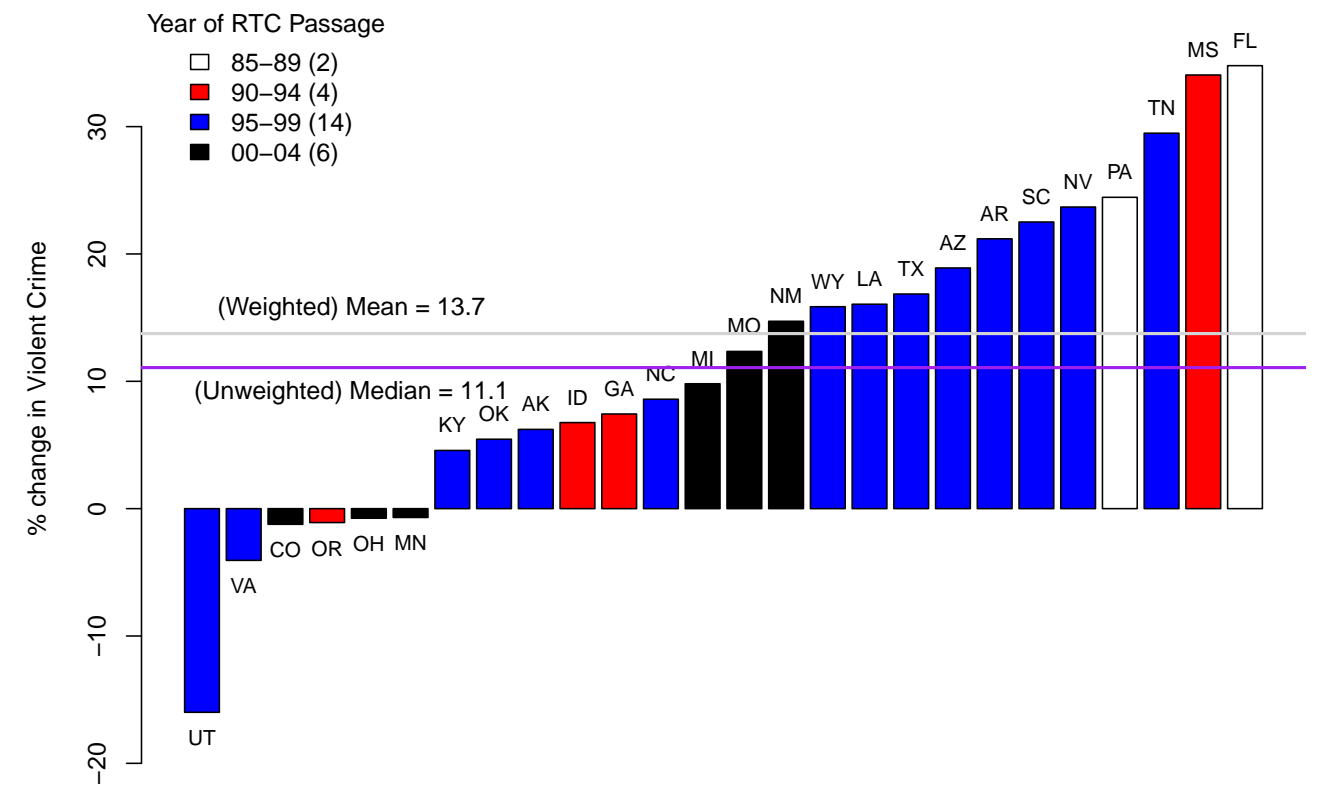

Figure D9 


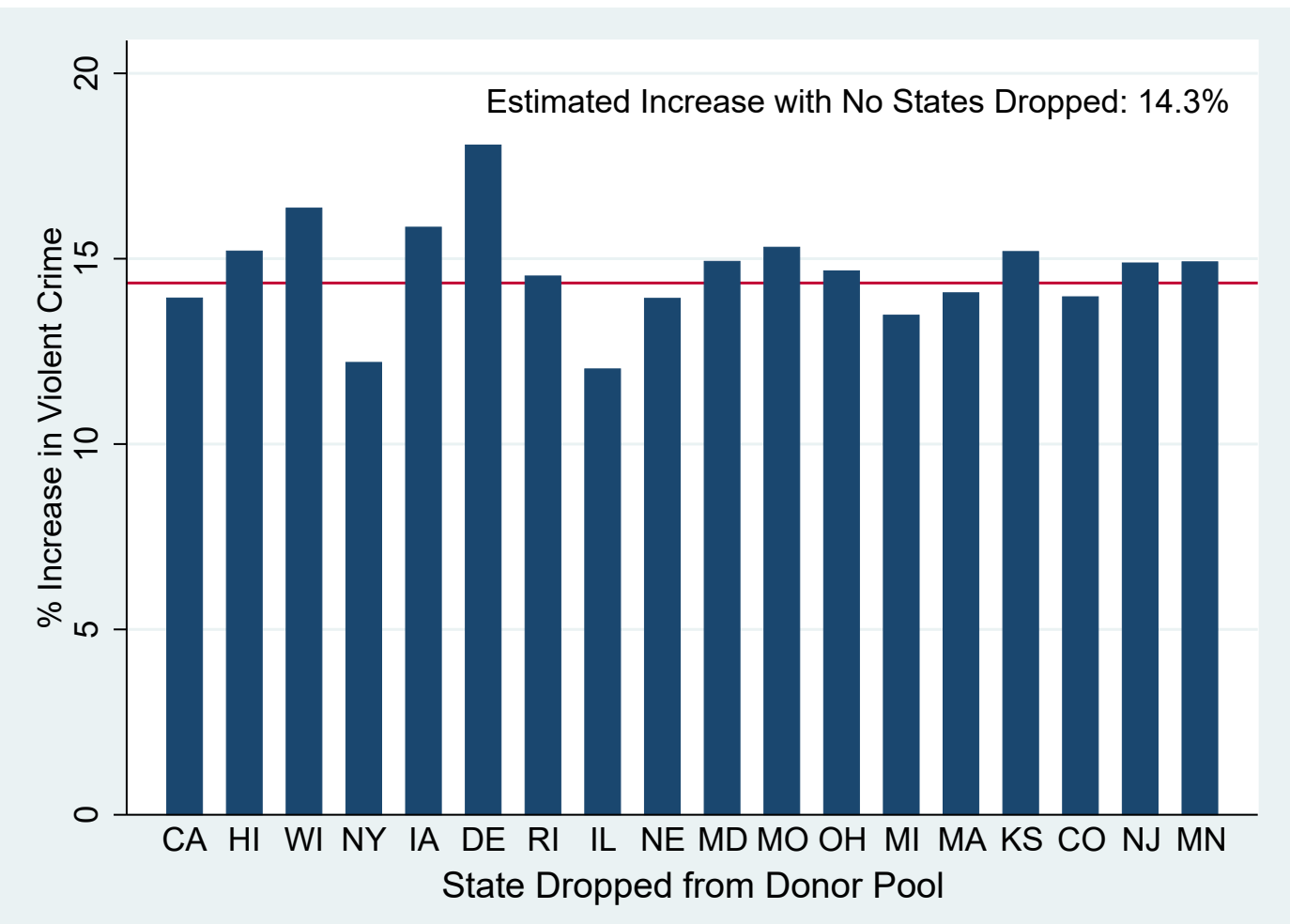

The graph shows the overall synthetic control estimate of the impact of RTC laws on violent crime ten years after adoption when barring individual states from inclusion in the synthetic control. (The horizontal line shows the estimate when no states are barred.) The states are arranged in declining order of population-weighted average contribution to synthetic controls (see Appendix Figure D8, from a high of 18.1 percent for California to a low of 0.2 percent for Minnesota.

Figure D10: Estimated increase in violent crime ten years after RTC adoption, dropping one donor state at a time

\section{Appendix E: Synthetic Control Estimates of the Impact of RTC Laws on Murder and Property Crime for the DAW and LM Models}

Our synthetic control estimates of the impact of RTC laws on murder and property crime appear in Appendix Tables E1,E4 of the appendix. In all cases the tenth-year effect for these crimes is positive, although not statistically significant. For murder, the point estimates suggest an increase of 4-5 percent, and for property crime, the point estimates range from 1-3.5 percent increases.

The relatively smaller impact of RTC laws on property crime is not surprising. Much property crime occurs when no one is around to notice, so gun use is much less potentially relevant in 
property crime scenarios than in the case of violent crime, where victims are necessarily present. Most of the pernicious effects of RTC laws-with the exception of gun thefts - are likely to operate to increase violent crime more powerfully than property crime. The fact that the synthetic control approach confirms the DAW panel data estimates showing that RTC laws increase violent crime while simultaneously showing far more modest effects on property crime (thereby conflicting with the DAW panel data estimate showing substantial increases in property crime) may be thought to enhance the plausibility of the synthetic control estimates.

But then what are we to make of the relatively small estimated impact of RTC laws on murder? This might seem to be at odds with our theoretical expectations, and in conflict with the estimated increases in overall violent crime since one might expect violent crime and murder to move together. A number of points should be noted. First, it is possible that we simply cannot rely on the murder estimates because of the relatively poor performance of the synthetic controls for this crime, compared to the violent crime estimates (see Appendix K). This is not conclusive because it is possible that our actual murder estimates become sufficiently accurate with the five more years of data that we actually use that we can rely on the resulting estimates. In that event, a 4.3 to 6.4 percent increase in murder over a ten-year period is not a small effect. Part of the explanation for the lower level of statistical significance for murder is that we are able to get more precise estimates of the impact of RTC laws on violent crime than for the far less numerous, and hence much more volatile, crime of murder. Indeed, the standard errors for the synthetic control estimate of increased murder in the tenth year is 26 percent higher than the comparable standard error for violent crime (compare Table 5 with Appendix Table E1).

But a second and possibly more important fact is also at work that likely causes the synthetic control approach to understate the increase in crime caused by RTC laws, particularly for murder. We know from Table 1 that RTC states increased police employment by 8.4 percent more and increased incarceration by almost seven percent more in the wake of RTC adoption than did nonRTC states. This suggests that our synthetic control estimates of the crime-increasing impact of RTC laws could be biased downward, and since police and incarceration are more effective in stopping murder than either overall violent or property crime, the extent of any bias would be greatest for the crime of murder. In other words, the greater ability of police and prison to stop murders than overall violent (or property) crime may explain why the synthetic control estimates for murder are weaker than those for violent crime. An increase in police employment of 8.4 percent alone would be expected to suppress murders in RTC states (relative to non-RTC states) by about 5.6 percent. ${ }^{72}$ Since the synthetic control approach does not control for the higher police

\footnotetext{
${ }^{72}$ The important recent paper by Professors Aaron Chalfin and Justin McCrary concludes that higher police employment has a dampening effect on crime, and, most strikingly, on murder. Specifically, Chalfin and McCrary (2013) find elasticities of -0.67 for murder but only -0.34 for violent crimes and -0.17 for property crimes.
} 
employment and incarceration in the post-adoption phase for RTC states, it may be appropriate to elevate the synthetic control estimates on murder to reflect the murder-dampening effect of the two factors.

To adjust our synthetic control estimates of the impact of RTC laws on murder to reflect the post-adoption changes in the rates of police employment and incarceration, we can compare how these crime-reducing elements change in the wake of adoption for each RTC-adopting state and for its particular synthetic control. Consistent with the panel data finding of Table 1 that police and incarceration grew more post-RTC-adoption, we found that the population-weighted average percent change in the incarceration rate from the year of adoption to the 10th year after adoption (the 7th year after adoption for Kansas and Nebraska) is 28 percent for the treated unit and only 20 percent for the synthetic control unit. For the police employee rate, the analogous numbers are 9.1 percent for the treated unit and 7.6 percent for the synthetic control unit. ${ }^{73}$

We correct for this underestimation by restricting the synthetic control unit to have the same growth rate in incarceration and police as the treated unit. ${ }^{74}$ Once we have computed an adjusted murder rate for the 31 synthetic control units in the 10th year after adoption, we then use the formula described in part IV to construct an adjusted aggregate treatment effect. ${ }^{75}$ The impact of controlling for police and incarceration is substantial: the 10th year impact of RTC laws rises from 4.30 percent $(\mathrm{t}=1.17)$ to 8.99 percent $(\mathrm{t}=1.76) .{ }^{76}$ In other words, the ostensible puzzle that RTC laws generated a large and statistically significant increase in overall violent crime but led to a smaller and less statistically significant increase in murder may be explained by the fact that RTC-adopting states constrained the RTC-induced increase in murder by elevating their rates of police and incarceration.

Finally, we have chosen to present synthetic control estimates that subtract off the initial year discrepancy between the actual and synthetic control crime figures, which we think is validated by our Appendix K analysis. While these would be be our preferred estimates, Appendix Tables

\footnotetext{
${ }^{73} 22$ of the 33 states experienced growth in the incarceration rate (17/33 for police employee rates) that was greater than their respective synthetic control growth rate (obtained using DAW covariates and the murder rate). The population-weighted fraction of states experiencing this greater increase was $67.3 \%$ for incarceration and $49.2 \%$ for police.

${ }^{74}$ By comparing the synthetic control unit's adjusted police/incarceration figures with its actual police/incarceration figures, and by applying standard estimates of the elasticity of murder with respect to police (-0.67) and incarceration $(-0.15)$, we can create an adjusted version of the control unit's murder rate for each year after RTC adoption. For example, if the police and incarceration rates for the synthetic control unit were both ten percent greater than the actual rates in the 10th year after adoption for an RTC-adopting state, we would adjust the murder rate for the synthetic control unit downwards by $0.67 * 10+0.15 * 10=8.2$ percent (thereby elevating the predicted impact of RTC laws on murder).

${ }^{75}$ Kansas and Nebraska, both 2007 adopters, have no comparable data for ten years after adoption and are thus not included in this calculation.

${ }^{76}$ If one only corrects for the larger jump in police experienced by the treatment states, the 10th year effect jumps from 4.30 percent $(t=1.17)$ to 7.08 percent $(t=1.49)$.
} 
F4 F6 show that without subtraction the DAW tenth year synthetic control estimates of the increase in the murder rate from RTC adoption range from 11-14 percent, and are statistically significant at or above the .05 level. ${ }^{77}$

Table E1: The Impact of RTC Laws on the Murder Rate, DAW covariates, Full Sample, 1977-2014

\begin{tabular}{|c|c|c|c|c|c|c|c|c|c|c|}
\hline & (1) & (2) & (3) & (4) & $\overline{(5)}$ & (6) & (7) & (8) & (9) & (10) \\
\hline Average normalized TEP & $\begin{array}{c}0.784 \\
(1.931)\end{array}$ & $\begin{array}{l}-2.195 \\
(4.189)\end{array}$ & $\begin{array}{l}-1.584 \\
(4.573)\end{array}$ & $\begin{array}{l}-2.635 \\
(4.722)\end{array}$ & $\begin{array}{c}-6.032 \\
(5.034)\end{array}$ & $\begin{array}{c}-6.412 \\
(4.504)\end{array}$ & $\begin{array}{c}-6.413 \\
(5.272)\end{array}$ & $\begin{array}{c}1.438 \\
(4.927)\end{array}$ & $\begin{array}{c}-0.498 \\
(4.355)\end{array}$ & $\begin{array}{l}.302 \\
(3.683)\end{array}$ \\
\hline $\mathrm{N}$ & 33 & 33 & 33 & 33 & 33 & 33 & 33 & 31 & 31 & 31 \\
\hline Pseudo p-value & 0.788 & 0.566 & 0.710 & 0.638 & 0.298 & 0.318 & 0.358 & 0.840 & 0.942 & 0.578 \\
\hline Proportion of corresponding placebo estimates significant at .10 level & 0.130 & 0.156 & 0.190 & 0.156 & 0.176 & 0.192 & 0.192 & 0.188 & 0.190 & 0.216 \\
\hline Proportion of corresponding placebo estimates significant at .05 level & 0.072 & 0.082 & 0.114 & 0.102 & 0.118 & 0.126 & 0.122 & 0.122 & 0.124 & 0.142 \\
\hline Proportion of corresponding placebo estimates significant at .01 level & 0.024 & 0.024 & 0.024 & 0.028 & 0.044 & 0.044 & 0.040 & 0.046 & 0.056 & 0.046 \\
\hline
\end{tabular}
Standard errors in parentheses

Column numbers indicate post-passage year under consideration; $\mathrm{N}=$ number of states in sample

Dependent variable is the difference between the percentage difference in the murder rate in treatment and synthetic control states at given post-treatment interval and at time of the treatment

Results reported for the constant term resulting from this regression

States in group: AK AR AZ CO FL GA ID KS KY LA ME MI MN MO MS MT NC ND NE NM NV OH OK OR PA SC SD TN TX UT VA WV WY

States excluded for poor pre-treatment fit:

The synthetic controls used to generate the placebo estimates in the table above were generated using the optimization technique described in our main text.

${ }^{*} p<0.10,{ }^{* *} p<0.05,{ }^{* * *} p<0.01$

Table E2: The Impact of RTC Laws on the Property Crime Rate, DAW covariates, Full Sample, 1977-2014

\begin{tabular}{|c|c|c|c|c|c|c|c|c|c|c|}
\hline & (1) & (2) & (3) & (4) & (5) & (6) & (7) & $(8)$ & (9) & (10) \\
\hline \multirow[t]{2}{*}{ Average normalized TEP } & -0.224 & 1.336 & 2.354 & 0.679 & 0.600 & 1.557 & 0.677 & 1.554 & 1.070 & 1.334 \\
\hline & $(0.998)$ & $(1.306)$ & $(2.535)$ & $(2.709)$ & (2.734) & $(2.580)$ & $(2.465)$ & $(2.319)$ & (2.406) & $(2.325)$ \\
\hline $\mathrm{N}$ & 33 & 33 & 33 & 33 & 33 & 33 & 33 & 31 & 31 & 31 \\
\hline Pseudo p-value & 0.852 & 0.456 & 0.348 & 0.822 & 0.864 & 0.650 & 0.864 & 0.708 & 0.800 & 0.784 \\
\hline Proportion of corresponding placebo estimates significant at .10 level & 0.144 & 0.176 & 0.166 & 0.196 & 0.192 & 0.206 & 0.182 & 0.200 & 0.198 & 0.204 \\
\hline Proportion of corresponding placebo estimates significant at .05 level & 0.070 & 0.088 & 0.084 & 0.090 & 0.114 & 0.120 & 0.106 & 0.120 & 0.130 & 0.132 \\
\hline Proportion of corresponding placebo estimates significant at .01 level & 0.024 & 0.020 & 0.030 & 0.034 & 0.024 & 0.030 & 0.044 & 0.048 & 0.040 & 0.040 \\
\hline
\end{tabular}

\begin{tabular}{l}
\hline Standard errors in parentheses \\
Column numbers indicate post-passage year under consideration; $\mathrm{N}=$ number of states in sample
\end{tabular}

Dependent variable is the difference between the percentage difference in the property crime rate in treatment and synthetic control states at given post-treatment interval and at time of the treatment

Results reported for the constant term resulting from this regression

States in group: AK AR AZ CO FL GA ID KS KY LA ME MI MN MO MS MT NC ND NE NM NV OH OK OR PA SC SD TN TX UT VA WV WY

States excluded for poor pre-treatment fit:

The synthetic controls used to generate the placebo estimates in the table above were generated using the optimization technique described in our main text.

${ }^{*} p<0.10,{ }^{* *} p<0.05,{ }^{* * *} p<0.01$

\footnotetext{
${ }^{77}$ The Appendix Table E1 DAW estimate for murder in the tenth year after the RTC adoption is 4.3 percent and not statistically significant (with subtraction) but rises to a statistically significant value of 11.2 percent without subtraction (Appendix Table F4). Similarly, when not subtracting the adoption year percentage difference, the tenth year TEP for property crime is over ten percentage points larger and becomes significant at the five percent level (Appendix Table F7).
} 
Table E3: The Impact of RTC Laws on the Murder Rate, LM covariates, Full Sample, 1977-2014

\begin{tabular}{|c|c|c|c|c|c|c|c|c|c|c|}
\hline & (1) & (2) & (3) & (4) & (5) & (6) & (7) & (8) & (9) & (10) \\
\hline Average normalized TEP & $\begin{array}{c}-0.107 \\
(1.713)\end{array}$ & $\begin{array}{l}-4.355 \\
(4.166)\end{array}$ & $\begin{array}{l}-2.770 \\
(4.501)\end{array}$ & $\begin{array}{l}-3.382 \\
(4.661)\end{array}$ & $\begin{array}{l}-5.337 \\
(5.323)\end{array}$ & $\begin{array}{c}-3.972 \\
(5.155)\end{array}$ & $\begin{array}{l}-4.913 \\
(5.484)\end{array}$ & $\begin{array}{c}2.498 \\
(5.562)\end{array}$ & $\begin{array}{c}1.501 \\
(5.019)\end{array}$ & $\begin{array}{l}4.542 \\
(4.141)\end{array}$ \\
\hline $\mathrm{N}$ & 33 & 33 & 33 & 33 & 33 & 33 & 33 & 31 & 31 & 31 \\
\hline Pseudo p-value & 0.962 & 0.236 & 0.556 & 0.510 & 0.350 & 0.514 & 0.462 & 0.750 & 0.824 & 0.598 \\
\hline Proportion of corresponding placebo estimates significant at .10 level & 0.132 & 0.148 & 0.154 & 0.164 & 0.182 & 0.182 & 0.170 & 0.172 & 0.218 & 0.220 \\
\hline Proportion of corresponding placebo estimates significant at .05 level & 0.078 & 0.088 & 0.074 & 0.088 & 0.090 & 0.106 & 0.102 & 0.114 & 0.132 & 0.142 \\
\hline Proportion of corresponding placebo estimates significant at .01 level & 0.022 & 0.018 & 0.024 & 0.036 & 0.038 & 0.026 & 0.036 & 0.034 & 0.040 & 0.044 \\
\hline
\end{tabular}

Standard errors in parentheses

Column numbers indicate post-passage year under consideration; $\mathrm{N}=$ number of states in sample

Dependent variable is the difference between the percentage difference in the murder rate in treatment and synthetic control states at given post-treatment interval and at time of the treatment

Results reported for the constant term resulting from this regression

States in group: AK AR AZ CO FL GA ID KS KY LA ME MI MN MO MS MT NC ND NE NM NV OH OK OR PA SC SD TN TX UT VA WV WY

States excluded for poor pre-treatment fit:

The synthetic controls used to generate the placebo estimates in the table above were generated using the regression methodology described in the main text.

${ }^{*} p<0.10,{ }^{* *} p<0.05,{ }^{* * *} p<0.01$

Table E4: The Impact of RTC Laws on the Property Crime Rate, LM covariates, Full Sample, 1977-2014

\begin{tabular}{|c|c|c|c|c|c|c|c|c|c|c|}
\hline & (1) & (2) & (3) & (4) & (5) & (6) & (7) & (8) & (9) & (10) \\
\hline Average normalized TEP & $\begin{array}{c}-0.208 \\
(1.005)\end{array}$ & $\begin{array}{c}1.262 \\
(1.163)\end{array}$ & $\begin{array}{c}2.211 \\
(2.616)\end{array}$ & $\begin{array}{c}1.039 \\
(2.688)\end{array}$ & $\begin{array}{c}0.077 \\
(2.719)\end{array}$ & $\begin{array}{c}1.099 \\
(2.575)\end{array}$ & $\begin{array}{c}1.525 \\
(2.387)\end{array}$ & $\begin{array}{c}3.218 \\
(2.380)\end{array}$ & $\begin{array}{c}2.544 \\
(2.719)\end{array}$ & $\begin{array}{l}3.420 \\
(3.050)\end{array}$ \\
\hline $\mathrm{N}$ & 33 & 33 & 33 & 33 & 33 & 33 & 33 & 31 & 31 & 31 \\
\hline Pseudo p-value & 0.836 & 0.446 & 0.346 & 0.714 & 0.992 & 0.758 & 0.692 & 0.414 & 0.510 & 0.430 \\
\hline Proportion of corresponding placebo estimates significant at .10 level & 0.138 & 0.162 & 0.178 & 0.188 & 0.200 & 0.214 & 0.184 & 0.208 & 0.204 & 0.198 \\
\hline Proportion of corresponding placebo estimates significant at .05 level & 0.066 & 0.102 & 0.100 & 0.120 & 0.116 & 0.134 & 0.122 & 0.128 & 0.112 & 0.122 \\
\hline Proportion of corresponding placebo estimates significant at .01 level & 0.022 & 0.014 & 0.026 & 0.030 & 0.038 & 0.034 & 0.048 & 0.054 & 0.044 & 0.046 \\
\hline
\end{tabular}

Standard errors in parentheses

Column numbers indicate post-passage year under consideration; $\mathrm{N}=$ number of states in sample

Dependent variable is the difference between the percentage difference in the property crime rate in treatment and synthetic control states at given post-treatment interval and at time of the treatment

Results reported for the constant term resulting from this regression

States in group: AK AR AZ CO FL GA ID KS KY LA ME MI MN MO MS MT NC ND NE NM NV OH OK OR PA SC SD TN TX UT VA WV WY

States excluded for poor pre-treatment fit:

The synthetic controls used to generate the placebo estimates in the table above were generated using the regression methodology described in the main text.

${ }^{*} p<0.10,{ }^{* *} p<0.05,{ }^{* * *} p<0.01$ 


\section{Appendix F: Synthetic Control Estimates of RTC Law Impact on Three Crimes Without Adoption Year Normalization (DAW)}

Table F1: The Impact of RTC Laws on the Violent Crime Rate, DAW covariates, Full Sample, 1977-2014, No Subtraction of Adoption Year Crime Differential

\begin{tabular}{|c|c|c|c|c|c|c|c|c|c|c|}
\hline & (1) & (2) & (3) & (4) & (5) & (6) & (7) & (8) & (9) & (10) \\
\hline Average normalized TEP & $\begin{array}{c}2.467 \\
(1.689)\end{array}$ & $\begin{array}{l}5.228^{* *} \\
(2.066)\end{array}$ & $\begin{array}{l}6.241^{* *} \\
(2.576)\end{array}$ & $\begin{array}{l}7.301^{* *} \\
(2.927)\end{array}$ & $\begin{array}{c}9.503^{* * * *} \\
(3.241)\end{array}$ & $\begin{array}{l}9.995^{* *} \\
(3.798)\end{array}$ & $\begin{array}{c}12.715^{* * * *} \\
(3.507)\end{array}$ & $\begin{array}{c}15.047^{* * *} \\
(4.605)\end{array}$ & $\begin{array}{c}16.613^{* * *} \\
(4.278)\end{array}$ & $\begin{array}{l}16.941^{* * * *} \\
(3.724)\end{array}$ \\
\hline $\mathrm{N}$ & 33 & 33 & 33 & 33 & 33 & 33 & 33 & 31 & 31 & 31 \\
\hline Pseudo p-value & 0.618 & 0.314 & 0.248 & 0.192 & 0.100 & 0.104 & 0.050 & 0.030 & 0.020 & 0.018 \\
\hline Proportion of corresponding placebo estimates significant at .10 level & 0.270 & 0.278 & 0.258 & 0.266 & 0.240 & 0.280 & 0.278 & 0.284 & 0.288 & 0.274 \\
\hline Proportion of corresponding placebo estimates significant at .05 level & 0.178 & 0.180 & 0.182 & 0.182 & 0.160 & 0.184 & 0.204 & 0.188 & 0.186 & 0.188 \\
\hline Proportion of corresponding placebo estimates significant at .01 level & 0.068 & 0.072 & 0.080 & 0.086 & 0.066 & 0.080 & 0.066 & 0.074 & 0.070 & 0.062 \\
\hline
\end{tabular}

Standard errors in parentheses

Column numbers indicate post-passage year under consideration; $\mathrm{N}=$ number of states in sample

Dependent variable is the percentage difference in the violent crime rate in treatment and synthetic control states at given post-treatment interval

Results reported for the constant term resulting from this regression

States in group: AK AR AZ CO FL GA ID KS KY LA ME MI MN MO MS MT NC ND NE NM NV OH OK OR PA SC SD TN TX UT VA WV WY

States excluded for poor pre-treatment fit:

The synthetic controls used to generate the placebo estimates in the table above were generated using the optimization technique described in our main text.

${ }^{*} p<0.10,{ }^{* *} p<0.05,{ }^{* * *} p<0.01$

Table F2: The Impact of RTC Laws on the Violent Crime Rate, DAW covariates, $<2 x$ Average Coefficient of Variation of the RMSPE, 1977-2014, No Subtraction of Adoption Year Crime Differential

\begin{tabular}{|c|c|c|c|c|c|c|c|c|c|c|}
\hline & 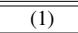 & $\overline{(2)}$ & (3) & (4) & $\overline{(5)}$ & (6) & (7) & (8) & (9) & (10) \\
\hline Average normalized TEP & $\begin{array}{l}3.722^{* *} \\
(1.552)\end{array}$ & $\begin{array}{c}6.377^{* * * *} \\
(1.980)\end{array}$ & $\begin{array}{c}7.588^{* * * *} \\
(2.455)\end{array}$ & $\begin{array}{c}8.573^{* * * *} \\
(2.851)\end{array}$ & $\begin{array}{c}10.996^{* * *} \\
(3.111)\end{array}$ & $\begin{array}{c}11.050^{* * *} \\
(3.771)\end{array}$ & $\begin{array}{c}13.773^{* * *} \\
(3.451)\end{array}$ & $\begin{array}{c}15.911^{* * *} \\
(4.621)\end{array}$ & $\begin{array}{c}16.873^{* * *} \\
(4.355)\end{array}$ & $\begin{array}{l}17.337^{* * *} \\
(3.777)\end{array}$ \\
\hline $\mathrm{N}$ & 29 & 29 & 29 & 29 & 29 & 29 & 29 & 27 & 27 & 27 \\
\hline Pseudo p-value & 0.420 & 0.212 & 0.152 & 0.122 & 0.052 & 0.066 & 0.032 & 0.020 & 0.020 & 0.020 \\
\hline Proportion of corresponding placebo estimates significant at .10 level & 0.284 & 0.278 & 0.270 & 0.274 & 0.266 & 0.266 & 0.282 & 0.286 & 0.274 & 0.274 \\
\hline Proportion of corresponding placebo estimates significant at .05 level & 0.194 & 0.178 & 0.182 & 0.180 & 0.178 & 0.182 & 0.192 & 0.188 & 0.180 & 0.186 \\
\hline Proportion of corresponding placebo estimates significant at .01 level & 0.074 & 0.072 & 0.064 & 0.082 & 0.064 & 0.078 & 0.074 & 0.068 & 0.068 & 0.054 \\
\hline
\end{tabular}

Standard errors in parentheses

Column numbers indicate post-passage year under consideration; $\mathrm{N}=$ number of states in sample

Dependent variable is the percentage difference in the violent crime rate in treatment and synthetic control states at given post-treatment interval

Results reported for the constant term resulting from this regression

States in group: AK AR AZ CO FL GA ID KS KY LA ME MI MN MO MS NC NE NM NV OH OK OR PA SC TN TX UT VA WY

States excluded for poor pre-treatment fit: MT ND SD WV

The synthetic controls used to generate the placebo estimates in the table above were generated using the optimization technique described in our main text.

${ }^{*} p<0.10,{ }^{* *} p<0.05,{ }^{* * *} p<0.01$

Table F3: The Impact of RTC Laws on the Violent Crime Rate, DAW covariates, $<$ 1x Average Coefficient of Variation of the RMSPE, 1977-2014, No Subtraction of Adoption Year Crime Differential

\begin{tabular}{|c|c|c|c|c|c|c|c|c|c|c|}
\hline & $(1)$ & (2) & (3) & (4) & (5) & (6) & (7) & (8) & (9) & (10) \\
\hline Average normalized TEP & $\begin{array}{l}4.209^{* *} \\
(1.537)\end{array}$ & $\begin{array}{c}6.994^{* * * *} \\
(1.953)\end{array}$ & $\begin{array}{c}8.311^{* * * *} \\
(2.410)\end{array}$ & $\begin{array}{c}9.367^{* * * *} \\
(2.814)\end{array}$ & $\begin{array}{c}11.806^{* * *} \\
(3.065)\end{array}$ & $\begin{array}{c}11.812^{* * *} \\
(3.748)\end{array}$ & $\begin{array}{c}14.533^{* * *} \\
(3.404)\end{array}$ & $\begin{array}{c}16.492^{* * *} \\
(4.574)\end{array}$ & $\begin{array}{c}17.487^{* * * *} \\
(4.299)\end{array}$ & $\begin{array}{l}17.893^{* * * *} \\
(3.736)\end{array}$ \\
\hline $\mathrm{N}$ & 27 & 27 & 27 & 27 & 27 & 27 & 27 & 26 & 26 & 26 \\
\hline Pseudo p-value & 0.292 & 0.116 & 0.078 & 0.070 & 0.030 & 0.050 & 0.028 & 0.016 & 0.020 & 0.018 \\
\hline Proportion of corresponding placebo estimates significant at .10 level & 0.216 & 0.234 & 0.252 & 0.252 & 0.250 & 0.258 & 0.262 & 0.260 & 0.262 & 0.262 \\
\hline Proportion of corresponding placebo estimates significant at .05 level & 0.160 & 0.142 & 0.146 & 0.152 & 0.158 & 0.164 & 0.174 & 0.180 & 0.166 & 0.170 \\
\hline Proportion of corresponding placebo estimates significant at .01 level & 0.066 & 0.046 & 0.054 & 0.060 & 0.056 & 0.062 & 0.062 & 0.048 & 0.058 & 0.050 \\
\hline
\end{tabular}

Standard errors in parentheses

Column numbers indicate post-passage year under consideration; $\mathrm{N}=$ number of states in sample

Dependent variable is the percentage difference in the violent crime rate in treatment and synthetic control states at given post-treatment interval

Results reported for the constant term resulting from this regression

States in group: AK AR AZ CO FL GA ID KS KY LA MI MN MO MS NC NM NV OH OK OR PA SC TN TX UT VA WY

States excluded for poor pre-treatment fit: ME MT ND NE SD WV

The synthetic controls used to generate the placebo estimates in the table above were generated using the optimization technique described in our main text.

${ }^{*} p<0.10,{ }^{* *} p<0.05,{ }^{* * *} p<0.01$ 
Table F4: The Impact of RTC Laws on the Murder Rate, DAW covariates, Full Sample, 1977-2014, No Subtraction of Adoption Year Crime Differential

\begin{tabular}{|c|c|c|c|c|c|c|c|c|c|c|}
\hline & (1) & (2) & (3) & (4) & (5) & 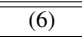 & (7) & 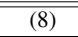 & (9) & (10) \\
\hline Average normalized TEP & $\begin{array}{l}8.565^{*} \\
(4.365)\end{array}$ & $\begin{array}{c}5.573 \\
(3.816)\end{array}$ & $\begin{array}{c}6.173 \\
(4.639)\end{array}$ & $\begin{array}{c}5.105 \\
(5.316)\end{array}$ & $\begin{array}{c}1.691 \\
(4.723)\end{array}$ & $\begin{array}{c}1.298 \\
(5.315)\end{array}$ & $\begin{array}{c}1.294 \\
(5.226)\end{array}$ & $\begin{array}{c}8.489 \\
(5.738)\end{array}$ & $\begin{array}{c}6.554 \\
(4.571)\end{array}$ & $\begin{array}{l}11.184^{* *} \\
(5.298)\end{array}$ \\
\hline $\mathrm{N}$ & 33 & 33 & 33 & 33 & 33 & 33 & 33 & 31 & 31 & 31 \\
\hline Pseudo p-value & 0.204 & 0.444 & 0.400 & 0.532 & 0.832 & 0.888 & 0.896 & 0.360 & 0.496 & 0.264 \\
\hline Proportion of corresponding placebo estimates significant at .10 level & 0.252 & 0.282 & 0.282 & 0.272 & 0.264 & 0.280 & 0.256 & 0.250 & 0.280 & 0.244 \\
\hline Proportion of corresponding placebo estimates significant at .05 level & 0.182 & 0.196 & 0.200 & 0.182 & 0.196 & 0.200 & 0.196 & 0.190 & 0.192 & 0.166 \\
\hline Proportion of corresponding placebo estimates significant at .01 level & 0.086 & 0.096 & 0.082 & 0.088 & 0.098 & 0.092 & 0.090 & 0.084 & 0.090 & 0.076 \\
\hline
\end{tabular}

Standard errors in parentheses

Column numbers indicate post-passage year under consideration; $\mathrm{N}=$ number of states in sample

Dependent variable is the percentage difference in the murder rate in treatment and synthetic control states at given post-treatment interval

Results reported for the constant term resulting from this regression

States in group: AK AR AZ CO FL GA ID KS KY LA ME MI MN MO MS MT NC ND NE NM NV OH OK OR PA SC SD TN TX UT VA WV WY

States excluded for poor pre-treatment fit:

The synthetic controls used to generate the placebo estimates in the table above were generated using the optimization technique described in our main text.

${ }^{*} p<0.10,{ }^{* *} p<0.05,{ }^{* * *} p<0.01$

Table F5: The Impact of RTC Laws on the Murder Rate, DAW covariates, $<2 x$ Average Coefficient of Variation of the RMSPE, 1977-2014, No Subtraction of Adoption Year Crime Differential

\begin{tabular}{|c|c|c|c|c|c|c|c|c|c|c|}
\hline & $(1)$ & (2) & (3) & (4) & 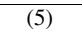 & (6) & (7) & 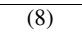 & (9) & (10) \\
\hline Average normalized TEP & $\begin{array}{l}9.575^{* *} \\
(4.533)\end{array}$ & $\begin{array}{c}6.497 \\
(3.903) \\
\end{array}$ & $\begin{array}{c}7.204 \\
(4.825)\end{array}$ & $\begin{array}{c}6.173 \\
(5.529) \\
\end{array}$ & $\begin{array}{c}2.607 \\
(4.885) \\
\end{array}$ & $\begin{array}{c}2.928 \\
(5.358) \\
\end{array}$ & $\begin{array}{c}2.906 \\
(5.292) \\
\end{array}$ & $\begin{array}{l}10.800^{*} \\
(5.764)\end{array}$ & $\begin{array}{c}7.395 \\
(4.750) \\
\end{array}$ & $\begin{array}{l}11.729^{* *} \\
(5.516)\end{array}$ \\
\hline $\mathrm{N}$ & 31 & 31 & 31 & 31 & 31 & 31 & 31 & 29 & 29 & 29 \\
\hline Pseudo p-value & 0.152 & 0.376 & 0.344 & 0.454 & 0.776 & 0.760 & 0.752 & 0.262 & 0.454 & 0.242 \\
\hline Proportion of corresponding placebo estimates significant at .10 level & 0.272 & 0.282 & 0.280 & 0.274 & 0.274 & 0.286 & 0.262 & 0.260 & 0.276 & 0.238 \\
\hline Proportion of corresponding placebo estimates significant at .05 level & 0.184 & 0.200 & 0.190 & 0.196 & 0.216 & 0.196 & 0.194 & 0.192 & 0.194 & 0.160 \\
\hline Proportion of corresponding placebo estimates significant at .01 level & 0.084 & 0.096 & 0.082 & 0.090 & 0.104 & 0.090 & 0.096 & 0.084 & 0.092 & 0.082 \\
\hline
\end{tabular}

Standard errors in parentheses

Column numbers indicate post-passage year under consideration; $\mathrm{N}=$ number of states in sample

Dependent variable is the percentage difference in the murder rate in treatment and synthetic control states at given post-treatment interval

Results reported for the constant term resulting from this regression

States in group: AK AR AZ CO FL GA ID KS KY LA ME MI MO MS MT NC NE NM NV OH OK OR PA SC SD TN TX UT VA WV WY

States excluded for poor pre-treatment fit: MN ND

The synthetic controls used to generate the placebo estimates in the table above were generated using the optimization technique described in our main text.

${ }^{*} p<0.10,{ }^{* *} p<0.05,{ }^{* * *} p<0.01$

Table F6: The Impact of RTC Laws on the Murder Rate, DAW covariates, $<$ 1x Average Coefficient of Variation of the RMSPE, 1977-2014, No Subtraction of Adoption Year Crime Differential

\begin{tabular}{|c|c|c|c|c|c|c|c|c|c|c|}
\hline & 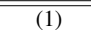 & (2) & (3) & 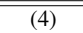 & (5) & $\overline{(26)}$ & (7) & (8) & (9) & 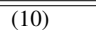 \\
\hline Average normalized TEP & $\begin{array}{c}9.660^{* * *} \\
(2.559)\end{array}$ & $\begin{array}{c}2.942 \\
(3.372)\end{array}$ & $\begin{array}{c}4.538 \\
(5.319)\end{array}$ & $\begin{array}{c}2.263 \\
(5.590)\end{array}$ & $\begin{array}{l}-0.348 \\
(5.513)\end{array}$ & $\begin{array}{c}1.171 \\
(5.550)\end{array}$ & $\begin{array}{l}-0.088 \\
(5.758)\end{array}$ & $\begin{array}{l}10.838^{*} \\
(5.909)\end{array}$ & $\begin{array}{l}8.871^{*} \\
(5.088)\end{array}$ & $\begin{array}{l}14.020^{* * *} \\
(4.789)\end{array}$ \\
\hline $\mathrm{N}$ & 21 & 21 & 21 & 21 & 21 & 21 & 21 & 21 & 21 & 21 \\
\hline Pseudo p-value & 0.120 & 0.720 & 0.586 & 0.804 & 0.972 & 0.920 & 0.992 & 0.290 & 0.390 & 0.184 \\
\hline Proportion of corresponding placebo estimates significant at .10 level & 0.260 & 0.276 & 0.312 & 0.286 & 0.290 & 0.290 & 0.282 & 0.254 & 0.268 & 0.238 \\
\hline Proportion of corresponding placebo estimates significant at .05 level & 0.184 & 0.190 & 0.200 & 0.196 & 0.206 & 0.210 & 0.212 & 0.174 & 0.190 & 0.162 \\
\hline Proportion of corresponding placebo estimates significant at .01 level & 0.068 & 0.092 & 0.082 & 0.088 & 0.094 & 0.094 & 0.090 & 0.088 & 0.088 & 0.088 \\
\hline
\end{tabular}

Standard errors in parentheses

Column numbers indicate post-passage year under consideration; $\mathrm{N}=$ number of states in sample

Dependent variable is the percentage difference in the murder rate in treatment and synthetic control states at given post-treatment interval

Results reported for the constant term resulting from this regression

States in group: AR AZ CO FL GA KY ME MI MO MS NC NM OH OK OR PA SC TN UT VA WV

States excluded for poor pre-treatment fit: AK ID KS LA MN MT ND NE NV SD TX WY

The synthetic controls used to generate the placebo estimates in the table above were generated using the optimization technique described in our main text.

${ }^{*} p<0.10,{ }^{* *} p<0.05,{ }^{* * *} p<0.01$ 
Table F7: The Impact of RTC Laws on the Property Crime Rate, DAW covariates, Full Sample, 1977-2014, No Subtraction of Adoption Year Crime Differential

\begin{tabular}{|c|c|c|c|c|c|c|c|c|c|c|}
\hline & (1) & (2) & (3) & (4) & (5) & (6) & (7) & (8) & (9) & (10) \\
\hline Average normalized TEP & $\begin{array}{l}9.654^{* *} \\
(3.980)\end{array}$ & $\begin{array}{c}11.289^{* *} \\
(4.197)\end{array}$ & $\begin{array}{c}12.368^{* *} \\
(4.886)\end{array}$ & $\begin{array}{c}10.740^{* * *} \\
(4.863)\end{array}$ & $\begin{array}{l}10.709^{*} \\
(5.484)\end{array}$ & $\begin{array}{c}11.725^{* *} \\
(5.593)\end{array}$ & $\begin{array}{c}10.903^{* *} \\
(4.680)\end{array}$ & $\begin{array}{c}11.698^{* *} \\
(4.781)\end{array}$ & $\begin{array}{c}11.288^{* *} \\
(5.271)\end{array}$ & $\begin{array}{l}11.606^{* *} \\
(5.183)\end{array}$ \\
\hline $\mathrm{N}$ & 33 & 33 & 33 & 33 & 33 & 33 & 33 & 31 & 31 & 31 \\
\hline Pseudo p-value & 0.016 & 0.004 & 0.004 & 0.010 & 0.014 & 0.006 & 0.022 & 0.008 & 0.032 & 0.020 \\
\hline Proportion of corresponding placebo estimates significant at .10 level & 0.206 & 0.198 & 0.224 & 0.232 & 0.230 & 0.206 & 0.198 & 0.202 & 0.182 & 0.182 \\
\hline Proportion of corresponding placebo estimates significant at .05 level & 0.138 & 0.130 & 0.134 & 0.152 & 0.156 & 0.146 & 0.128 & 0.116 & 0.108 & 0.118 \\
\hline Proportion of corresponding placebo estimates significant at .01 level & 0.038 & 0.034 & 0.042 & 0.054 & 0.052 & 0.044 & 0.050 & 0.046 & 0.038 & 0.040 \\
\hline
\end{tabular}

Standard errors in parentheses

Column numbers indicate post-passage year under consideration; $\mathrm{N}=$ number of states in sample

Dependent variable is the percentage difference in the property crime rate in treatment and synthetic control states at given post-treatment interval

Results reported for the constant term resulting from this regression

States in group: AK AR AZ CO FL GA ID KS KY LA ME MI MN MO MS MT NC ND NE NM NV OH OK OR PA SC SD TN TX UT VA WV WY

States excluded for poor pre-treatment fit:

The synthetic controls used to generate the placebo estimates in the table above were generated using the optimization technique described in our main text.

${ }^{*} p<0.10,{ }^{* *} p<0.05,{ }^{* * *} p<0.01$

Table F8: The Impact of RTC Laws on the Property Crime Rate, DAW covariates, $<2 x$ Average Coefficient of Variation of the RMSPE, 1977-2014, No Subtraction of Adoption Year Crime Differential

\begin{tabular}{|c|c|c|c|c|c|c|c|c|c|c|}
\hline & (1) & (2) & (3) & (4) & $(5)$ & (6) & (7) & $(8)$ & (9) & (10) \\
\hline Average normalized TEP & $\begin{array}{c}11.231^{* * * *} \\
(4.063)\end{array}$ & $\begin{array}{c}12.864^{* * * *} \\
(4.289)\end{array}$ & $\begin{array}{c}13.926^{* * * *} \\
(5.000)\end{array}$ & $\begin{array}{c}12.195^{* *} \\
(4.985)\end{array}$ & $\begin{array}{c}12.457^{* *} \\
(5.597)\end{array}$ & $\begin{array}{c}13.402^{* *} \\
(5.727)\end{array}$ & $\begin{array}{r}12.286^{* *} \\
(4.794)\end{array}$ & $\begin{array}{c}13.218^{* *} \\
(4.896)\end{array}$ & $\begin{array}{c}12.497^{* *} \\
(5.463)\end{array}$ & $\begin{array}{l}12.904^{* *} \\
(5.363)\end{array}$ \\
\hline $\mathrm{N}$ & 30 & 30 & 30 & 30 & 30 & 30 & 30 & 28 & 28 & 28 \\
\hline Pseudo p-value & 0.000 & 0.000 & 0.000 & 0.000 & 0.000 & 0.000 & 0.004 & 0.004 & 0.014 & 0.016 \\
\hline Proportion of corresponding placebo estimates significant at .10 level & 0.186 & 0.156 & 0.194 & 0.192 & 0.206 & 0.212 & 0.188 & 0.182 & 0.170 & 0.168 \\
\hline Proportion of corresponding placebo estimates significant at .05 level & 0.114 & 0.094 & 0.112 & 0.116 & 0.144 & 0.124 & 0.124 & 0.100 & 0.106 & 0.098 \\
\hline Proportion of corresponding placebo estimates significant at .01 level & 0.026 & 0.026 & 0.032 & 0.036 & 0.040 & 0.040 & 0.038 & 0.044 & 0.036 & 0.036 \\
\hline
\end{tabular}

Standard errors in parentheses

Column numbers indicate post-passage year under consideration; $\mathrm{N}=$ number of states in sample

Dependent variable is the percentage difference in the property crime rate in treatment and synthetic control states at given post-treatment interval

Results reported for the constant term resulting from this regression

States in group: AK AR AZ CO FL GA ID KS LA ME MI MN MO MT NC ND NE NM NV OH OK OR PA SC SD TN TX UT VA WY

States excluded for poor pre-treatment fit: KY MS WV

The synthetic controls used to generate the placebo estimates in the table above were generated using the optimization technique described in our main text.

${ }^{*} p<0.10,{ }^{* *} p<0.05,{ }^{* * *} p<0.01$

Table F9: The Impact of RTC Laws on the Property Crime Rate, DAW covariates, $<1 x$ Average Coefficient of Variation of the RMSPE, 1977-2014, No Subtraction of Adoption Year Crime Differential

\begin{tabular}{|c|c|c|c|c|c|c|c|c|c|c|}
\hline & (1) & (2) & (3) & (4) & (5) & (6) & (7) & (8) & (9) & (10) \\
\hline Average normalized TEP & $\begin{array}{c}14.559^{* * *} \\
(3.990)\end{array}$ & $\begin{array}{c}15.329^{* * * *} \\
(4.073)\end{array}$ & $\begin{array}{c}14.329^{* * * *} \\
(4.003)\end{array}$ & $\begin{array}{c}11.856^{* * * *} \\
(3.840)\end{array}$ & $\begin{array}{c}13.038^{* *} \\
(5.073)\end{array}$ & $\begin{array}{c}14.723^{* *} \\
(5.639)\end{array}$ & $\begin{array}{c}13.131^{* * * *} \\
(4.650)\end{array}$ & $\begin{array}{c}14.659^{* * * *} \\
(4.956)\end{array}$ & $\begin{array}{c}14.482^{* *} \\
(5.696)\end{array}$ & $\begin{array}{l}15.266^{* *} \\
(5.740)\end{array}$ \\
\hline $\mathrm{N}$ & 23 & 23 & 23 & 23 & 23 & 23 & 23 & 22 & 22 & 22 \\
\hline Pseudo p-value & 0.000 & 0.000 & 0.000 & 0.002 & 0.002 & 0.000 & 0.002 & 0.004 & 0.004 & 0.010 \\
\hline Proportion of corresponding placebo estimates significant at .10 level & 0.184 & 0.162 & 0.164 & 0.168 & 0.172 & 0.182 & 0.178 & 0.192 & 0.158 & 0.154 \\
\hline Proportion of corresponding placebo estimates significant at .05 level & 0.096 & 0.088 & 0.084 & 0.088 & 0.096 & 0.106 & 0.122 & 0.104 & 0.100 & 0.104 \\
\hline Proportion of corresponding placebo estimates significant at .01 level & 0.024 & 0.028 & 0.014 & 0.016 & 0.024 & 0.024 & 0.030 & 0.024 & 0.024 & 0.028 \\
\hline
\end{tabular}

Standard errors in parentheses

Column numbers indicate post-passage year under consideration; $\mathrm{N}=$ number of states in sample

Dependent variable is the percentage difference in the property crime rate in treatment and synthetic control states at given post-treatment interval

Results reported for the constant term resulting from this regression

States in group: AK AR CO FL GA ID KS LA ME MI MO MT NC NM NV OH OK OR SC TN UT VA WY

States excluded for poor pre-treatment fit: AZ KY MN MS ND NE PA SD TX WV

The synthetic controls used to generate the placebo estimates in the table above were generated using the optimization technique described in our main text.

${ }^{*} p<0.10,{ }^{* *} p<0.05,{ }^{* * *} p<0.01$ 


\section{Appendix G: Data Methodologies}

The state-level data set used in this paper updated through 2014 earlier data sets used in Aneja, Donohue, and Zhang (2014) and Aneja, Donohue, and Zhang (2011). We further update this data set to incorporate changes to the various primary sources that have occurred since first released, and to include the additional predictor variables that are featured in the DAW model. All variables are collected for the years 1977-2014 unless otherwise noted. ${ }^{78}$

Annual state-level crime rates are taken from the FBI's Uniform Crime Reporting program. ${ }^{79}$ Four state-level income variables (personal income, income maintenance payments, retirement payments, and unemployment insurance payments) are taken from the BEA's Regional Economic Accounts. The personal income, income maintenance, and unemployment insurance payment variables are estimated in real per capita terms (defined using the CPI). The LM specification uses alternative versions of the retirement variable that are described in footnote 78. State-level population and the proportional size of LM's 36 age-race-sex demographic groups are estimated using the Census Bureau's intercensal population estimates. (When the most recent form of these data were not accessible at the state level, state-level figures were generated by aggregating the Census Bureau's county-level population estimates by age, sex, and race.) Population density is estimated by dividing a state's population by the area of that state reported in the previous decennial census. State-level unemployment rate data is taken from the Bureau of Labor Statistics, while the poverty rate is taken from two Census series (the 1979 state-level poverty rate is derived from the Decennial Census and the 1980-2014 poverty rates are generated using the Current Population Survey). The percentage of population living in an MSA was constructed as a hybrid of two measures to account for shifts over time. ${ }^{80}$ A measure of incarceration (incarcerated individuals per 100,000

\footnotetext{
${ }^{78}$ Many of the data sources that we used in our earlier analysis are revised continuously, and we use a newer version of these data series in this paper than we did in the earlier ADZ analysis. We sometimes made data changes during the data cleaning process. For instance, a detailed review of the raw data underlying arrest statistics uncovered a small number of agencies that reported their police staffing levels twice, and we attempted to delete these duplicates whenever possible. Moreover, we sometimes use variables that are defined slightly differently from the corresponding variable used in Lott and Mustard (1997). For example, after examining the extension of Lott's county data set to the year 2000, we found that our estimates more closely approximated Lott's per capita retirement payment variable when we (a) used the total population as the denominator rather than population over 65 and (b) used as our numerator a measurement that includes retirement payments along with some other forms of government assistance. Our retirement variable in the LM specification uses the population over 65 as a denominator and uses a tighter definition of retirement payments.

${ }^{79}$ For our main analysis, we formulate our crime rates by dividing FBI reported crime counts by FBI reported state-level populations. As a robustness check we used the rounded state-level crime rates reported by the FBI while using the DAW regressors and aggregate violent crime as an outcome variable. We find that this alternative crime rate definition does not qualitatively affect our findings.

${ }^{80}$ We use Census delineation and NBER population files to find the fraction of individuals residing in a county which at least partially overlap with an MSA in 1980 (some New England counties were assigned by town). Since MSA definitions shift over time, we use the UCR implied fraction of population living in an MSA beginning in 1981. Observations for states incorrectly reported as 0 percent MSA by UCR in those early years were replaced according to
} 
state residents) is calculated from tables published by the Bureau of Justice Statistics counting the number of prisoners under the jurisdiction of different state penal systems. Our primary estimates for crime-specific state-level arrest rates are generated by adding together estimates of arrests by age, sex, and race submitted by different police agencies. We then divided this variable by the estimated number of incidents occurring in the same state (according to the UCR) in the relevant crime category. ${ }^{81}$

Abadie, Diamond, and Hainmueller (2010) emphasize that researchers may want to "[restrict] the comparison group to units that are similar to the exposed units [in terms of the predictors which are included in the model]" (496). Given that the District of Columbia had the highest per capita personal income, murder rate, unemployment rate, poverty rate, and population density at various points in our sample, Abadie's admonition would seem to support omitting the District as one of our potential control units. ${ }^{82}$ Consequently, we decided to exclude the District of Columbia from the synthetic control analysis owing to its status as a clear outlier whose characteristics are less likely to be meaningfully predictive for other geographic areas. We should note, however, that including DC in the synthetic control analysis has little impact on our estimates showing that RTC laws increase violent crime.

We collected data on two separate police measures. Our reported results are based on the same police variable that we used in Aneja, Donohue, and Zhang (2014). To construct this variable, we take the most recent agency-level data provided by the FBI and use this information to estimate the number of full-time police employees present in each state per 100,000 residents. We fill in missing observations with staffing data from previous years in cases where the FBI chose to append this information to their agency entries, and we divide the resulting estimate of the total number of police employees by the population represented by these agencies. This variable, which was originally constructed for our regression analysis, has the advantage of not having any missing entries and is closely correlated $(r=.96)$ with an alternative measure of police staffing generated by extrapolating missing police agency data based on the average staffing levels reported by agencies in

the 1980 definition with updated Census population estimates. These values jump due to MSA redefinition over time. When we checked the robustness of our panel results by replacing our percentage MSA definition with the predictions from state-specific second-order time trends to smooth out jumps (compare Appendix Table B1), DAW right-to-carry dummy variable estimates for violent crime increased by 1.5 to 10.56 and spline estimates increased by 0.17 to 0.20 .

${ }^{81}$ We chose this variable as the primary one that we would use in this analysis after confirming that this variable was more closely correlated with Lott's state-level arrest variables in the most recent data set published on his website (a data set which runs through the year 2005) than several alternatives that we constructed.

${ }^{82}$ Another advantage of excluding the District of Columbia from our sample is that the Bureau of Justice Statistics stops estimating the incarcerated population of the District of Columbia after the year 2001 owing to the transfer of the district's incarcerated population to the federal prison system and the DC Jail. While we have tried to reconstruct incarceration data for DC for these years using other data sources, the estimates resulting from this analysis were not, in our view, plausible substitutes for the BJS estimates we use for all other states. The raw data set that we use to gather information about state-level arrest rates is also missing a large number of observations from the District of Columbia's main police department, which further strengthens the case for excluding DC from our data set. 
the same year and type of area served (represented by a variable incorporating nineteen categories separating different types of suburban, rural, and urban developments.)

As an alternative, we use data published by the Bureau of Justice Statistics on the number of full-time equivalent employees working for police agencies. These figures were also included in the data set featured in Lott and Mustard (1997). ${ }^{83}$ We find that our estimated average treatment effects for aggregate violent crime and the conclusions that we draw from these averages are qualitatively unaffected by substituting one police employment measure for another, which suggests that measurement error associated with our estimates of police activity is not driving our results.

\section{Appendix H: Replicating Our Analysis}

In implementing the synthetic control methodology, we discovered that our estimates could be affected by seemingly inconsequential details when using maximum likelihood to select the weights associated with different predictors in our analysis. Specifically, when using the excellent "synth" package for Stata created by Abadie, Hainmueller, and Diamond along with the nested option, the version of Stata (e.g., SE vs. MP), the specifications of the computer running the command, and the order in which predictors are listed can affect the composition of the synthetic control and by extension the size of the estimated treatment effect.

The root cause of the differences between Stata versions is explained by a 2008 StataCorp memo, which noted that:

"When more than one processor is used in Stata/MP, the computations for the likelihood are split into pieces (one piece for each processor) and then are added at the end of the calculation on each iteration. Because of round-off error, addition is not associative in computer science as it is in mathematics. This may cause a slight difference in results. For example, a1+a2+a3+a4 can produce different results from $(\mathrm{a} 1+\mathrm{a} 2)+(\mathrm{a} 3+\mathrm{a} 4)$ in numerical computation. When changing the number of processors used in Stata, the order in which the results from each processor are combined in calculations may not be the same depending on which processor completes its calculations first." 84

Moreover, this document goes on to note that the differences associated with using different versions of Stata can be minimized by setting a higher threshold for nrtolerance(). This optimization condition is actually relaxed by the synth routine in situations where setting this threshold at its

\footnotetext{
${ }^{83} \mathrm{We}$ do not rely on this variable in our main analysis owing to the large number of missing years present in this data set and owing to discrepancies in the raw data provided by the BJS, which sometimes needed to be corrected using published tables.

${ }^{84}$ This memo can be found at the following link: http://www.webcitation.org/6YeLV03SN
} 
default level causes the optimization routine to crash, and we would therefore expect the results of Stata SE and MP to diverge whenever this occurs. In our analysis, we use the UNIX version of Stata/MP owing to the well-documented performance gains associated with this version of the software package.

Another discrepancy that we encountered is that memory limitations sometimes caused our synthetic control analyses to crash when using the nested option. When this occurred, we would generate our synthetic control using the regression-based technique for determining the relative weights assigned to different predictors. We encountered this situation several times when running our Stata code on standard desktop computers, but this problem occurred less often when using more powerful computers with greater amounts of memory. For this reason, to replicate our results with the greatest amount of precision, we would recommend that other researchers run our code on the same machines that we ran our own analysis: a 24-core UNIX machine with 96GB of RAM or a 16-core UNIX machine with 64GB of RAM running Stata/MP. 


\section{Appendix I: Synthetic Control Graphs Estimating Impact of RTC Laws On Violent Crime Using the DAW Model ${ }^{85}$}

Figures I1. I33

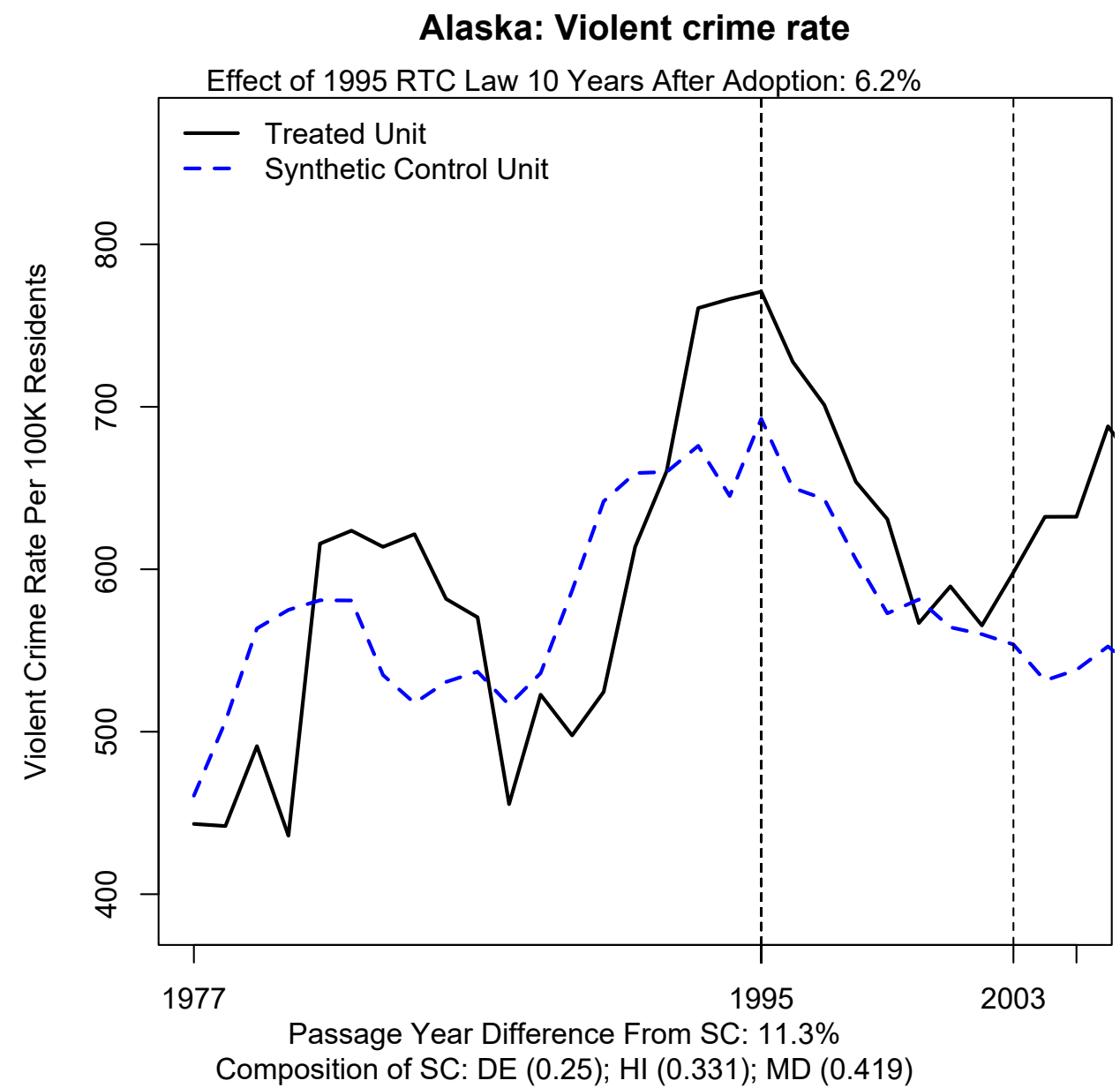

CVRMSPE: 0.133 (23 of 33 states, where 1 denotes the state with the best pre-passage fit.)

States Never Passing RTC Laws Included in Synthetic Control: DE ; HI ; MD

RTC Adopting States Included in Synthetic Control:

Figure I1

\footnotetext{
${ }^{85}$ Recall that each state's effective year of passage is defined as the first year in which an RTC law was in effect for the majority of that year.
} 


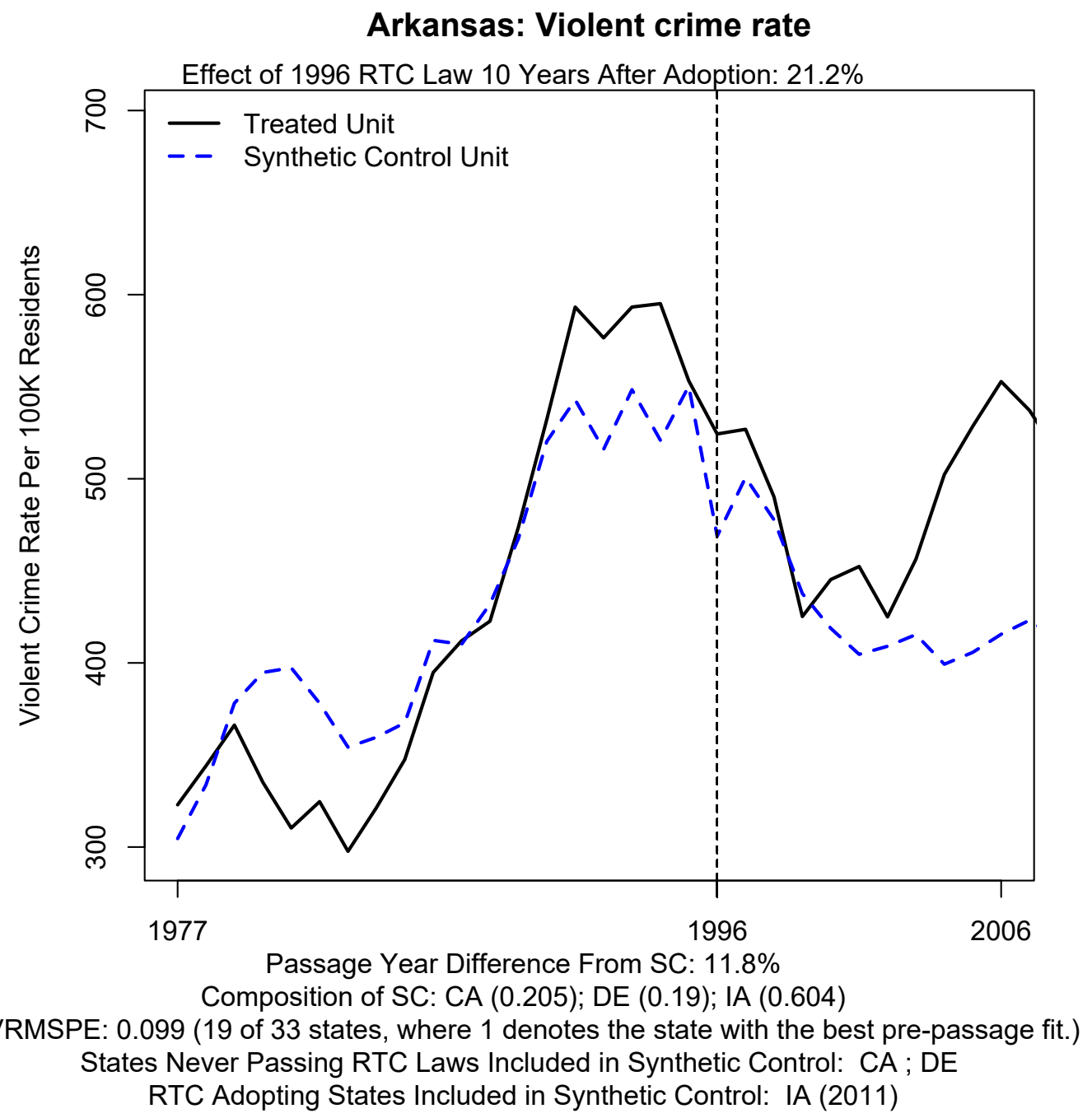

Figure I2 


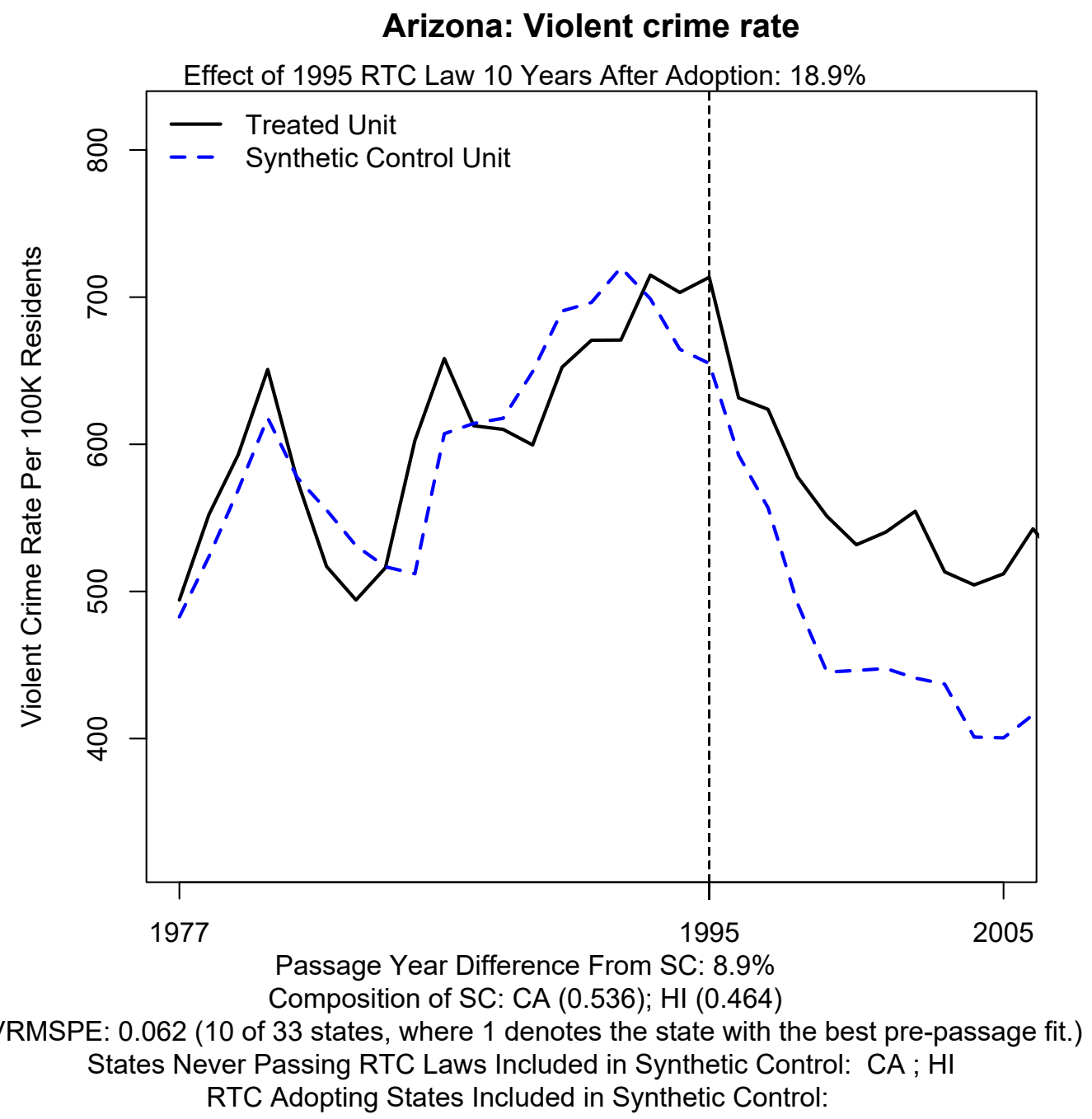

Figure I3 


\section{Colorado: Violent crime rate}

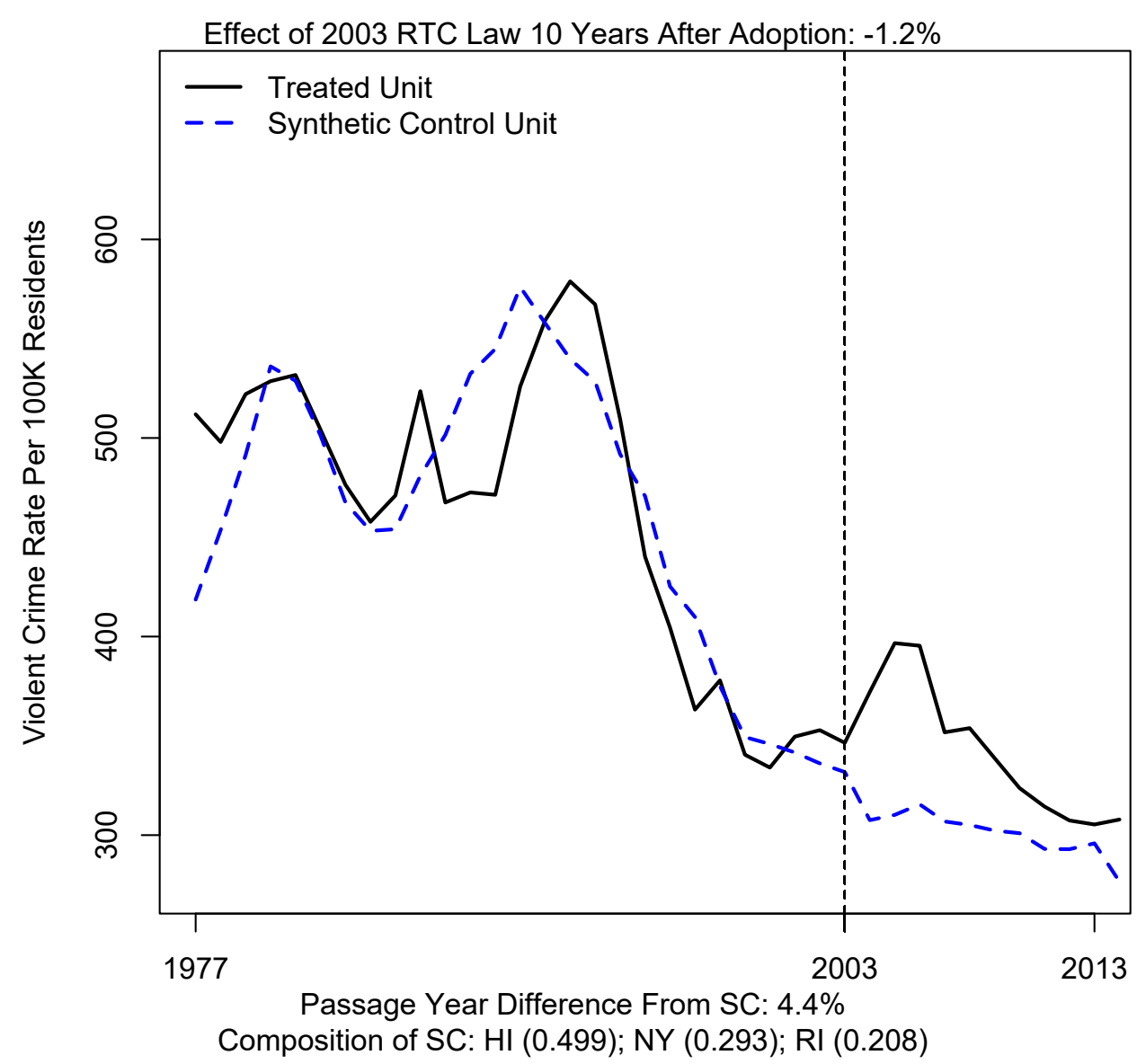

CVRMSPE: 0.077 (15 of 33 states, where 1 denotes the state with the best pre-passage fit.)

States Never Passing RTC Laws Included in Synthetic Control: HI ; NY ; RI

RTC Adopting States Included in Synthetic Control:

Figure I4 
Florida: Violent crime rate

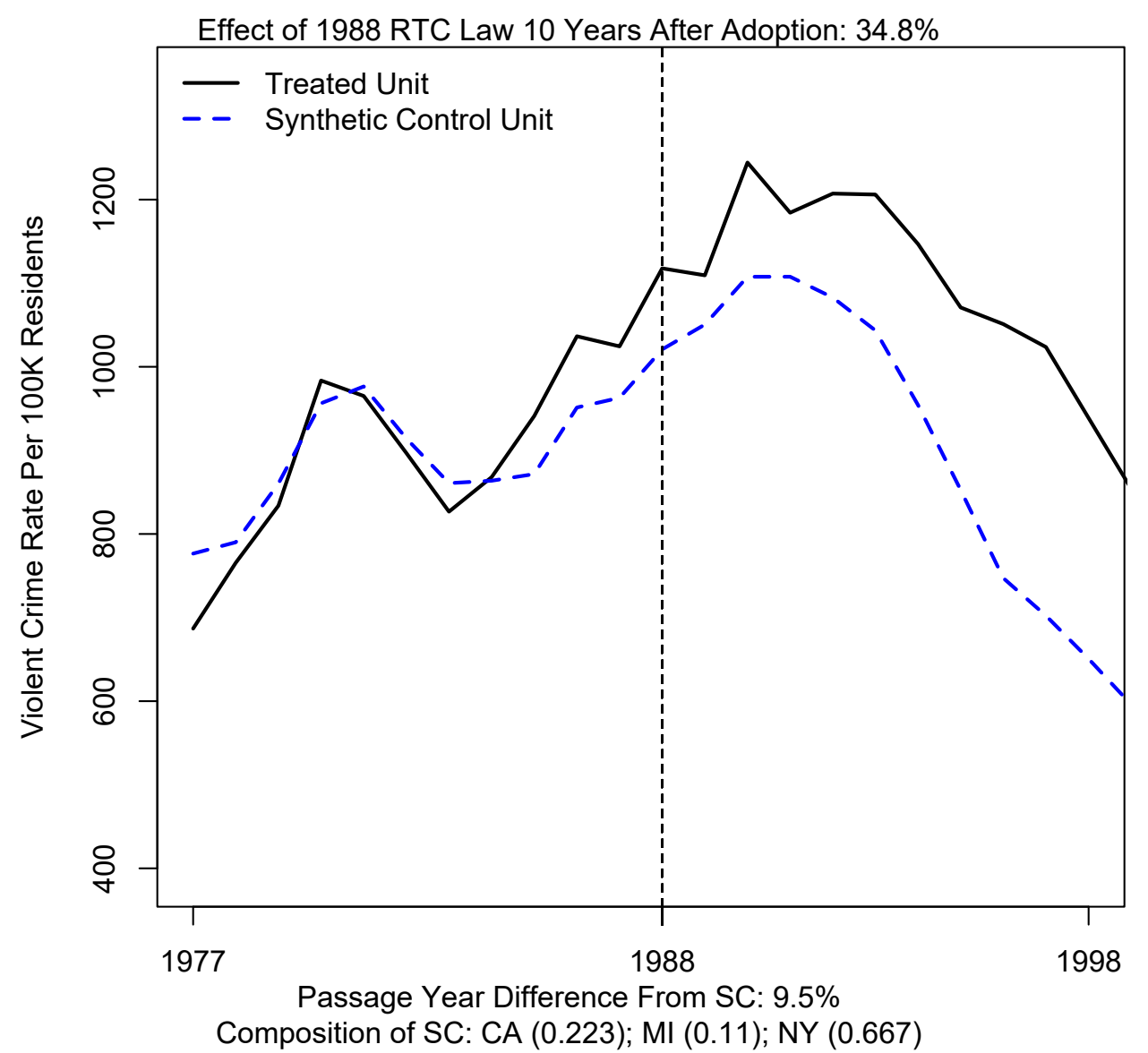

CVRMSPE: 0.056 ( 7 of 33 states, where 1 denotes the state with the best pre-passage fit.) States Never Passing RTC Laws Included in Synthetic Control: CA ; NY RTC Adopting States Included in Synthetic Control: MI (2001)

Figure I5 


\section{Georgia: Violent crime rate}

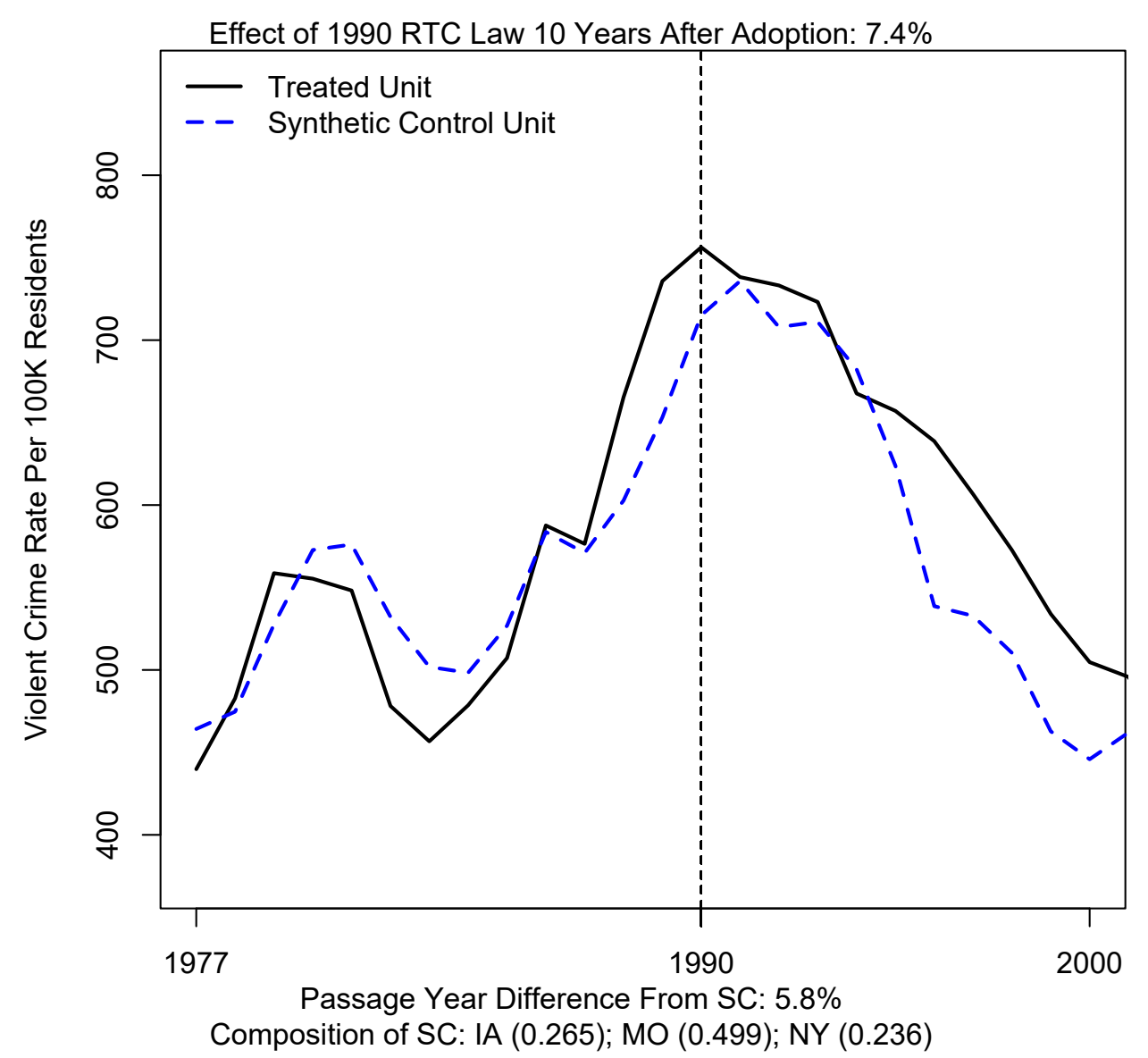

CVRMSPE: 0.071 (13 of 33 states, where 1 denotes the state with the best pre-passage fit.)

States Never Passing RTC Laws Included in Synthetic Control: NY

RTC Adopting States Included in Synthetic Control: IA (2011); MO (2004)

Figure I6 


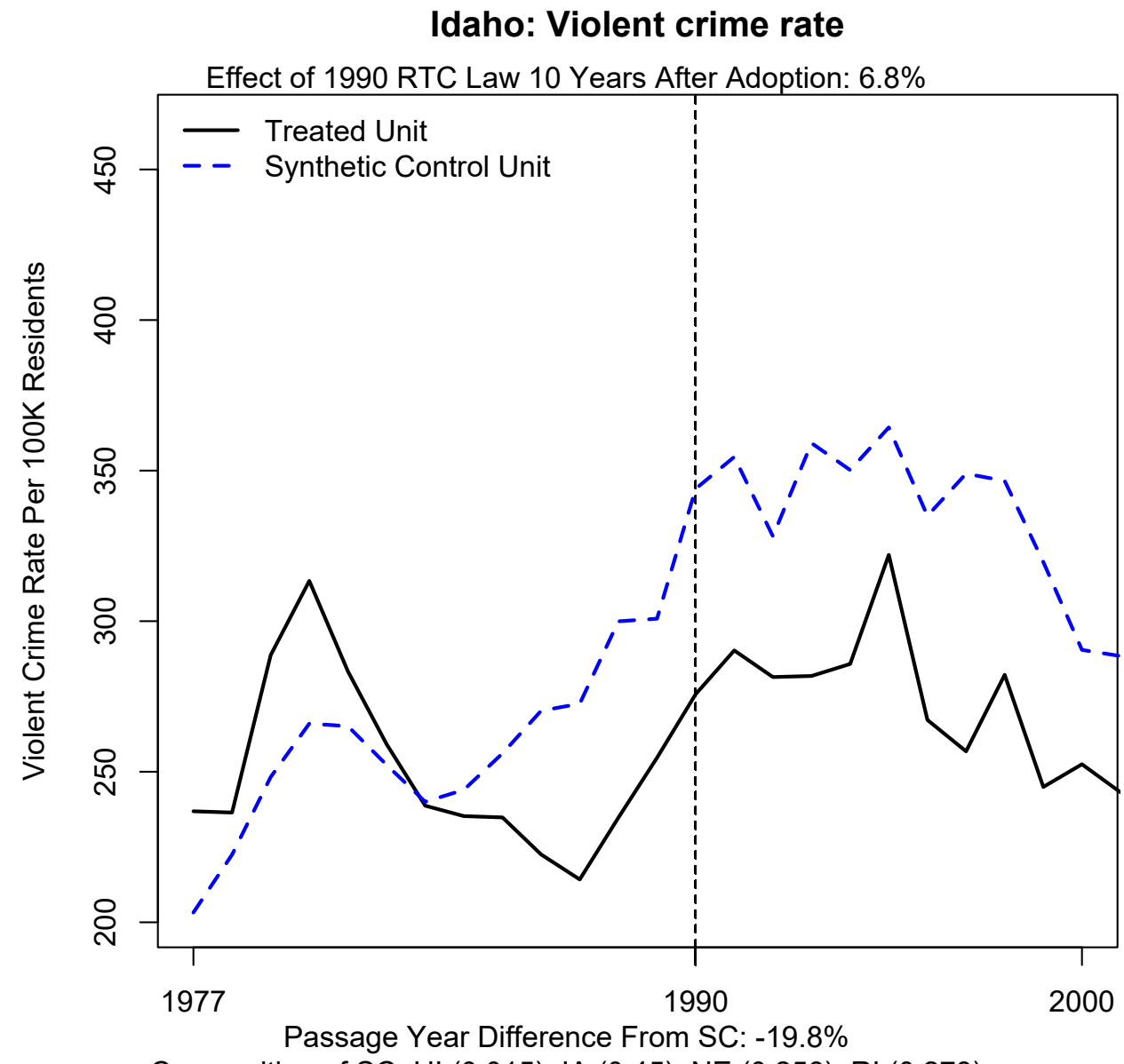

Composition of SC: HI (0.015); IA (0.45); NE (0.256); RI (0.278)

CVRMSPE: 0.149 (24 of 33 states, where 1 denotes the state with the best pre-passage fit.)

States Never Passing RTC Laws Included in Synthetic Control: HI ; RI

RTC Adopting States Included in Synthetic Control: IA (2011); NE (2007)

Figure I7 


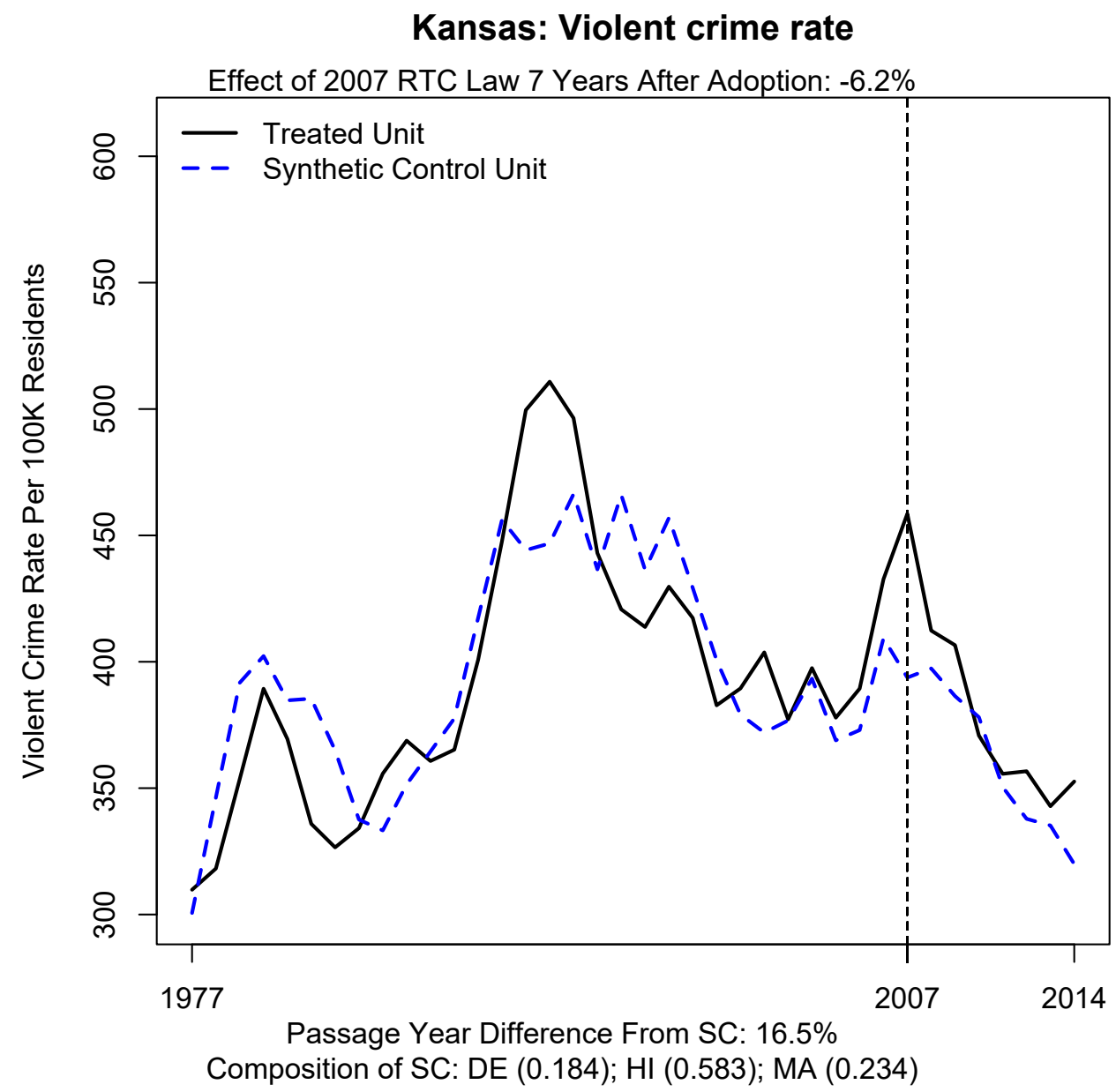

CVRMSPE: 0.069 (12 of 33 states, where 1 denotes the state with the best pre-passage fit.)

States Never Passing RTC Laws Included in Synthetic Control: DE ; HI ; MA RTC Adopting States Included in Synthetic Control:

Figure I8 


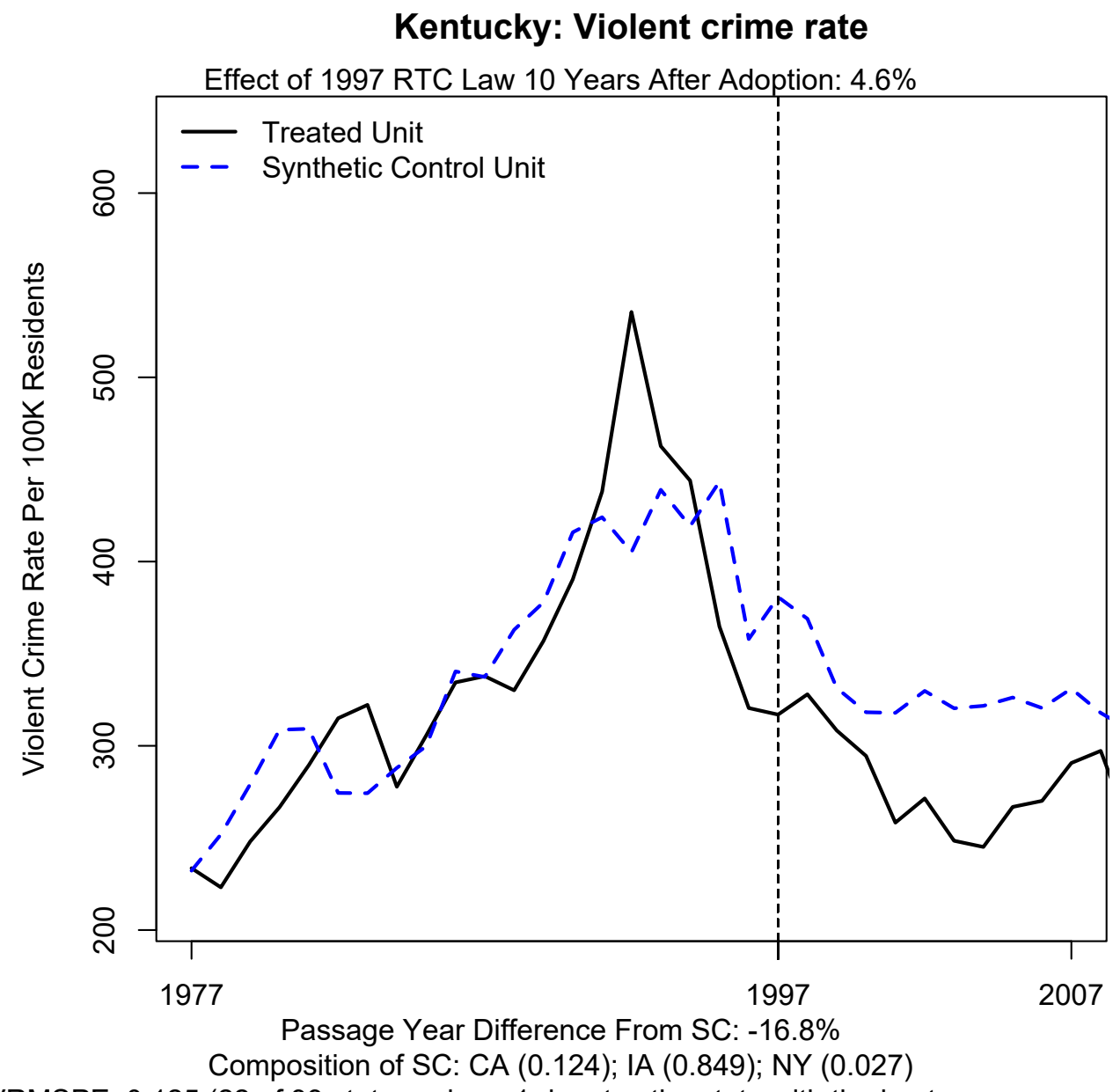

CVRMSPE: 0.125 (22 of 33 states, where 1 denotes the state with the best pre-passage fit.) States Never Passing RTC Laws Included in Synthetic Control: CA ; NY RTC Adopting States Included in Synthetic Control: IA (2011)

Figure I9 


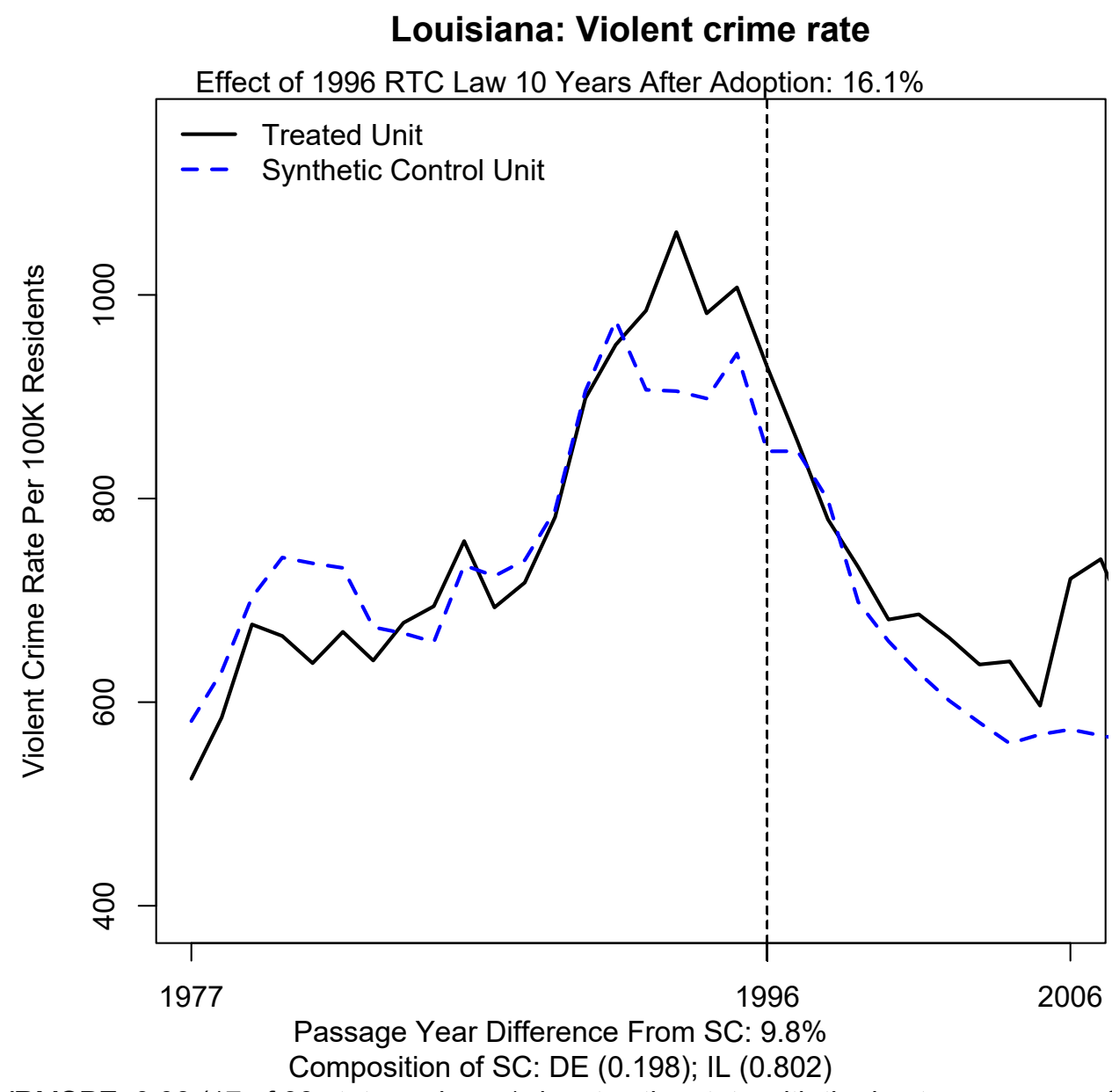

CVRMSPE: 0.08 (17 of 33 states, where 1 denotes the state with the best pre-passage fit.) States Never Passing RTC Laws Included in Synthetic Control: DE RTC Adopting States Included in Synthetic Control: IL (2014)

Figure I10 


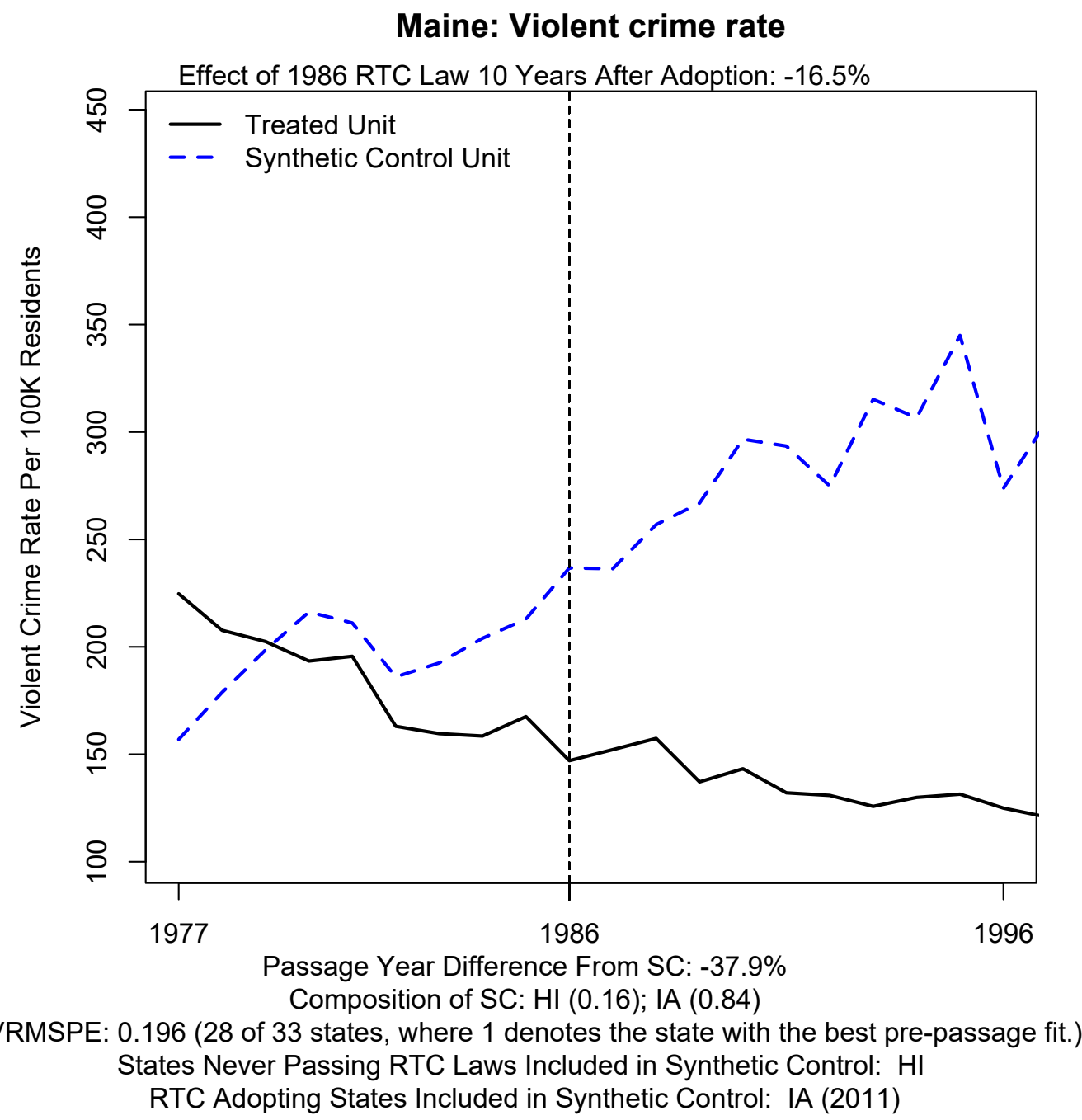

Figure I11 


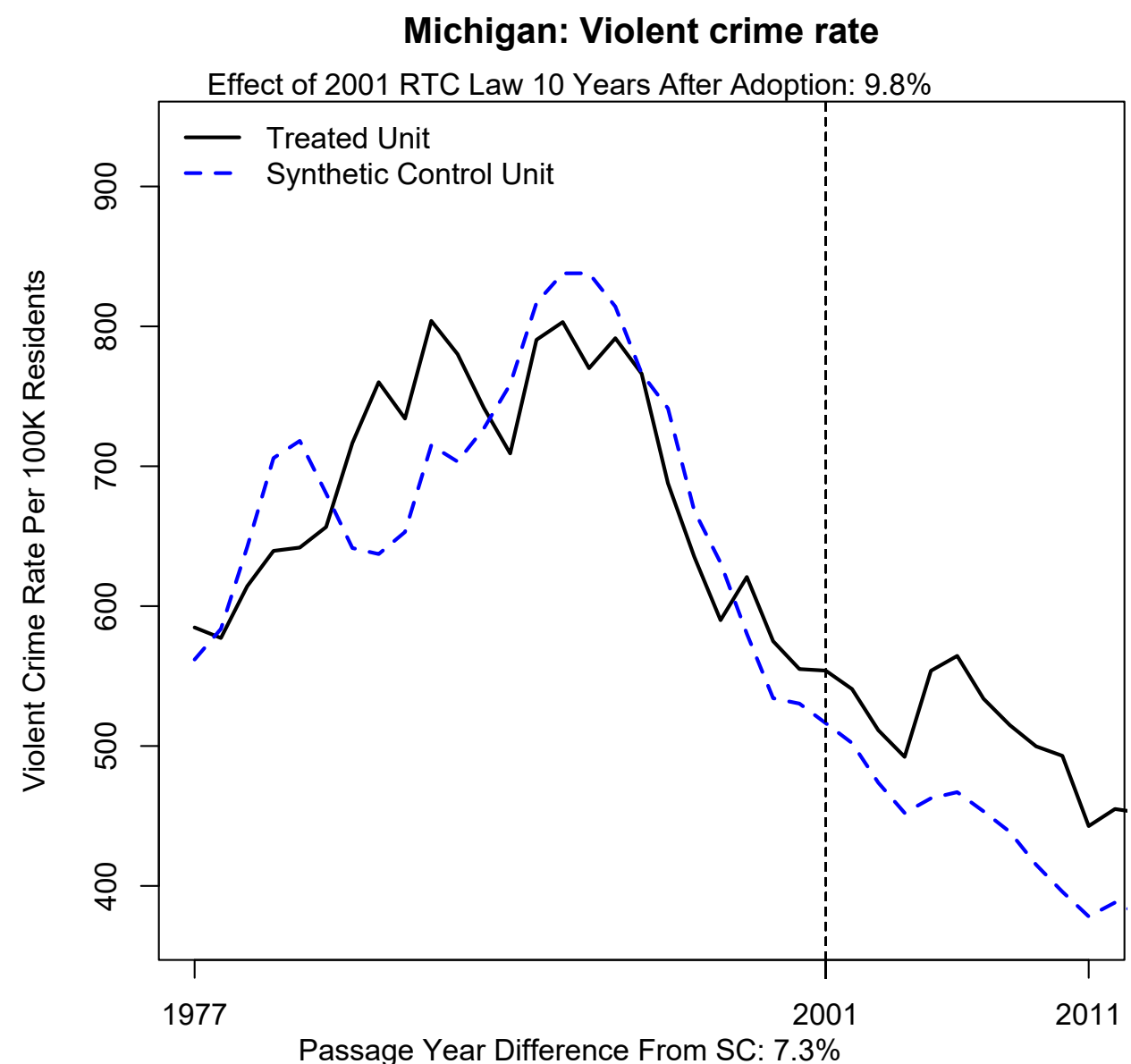

Composition of SC: CA (0.199); IL (0.054); MD (0.217); NY (0.231); RI (0.031); WI (0.268) CVRMSPE: 0.08 (16 of 33 states, where 1 denotes the state with the best pre-passage fit.) States Never Passing RTC Laws Included in Synthetic Control: CA ; MD ; NY ; RI RTC Adopting States Included in Synthetic Control: IL (2014); WI (2012)

Figure I12 


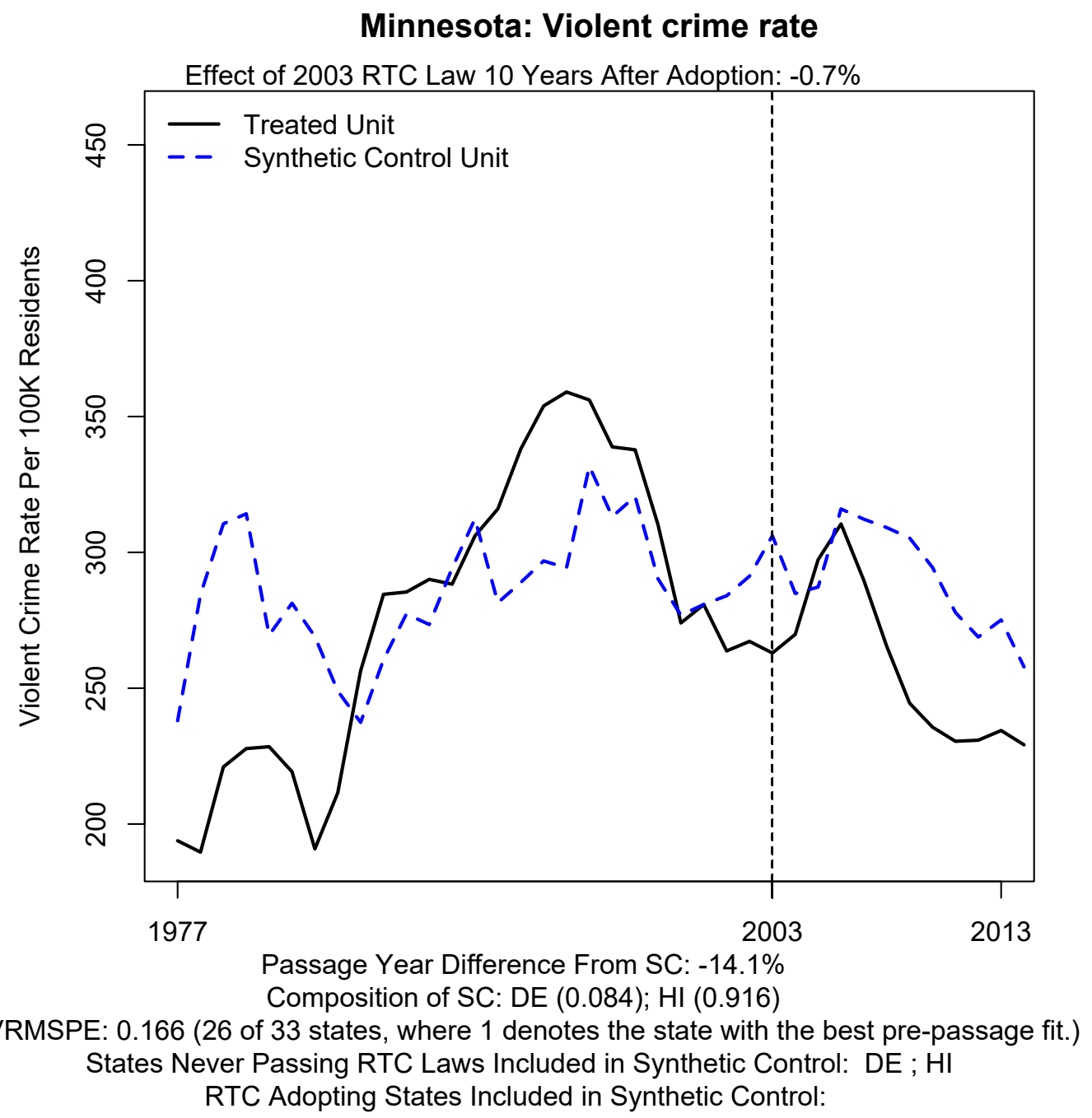

Figure I13 


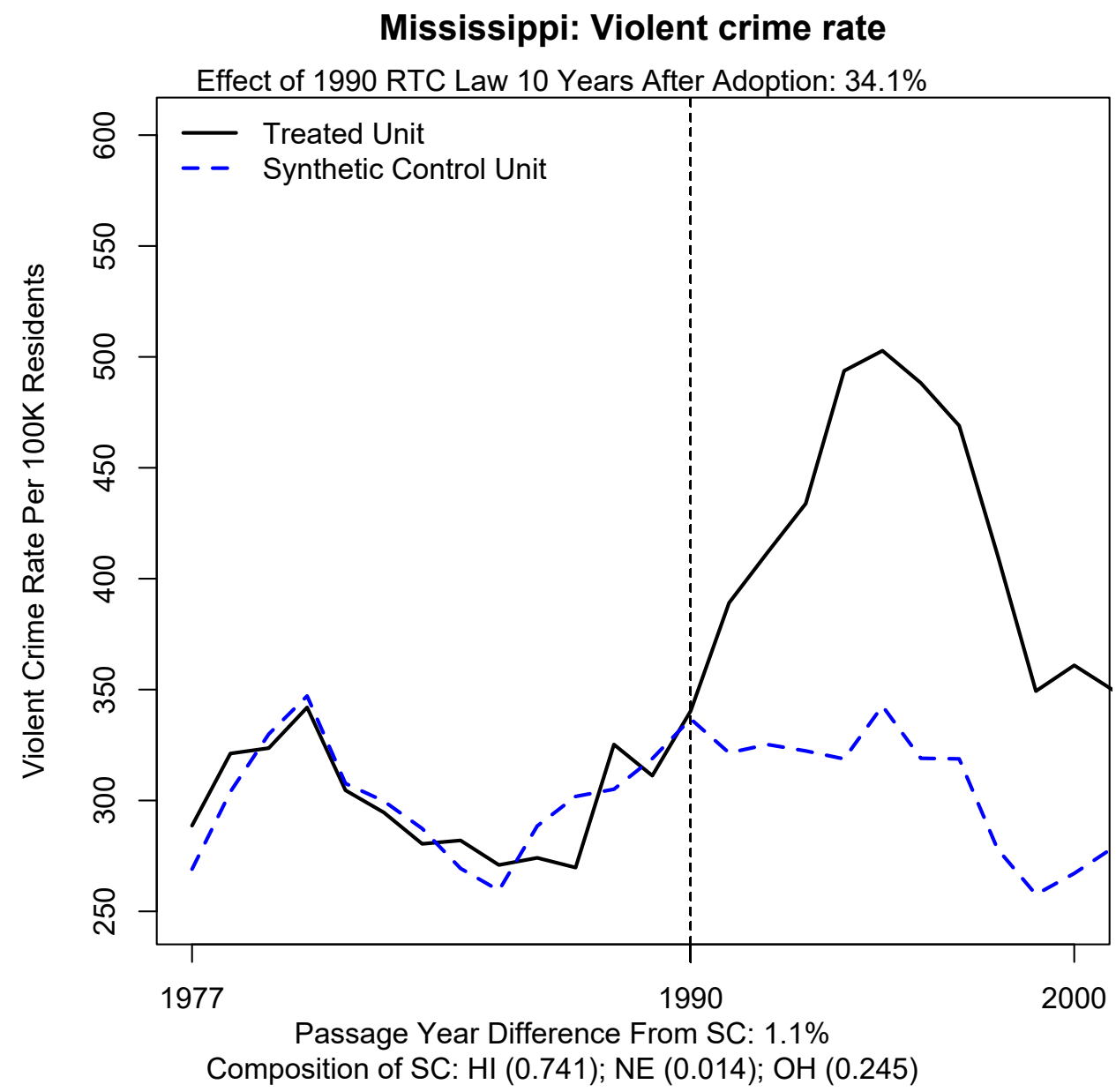

CVRMSPE: 0.049 ( 5 of 33 states, where 1 denotes the state with the best pre-passage fit.) States Never Passing RTC Laws Included in Synthetic Control: HI RTC Adopting States Included in Synthetic Control: NE (2007); OH (2004)

Figure I14 


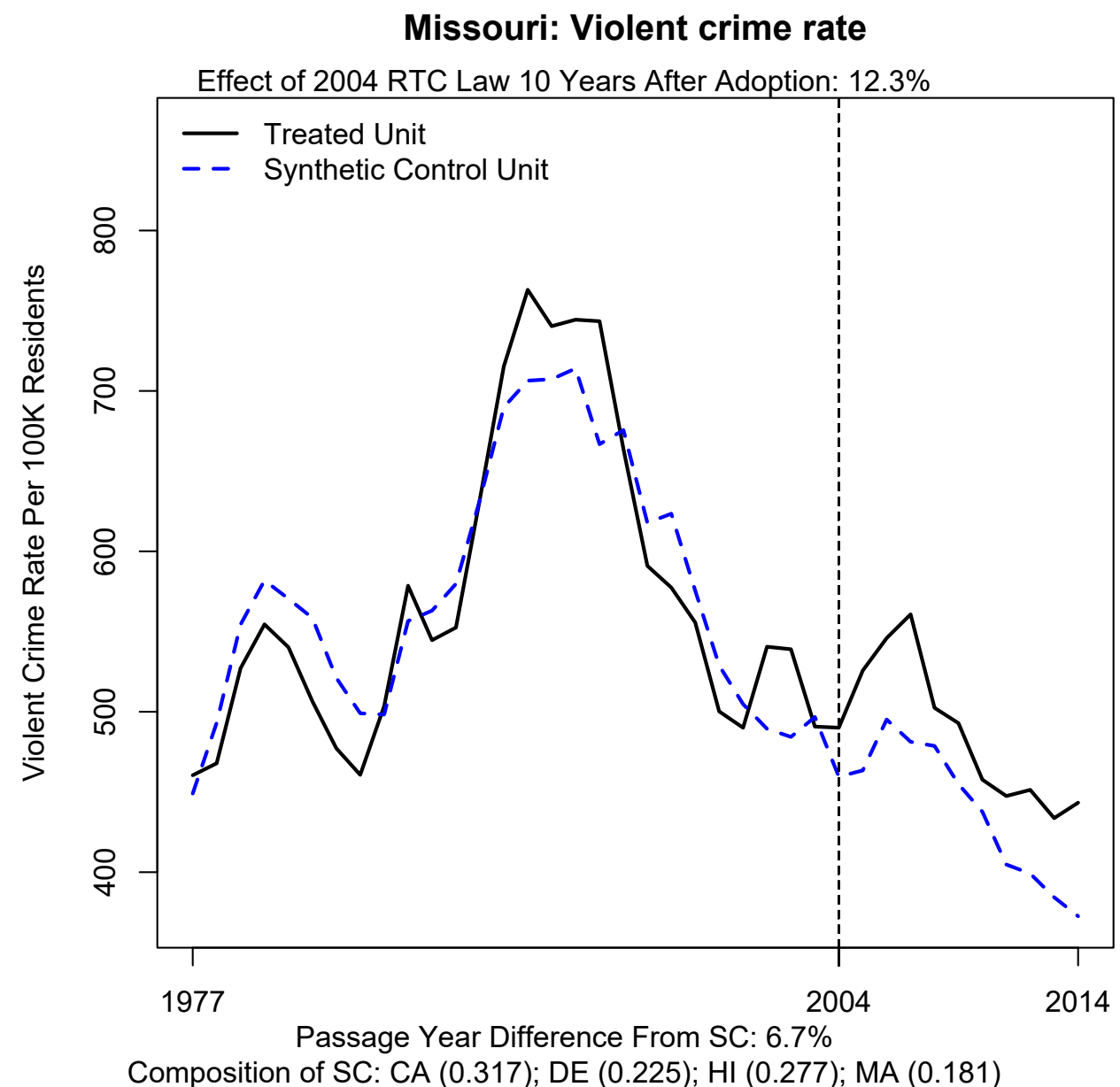

CVRMSPE: 0.061 ( 9 of 33 states, where 1 denotes the state with the best pre-passage fit.)

States Never Passing RTC Laws Included in Synthetic Control: CA ; DE ; HI ; MA RTC Adopting States Included in Synthetic Control:

Figure I15 


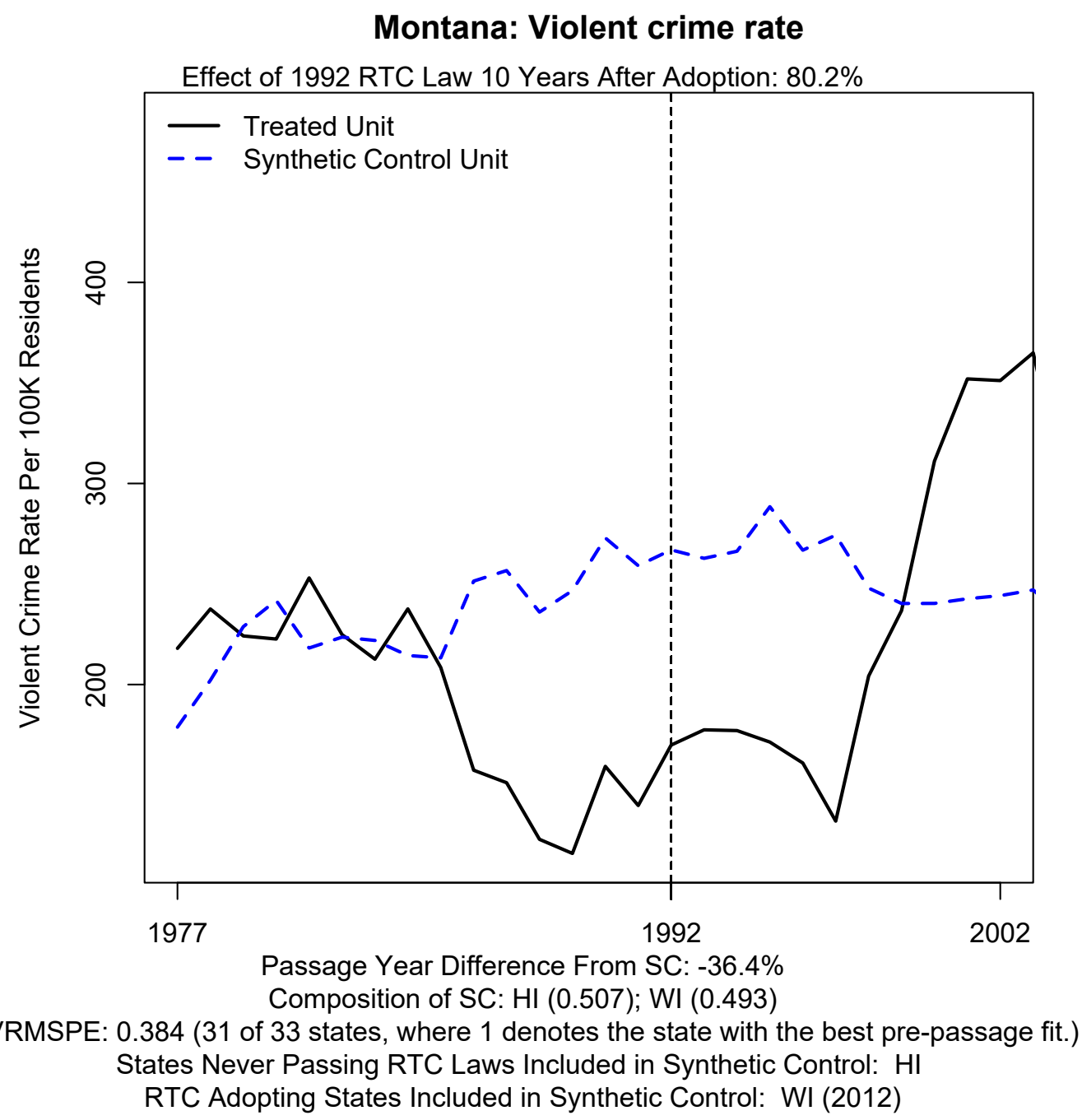

Figure I16 


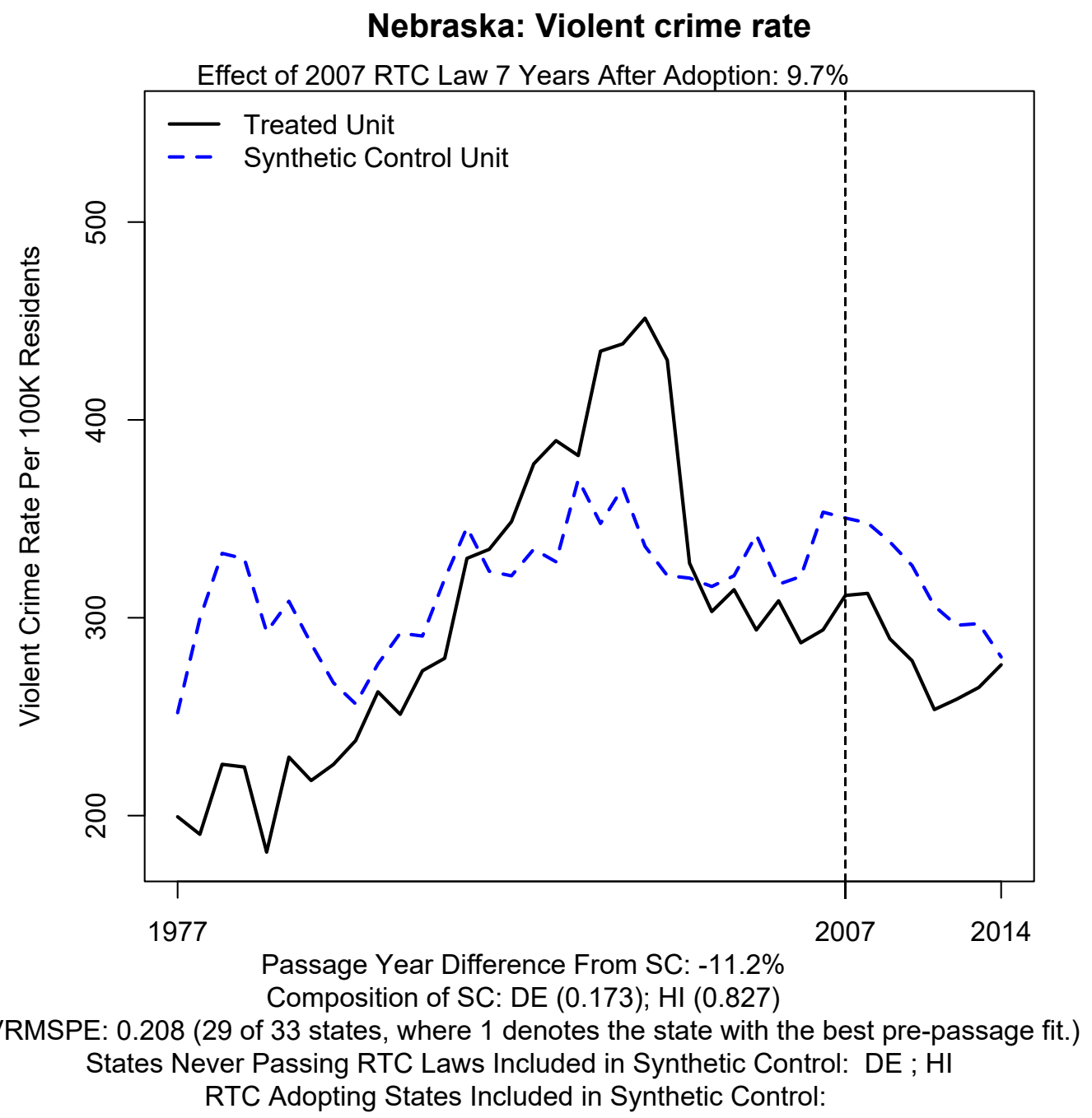

Figure I17 


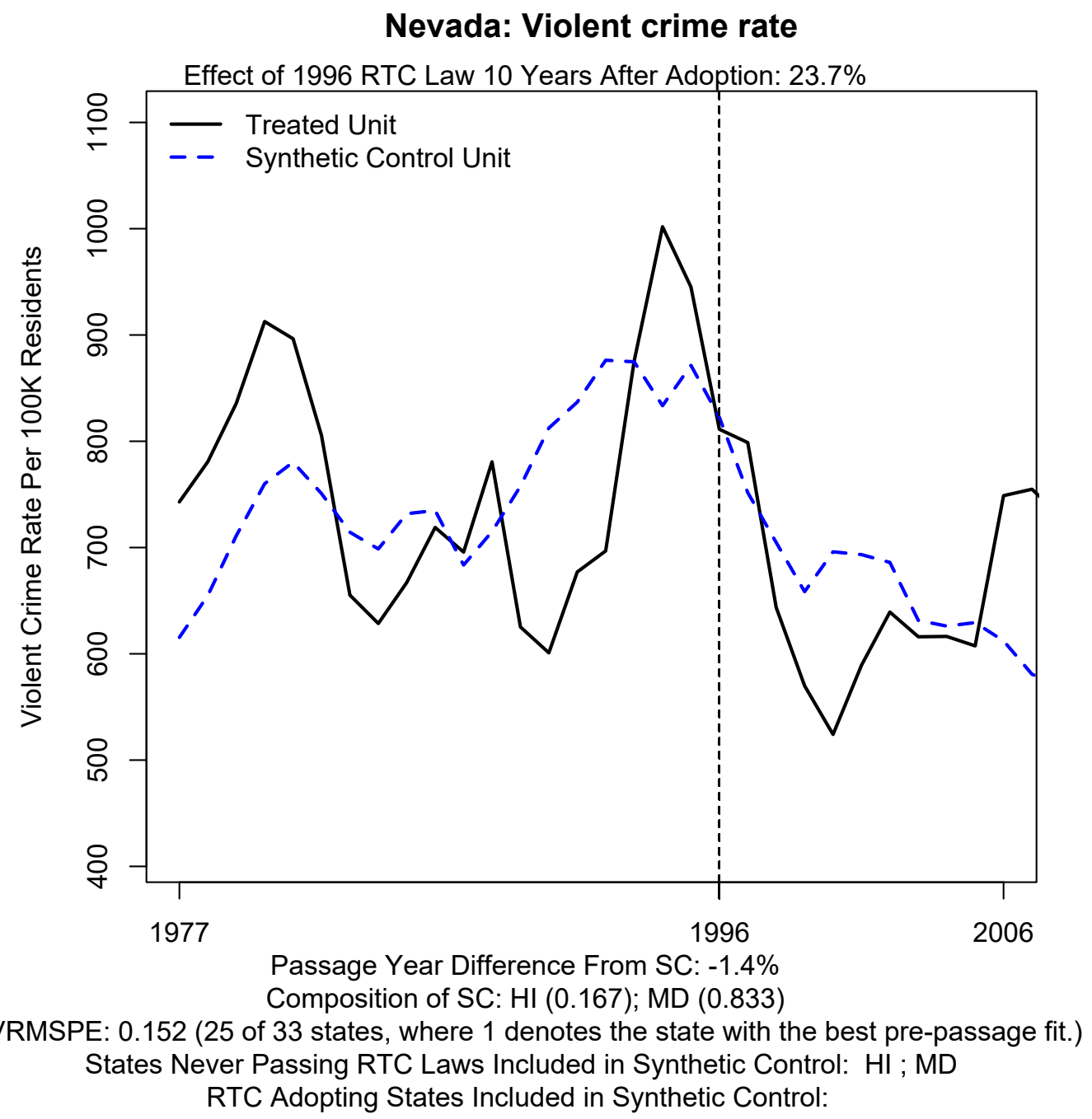

Figure I18 


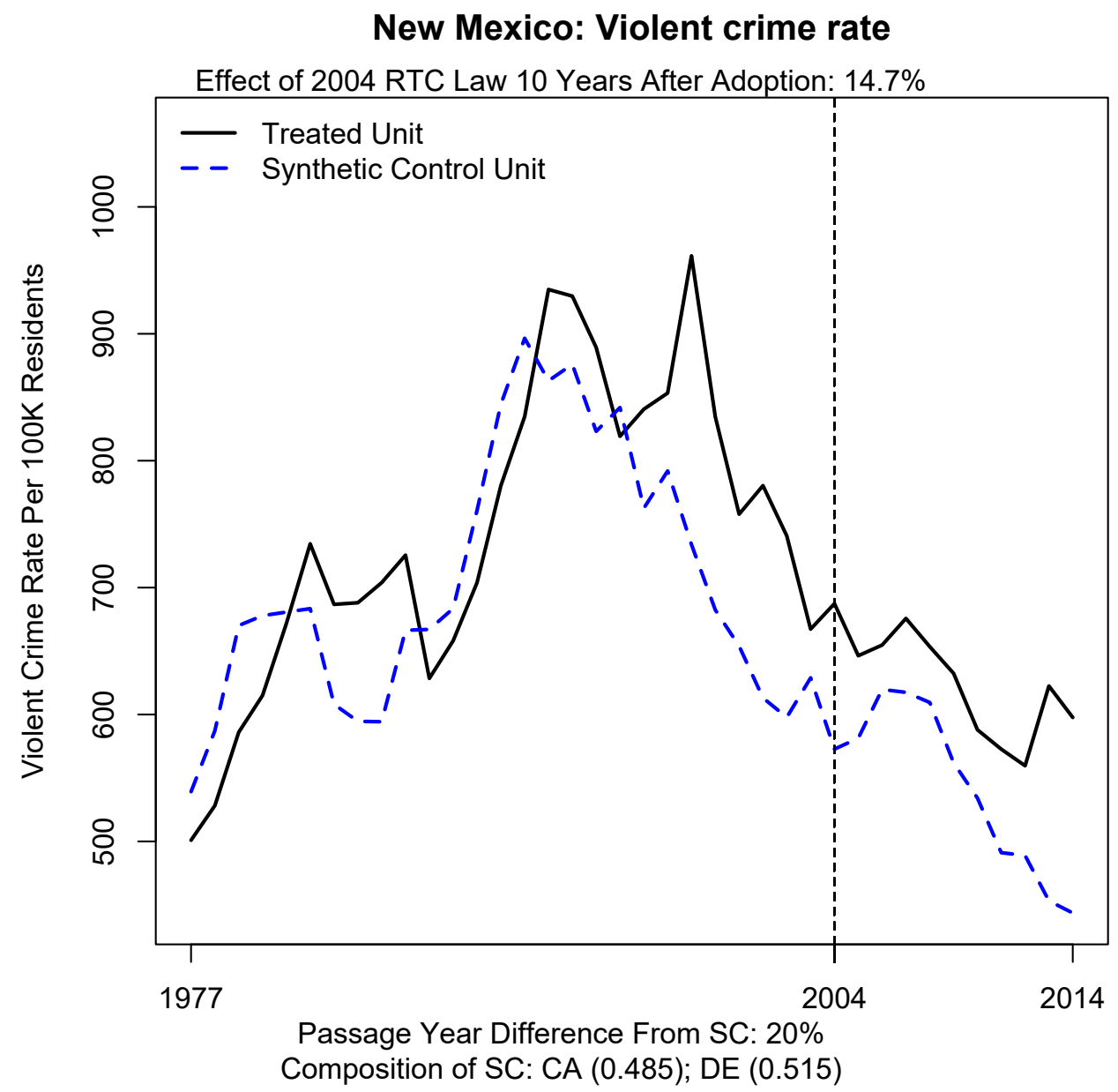

CVRMSPE: 0.122 (20 of 33 states, where 1 denotes the state with the best pre-passage fit.) States Never Passing RTC Laws Included in Synthetic Control: CA ; DE RTC Adopting States Included in Synthetic Control:

Figure I19 


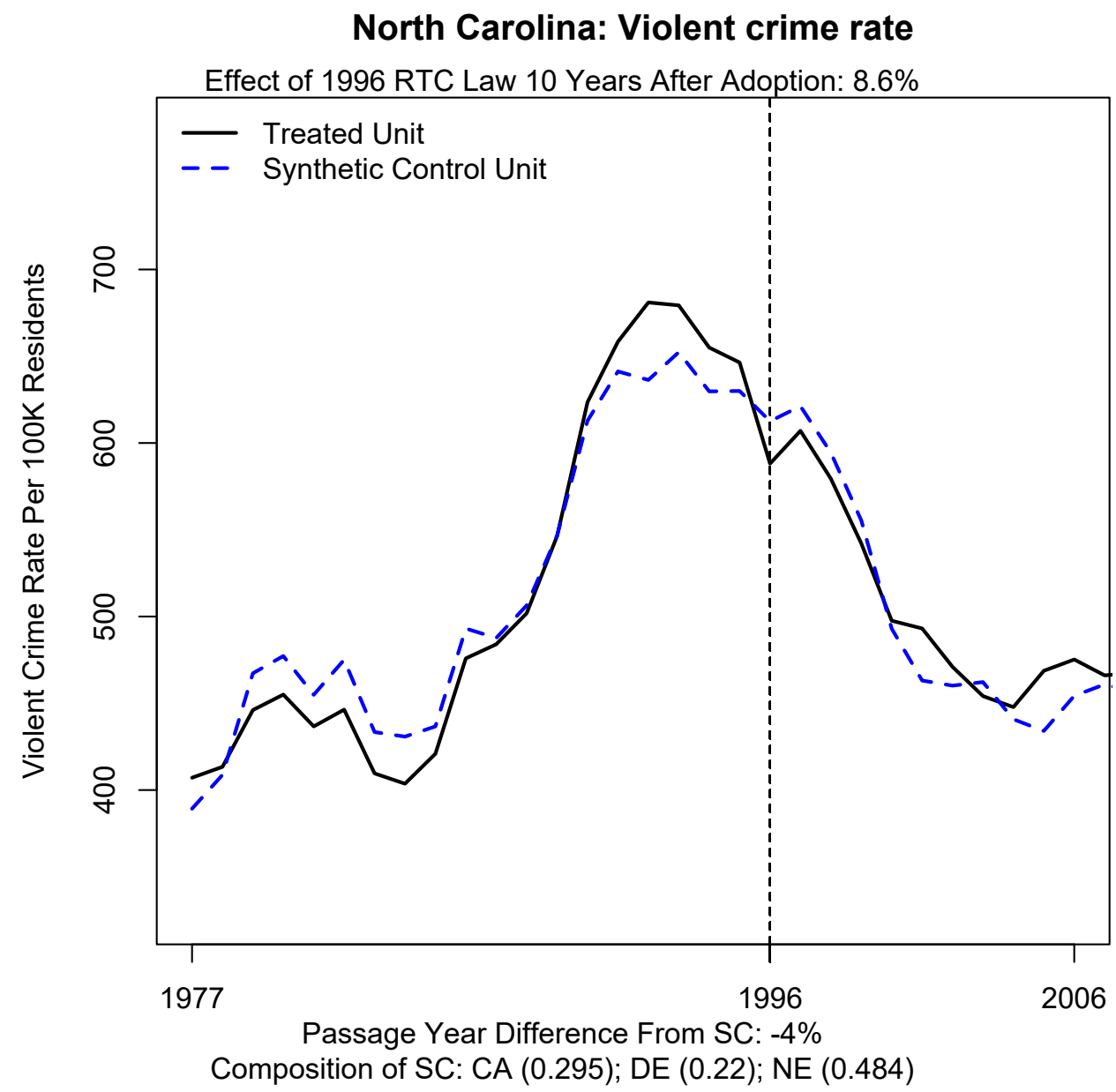

CVRMSPE: 0.041 ( 3 of 33 states, where 1 denotes the state with the best pre-passage fit.) States Never Passing RTC Laws Included in Synthetic Control: CA ; DE RTC Adopting States Included in Synthetic Control: NE (2007)

Figure I20 


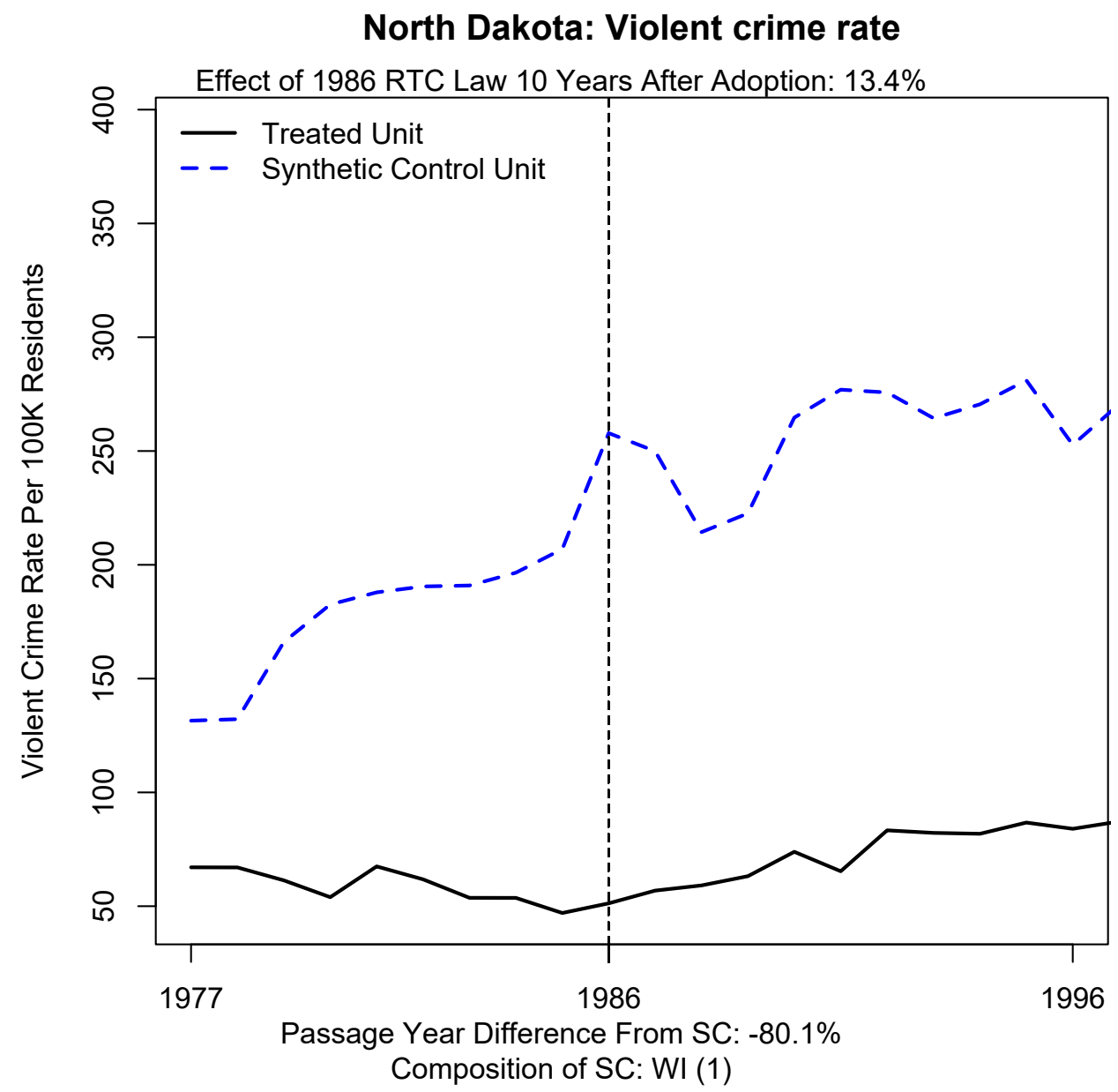

CVRMSPE: 2.043 (33 of 33 states, where 1 denotes the state with the best pre-passage fit.) States Never Passing RTC Laws Included in Synthetic Control: RTC Adopting States Included in Synthetic Control: WI (2012)

Figure I21 


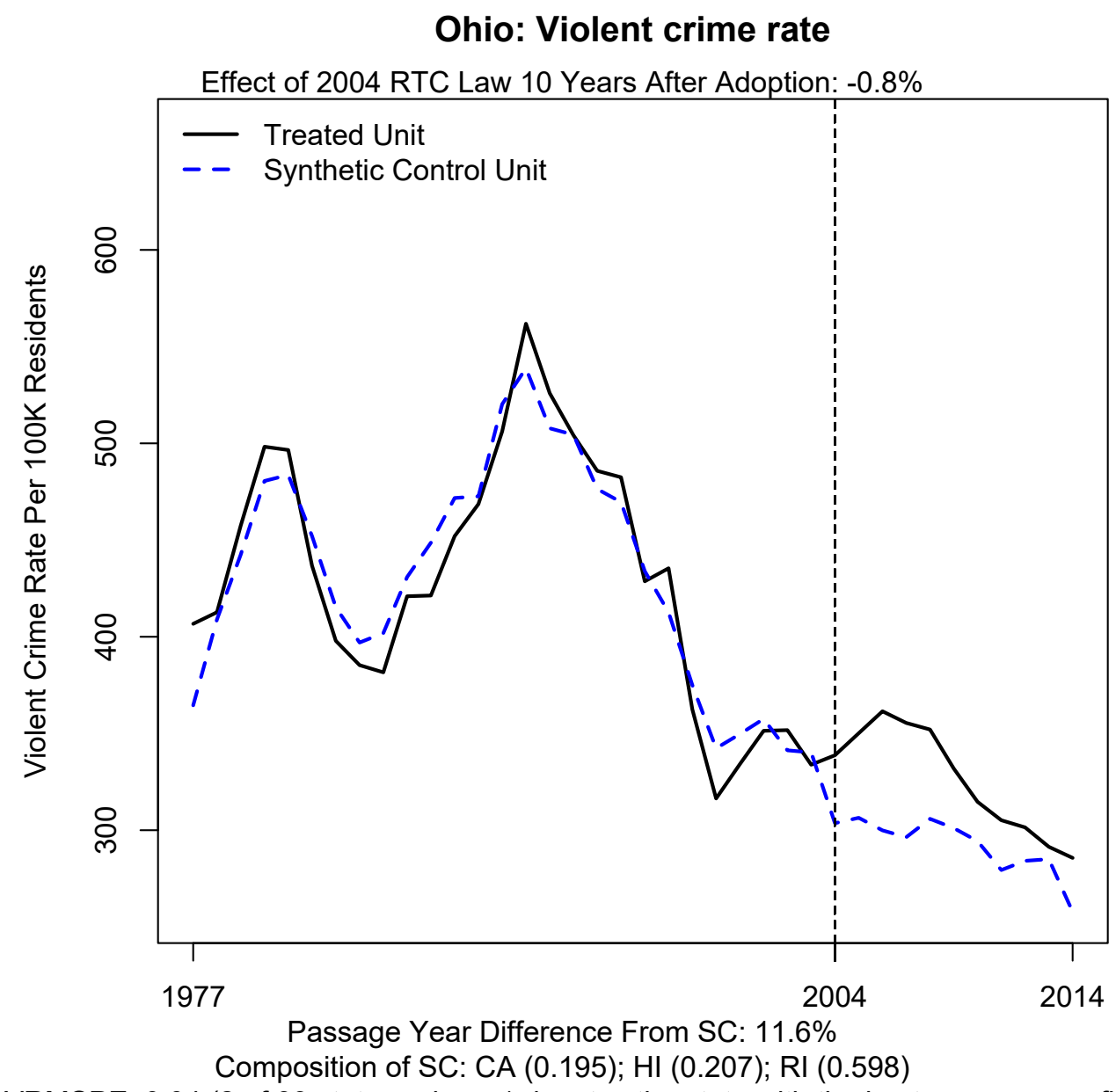

CVRMSPE: 0.04 (2 of 33 states, where 1 denotes the state with the best pre-passage fit.)

States Never Passing RTC Laws Included in Synthetic Control: CA ; HI ; RI RTC Adopting States Included in Synthetic Control:

Figure I22 


\section{Oklahoma: Violent crime rate}

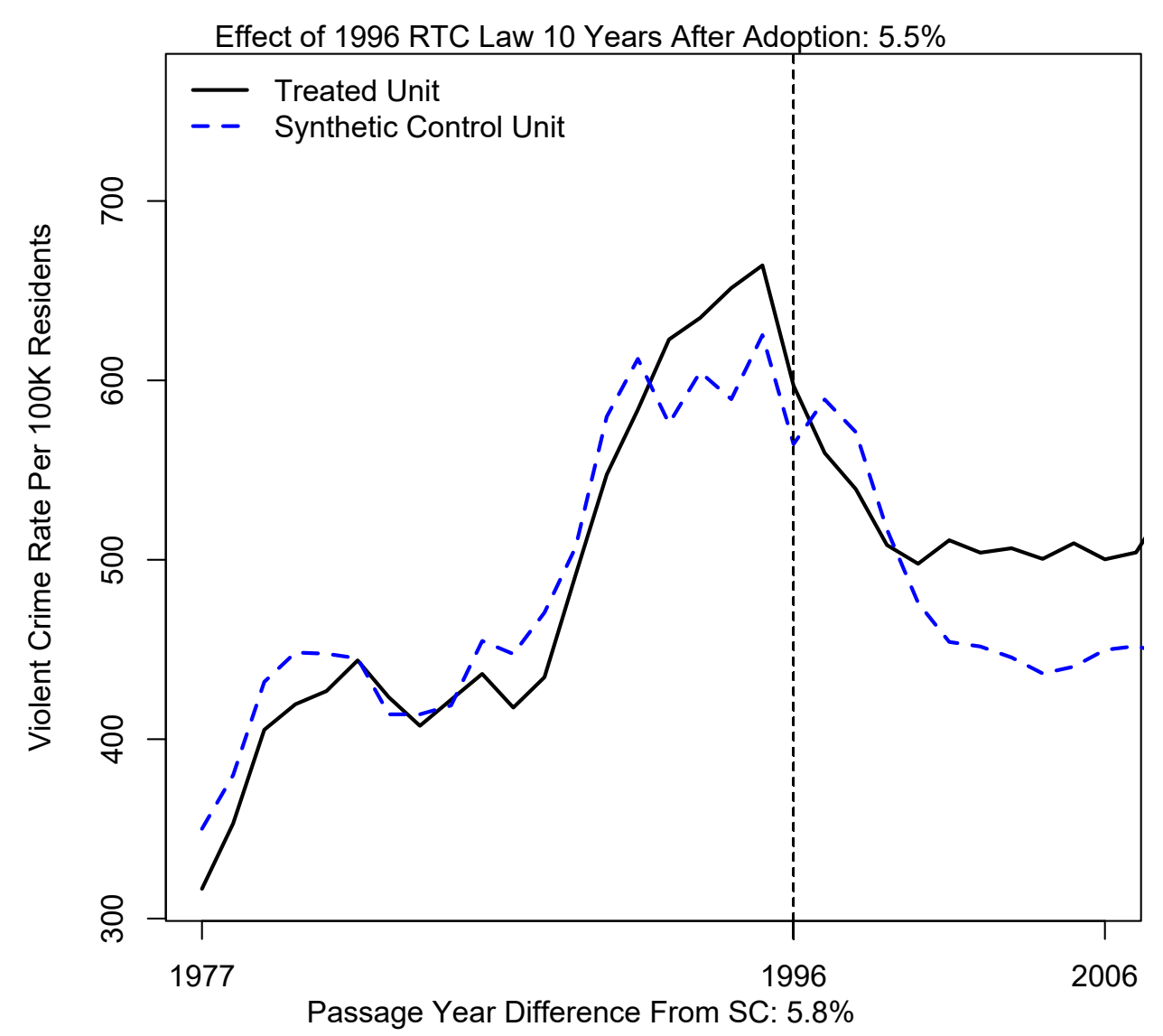

Composition of SC: DE (0.182); IL (0.259); IA (0.333); MD (0.026); MA (0.05); NE (0.15) CVRMSPE: 0.063 (11 of 33 states, where 1 denotes the state with the best pre-passage fit.)

States Never Passing RTC Laws Included in Synthetic Control: DE ; MA ; MD

RTC Adopting States Included in Synthetic Control: IA (2011); IL (2014); NE (2007)

Figure I23 


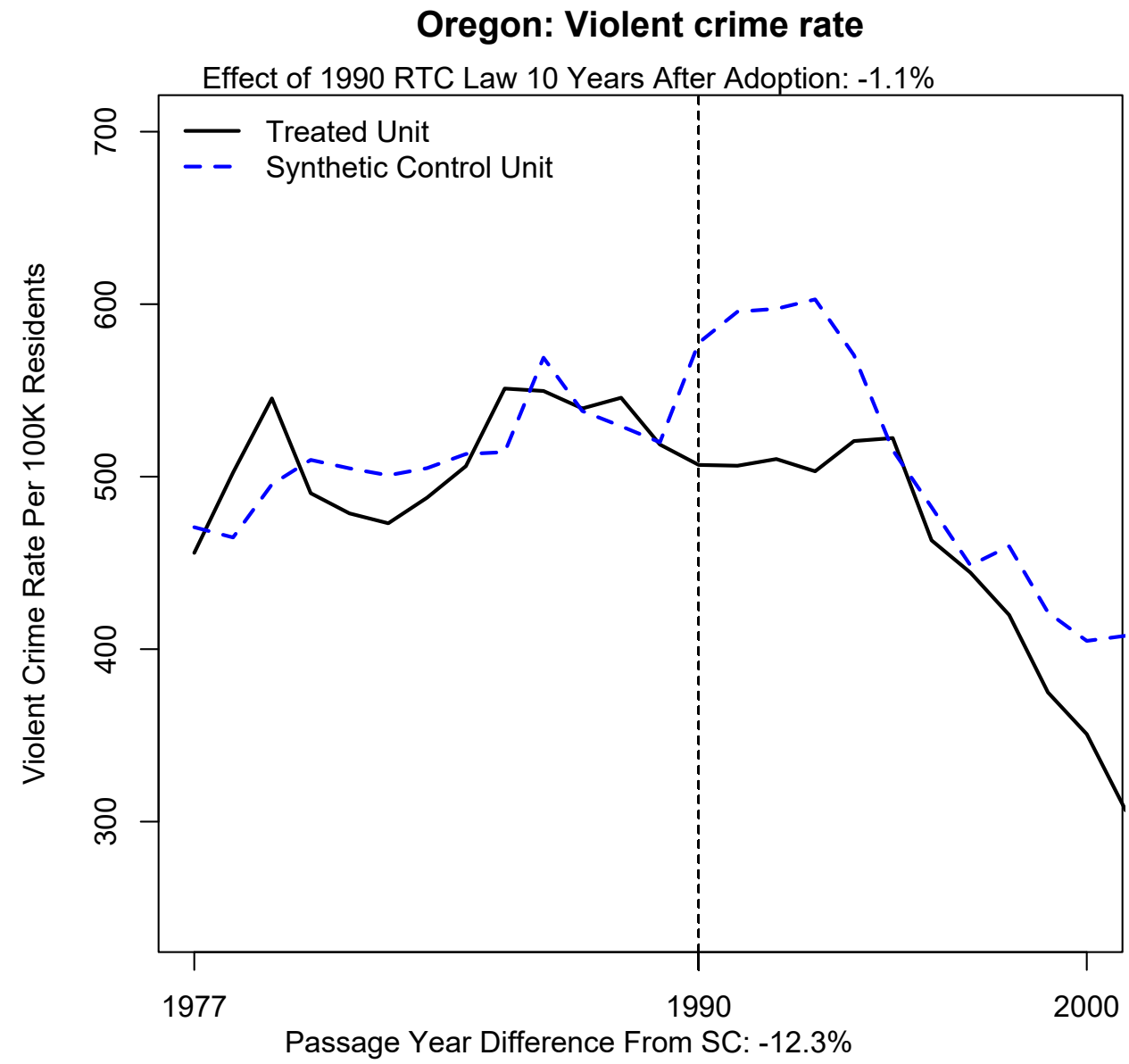

Composition of SC: CA (0.023); CO (0.411); HI (0.057); MI (0.338); MN (0.092); NE (0.079) CVRMSPE: 0.049 (6 of 33 states, where 1 denotes the state with the best pre-passage fit.) States Never Passing RTC Laws Included in Synthetic Control: CA ; HI :TC Adopting States Included in Synthetic Control: CO (2003); MI (2001); MN (2003); NE (2007

Figure I24 


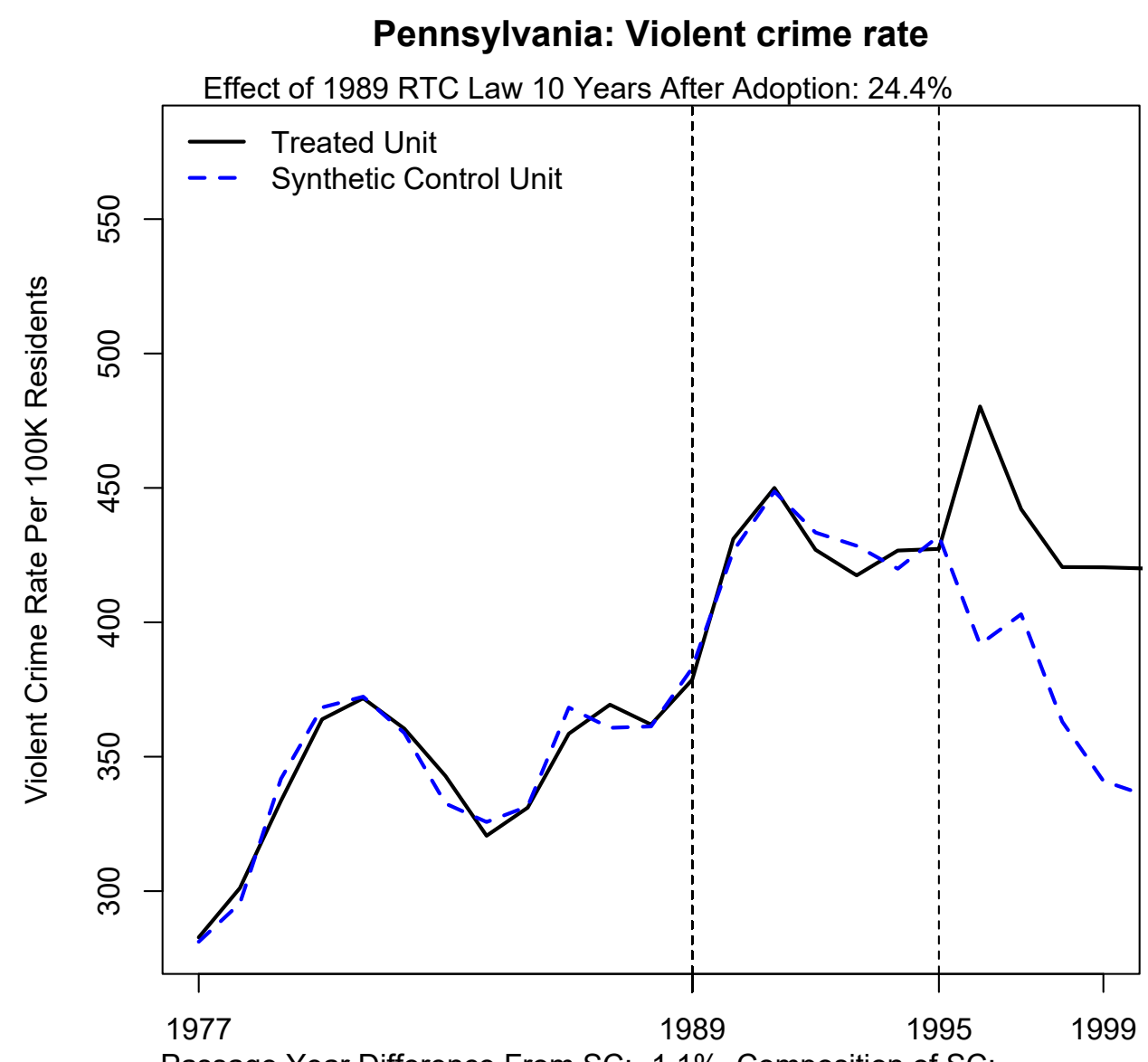

Passage Year Difference From SC: $-1.1 \%$. Composition of SC:

DE (0.078); HI (0.073); MD (0.038); NE (0.016); NJ (0.103); OH (0.27); WI (0.424)

CVRMSPE: 0.017 ( 1 of 33 states, where 1 denotes the state with the best pre-passage fit.)

States Never Passing RTC Laws Included in Synthetic Control: DE ; HI ; MD ; NJ

RTC Adopting States Included in Synthetic Control: NE (2007); OH (2004); WI (2012)

Figure I25 


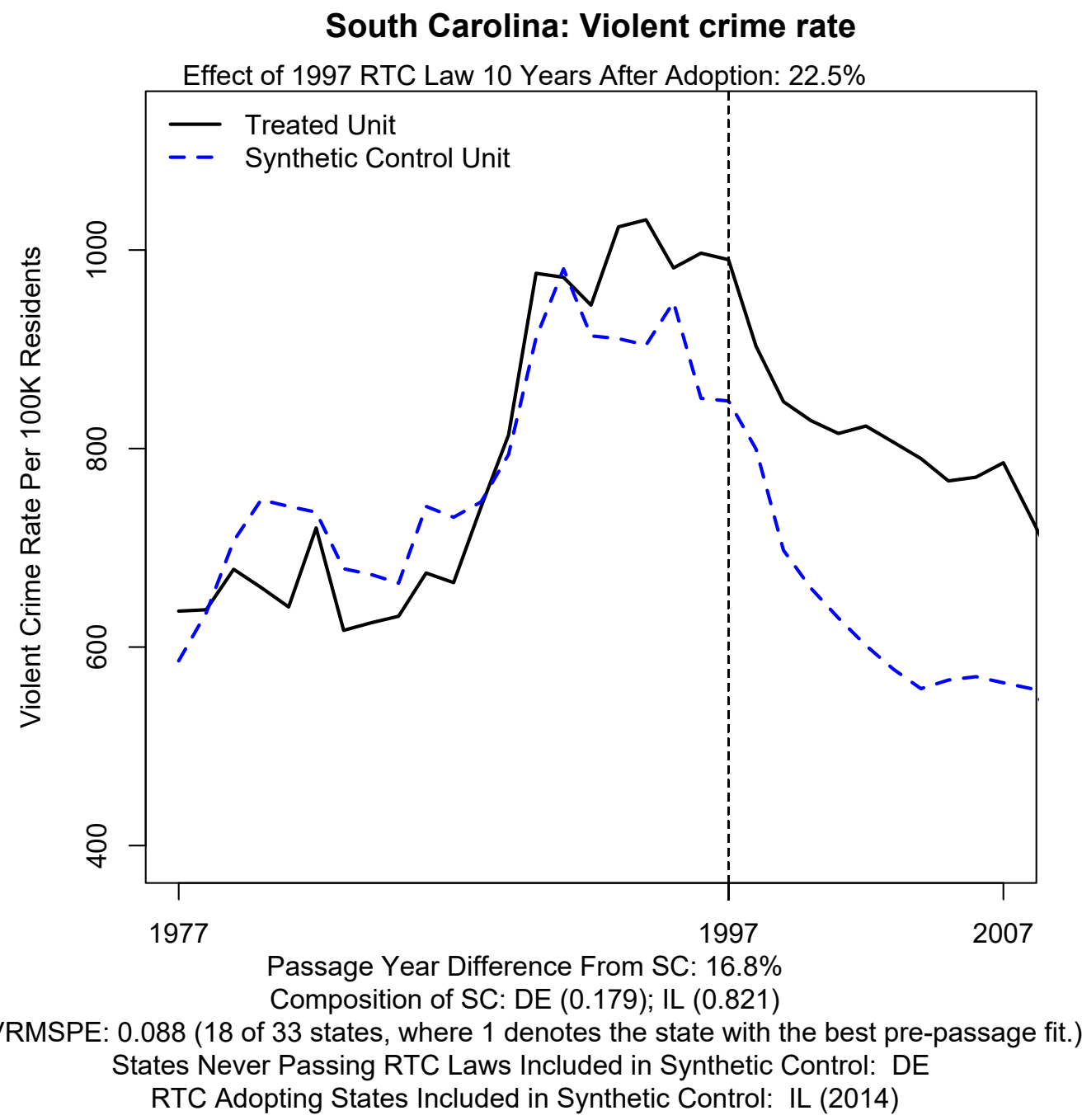

Figure I26 


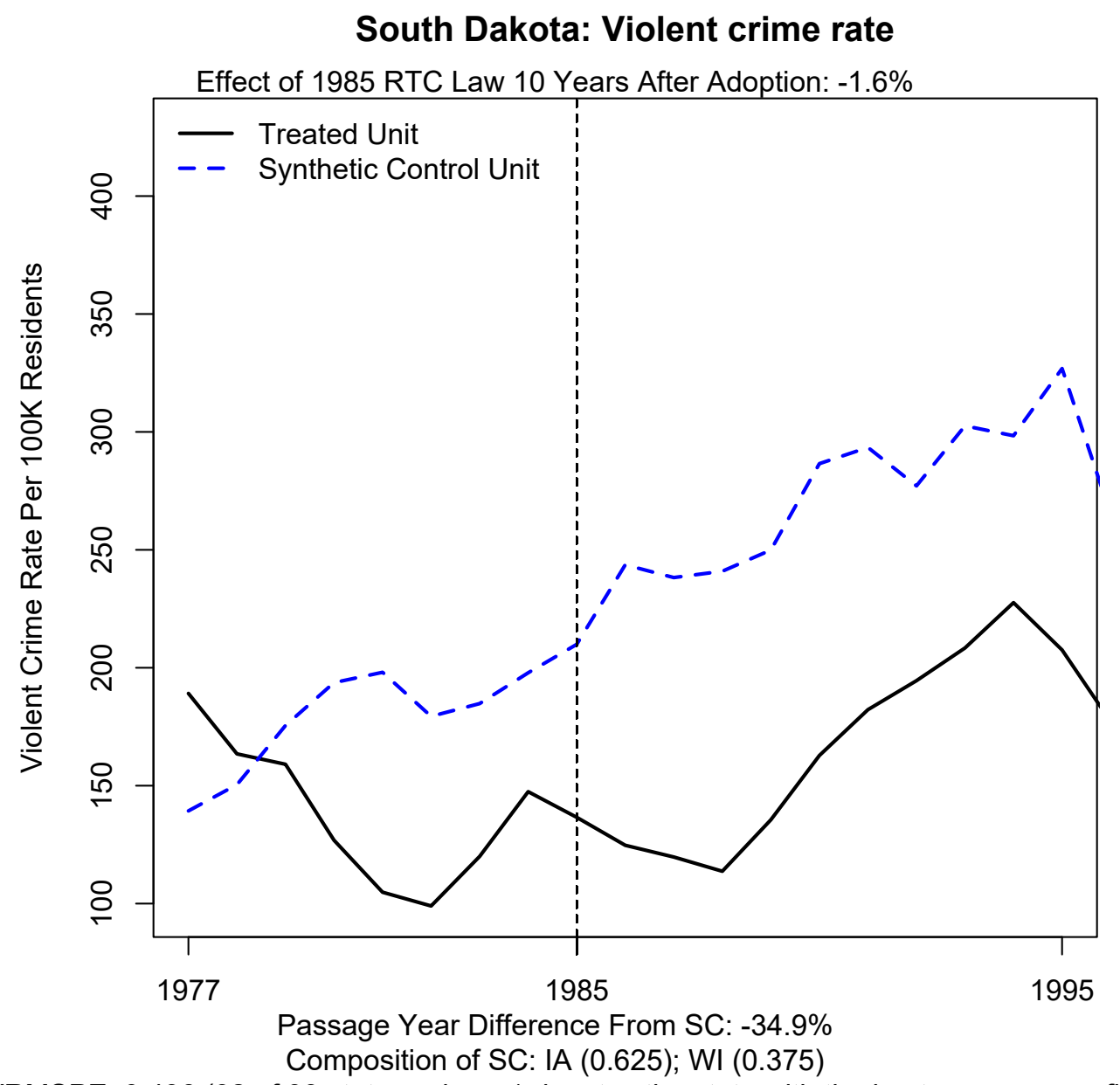

CVRMSPE: 0.436 (32 of 33 states, where 1 denotes the state with the best pre-passage fit.) States Never Passing RTC Laws Included in Synthetic Control:

RTC Adopting States Included in Synthetic Control: IA (2011); WI (2012)

Figure I27 
Tennessee: Violent crime rate

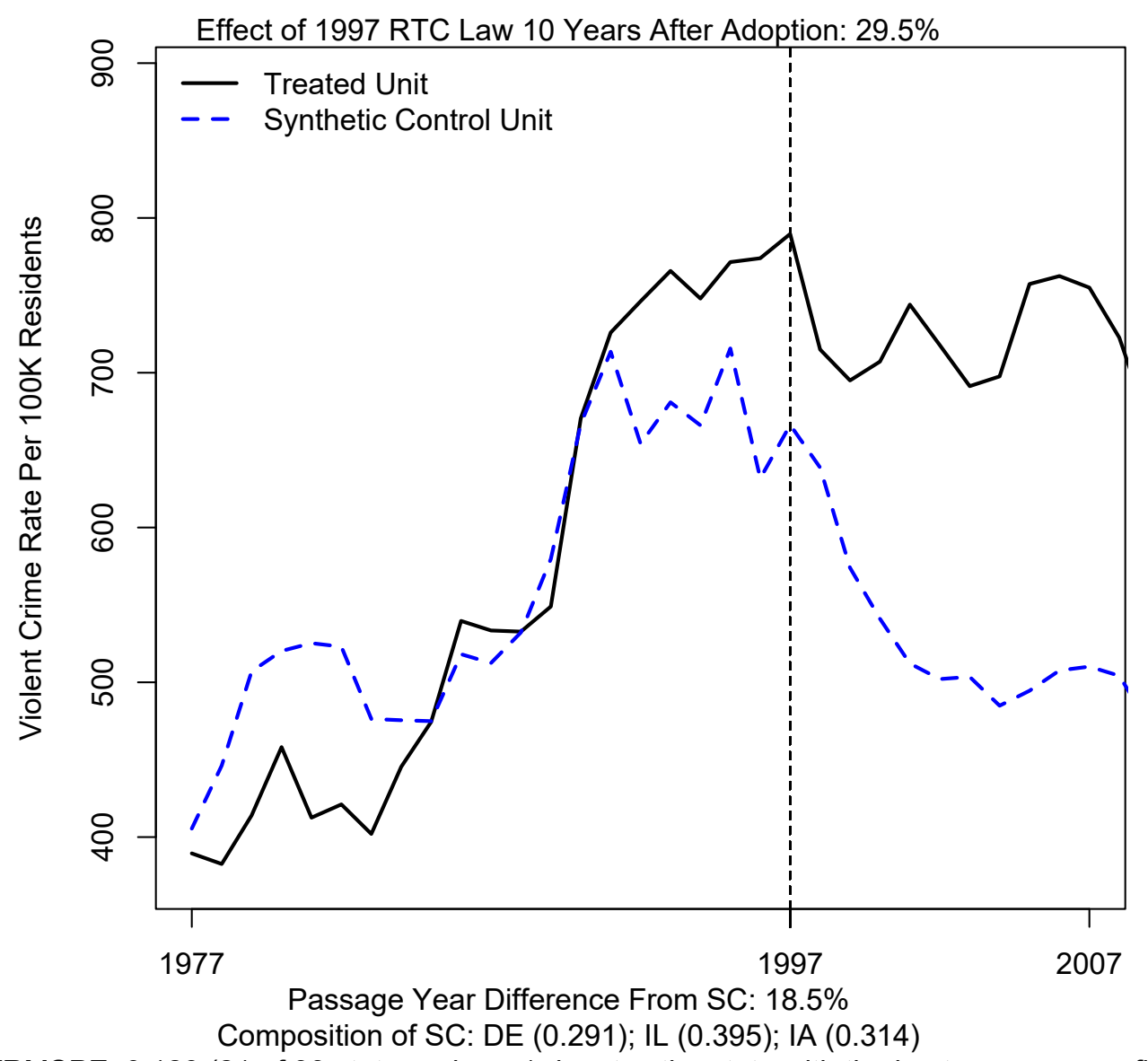

CVRMSPE: 0.123 (21 of 33 states, where 1 denotes the state with the best pre-passage fit.) States Never Passing RTC Laws Included in Synthetic Control: DE RTC Adopting States Included in Synthetic Control: IA (2011); IL (2014)

Figure I28 
Texas: Violent crime rate

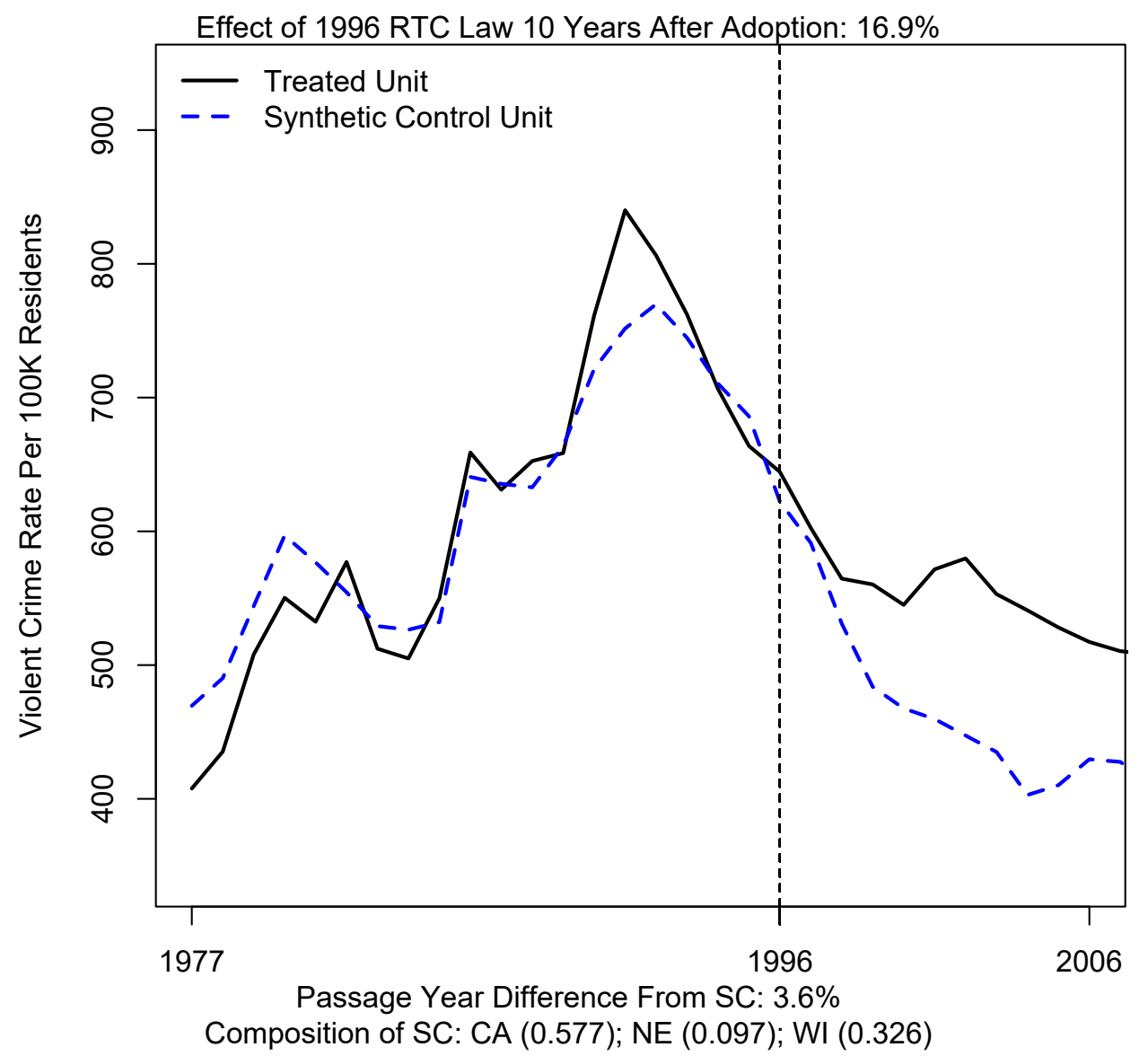

CVRMSPE: 0.06 ( 8 of 33 states, where 1 denotes the state with the best pre-passage fit.) States Never Passing RTC Laws Included in Synthetic Control: CA

RTC Adopting States Included in Synthetic Control: NE (2007); WI (2012)

Figure I29 


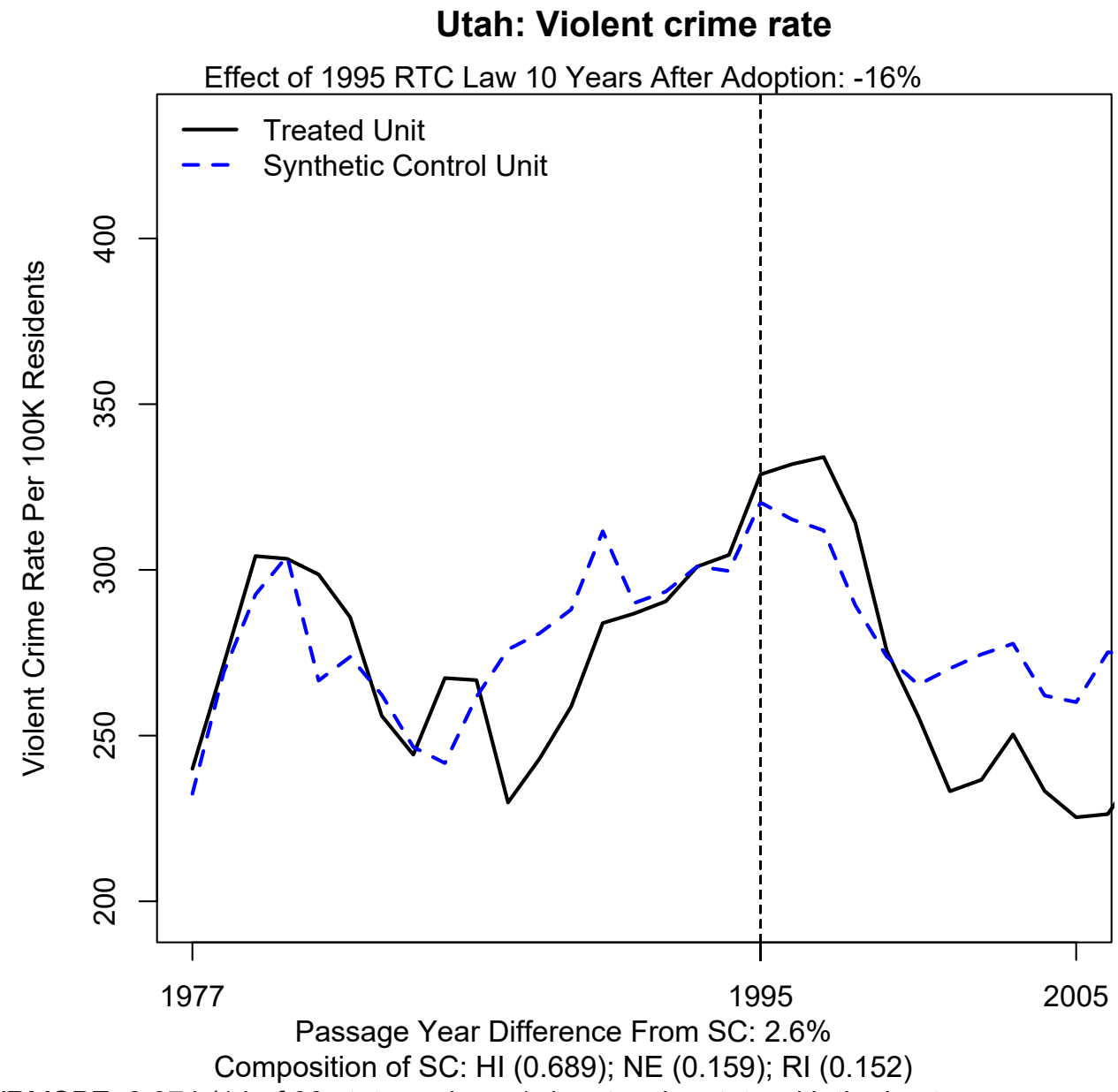

CVRMSPE: 0.074 (14 of 33 states, where 1 denotes the state with the best pre-passage fit.) States Never Passing RTC Laws Included in Synthetic Control: HI ; RI RTC Adopting States Included in Synthetic Control: NE (2007)

Figure I30 


\section{Virginia: Violent crime rate}

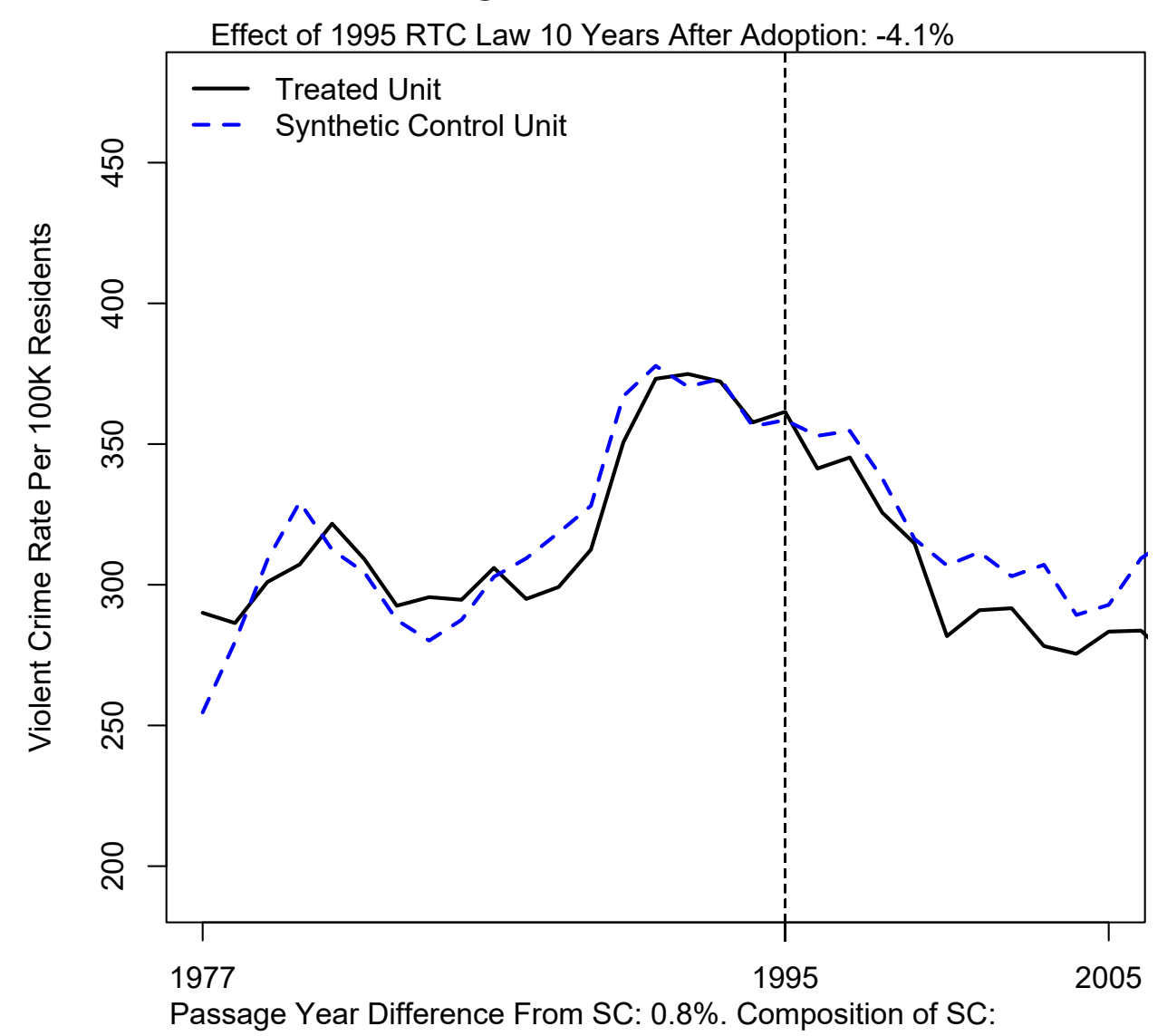

DE (0.003); HI (0.279); KS (0.238); MD (0.003); NE (0.151); RI (0.246); WI (0.079)

CVRMSPE: 0.043 (4 of 33 states, where 1 denotes the state with the best pre-passage fit.)

States Never Passing RTC Laws Included in Synthetic Control: DE ; HI ; MD ; RI

RTC Adopting States Included in Synthetic Control: KS (2007); NE (2007); WI (2012)

\section{Figure I31}




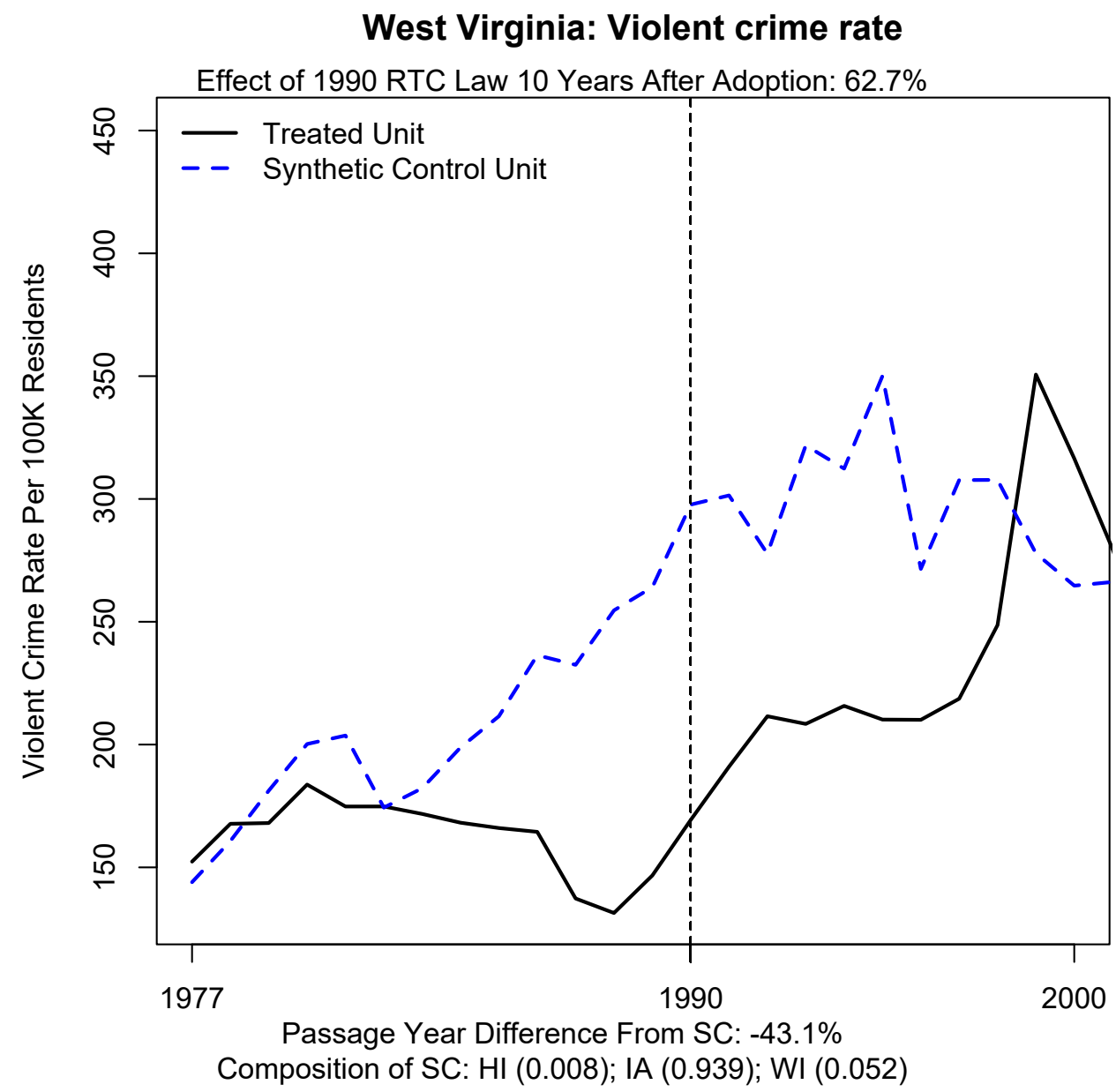

CVRMSPE: 0.374 (30 of 33 states, where 1 denotes the state with the best pre-passage fit.) States Never Passing RTC Laws Included in Synthetic Control: HI RTC Adopting States Included in Synthetic Control: IA (2011); WI (2012)

Figure I32 


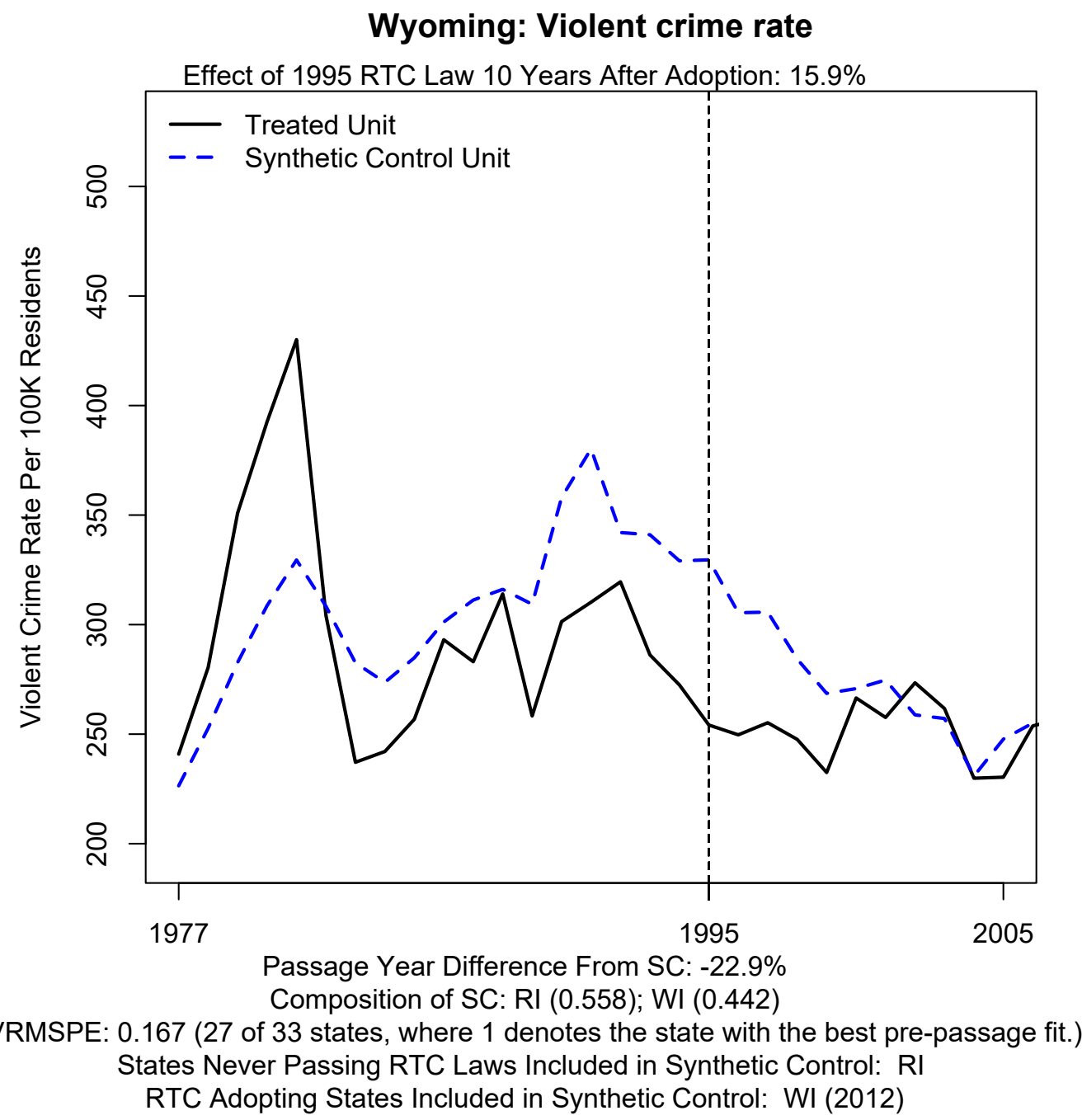

Figure I33 


\section{Appendix J: Data Sources}

\begin{tabular}{|c|c|c|c|c|}
\hline $\operatorname{Variable}(s)$ & $\begin{array}{c}\text { Years } \\
\text { Available }\end{array}$ & Source & $\operatorname{Model}(s)$ & Notes \\
\hline $\begin{array}{l}\text { RTC variables } \\
(\text { shalll \& aftr })\end{array}$ & $1977-2014$ & $\begin{array}{l}\text { State } \\
\text { session } \\
\text { laws }\end{array}$ & $\begin{array}{c}\text { DAW, } \\
\text { LM }\end{array}$ & $\begin{array}{l}\text { Statutes researched via Westlaw and HeinOnline. See footnote } 35 \text { for explanations of these } \\
\text { variables' constructions. Note that the spline variable is coded as } 0 \text { in all years for states that } \\
\text { passed before the data period, which depends on the model under consideration. For example, } \\
\text { for the DAW model (1979-2014), it is coded as } 0 \text { for states that passed before } 1979 \text {. }\end{array}$ \\
\hline Crime & $1977-2014$ & FBI & $\begin{array}{c}\text { DAW, } \\
\text { LM }\end{array}$ & $\begin{array}{l}\text { UCR Data Tool for data through } 2013 \text {; Table } 4 \text { of } 2015 \text { crime report for data in } 2014 \text {. Each } \\
\text { crime rate is the corresponding crime count, divided by the population metric used by the FBI, } \\
\text { times } 100,000 \text {. }\end{array}$ \\
\hline Police staffing & $1977-2014$ & FBI & DAW & $\begin{array}{l}\text { Agency-year-level police employment data were acquired from the FBI and aggregated to the } \\
\text { state-year level. The police employee rate is the total number of employees, divided by the } \\
\text { population as given in the same dataset. }\end{array}$ \\
\hline Population & $1977-2014$ & Census & $\begin{array}{c}\text { DAW, } \\
\text { LM }\end{array}$ & $\begin{array}{l}\text { Intercensal estimates are used, except in } 1970 \text { and 1980, for which decadal-census estimates are } \\
\text { used.The DAW model weights regressions by population; the LM also includes it as a covariate. }\end{array}$ \\
\hline $\begin{array}{l}\text { Population by age, } \\
\text { sex, and race }\end{array}$ & $1977-2014$ & Census & $\begin{array}{c}\text { DAW, } \\
\text { LM }\end{array}$ & Intercensal estimates are used. \\
\hline Income metrics & $1977-2014$ & BEA & $\begin{array}{c}\text { DAW, } \\
\text { LM }\end{array}$ & $\begin{array}{l}\text { Includes personal income, unemployment insurance, retirement payments and other, and } \\
\text { income maintenance payments. All } 4 \text { measures are divided by the CPI to convert to real terms. }\end{array}$ \\
\hline $\begin{array}{l}\text { Consumer price } \\
\quad \text { index }\end{array}$ & $1977-2014$ & BLS & $\begin{array}{c}\text { DAW, } \\
\text { LM }\end{array}$ & CPI varies by year but not by state. \\
\hline Incarceration & 1977-2014 & BJS & DAW & $\begin{array}{l}\text { The number of prisoners under the jurisdiction of a state as a percentage of its intercensal } \\
\text { population. }\end{array}$ \\
\hline Land area & 1977-2014 & Census & LM & $\begin{array}{l}\text { Land area over a given decade is taken from the most recent decadal Census. The density } \\
\text { variable is intercensal population divided by land area. }\end{array}$ \\
\hline Poverty rate & $1979-2014$ & Census & DAW & The Census directly reports the percentage of the population earning less than the poverty line. \\
\hline $\begin{array}{l}\text { Unemployment } \\
\text { rate }\end{array}$ & $1977-2014$ & BLS & $\begin{array}{c}\text { DAW, } \\
\text { LM }\end{array}$ & \\
\hline Arrests & $1977-2014$ & FBI & LM & $\begin{array}{l}\text { Agency-month-year-level arrests data, separated by age, sex, race, and crime category, were } \\
\text { acquired from the FBI and aggregated by state-year. For each crime category, the arrest rate is } \\
\text { the number of arrests for that crime as a percentage of the (UCR-reported) number of crimes. }\end{array}$ \\
\hline Beer & $1977-2015$ & $\mathrm{NIH}$ & DAW & $\begin{array}{l}\text { The NIH reports per-capita consumption of ethanol broken down by beverage type, including } \\
\text { beer. }\end{array}$ \\
\hline $\begin{array}{l}\text { Population in } \\
\text { metropolitan } \\
\text { statistical areas }\end{array}$ & 1977-2014 & $\begin{array}{l}\text { Census / } \\
\text { NBER, } \\
\text { FBI / } \\
\text { ICPSR }\end{array}$ & DAW & $\begin{array}{l}\text { 1977-1980: Intercensal estimated population in counties that at least overlapped with an MSA } \\
\text { in 1980. 1981-2014: Obtained from ICPSR-provided UCR arrests data. }\end{array}$ \\
\hline
\end{tabular}

All variables are at the state-year level unless otherwise noted. Variable creation scripts are available from the authors upon request. 


\section{Appendix K: Methodology to Choose the Number of Lags of the Dependent Variable to Include as Predictors in Synthetic Con- trol}

The prior synthetic control literature has used five different approaches concerning the inclusion of the dependent variable in selecting the best synthetic control: 1) lags of the dependent variable in every pre-treatment year, 2) three lags of the dependent variable, ${ }^{86} 3$ ) the average of the dependent variable in the pre-treatment period, 4) the value of the dependent variable in the year prior to RTC adoption, and 5) no lags of the dependent variable. ${ }^{87}$ To choose the optimal approach among these five options, we use the following cross-validation procedure with overall violent crime rate as the dependent variable: we first define our training period as 1977 through the sixth year prior to RTC adoption, the validation period as the fifth year prior to RTC adoption through one year prior to RTC adoption, and the full pre-treatment period as 1977 through one year prior to RTC adoption. We then use data from the training period to determine the composition of the synthetic control (essentially acting as if the RTC law were adopted five years earlier than it was). Specifically, for each of the 33 treatment units, we assign the treatment five years before the treatment actually occurred, and then run the synthetic control program using the standard DAW predictors and a five year reporting window. We then examine the fit during the training period, the validation period, and the entire pre-treatment period to see how closely for each of our five lag options the synthetic control estimate matches each adopting state's violent crime time-series.

Tables K1 K3 (Panel A) compare the fit of the five synthetic control estimates during the training period, validation period, and the entire pre-treatment period using three different loss functions. Table K1 defines the error using the mean squared error between the actual value of the dependent variable and the synthetic control estimate during a given period; Table $\mathrm{K} 2$ uses the mean of the absolute value of this difference between the actual value and synthetic control estimate; finally, Table $\mathrm{K} 3$ uses the $\mathrm{CV}$ of the RMSPE. For Tables $\mathrm{K} 1$, $\mathrm{K} 3$, an unweighted average of the error for each of the 33 treatment states is presented. For Tables K4 K6 (Panel B) a populationweighted average of the error for each of the 33 treatment states is presented, where population from the first year of the relevant period is used. ${ }^{88}$

The results from Tables K1 K6 provide strong evidence that using yearly lags of the depen-

\footnotetext{
${ }^{86}$ In the three-lag model, the first lag is the value of the dependent variable in 1977, the second lag is the value of the dependent variable in the year prior to RTC adoption, and the third lag is the value of the dependent variable in the year that is midway between the year corresponding to the first and second lag.

${ }^{87}$ The first choice is used, for example, in Bohn, Lofstrom, and Raphael (2014), the second choice is used by Abadie, Diamond, and Hainmueller (2010), and the third and fourth choices are suggested by Kaul et al. (2016).

${ }^{88}$ The first year of the training and full pre-treatment period is 1977, while the first year of the validation period is the fifth year prior to RTC adoption.
} 
dent variable generates the best fit among the five options. As expected, across all six tables, the error in the training period is lowest using yearly lags, regardless of how the error is defined or whether population weights are used to aggregate the measure of error over all treatment states. Additionally, yearly lags provide the lowest error in the validation period in four of the six cases, being surpassed only marginally by the one lag average specification twice when using population weights (Tables K4 and K5). Finally, yearly lags have the lowest error in all six tables over the full pre-treatment period.

A potential concern with using all pre-intervention outcomes of the dependent variable as synthetic control predictors is that the synthetic control unit will not closely match the treated unit on the explanatory variables during the pre-treatment period. ${ }^{89}$ To explore this issue, we calculated for each DAW variable, state, and year, the absolute percentage difference between the true value of the variable and the value for the corresponding synthetic control across all five lag options. We then average by state and finally average across all RTC-adopting states for each explanatory variable. We then create the ratio of this statistic using a particular lag choice to the average of this statistic across all five lag choices. This ratio allows us to assess the predictor fit generated by each individual lag specification relative to the average fit.

Table K7 reveals that while yearly lags produces a good fit for an array of variables, the fit for the demographic variables is less good, particularly for the non-white non-black categories. To summarize the findings in Table K7, using all of the lags of the violent crime rate in generating a synthetic control generates the best fit in a number of measures of fit and prediction, but there are tradeoffs among the lag choices in terms of generating synthetic controls that more closely match all the explanatory variables of the DAW model. While we opted to rely on yearly lags in our main presentation to take advantage of the generally superior fit, a reasonable alternative might be the one lag average model. This specification better matches explanatory variables, while maintaining a reasonably close (but worse) fit of the dependent variable.

Importantly, our treatment effect percentage (TEP) results are robust to any of these five lag specifications. As Table K8 shows for violent crime using DAW covariates and five alternative lag specifications, ${ }^{90}$ the point estimate of the tenth-year average treatment effect percentage ranges from 11.8 percent (one lag average) to 15.4 percent (three lags), while we highlight the estimate for yearly lags of 14.3 percent (which has the lowest standard error in the tenth year across all five models). In other words, for all five lag choices, we estimate RTC laws generate at least double-digit increases in the rate of violent crime.

\footnotetext{
${ }^{89}$ See Kaul et al. (2016).

${ }^{90}$ Our results are also robust to the LM specifications as well as crime rates for murder, property, aggravated assault, rape and robbery. Furthermore, lag choices do not influence TEP results after CVRMSPE-based exclusion. Results are available upon request.
} 


\section{A. Violent Crime Fit Comparison of 5 Lag Choices - Unweighted Average}

Table K1: Define Fit Using Mean Squared Error

\begin{tabular}{cccc}
\hline \hline & Training Period; Mean Squared Error & Validation Period; Mean Squared Error & Full Pre-Treatment Period; Mean Squared Error \\
\hline Three lags & $2,686.622$ & $7,595.525$ & $4,207.864$ \\
Yearly lags & $1,377.452$ & $6,433.835$ & $2,946.029$ \\
One lag average & $1,752.449$ & $7,855.294$ & $3,546.032$ \\
One lag final pre-treatment year & $3,903.140$ & $8,920.437$ & $5,517.578$ \\
No lags & $2,421.579$ & $8,559.487$ & $4,253.367$ \\
\hline
\end{tabular}

Notes: After getting a measure of fit for each state, an unweighted average is taken to arrive at a single measure of fit.Training Period from 1977 through RTC year - 6;

Validation Period from RTC year - 5 through RTC year - 1

Table K2: Define Fit Using Mean Absolute Difference

\begin{tabular}{cccc}
\hline \hline & Training Period; Mean Absolute Difference & Validation Period; Mean Absolute Difference & Full Pre-Treatment Period; Mean Absolute Difference \\
\hline Three lags & 33.414 & 65.556 & 43.740 \\
Yearly lags & 24.069 & 60.085 & 35.614 \\
One lag average & 27.885 & 65.127 & 39.546 \\
One lag final pre-treatment year & 38.077 & 67.925 & 47.813 \\
No lags & 34.676 & 71.569 & 46.511 \\
\hline
\end{tabular}

Notes: After getting a measure of fit for each state, an unweighted average is taken to arrive at a single measure of fit.Training Period from 1977 through RTC year - 6;

Validation Period from RTC year - 5 through RTC year - 1

Table K3: Define Fit Using CVRMSPE

\begin{tabular}{cccc}
\hline \hline & Training Period; CVRMSPE & Validation Period; CVRMSPE & Full Pre-Treatment Period; CVRMSPE \\
\hline Three lags & 0.132 & 0.251 & 0.191 \\
Yearly lags & 0.105 & 0.229 & 0.168 \\
One lag average & 0.116 & 0.245 & 0.179 \\
One lag final pre-treatment year & 0.146 & 0.261 & 0.201 \\
No lags & 0.143 & 0.274 & 0.206 \\
\hline
\end{tabular}

Notes: After getting a measure of fit for each state, an unweighted average is taken to arrive at a single measure of fit.Training Period from 1977 through RTC year - 6 ;

Validation Period from RTC year - 5 through RTC year - 1

\section{B. Violent Crime Fit Comparison of 5 Lag Choices - Population Weighted Average}

Table K4: Define Fit Using Mean Squared Error

\begin{tabular}{cccc}
\hline \hline & Training Period; Mean Squared Error & Validation Period; Mean Squared Error & Full Pre-Treatment Period; Mean Squared Error \\
\hline Three lags & $1,831.318$ & $5,432.279$ & $2,940.866$ \\
Yearly lags & 805.011 & $5,309.441$ & $2,120.682$ \\
One lag average & $1,135.997$ & $5,285.855$ & $2,329.984$ \\
One lag final pre-treatment year & $2,551.610$ & $6,075.208$ & $3,694.090$ \\
No lags & $1,718.201$ & $6,197.124$ & $3,015.222$ \\
\hline
\end{tabular}

Notes: After getting a measure of fit for each state, a population weighted average is taken to arrive at a single measure of fit.Training Period from 1977 through RTC year - 6 ;

Validation Period from RTC year - 5 through RTC year - 1. Population from first year of relevant period is used.

Table K5: Define Fit Using Mean Absolute Difference

\begin{tabular}{cccc}
\hline \hline & Training Period; Mean Absolute Difference & Validation Period; Mean Absolute Difference & Full Pre-Treatment Period; Mean Absolute Difference \\
\hline Three lags & 26.799 & 53.647 & 35.243 \\
Yearly lags & 18.646 & 51.913 & 28.715 \\
One lag average & 22.887 & 50.601 & 31.491 \\
One lag final pre-treatment year & 29.342 & 54.235 & 37.234 \\
No lags & 30.319 & 60.414 & 39.664 \\
\hline
\end{tabular}

Notes: After getting a measure of fit for each state, a population weighted average is taken to arrive at a single measure of fit.Training Period from 1977 through RTC year - 6;

Validation Period from RTC year - 5 through RTC year - 1. Population from first year of relevant period is used.

Table K6: Define Fit Using CVRMSPE

\begin{tabular}{cccc}
\hline \hline & Training Period; CVRMSPE & Validation Period; CVRMSPE & Full Pre-Treatment Period; CVRMSPE \\
\hline Three lags & 0.074 & 0.129 & 0.105 \\
Yearly lags & 0.052 & 0.119 & 0.089 \\
One lag average & 0.062 & 0.121 & 0.094 \\
One lag final pre-treatment year & 0.082 & 0.135 & 0.111 \\
No lags & 0.086 & 0.149 & 0.119 \\
\hline
\end{tabular}

Notes: After getting a measure of fit for each state, a population weighted average is taken to arrive at a single measure of fit.Training Period from 1977 through RTC year - 6;

Validation Period from RTC year - 5 through RTC year - 1. Population from first year of relevant period is used. 
Table K7: Comparing DAW Explanatory Variables in the RTC adopting states and their synthetic controls: Ratio of mean absolute percentage difference between treatment and synthetic controls for each variable to the average of this value for all five lag specifications

\begin{tabular}{|c|c|c|c|c|c|}
\hline Variable & 3 Lags & Yearly Lags & 1 Lag Average & $\begin{array}{c}\text { I Lag final } \\
\text { pre-Treatment Year }\end{array}$ & No Lags \\
\hline Population & 0.84 & 0.85 & 0.98 & 1.19 & 1.13 \\
\hline Poverty rate & 0.99 & 1.00 & 1.03 & 1.01 & 0.97 \\
\hline Lagged incarceration rate & 0.95 & 1.01 & 1.00 & 1.03 & 1.00 \\
\hline Beer & 0.95 & 1.02 & 1.02 & 1.05 & 0.96 \\
\hline Unemployment rate & 1.03 & 1.05 & 1.01 & 0.96 & 0.96 \\
\hline Lagged police employment & 0.85 & 1.07 & 1.03 & 1.02 & 1.03 \\
\hline Real income (p.c.) & 0.97 & 1.07 & 1.00 & 0.94 & 1.01 \\
\hline Percent MSA & 0.99 & 1.12 & 1.07 & 0.94 & 0.88 \\
\hline Age white male $20-39$ & 1.12 & 1.16 & 1.00 & 0.91 & 0.81 \\
\hline Age black male $15-19$ & 1.08 & 1.16 & 1.03 & 1.00 & 0.72 \\
\hline Age black male 20-39 & 1.09 & 1.24 & 1.03 & 0.95 & 0.69 \\
\hline Age white male $15-19$ & 1.11 & 1.27 & 0.97 & 0.87 & 0.79 \\
\hline Age other male $15-19$ & 0.92 & 1.56 & 1.16 & 0.72 & 0.65 \\
\hline Age other male $20-39$ & 0.91 & 1.59 & 1.14 & 0.72 & 0.63 \\
\hline Mean, non-demographic variables & 0.95 & 1.02 & 1.02 & 1.02 & 1.00 \\
\hline Mean, demographic variables & 1.04 & 1.33 & 1.05 & 0.86 & 0.72 \\
\hline Overall mean & 0.99 & 1.15 & 1.03 & 0.95 & 0.88 \\
\hline
\end{tabular}

Notes: We take the average of the absolute percentage difference in economic predictors between Treatment and Synthetic Control states using five lag specifications. The values reported are the ratio of this statistic for each lag specification to the average of this statistic for all five lag choices.

Age groups represent the percent of population that is white male, black male or other male in two age brackets (15-19 and 20-39).

Table K8: The Impact of RTC Laws on the Violent Crime Rate, DAW covariates, Various Lag specifications, Full Sample, 1977-2014

\begin{tabular}{|c|c|c|c|c|c|c|c|c|c|c|}
\hline & (1) & (2) & (3) & (4) & (5) & (6) & (7) & (8) & (9) & (10) \\
\hline Average normalized TEP & -0.328 & 2.190 & $3.961^{* *}$ & $4.957^{* *}$ & $7.617^{* * *}$ & $8.210^{* * *}$ & $11.047^{* * *}$ & $13.577^{* * *}$ & $14.847^{* * *}$ & $15.411^{* * *}$ \\
\hline 3 Lags & (1.076) & (1.444) & $(1.884)$ & $(2.096)$ & $(2.380)$ & $(2.911)$ & $(2.885)$ & $(3.994)$ & (3.976) & (3.284) \\
\hline $\mathrm{N}$ & 33 & 33 & 33 & 33 & 33 & 33 & 33 & 31 & 31 & 31 \\
\hline Average normalized TEP & -0.117 & $2.629^{*}$ & $3.631^{*}$ & $4.682^{* *}$ & $6.876^{* * *}$ & $7.358^{* *}$ & $10.068^{* * *}$ & $12.474^{* * *}$ & $14.021^{* * *}$ & $14.344^{* * *}$ \\
\hline Yearly lag & $(1.076)$ & $(1.310)$ & $(1.848)$ & $(2.068)$ & $(2.499)$ & $(3.135)$ & $(2.823)$ & $(3.831)$ & $(3.605)$ & $(2.921)$ \\
\hline $\mathrm{N}$ & 33 & 33 & 33 & 33 & 33 & 33 & 33 & 31 & 31 & 31 \\
\hline " Average normalized TEP & 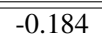 & 2.045 & $3.366^{*}$ & $3.885^{*}$ & $5.856^{* *}$ & $6.256^{*}$ & $8.595^{* * *}$ & $111.295^{* *}$ & $111.840^{* * *}$ & $111.770^{* * *}$ \\
\hline 1 Lag average & $(1.157)$ & $(1.355)$ & $(1.924)$ & $(2.151)$ & $(2.492)$ & (3.076) & $(2.877)$ & $(4.327)$ & $(4.219)$ & (3.734) \\
\hline $\mathrm{N}$ & 33 & 33 & 33 & 33 & 33 & 33 & 33 & 31 & 31 & 31 \\
\hline " Average normalized TEP & 0.325 & $3.293^{* *}$ & $4.639^{* *}$ & 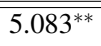 & $7.432^{* * *}$ & $8.084^{* *}$ & $10.859^{* * *}$ & $13.187^{* * *}$ & $13.899^{* * *}$ & $14.222^{* * *}$ \\
\hline $1 \mathrm{Lag}$ final year & $(1.175)$ & (1.539) & $(1.921)$ & $(2.094)$ & $(2.371)$ & $(3.047)$ & $(2.887)$ & (4.175) & $(4.187)$ & $(3.359)$ \\
\hline $\mathrm{N}$ & 33 & 33 & 33 & 33 & 33 & 33 & 33 & 31 & 31 & 31 \\
\hline Average normalized TEP & -0.485 & 1.458 & $3.193^{* *}$ & $4.183^{* *}$ & $6.028^{* *}$ & $6.320^{*}$ & $10.061^{* * *}$ & $12.266^{* * *}$ & $12.631^{* * *}$ & $13.751^{* * *}$ \\
\hline No lags & $(1.155)$ & $(1.723)$ & $(1.536)$ & $(1.879)$ & $(2.443)$ & (3.183) & $(3.557)$ & $(4.144)$ & (4.115) & $(3.917)$ \\
\hline $\mathrm{N}$ & 33 & 33 & 33 & 33 & 33 & 33 & 33 & 31 & 31 & 31 \\
\hline
\end{tabular}

Standard errors in parentheses

Column numbers indicate post-passage year under consideration; $\mathrm{N}=$ number of states in sample

Dependent variable is the difference between the percentage difference in the violent crime rate in treatment and synthetic control states

at given post-treatment interval and at time of the treatment

Results reported for the constant term resulting from this regression

States in group: AK AR AZ CO FL GA ID KS KY LA ME MI MN MO MS MT NC ND NE NM NV OH OK OR PA SC SD TN TX UT VA WV WY

${ }^{*} p<0.10,{ }^{* *} p<0.05,{ }^{* * *} p<0.01$ 


\section{Appendix L: Simulating Earlier RTC Passage}

Footnote 55 in the text outlined an approach to validate our synthetic control estimates, using a "phantom-adoption" test. Essentially, we pretend that the RTC states adopted their laws five years earlier than they did, and we then used our synthetic control approach to estimate what the crime rate was for the five pre-adoption years. A perfect result would show a zero effect over that preadoption period.

Tables L1,L6 present both normalized and non-normalized synthetic control estimates for violent crime, murder, and property crime with a phantom RTC law five years before actual passage. Each table thus shows estimated effects of RTC laws on the five years prior to their adoption, as well as the ten years after. For the normalized versions, none of the estimates for pre-passage years are statistically significant, other than the year prior to true adoption for property crime. Conversely, for the non-normalized models, the pre-passage estimates are considerably larger and often highly significant. This distinction lends further credibility to the choice to use normalized estimates (subtracting off the differential between actual and synthetic control estimates in the last pre-adoption year) rather than using unadjusted figures.

This "phantom-adoption" test is particularly reassuring for violent crime since it yields relatively modest pre-treatment values (only a statistically insignificant 3.2 percent in the year prior to actual adoption, as seen in Table A28), and the estimates rise sharply after RTC adoption. Unfortunately, the results from this "phantom-adoption" test for the murder and property crime estimates are not as reassuring. For example, the synthetic control estimate for the year prior to adoption in our preferred normalized approach is roughly 8 percent for murder (Table A30) and 7 percent for property crime (Table A32). While neither of these estimates is statistically significant, they are both more than twice the size of the estimates for violent crime, which leads us to emphasize the results for violent crime more than those for our other crime measures. 
Table L1: The Impact of RTC Laws on the Violent Crime Rate, DAW covariates, Full Sample, 1977-2014

\begin{tabular}{|c|c|c|c|c|c|c|c|c|c|c|c|c|c|c|c|}
\hline & \multicolumn{5}{|c|}{ Prior to RTC Passage } & \multicolumn{10}{|c|}{ After RTC Passage } \\
\hline & (1) & (2) & (3) & (4) & (5) & (1) & (2) & (3) & (4) & (5) & (6) & (7) & (8) & (9) & (10) \\
\hline Average normalized TEP & $\begin{array}{l}-0.889 \\
(1.437)\end{array}$ & $\begin{array}{c}1.896 \\
(2.289)\end{array}$ & $\begin{array}{c}2.600 \\
(3.098)\end{array}$ & $\begin{array}{c}1.065 \\
(3.054)\end{array}$ & $\begin{array}{c}3.241 \\
(3.148)\end{array}$ & $\begin{array}{c}3.066 \\
(3.087)\end{array}$ & $\begin{array}{l}6.103^{*} \\
(3.389)\end{array}$ & $\begin{array}{l}7.409^{* *} \\
(3.195)\end{array}$ & $\begin{array}{l}7.640^{* *} \\
(3.429)\end{array}$ & $\begin{array}{c}10.289^{* * *} \\
(3.318)\end{array}$ & $\begin{array}{c}11.294^{* * *} \\
(3.609)\end{array}$ & $\begin{array}{c}14.262^{* * *} \\
(3.748)\end{array}$ & $\begin{array}{c}17.476^{* * *} \\
(4.796)\end{array}$ & $\begin{array}{c}18.081^{* * *} \\
(5.027)\end{array}$ & $\begin{array}{c}18.396^{* * *} \\
(5.267)\end{array}$ \\
\hline $\mathrm{N}$ & 30 & 30 & 30 & 30 & 30 & 30 & 30 & 30 & 30 & 30 & 30 & 30 & 28 & 28 & 28 \\
\hline
\end{tabular}

Standard errors in parentheses

Column numbers indicate post-passage year under consideration; $\mathrm{N}=$ number of states in sample

Dependent variable is the difference between the percentage difference in the violent crime rate in treatment and synthetic control states at given simulated post-treatment interval and at time of the treatment Results reported for the constant term resulting from this regression

States in group: AK AR AZ CO FL GA ID KS KY LA MI MN MO MS MT NC NE NM NV OH OK OR PA SC TN TX UT VA WV WY

States excluded for poor pre-treatment fit:

${ }^{*} p<0.10,{ }^{* *} p<0.05,{ }^{* * *} p<0.01$

Table L2: The Impact of RTC Laws on the Violent Crime Rate, DAW covariates, Full Sample, 1977-2014, No Subtraction

\begin{tabular}{|c|c|c|c|c|c|c|c|c|c|c|c|c|c|c|c|}
\hline & \multicolumn{5}{|c|}{ Prior to RTC Passage } & \multicolumn{10}{|c|}{ After RTC Passage } \\
\hline & (1) & (2) & (3) & (4) & (5) & (1) & (2) & (3) & (4) & (5) & (6) & (7) & (8) & (9) & (10) \\
\hline Average non-normalized TEP & $\begin{array}{c}1.104 \\
(1.997)\end{array}$ & $\begin{array}{l}3.916^{*} \\
(1.958)\end{array}$ & $\begin{array}{l}4.643^{* *} \\
(1.920)\end{array}$ & $\begin{array}{c}3.125 \\
(2.483) \\
\end{array}$ & $\begin{array}{l}5.316^{* *} \\
(2.514)\end{array}$ & $\begin{array}{l}5.150^{* *} \\
(2.060)\end{array}$ & $\begin{array}{c}8.194^{* * *} \\
(2.760)\end{array}$ & $\begin{array}{c}9.508^{* * *} \\
(3.398)\end{array}$ & $\begin{array}{l}9.744^{* *} \\
(3.815)\end{array}$ & $\begin{array}{c}12.399^{* * *} \\
(4.102)\end{array}$ & $\begin{array}{c}13.418^{* * *} \\
(4.606)\end{array}$ & $\begin{array}{c}16.400^{* * *} \\
(4.161)\end{array}$ & $\begin{array}{c}19.715^{* * *} \\
(5.641)\end{array}$ & $\begin{array}{c}20.337^{* * *} \\
(5.583)\end{array}$ & $\begin{array}{c}20.679^{* * *} \\
(5.074)\end{array}$ \\
\hline $\mathrm{N}$ & 30 & 30 & 30 & 30 & 30 & 30 & 30 & 30 & 30 & 30 & 30 & 30 & 28 & 28 & 28 \\
\hline
\end{tabular}

Standard errors in parentheses

Column numbers indicate post-passage year under consideration; $\mathrm{N}=$ number of states in sample

Dependent variable is the percentage difference in the violent crime rate in treatment and synthetic control states at given post-treatment interval

Results reported for the constant term resulting from this regression

States in group: AK AR AZ CO FL GA ID KS KY LA MI MN MO MS MT NC NE NM NV OH OK OR PA SC TN TX UT VA WV WY

States excluded for poor pre-treatment fit:

${ }^{*} p<0.10,{ }^{* *} p<0.05,{ }^{* * *} p<0.01$ 
Table L3: The Impact of RTC Laws on the Murder Rate, DAW covariates, Full Sample, 1977-2014

\begin{tabular}{|c|c|c|c|c|c|c|c|c|c|c|c|c|c|c|c|}
\hline & \multicolumn{5}{|c|}{ Prior to RTC Passage } & \multicolumn{10}{|c|}{ After RTC Passage } \\
\hline & (1) & (2) & (3) & (4) & (5) & (1) & (2) & (3) & (4) & (5) & (6) & (7) & (8) & (9) & (10) \\
\hline Average normalized TEP & $\begin{array}{c}1.117 \\
(3.713)\end{array}$ & $\begin{array}{c}1.596 \\
(5.302)\end{array}$ & $\begin{array}{c}3.091 \\
(5.549)\end{array}$ & $\begin{array}{c}3.912 \\
(6.764)\end{array}$ & $\begin{array}{c}7.756 \\
(6.430)\end{array}$ & $\begin{array}{c}8.580 \\
(6.697)\end{array}$ & $\begin{array}{c}4.947 \\
(5.077)\end{array}$ & $\begin{array}{c}5.408 \\
(6.163)\end{array}$ & $\begin{array}{c}5.004 \\
(6.766)\end{array}$ & $\begin{array}{c}1.529 \\
(6.157)\end{array}$ & $\begin{array}{c}2.042 \\
(7.394)\end{array}$ & $\begin{array}{c}1.172 \\
(6.798)\end{array}$ & $\begin{array}{c}8.539 \\
(8.264)\end{array}$ & $\begin{array}{c}5.682 \\
(6.482)\end{array}$ & $\begin{array}{c}8.267 \\
(7.206)\end{array}$ \\
\hline $\mathrm{N}$ & 30 & 30 & 30 & 30 & 30 & 30 & 30 & 30 & 30 & 30 & 30 & 30 & 28 & 28 & 28 \\
\hline
\end{tabular}

Standard errors in parentheses

Column numbers indicate post-passage year under consideration; $\mathrm{N}=$ number of states in sample

Dependent variable is the difference between the percentage difference in the murder rate in treatment and synthetic control states at given post-treatment interval and at time of the treatment

Results reported for the constant term resulting from this regression

States in group: AK AR AZ CO FL GA ID KS KY LA MI MN MO MS MT NC NE NM NV OH OK OR PA SC TN TX UT VA WV WY

States excluded for poor pre-treatment fit:

${ }^{*} p<0.10,{ }^{* *} p<0.05,{ }^{* * *} p<0.01$

Table L4: The Impact of RTC Laws on the Murder Rate, DAW covariates, Full Sample, 1977-2014, No Subtraction

\begin{tabular}{|c|c|c|c|c|c|c|c|c|c|c|c|c|c|c|c|}
\hline & \multicolumn{5}{|c|}{ Prior to RTC Passage } & \multicolumn{10}{|c|}{ After RTC Passage } \\
\hline & (1) & (2) & (3) & (4) & (5) & (1) & (2) & (3) & (4) & (5) & (6) & (7) & (8) & (9) & (10) \\
\hline Average non-normalized TEP & $\begin{array}{c}3.043 \\
(3.460)\end{array}$ & $\begin{array}{c}3.576 \\
(4.377)\end{array}$ & $\begin{array}{c}5.123 \\
(4.357)\end{array}$ & $\begin{array}{c}5.984 \\
(4.768)\end{array}$ & $\begin{array}{l}9.853^{*} \\
(5.072)\end{array}$ & $\begin{array}{c}10.699^{* *} \\
(4.985)\end{array}$ & $\begin{array}{l}7.090^{*} \\
(4.142)\end{array}$ & $\begin{array}{c}7.575 \\
(4.906)\end{array}$ & $\begin{array}{c}7.198 \\
(5.668)\end{array}$ & $\begin{array}{c}3.751 \\
(5.084)\end{array}$ & $\begin{array}{c}4.296 \\
(6.128)\end{array}$ & $\begin{array}{c}3.445 \\
(5.425)\end{array}$ & $\begin{array}{l}11.855^{*} \\
(6.815)\end{array}$ & $\begin{array}{l}9.003^{*} \\
(4.685)\end{array}$ & $\begin{array}{c}11.558^{* *} \\
(5.608)\end{array}$ \\
\hline $\mathrm{N}$ & 30 & 30 & 30 & 30 & 30 & 30 & 30 & 30 & 30 & 30 & 30 & 30 & 28 & 28 & 28 \\
\hline
\end{tabular}

Standard errors in parentheses

Column numbers indicate post-passage year under consideration; $\mathrm{N}=$ number of states in sample

Dependent variable is the percentage difference in the murder rate in treatment and synthetic control states at given post-treatment interval

Results reported for the constant term resulting from this regression

States in group: AK AR AZ CO FL GA ID KS KY LA MI MN MO MS MT NC NE NM NV OH OK OR PA SC TN TX UT VA WV WY

States excluded for poor pre-treatment fit:

${ }^{*} p<0.10,{ }^{* *} p<0.05,{ }^{* * *} p<0.01$ 
Table L5: The Impact of RTC Laws on the Property Crime Rate, DAW covariates, Full Sample, 1977-2014

\begin{tabular}{|c|c|c|c|c|c|c|c|c|c|c|c|c|c|c|c|}
\hline & \multicolumn{5}{|c|}{ Prior to RTC Passage } & \multicolumn{10}{|c|}{ After RTC Passage } \\
\hline & (1) & (2) & (3) & (4) & (5) & (1) & (2) & (3) & (4) & (5) & $(6)$ & (7) & $(8)$ & (9) & (10) \\
\hline Average normalized TEP & $\begin{array}{l}-0.259 \\
(1.595)\end{array}$ & $\begin{array}{c}0.845 \\
(2.828)\end{array}$ & $\begin{array}{c}1.044 \\
(3.707)\end{array}$ & $\begin{array}{c}4.059 \\
(4.180)\end{array}$ & $\begin{array}{l}6.879^{*} \\
(3.478)\end{array}$ & $\begin{array}{l}6.223^{*} \\
(3.149)\end{array}$ & $\begin{array}{l}7.394^{* *} \\
(3.397)\end{array}$ & $\begin{array}{l}8.239^{* *} \\
(3.661)\end{array}$ & $\begin{array}{l}7.870^{*} \\
(3.923)\end{array}$ & $\begin{array}{c}7.145 \\
(4.485)\end{array}$ & $\begin{array}{l}8.716^{*} \\
(4.724)\end{array}$ & $\begin{array}{c}10.188^{* *} \\
(4.452)\end{array}$ & $\begin{array}{c}11.625^{* *} \\
(4.951)\end{array}$ & $\begin{array}{l}10.665^{*} \\
(5.280)\end{array}$ & $\begin{array}{l}11.518^{*} \\
(6.047)\end{array}$ \\
\hline $\mathrm{N}$ & 30 & 30 & 30 & 30 & 30 & 30 & 30 & 30 & 30 & 30 & 30 & 30 & 28 & 28 & 28 \\
\hline
\end{tabular}

Standard errors in parentheses

Column numbers indicate post-passage year under consideration; $\mathrm{N}=$ number of states in sample

Dependent variable is the difference between the percentage difference in the property crime rate in treatment and synthetic control states at given post-treatment interval and at time of the treatment Results reported for the constant term resulting from this regression

States in group: AK AR AZ CO FL GA ID KS KY LA MI MN MO MS MT NC NE NM NV OH OK OR PA SC TN TX UT VA WV WY

States excluded for poor pre-treatment fit:

${ }^{*} p<0.10,{ }^{* *} p<0.05,{ }^{* * *} p<0.01$

Table L6: The Impact of RTC Laws on the Property Crime Rate, DAW covariates, Full Sample, 1977-2014, No Subtraction

\begin{tabular}{|c|c|c|c|c|c|c|c|c|c|c|c|c|c|c|c|}
\hline & \multicolumn{5}{|c|}{ Prior to RTC Passage } & \multicolumn{10}{|c|}{ After RTC Passage } \\
\hline & (1) & (2) & (3) & (4) & (5) & (1) & (2) & (3) & (4) & (5) & (6) & (7) & (8) & (9) & (10) \\
\hline Average non-normalized TEP & $\begin{array}{l}9.344^{* *} \\
(3.607)\end{array}$ & $\begin{array}{c}10.512^{* * *} \\
(3.709)\end{array}$ & $\begin{array}{c}10.771^{* *} \\
(4.169)\end{array}$ & $\begin{array}{c}13.844^{* * *} \\
(4.644)\end{array}$ & $\begin{array}{c}16.716^{* * *} \\
(4.682)\end{array}$ & $\begin{array}{c}16.096^{* * *} \\
(4.693)\end{array}$ & $\begin{array}{c}17.292^{* * *} \\
(5.147)\end{array}$ & $\begin{array}{c}18.165^{* * *} \\
(6.206)\end{array}$ & $\begin{array}{c}17.827^{* *} \\
(6.476)\end{array}$ & $\begin{array}{c}17.135^{* *} \\
(6.973)\end{array}$ & $\begin{array}{c}18.736^{* *} \\
(7.039)\end{array}$ & $\begin{array}{c}20.234^{* * *} \\
(6.645)\end{array}$ & $\begin{array}{c}21.557^{* * *} \\
(6.790)\end{array}$ & $\begin{array}{c}20.629^{* * *} \\
(6.951)\end{array}$ & $\begin{array}{c}21.549^{* * *} \\
(7.279)\end{array}$ \\
\hline $\mathrm{N}$ & 30 & 30 & 30 & 30 & 30 & 30 & 30 & 30 & 30 & 30 & 30 & 30 & 28 & 28 & 28 \\
\hline
\end{tabular}

Standard errors in parentheses

Column numbers indicate post-passage year under consideration; $\mathrm{N}=$ number of states in sample

Dependent variable is the percentage difference in the property crime rate in treatment and synthetic control states at given post-treatment interval

Results reported for the constant term resulting from this regression

States in group: AK AR AZ CO FL GA ID KS KY LA MI MN MO MS MT NC NE NM NV OH OK OR PA SC TN TX UT VA WV WY

States excluded for poor pre-treatment fit:

${ }^{*} p<0.10,{ }^{* *} p<0.05,{ }^{* * *} p<0.01$ 